\title{
TRANSLATION AFTER WITTGENSTEIN
}

\section{PHILIP WILSON}

Thesis submitted for the degree of Doctor of Philosophy in Literary Translation

University of East Anglia

School of Literature, Drama and Creative Writing

August 2012

(C) This copy of the thesis has been supplied on condition that anyone who consults it is understood to recognise that its copyright rests with the author and that use of any information derived there from must be in accordance with current UK Copyright Law. In addition, any quotation or extract must include full attribution. 


\section{ABSTRACT}

In this thesis, I examine how a reading of the later philosophy of Ludwig Wittgenstein can be of use to the reflective practitioner of literary translation. Wittgenstein, whilst a key figure in twentieth-century philosophy, remains peripheral to the field of translation studies and I argue that his later work, because it deals with the nature of language and meaning, is potentially of great significance: the story that Wittgenstein tells can change the field. It can rid translators of pictures of translation that are detrimental to literary translation and can also offer tools that will facilitate the task of literary translation, such as: the language-game; the form of life; the surveyable representation.

In Chapter 1, I discuss the relation between philosophy and translation studies, presenting the later work of Wittgenstein, in particular the 1953 Philosophical Investigations. In Chapters 2, 3 and 4, I relate Wittgenstein's work to translation by examining respectively: the reading for translation of the source text; the writing of the target text; the theorising of the target text. In Chapter 5, I draw conclusions. In the central three chapters, I offer case studies of the translation of the poetry of Eduard Mörike and of the New Testament to illustrate my arguments. My aim is that the thesis will form the basis for a greater concern for Wittgenstein in translation studies than has previously been the case. 


\section{CONTENTS}

Preface

Acknowledgements

TRANSLATION AFTER WITTGENSTEIN

1.1 Aim

$\begin{array}{lll}1.2 & \text { Translation studies and philosophy } & 17\end{array}$

$\begin{array}{ll}1.3 & \text { Why Wittgenstein? } \\ 1.4 & 20\end{array}$

$\begin{array}{ll}1.4 & \text { The later Wittgenstein } \\ 1.5 & 24\end{array}$

1.5 Applying Wittgenstein 32

1.5.1 Wittgenstein's work on medical research 35

1.5.2 Moore's theological investigations 36

1.5.3 Perloff on poetic translatability 38

$\begin{array}{lll}1.6 & \text { Conclusions } & 41\end{array}$

$2 \quad$ Reading the source text for translation 42

2.1 On not thinking but looking 43

$\begin{array}{lll}2.2 & \text { Language-games } & 60\end{array}$

$\begin{array}{lll}2.3 & \text { Forms of life } & 74\end{array}$

$\begin{array}{lll}2.4 & \text { Philosophical descriptions } & 82\end{array}$

$\begin{array}{lll}2.5 & \text { Case studies } & 91\end{array}$

2.5.1 The poetry of Mörike 92

2.5.2 The New Testament 95

$\begin{array}{lll}2.6 & \text { Conclusions } & 101\end{array}$

$3 \quad$ Writing the target text 103

$\begin{array}{lll}3.1 & \text { The translator and the fly-bottle } & 104\end{array}$

$\begin{array}{lll}3.2 & \text { The language-game of translation } & 116\end{array}$

3.3 The forms of life of the literary translator 122

$\begin{array}{lll}3.4 & \text { Translating a play on words } & 132\end{array}$

3.5 Case study: translating the poetry of Mörike 144

$\begin{array}{lll}3.6 & \text { Conclusions } & 153\end{array}$ 
4.1 The beetle in the box 155

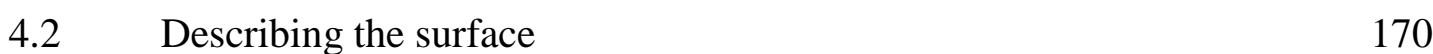

$\begin{array}{lll}4.3 & \text { Translated to our satisfaction } & 181\end{array}$

$\begin{array}{lll}4.4 & \text { Grammatical investigations } & 197\end{array}$

$\begin{array}{lll}\text { 4.4.1 Investigating the supermemes } & 198\end{array}$

$\begin{array}{lll}\text { 4.4.1.1 Source-target } & 198\end{array}$

$\begin{array}{lll}4.4 .1 .2 & \text { Equivalence } & 199\end{array}$

$\begin{array}{lll}\text { 4.4.1.3 Untranslatability } & 201\end{array}$

4.4.1.4 Free-vs-literal 202

4.4.1.5 All-writing-is-translation 204

4.4.1.6 Conclusions about the supermemes 205

4.4.2 Translation theories after Wittgenstein 207

4.5. Case study: New Testament translation 210

4.5.1 New Testament translation: a cluster concept 210

4.5.2 A description of Barnstone's The Restored New Testament 216

$\begin{array}{lll}4.6 & \text { Conclusions } & 225\end{array}$

5 Conclusion $\quad 227$

$\begin{array}{lll}5.1 & \text { Wittgenstein's story } & 228\end{array}$

5.2 Practice and theory 235

5.3 Why Wittgenstein 243

$\begin{array}{ll}5.4 & \text { Translation after Wittgenstein } \\ 5.5 & 251\end{array}$

$\begin{array}{lll}5.5 & \text { Story's end } & 255\end{array}$

$\begin{array}{ll}\text { Bibliography } & 259\end{array}$ 


\section{LIST OF FIGURES AND TABLES}

\section{FIGURES}

$1 \quad$ The duck-rabbit 56

2 A Wittgensteinian reading list for translation 242

\section{TABLES}

$1 \quad$ Stylistic effects according to Moyal-Sharrock

$2 \quad$ The word in context 75

$3 \quad$ Forms of life in Table $2 \quad 76$

$4 \quad$ Mörike's poetry $\quad 92$

$5 \quad$ Translation polarities $\quad 165$

$6 \quad$ Ovid as a cluster of translations 168

$\begin{array}{lll}7 & \text { Translators' note to Effi Briest } & 175\end{array}$

$8 \quad$ Reading Weinberger as Wittgensteinian 190

9 The evaluation of quality in translation studies 194

10 A sample of major translation studies 207

11 Some NT translations 211

$12 \quad$ Extending the cluster 214

13 Nomenclature in Barnstone 220

14 Translation theories, Wittgenstein and Barnstone 222

15 Wittgenstein's stories 229

16 Wittgensteinian tools for translation studies 237

17 A surveyable representation of (140) 246 


\section{PREFACE}

My own interest in Wittgenstein began some twenty years ago. He was initially recommended to me by Michael Finnissy, who informed me in conversation that Wittgenstein had been inspirational to him in his work as a composer. My intellectual position at that time was Thomist, following the thought of Thomas Aquinas. Friends in the Dominican Order, of which I was for a time a member, later recommended reading Wittgenstein as a way of approaching Aquinas's thought and I was influenced by my reading of Fergus Kerr (1988) and Gareth Moore (1998). When my professional interests turned to translation, I used my reading of Wittgenstein as a way of approaching the texts on which I was working, for example, in my translations from Martin Luther (Gledhill and Wilson, 2007), where I sought to play the same language-games in my translations that I found in Luther's sermons. My motivation for researching translation after Wittgenstein can therefore be seen as a coming together of my philosophical and professional interests. I would no longer call myself a Thomist, but I continue to turn to the writings of Wittgenstein. I owe to John Gledhill the notion of linking Wittgenstein to translation: my thesis 'Translation after Wittgenstein' is in many ways an application of an insight he expresses in his book on translating Thomas Mann (2007) and a continuation of a dialogue that has gone on for more than forty years. 


\section{ACKNOWLEDGEMENTS}

I should like to thank my supervisors at the University of East Anglia: Jean BoaseBeier, Valerie Henitiuk, Marie McGinn and Ross Wilson. David Cockburn and Gareth Jones gave generously of their time for philosophical discussion.

Thanks also to those who helped me to find my path to Wittgenstein: Michael Finnissy, John Gledhill, Fergus Kerr, Gareth Moore.

And to the following for their support: Odai Alzoubi, Anna Clover, Tamara Dobler, Chris Doman, B.J. Epstein, Antoinette Fawcett, Marc Fielder, Lina Fisher, Hiroko Furukawa, Tom Greaves, Peter Green, Jon Hills, Susanne Klinger, Oskari Kuusela, Richard Lewis, Andrei Nasta, Ben Needham, Trudi Needham, Silvia Panizza, Rupert Read, Catherine Rowett, Lorna Savage, Maria Serban, Clara Stern, Simon Summers, Helen Tierney, Vlad Vexler, Ben Walker.

I have been able to undertake doctoral research thanks to the Arts and Humanities Scholarship awarded by the University of East Anglia.

This thesis is dedicated to the memory of my parents. 


\section{ABBREVIATIONS}

Works by Wittgenstein:

BT Big Typescript

CV Culture and Value

LA Lectures and Conversations on Aesthetics, Psychology and Religious Belief

LWPP Last Writings on Philosophical Psychology

NB Notebooks 1914-1916

OC On Certainty

PI Philosophical Investigations

$P G \quad$ Philosophical Grammar

PPF Philosophy of Psychology - A Fragment

RPP Remarks on the Philosophy of Psychology

PR Philosophical Remarks

RFM Remarks on the Foundations of Mathematics

TL-P Tractatus Logico-Philosophicus

WFV Wörterbuch für Volksschulen

Z Zettel

Other abbreviations:

DTS Descriptive Translation Studies

HG Hellenistic Greek

NT New Testament

SL source language

ST source text

TL target language

TT target text

(dir) director

ed. edited

(ed) editor

(eds) editors

np no page

tr. translated

(tr) translator

(trs) translators 


\section{A NOTE ON REFERENCING}

1. Works are referred to by author, year and (where relevant) page, e.g. 'Adair (1995:5)'.

2. I follow practice in philosophical scholarship by referring to the works of Wittgenstein by title and section or page, and by referring to the works of Plato by section, e.g. 'Wittgenstein (PI 1)'; 'Wittgenstein ( $C V$ p.5)'; 'Plato (514a)'.

3. I follow practice in theological scholarship by referring to the Bible by chapter and verse, while making clear which edition is being used when relevant, e.g. 'King James Bible, John 1:1'.

4. If a translation is being discussed, then the translator is given as the author in the main text and in the Bibliography, e.g. 'Constantine, D. (tr) (2005) Johann Wolfgang von Goethe: Faust Part I, London: Penguin'. No translator is given for group translations of the Bible.

5. Where a translated text is considered in its own right, the translator is credited in the Bibliography but the text is given under the name of the source text author, e.g. 'Tolstoy, L. (1997) The Gospel in Brief, tr. by F.A. Flowers III, Lincoln \& London: University of Nebraska Press'.

6. Internet references in the Bibliography include the full date on which a website was viewed, e.g. 'AQA (9 May 2010) http://store.aqa.org.uk'. In the text, reference is by year only, e.g. 'AQA (2010)'. 


\section{TRANSLATION AFTER WITTGENSTEIN}

While we all use language, none of us actually owns it.

Spence (2010:42) 


\section{INTRODUCTION}

In the beginning was the Deed!

Goethe (1972:44) ${ }^{1}$

${ }^{1}$ My translation. 


\title{
1.1 Aim
}

The Austrian philosopher Ludwig Wittgenstein (1889-1951) is the subject of a poem by Herbert Lomas (2009:41), which is given as (1). Lomas addresses the concern with meaning associated with the later work of Wittgenstein.

\author{
NOTES ON WITTGENSTEIN \\ What does it mean to say I hear? \\ The piano, the air, the ear, the player? \\ What does it mean to say I hope? \\ Is hope a feeling? How long can I hope you come? \\ And what does it mean to say I love? \\ Your skin, your boots, your smell, your world? \\ No one says No. That wasn't true pain. \\ True pain wouldn't have faded - or faded so quickly. \\ Is it you I love or myself? \\ And are roses red in the dark?
}

The poem exemplifies the influence Wittgenstein has exerted outside the field of philosophy. As Terry Eagleton (1994:153) notes: 'Frege is a philosopher's philosopher, Sartre the media's idea of an intellectual, and Bertrand Russell every shopkeeper's image of the sage. ... But Wittgenstein is the philosopher of poets and composers, playwrights and novelists.' Eagleton's assertion is easily supported: Wittgenstein's early work has been set to music by M.A. Numminen (1987); Derek Jarman has made a film of his life (1993); Tom Stoppard's play Dogg's Hamlet, Cahoots Macbeth (1980) is derived from his later philosophy; he is the protagonist of Bruce Duffy's novel The World As I Found It (1987); his eyes stare out at the reader at the start of W.G. Sebald's prose fiction Austerlitz (2001:3); Wolfgang Huemer (2004:2) records that Wittgenstein's centenary was celebrated in Vienna by an exhibition of works of art influenced by his philosophy. In addition, Wittgenstein's work has been used by literary critics: The Literary Wittgenstein, for example, is a collection of essays addressing the implications of his writings for 
literature (Gibson \& Huemer, 2004). His work therefore ought to be of interest to those engaged with the translation of poems, plays and novels.

The aim of this thesis is to investigate the relevance to literary translation of the later Wittgenstein of the Philosophical Investigations (PI), first published posthumously in 1953 in an edition including Wittgenstein's German text with a facing English translation by Elizabeth Anscombe; I use the 2009 revised edition by Peter Hacker and Joachim Schulte that modifies but generally maintains Anscombe's translation. I hold the PI to be representative of the thought of the later Wittgenstein in its 'attempt to produce an overall shift in how we approach philosophical questions or the desire for understanding that they express' (McGinn 2008:30). It deals with the philosophy of language and the philosophy of psychology in two parts, formerly known as PI I and PI II, now re-titled by Hacker and Schulte as PI and Philosophy of Psychology - A Fragment (PPF) respectively. The central contention of the PI is that what are commonly held to be philosophical confusions originate in grammatical confusions. My choice of basing discussion primarily on the $P I$ is considered in 1.3. All quotations from Wittgenstein are in English from published translations unless the translation itself is being discussed, in which case a glossed ST is used.

I address Wittgenstein from the point of view of translation studies rather than of philosophy. Wittgenstein did not address the topic of translation directly at any length. I hope that my thesis will show, however, that his work can be used in describing the translation process and that it is also of potential value to the practising translator. By 'translation' I refer to 'literary translation', in the sense that this term is usually understood in translation studies (Hermans, 2007a:77), that is, translation with respect to a certain kind of text that in turn demands a certain type of strategy. Willis Barnstone (1993:4) distinguishes literary translation from routine information transfer. Literary translation deals with texts that have been valued as literature by individual cultures, and produces texts that themselves aim to be literary in nature. Examples of literary translation examined in this thesis are: the translation of the poetry of Eduard Mörike (1975) in 2.5 and 3.5; the translation of the New Testament (NT) (Aland et al., 1963) in 2.5 and 4.5. 'Literature' is itself a highly contested term (Attridge, 2004; Eagleton, 1996). An advertisement for a car, for instance, is unlikely to be set for critical commentary in a GCSE English Literature poetry examination, but its translation may tax the most experienced literary 
translator, because it may involve word play, cultural background, intertextual referencing etc. (Boase-Beier, 2011:21). What is at issue is the literariness of the text being examined (Eagleton, 2007:3), as discussed in 2.1.

My overall strategy is heavily influenced by Fergus Kerr, whose primary purpose (1988:vii) is 'to show students of theology that they have much more to gain from reading Wittgenstein's later writings than is commonly supposed'. Kerr's book is entitled Theology after Wittgenstein. My thesis, 'Translation after Wittgenstein', aims to show that the same point can be made to students of translation. I write as a translation theorist, but also as a translation theorist who translates. In this sense, I am a reflective practitioner, defining this term following Donald Schön (1987:4) as the practitioner who 'selects things for attention and organises them, guided by an appreciation of the situation that gives it coherence and sets a direction for action'. In my own translation work, I have found Wittgenstein to be inspirational and I follow the approach of Rupert Read (2007a:3): 'The true test of Wittgenstein's philosophy, the test of its vitality, of its reach, of its being more than a set of observations which are of use in the areas where he made them, is to apply his methods where he did not much apply them'. I owe the notion of linking Wittgenstein to translation studies to John Gledhill (2007:5), whose remark on applying Wittgenstein to translation is discussed in 3.2 .

Wittgenstein is regarded as one of the most significant figures in the history of philosophy. David Edmonds and John Eidinow (2001:231) refer to his reputation being 'unsurpassed ... he has joined the philosophical canon'. He occupies a marginal position in translation studies, however. Anthony Pym (2007:36) makes only one oblique reference to Wittgenstein in his essay on philosophy and translation; Andrew Benjamin (1989), Rosemary Arrojo (2010) and Kirsten Malmkjaer (2010) make none at all in their surveys of translation and philosophy. Overviews of translation studies by Susan Bassnett (2003) and Jeremy Munday (2001) similarly ignore Wittgenstein.

Wittgenstein may be a peripheral figure for translation studies because, as mentioned above, he did not address translation at any significant length, whereas many philosophers have been very interested in translation. Jacques Derrida (1995), for example, produced detailed philosophical considerations of the problems involved in translating, and has been very influential in the field (Bassnett, 2003:9). Martin Heidegger (1996) addressed translation issues directly in his writings, so that 
'it cannot be denied that there is a coherent, if not systematic, teaching about the nature of translation' in his works (Groth, 2004:7). By contrast, while it is possible to survey Wittgenstein's work in order to garner statements about translation, Dinda Gorlée (1994:88) notes that 'many of these references are not meant to discuss translation for its own sake, as the actual linguistic activity in its own right, but rather as a heuristic device aimed at clarifying by analogy some of the fundamental topics discussed by Wittgenstein throughout his intellectual career'. My interest in Wittgenstein is motivated precisely by the fact that he did not address translation directly, by the fact that his later writings are about language, and that translation is rooted in language. The aim of this thesis will therefore be to apply Wittgenstein's philosophy to the area of translation, not to use Wittgenstein's statements on translation to illuminate the phenomenon of translation, although some of these statements will be referenced and will prove very useful.

The peripheral status of Wittgenstein within translation studies could also be because Wittgenstein has often been perceived as a vatic writer whose work has accordingly become 'the esoteric preoccupation of a clique' (Read, 2007a:4), occupying intellectual heights far removed from such a practical activity as translating and generating a whole industry of exegesis (cf. Kahane et al., 2007). In a letter in 1944 to Norman Malcolm (McGuinness 2008:320), however, Wittgenstein asks Malcolm what is the use of studying philosophy 'if all that it does for you is to enable you to talk with some plausibility about some abstruse questions of logic etc., $\&$ if it does not improve your thinking about the important questions of everyday life'. Translation, in my opinion, is one of these important questions of everyday life and the contention of my thesis is that a reading of Wittgenstein can improve our thinking about translation, even though the topic is not central to his work. Martin Klebes (2006:47), writing on Wittgenstein and the novel, notes that it may be precisely the fact that Wittgenstein did not map out an aesthetic grid that makes him inspirational to novelists and literary theorists, because he does not present a doctrine but a method, not a set of instructions but an approach to practice. The same could be true for translation. What is this method?

The project of the later Wittgenstein is concerned with making us see things differently. As Ray Monk (1990:533) asserts: 'Wittgenstein's remark about philosophy - that it "leaves everything as it is" [PI 124] - is often quoted, but it is less often realized that, in seeking to change nothing but the way we look at things, 
Wittgenstein was attempting to change everything'. ${ }^{2}$ Hence Read (2007a:1) describes the $P I$ as 'a philosophical self-help book' that can help its audience 'to cease to be tortured by various intellectual delusions' through its focus on the circumstances of ordinary lives. To view Wittgenstein in this way can set him free for the translator as reflective practitioner, so that - again to refer to Read (2007a:4) - instead of being 'the esoteric preoccupation of a clique', Wittgenstein's work can become 'the valuable activity of a growing cultural force', which means that philosophy after Wittgenstein is 'something that we practise rather than recite'. The same may be true of translation after Wittgenstein.

However, there has been some significant work done on Wittgenstein within translation studies, on which I build and which opens the possibility for further integration of his methods. To give three examples: Wittgenstein has been cited by Gideon Toury (1980:17-18) as an inspiration for Descriptive Translation Studies (DTS) (discussed in 4.2); Maria Tymoczko (2007:83-90) uses Wittgenstein's approach to meaning in order to come to a view of translation as a 'cluster concept' (discussed in 4.1 and elsewhere); Marjorie Perloff (2004) uses Wittgenstein to examine the notion of poetic translatability (discussed in 1.5.3). In her survey of the many turns that have occurred in the short history of translation studies, Mary SnellHornby (2006:172) lists the 'sociological turn' as the most recent. It is time for a philosophical turn. George Steiner's work on translation, After Babel (1998), is an example of a literary survey of translation that has taken this philosophical turn and that frequently references Wittgenstein. What is needed now is an application from the point of view of the reflective practitioner in order to build on work already done and move Wittgenstein from the periphery to the centre.

\footnotetext{
${ }^{2}$ An example of this happening within translation studies is how Friedrich Schleiermacher's remarks on the nature of translation have consequences for the field, i.e. in introducing a foreignising approach (2004).
} 


\subsection{Translation studies and philosophy}

It is useful to examine the relationship between philosophy and translation studies, between one of the oldest intellectual practices known to humanity and a recent discipline, sometimes considered to have been formalised by a 1972 paper by James Holmes (2004). To turn to a discipline outside his or her own is a useful strategy for any theorist in the humanities. I follow the distinction made by Wolfgang Iser (2006:5) between soft theory in the humanities and hard-core theory in the sciences, between mapping and predicting respectively. Iser (2006:9) asserts that soft theories in the humanities 'derive their components from sources outside themselves, thus obtaining a more reliable basis than the contrived speculations of aesthetics could ever provide'. An example is the examination of literary theory by Eagleton (1996), where the theories chosen for discussion come from outside literature. Eagleton (1996:151-155), for example, uses ideas drawn from Freudianism to drive a psychoanalytical reading of D.H. Lawrence's novel Sons and Lovers, interpreting the various family conflicts in that book by reference to concepts such as the Oedipus complex, which allows him to develop what he refers to as a “"sub-text” for the work - a text which runs within it ... which we as readers are able to "write" even if the novel itself does not'. Writing this particular sub-text for Sons and Lovers is a possibility only for the reader who knows his or her psychoanalysis, and Eagleton (1996:153) stresses that other readings (such as a social reading) are available to readers who look to other theories (such as Marxism). With respect to translation, Jean Boase-Beier (2008) has similarly argued that the sort of theory that might be used to drive a translation is one that is peripheral to translation studies rather than a theory about translation as such and (2006a) uses relevance theory (Sperber \& Wilson, 1995) - a theory about meaning, not translation - to drive and explain her own translation of an Ernst Meister poem. By looking to another field, the theorist can establish whether his or her way of proceeding is sound, though this raises the question of whether the theory used is in turn a sound one. Emma Wagner, for example, rejects Derrida, offered by Andrew Chesterman as a possible inspiration for translation, because she sees his theory of meaning as nonsensical (Chesterman \& Wagner, 2002:24-25). I think that the presentation of Derrida given by Chesterman is over-simplified, but Wagner is right to refuse to use a theory that she does not see as sound. 
The same need to look outside a discipline can be found with respect to the creative process. The composer Michael Finnissy (Brougham et al., 1977:2) cites as a major influence on his work the Pedagogical Sketchbook by Paul Klee (1988), not a musical textbook but a manual of instruction for the Bauhaus, a school of functional architecture and design that flourished in Weimar Germany. Such outside influence can be crucial for artistic development. The poet Gerard Manley Hopkins found inspiration in the work of the philosopher and theologian Duns Scotus, whose notion of haeccitas ${ }^{3}$ showed Hopkins a way of looking at the world that helped him to release his own creative energy by developing the concept of 'inscape' (Martin 1991:133). If translation, as has often been noted, is a creative act rather than a mechanical transference of meaning for which good dictionary skills are the primary requisite (Weinberger \& Paz, 1987:43), then the practising translator might also benefit by looking sidewards.

Philosophy is a discipline to which a writer in the humanities might turn in order to support his or her work. The novels of Iris Murdoch, for example, such as The Black Prince (1993), draw heavily on Plato's philosophy, and she also uses Plato in her aesthetic writings (1997) to give her a context in which to work out her own theory of art: even where she disagrees with Plato's dismissal of representative art, her framework of reference remains Platonic. Pym (2007:24) describes philosophy 'as a set of discourses that do not ostensibly borrow authority from external disciplines'. In this, philosophy differs from other fields of study in the humanities, and may be said to be a foundational subject in its unaided quest for truth, giving rise to a number of sub-disciplines that attempt to elucidate other fields, such as: the philosophy of language; the philosophy of law; the philosophy of mathematics; the philosophy of science etc.

Translation studies, by contrast, is an interdisciplinary field, what Tymoczko (2007:52) describes as an 'interdiscipline', which of necessity looks to other fields for support. The essays in Piotr Kuhiwczak and Karin Littau's guide to key approaches in translation studies (2007) indicate this. Chapters are devoted to the relationship between translation and the following (in chapter order): culture; philosophy; linguistics; history; literature; gender; politics. In the relationship between translation studies and philosophy, translation studies is a 'client discipline'

\footnotetext{
${ }^{3}$ Latin: 'thisness'.
} 
(Pym 2007:4), with the direction of authority being primarily from philosophy to translation studies.

Pym (ibid.) asserts that there are three ways in which philosophy and translation are linked. These are quoted as (2).

(1) Philosophers of various kinds have used translation as a case study or metaphor for issues of more general application.

(2) Translation theorists and practitioners have referred to philosophical discourses for support and authority for their ideas.

(3) Philosophers, scholars and translators have commented on the translation of philosophical discourses.

Examples of these three ways are, respectively: Friedrich Nietzsche's statement on translation and power (2004); Steiner's use of Wittgenstein (1998:169 ff.); Lawrence Venuti's discussion of the translation of philosophical texts (1998:106-123). In this thesis, I, as a reflective practitioner, shall address the second connection noted by Pym. Wittgenstein, as philosopher, can be seen to exemplify Pym's first link.

Christopher Norris (2007:1) asserts that the relationship between philosophy and literary theory (of which part of translation studies can be considered a subdiscipline) is problematic, owing to the "tendency of literary theorists to advance farreaching speculative claims on a frankly inadequate philosophic basis'. I assume that translation is a process that is an interface of various disciplines. To translate a poem, for example, involves a writer in a process that is simultaneously literary, cultural, linguistic etc. I ask what philosophy (in particular the philosophy of Wittgenstein) can tell me about this process. My approach will mean that I can hope to avoid advancing the far-reaching speculative claims identified by Norris, because I shall be writing descriptively rather than as a modern sage. My thesis is addressed to the specialist in translation studies rather than to the philosopher but it is my hope that my engagement with philosophy will not be inadequate. 


\subsection{Why Wittgenstein?}

Twentieth-century philosophy is often described in terms of two major trends: the analytic (Anglo-American) and the continental (what Pym (2007:42) calls 'the hermeneutic-deconstructive complex'). Whilst these are contested terms, the two trends can be defined, following Simon Critchley (2001:i-vii), as follows. Analytic philosophy is concerned with questions of logic and language, for example, whether the sentence 'The King of France is bald' is true or false or meaningless. Continental philosophy is concerned with existential questions, for example, whether history can be said to progress. Philosophers such as A.J. Ayer and Bertrand Russell are categorised as working within the analytic tradition. Philosophers such as Derrida and Heidegger are categorised as working within the continental tradition. The split has been seen by many writers to have had harmful effects in philosophy: Pym (2007:42) notes 'not just a lack of dialogue but serious misunderstandings'.

Wittgenstein can resolve this dilemma, because the traditional categorisation of his work as analytic does not, according to Critchley (2001:11), explain his appeal, which 'might be said to be based on the way philosophical truth comes together with a certain conception of existential meaning, indeed a certain way of life'. Like Immanuel Kant, Wittgenstein is a thinker who encompasses both the analytic and the continental traditions (Critchley, 2001:iii). His contention in Philosophical Remarks $(P R) 3$ is that inquiry has to be about language as we find it and his discussions of language in the $P I$ are based on practical examples and stories, on ordinary life, everyday language and everyday activities.

The translator must likewise deal with language as it is found in the text being translated, not with an ideal language. Wittgenstein's insistence on language as it is used in ordinary life supports the approach to translation studies suggested by Benjamin (1989:86) of shifting the emphasis 'to the text itself', a move with which Pym (2007:44) is in agreement, concluding that a 'bottom-up' approach is needed that would not miss 'the logics of the more everyday activities'. I shall also argue that Wittgenstein can provide a corrective to the non-literary ways in which many literary translators have dealt with the text to be translated (Chapter 3). My thesis examines various conceptual problems that face the translation theorist and the translator, and will suggest how a reading of Wittgenstein can enable these problems to be solved. The ultimate aim of Wittgenstein's project, as Kerr (1988) stresses, is clarity, a new way of seeing. As Boase-Beier asserts (2006b:147), knowledge of 
theory 'is another possible tool, a way of broadening the mind, an added perspective', a way in which theory and practice can be improved in translation.

It is important to be clear about the term 'theory', which is used in ways that differ according to context, and is thus a potential source of confusion. Iser (2006:5) makes the distinction between soft and hard-core theory precisely because he believes that the term 'theory' is used in different ways in the humanities and the sciences, so that he is attempting to clear away confusion. For Wittgensteinian scholarship, the problem of how to understand 'theory' is acute because of Wittgenstein's insistence in the $P I$ that 'we may not advance any kind of theory' (PI 109).

Boase-Beier (2010c:26) argues that a theory of the pavement is necessary to walk down a street in icy weather, in order to avoid slipping over in unforeseen conditions. A theory of the pavement is in this sense a view of the pavement. Charlie Louth (1998:56) uses the term analogously when describing Friedrich Hölderlin's translation of Sophocles from Greek to German: 'a kind of intense reading ... a kind of theory in practice, where the root sense of the Greek $\theta \varepsilon \omega \rho i \alpha$ [theôria], a viewing, a contemplation, intimates the process'. To be a functional human being involves having theories in the sense of having viewpoints, angles we take on things to get us through the day. It can be argued that Wittgenstein does write theoretically about language, because he inevitably has a viewpoint. Anthony Kenny (2006:126), for example, concludes that Wittgenstein's contention that meaning is use is a theory. What Wittgenstein does not do, however, is to offer a theory in the sense of a systematisation, in the way that the Marxist theory of history, for example, is a systemised view (Marx \& Engels, 1970). In Culture and Value (CV) p.26, Wittgenstein expresses admiration for Copernicus and Darwin not for discovering theories but for providing fertile new points of view. A useful term to introduce here is 'doctrine', to indicate a formalised teaching of some kind. Thus I could refer to the 'Catholic doctrine on the incarnation', if I wanted to discuss the ontological status attributed to Jesus of Nazareth by the magisterium of the Catholic Church within systematic theology. In this sense, it is clear that Wittgenstein offers no doctrines; as Marie McGinn (2008:10) states, 'it is a method or style of thought, rather than doctrines, that characterises his later philosophy'. McGinn's view contrasts with what some interpreters of Wittgenstein have done with his later work. William Lycan (2008:85), for example, presents what he calls the 'Wittgensteinian "use 
theory" that he places among the theories of language catalogued in his overview, such as 'truth condition theories' (2008:109). Such an approach fails to take any account of Wittgenstein's insistence throughout the $P I$ that he is not putting forward a theory (PI 109), that the task of philosophy is description and not explanation (PI 126), that the emphasis must always be on the particular case (PI 66) and goes, I think, too far, because it aligns Wittgenstein's insights with very different sorts of theory. Wittgenstein ( $C V$ p.30) criticises beginning with a preconception of how things must be as an example of 'the dogmatism into which philosophy can so easily degenerate'.

I follow in addition standard practice in using the term 'theory' to categorise those phenomena categorised as such in the humanities, which attempt to explain other phenomena. Skopos ${ }^{4}$ theory, for example (Reiss \& Vermeer, 1984), looks at finished translations in the light of the function or functions that they fulfil, so that the style of one translation of the Bible might be explained by it being aimed at children, whilst another could be explained by it being aimed at an Anglican audience etc. The notion of theory will be further examined in Chapter 4 and in the Conclusion.

Given that I hold that there is no Wittgensteinian doctrine of language to be extracted from the $P I$, my intention is not to offer what I could call a 'Wittgensteinian theory of translation', to be placed alongside skopos theory, postcolonial theory, equivalence theory etc. on courses in translation studies. My aim is to show how a reading of Wittgenstein may be of benefit to the translation theorist and to the practising translator. There will be no set of instructions in the Conclusion about how to translate, although I do believe that there are Wittgensteinian approaches to translating, just as there are Wittgensteinian approaches to philosophy. I am not referring to a methodology, but to a set of methods: 'There is not a single philosophical method, though there are indeed methods, different therapies, as it were' (PI 133).

I note, as I read what I have written, that I have made many statements in the first person singular, making no attempt to keep myself out of the argument, in a way that is very different from educational research that I carried out for the University of Leicester between 1997-1999 as a reflective practitioner of education, when I was

\footnotetext{
${ }^{4}$ Greek: 'purpose'.
} 
advised to write in the third person impersonal singular at all times in order to maintain objectivity. Ten years later I am influenced by the assertion of Mona Baker (2008:xiii) that research 'now firmly acknowledges and engages with the role of the researcher's subjectivity in shaping the course and outcome of research'. Here Wittgenstein is a model: the first person singular is used frequently in the $P I$, at times in dialogue with an imagined reader, as in text (3) (PI 35), which is quoted by way of an illustration of a method that is reminiscent of the dialogue approach used by Plato, and that begins with a question from an interlocutor, who is perhaps the reader or perhaps the early Wittgenstein.

Can I say 'bububu' and mean 'If it doesn't rain, I shall go for a walk?' - It is only in a language that I can mean something by something. This shows clearly that the grammar of 'to mean' does not resemble that of the expression 'to imagine' and the like.

Philosophy is a dialogical undertaking for Wittgenstein. Research in translation studies can also be dialogical, and there is indeed a trend of bringing the researcher into the research. Paschalis Nikolaou and Maria-Venetia Kyritsi (2008:7) refer to this as the 'inward turn' in the discipline, which involves 'theorists themselves embarking on more personal journeys of self-discovery'.

In this thesis, I shall be in dialogue with both Wittgenstein and my reader, and the overall result will be part of a personal journey of self-discovery, which is why examples used will include my own translations of Mörike (in 3.5.2) written specially for this thesis. 


\subsection{The later Wittgenstein}

In their book on understanding philosophy through jokes (2007:136), Thomas Cathcart and Daniel Klein reproduce a cartoon in which an annoyed man is making this comment to an annoyed woman: "I never said, "I love you". I said, "I love $y a$ ". Big difference.' Cathcart and Klein (2007:137) interpret this scene as Wittgenstein talking to a more traditional philosopher, who finds the expressions 'I love you' and 'I love $y a$ ' equivalent. Wittgenstein corrects her by explaining how the meaning of a word is determined by its use, so that, because the two expressions in question are used differently, they have 'very different social implications': 'I love $y a$ ' is a declaration of affection at best, not of love, despite the dictionary meaning of the words 'I love $y a$ ' being the same as 'I love you'. Here, in a vignette, is the essence of the later Wittgenstein (cf. PI 43).

Introducing Wittgenstein's philosophy through a joke is appropriate, for he once said that 'a serious and good philosophical work could be written in jokes (without being facetious)' (Malcolm, 1958:27). It can be said to be in the spirit of Wittgenstein. Monk (2002:11) asserts that literature on Wittgenstein often fails because it misses the spirit in which Wittgenstein wrote, a spirit that Monk defines as the linking of the search to become a decent person with the search for clarity, as epitomised in the story of Russell asking Wittgenstein whether he was thinking of logic or of his sins and receiving the answer that Wittgenstein was thinking about both (2002:14). Eagleton (2008) similarly seeks to capture the idiosyncratic nature of Wittgenstein's thought by describing him as 'an arresting combination of monk, mystic and mechanic ... a high European intellectual who yearned for a Tolstoyan holiness and simplicity of life, a philosophical giant with scant respect for philosophy'. In what follows, I make numerous biographical references to Wittgenstein, following Monk's philosophical biography (1990).

As mentioned in 1.3, Wittgenstein in the $P I$ is often in dialogue, arguably with his younger self, the author of the 1921 Tractatus Logico-Philosophicus (TL-P), a book that stands in continuity with work done in formal logic by his Cambridge mentor Russell (Russell \& Whitehead, 1927). The TL-P and the PI represent the work of the early Wittgenstein and the later Wittgenstein respectively. So different are the approaches of the two works (Crary \& Read, 2000) that it can easily seem that there are two philosophers of the same name. There is controversy about how far any continuity can be asserted between the early and the later work, with self-styled 
New Wittgensteinian philosophers such as Alice Crary and Read (2000) asserting that there is no break, in contrast to what Guy Kahane, Edward Kanterian and Oskari Kuusela (2007:2) call the orthodox interpretation, as exemplified by Hacker (2004), which treats the later and the early work separately. I avoid this controversy by concentrating on the $P I$, with reference to other later writings, but my sympathy lies with the orthodox interpretation, based on the reference by Wittgenstein (PI p.4) to the 'grave mistakes' made in the $T L-P$. There seems to be no reason not to take him at his word here. As Hans-Johann Glock (2008:46) comments: 'In Wittgenstein's case ... we have two powerful philosophical visions, distinct and self-contained, except that the later work evolves partly out of sharp and explicit criticisms of the early work'. It is accordingly necessary to give some attention to the $T L-P$ in order fully to understand the $P I$.

Central to the $T L-P$ is Wittgenstein's aim of constructing a theory of how language pictures the world, for example, remarks 2.1 and 2.161, quoted as (4) and (5) respectively.

We make to ourselves pictures of facts.

In the picture and the pictured there must be something identical in order that the one can be a picture of the other at all.

In Notebooks 1914-1916 (NB) p.7, Wittgenstein refers to a report he had read in a magazine of a French lawsuit about a road accident while working on the $T-L P$, in which a model had been used in court to represent what had happened, a toy car representing a real car, dolls representing people etc. The picture theory of language (NB p.55) maintains that we similarly form pictures that correspond to possible states of affairs, so that propositions are atomic and foundational.

The picture theory implies that translation is a mechanical process, e.g. TL-P 3.343: 'Definitions are rules for the translation of one language into another. Every correct symbolism must be translatable into every other according to such rules. It is this which all have in common'. Such a mechanical view of translation follows from 
the book's concern with logical symbolism, the way that ordinary language sentences can be given symbolic form through propositional calculus, to which truth values can be applied. Thus, following the picture theory of language, the sentence in (6) can be rendered as (7), where A stands for 'Anna is in the house', B stands for 'Ben has eaten her shoes' and C stands for 'Chris has taken Ben for a walk', while the logical constants '-', ' $\mathrm{v}$ ' and ' $\&$ ' represent 'not', 'or' and 'and' respectively (following Copi \& Cohen, 1994).

(6)

Either Anna is not in the house or else Ben has eaten her shoes and Chris has taken him for a walk.

$-A \vee(B \& C)$

Similarly, the meaning of the constant ' $v$ ' can be defined by the truth table in (8), using ' $\mathrm{T}$ ' to signify 'true' and ' $\mathrm{F}$ ' to signify 'false'. The table shows that the only situation in which the relation ( $p \vee q$ ) can be false is when both $p$ and $q$ are false. (The symbol ' $\mathrm{v}$ ' is understood to be inclusive, i.e. to signify 'either ... or ... or both'.)

$\begin{array}{ccc}\mathrm{p} & \mathrm{v} & \mathrm{q} \\ \mathrm{T} & \mathrm{T} & \mathrm{T} \\ \mathrm{T} & \mathrm{T} & \mathrm{F} \\ \mathrm{F} & \mathrm{T} & \mathrm{T} \\ \mathrm{F} & \mathrm{F} & \mathrm{F}\end{array}$

If (6) translates into (7), it ought to be possible to translate (7) into, say, German, without too much trouble, for we have discovered an ideal way of mapping language (Glock, 2008:39). For the early Wittgenstein, 'I love you' and 'I love $y a$ ' would be the same proposition. 
The work of the later Wittgenstein tells a different story about language and it is this story that is relevant to the theory and practice of translation. The approach of the later work is foreshadowed in the second and final book Wittgenstein published in his lifetime, the 1926 Wörterbuch für Volksschulen (WFV) ('Dictionary for Elementary Schools'), which he designed to facilitate independent learning by providing a reference work for Austrian pupils who needed to check the spelling of a word. Most items accordingly appear without definition, so that the text has the appearance of a vocabulary list. The choice of words is governed by pragmatic considerations. In his Preface ${ }^{5}$ ( $W F V$ p.XXXIII), Wittgenstein stresses that he did not include many good German words because they were not current in Austria, e.g. abgefeimt ('cunning'). Similarly, dialectal items that are part of the educated language are included: an example he gives is Häferl, which he defines by the High German synonym Töpfchen ('little pot'). The ordering of words in the WFV is similarly pragmatic, so that strict alphabetical order is not always followed, as in (9) (WFV p.1). To avoid giving Wittgenstein's text the appearance of a bilingual dictionary, I gloss it separately, in (10).

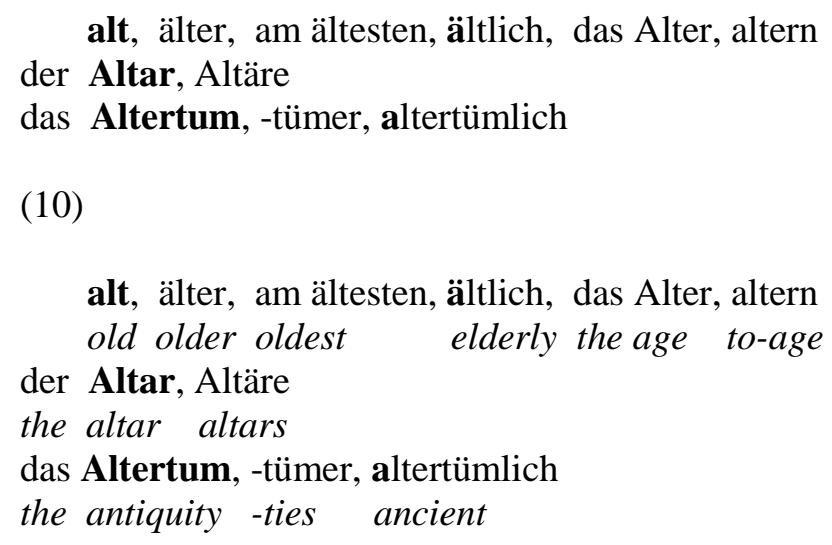

Here, as Wittgenstein comments (WFV p.XXXIV), the noun das Alter ('the age') is placed before der Altar ('the altar') to make it easier for pupils to look up the word, by placing it on the same line as the root adjective alt ('old'), even though this puts it out of alphabetical order: 'each instance of clinging to a dogmatic principle tends to

${ }^{5}$ Omitted in the 1926 edition but included in the second edition of 1977, aimed at Wittgenstein scholars. 
an arrangement that does not suit our purpose and has to be abandoned'. The dictionary is an example of the abandonment of doctrine that characterises Wittgenstein's later work. It is also the work of an educator. Wittgenstein's time in the classroom should be remembered when reading the $P I$, just as his training as an engineer may explain the mechanical view of translation taken by the $T-L P$.

Wittgenstein, who had abandoned philosophy for teaching after the First World War, returned in 1929 to Cambridge and to academic philosophy, convinced that he had been mistaken to believe that he had solved the problems of philosophy in the $T L-P$. He had come to realise in dialogue with the philosopher of mathematics Frank Ramsey that certain propositions are mutually exclusive. A point in a visual field that is red cannot also be yellow, and this is because of the laws of physics rather than the laws of logic. This simple realisation destroyed the whole crystalline purity of logic for Wittgenstein. In PI 107, he describes the world of the TL-P as one of ice, where there was no friction and where consequently it was easy to fall; the new work would represent a move 'to the rough ground', where walking is difficult but at least possible. To give an example of the limitations of the approach of the $T$ $L P$, the sentence in (11) admits of two radically different readings. ${ }^{6}$

I saw her duck under the table.

Did the narrator watch as a female dived beneath the table or did the narrator observe a female's pet bird beneath the table? In the first reading, 'her' is a possessive adjective and 'duck' is a noun. In the second, 'her' is a direct object and 'duck' is a verb. The context is crucial. Without knowing the context, it is not possible to offer a single translation into, say, German, nor a satisfactory symbolisation.

The $P I$ is a very unusual book. It proceeds in numbered paragraphs, referred to by Wittgenstein (PI p.3) as 'philosophical remarks', without chapters and without titles or headings. Paragraphs may or may not be related to what has immediately gone before. Topics come and go and return. Questions are raised but not answered. In contrast to the $T L-P$, the $P I$ has an approach that Monk (1990:261) characterises

\footnotetext{
${ }^{6}$ Thanks to David Cockburn for this example.
} 
as 'anthropological', in the sense that it is set in the world of people, using examples, stories, dialogue, concrete instances of the use of words: the 'stream of life which gives linguistic utterances their meaning'. Symbolism and truth tables are absent: the $P I$, unlike the $T L-P$, is not the work of Russell's successor. Whereas the anecdote of the modelled accident is held to have inspired the $T L-P$, a gesture by the Italian economist Piero Sraffa is similarly held to have instigated the new approach. Sraffa had brushed his chin with his fingertips (a Neapolitan sign of dismissal) and asked: 'What is the logical form of that?' For Wittgenstein this was a revelation: communication depends on many phenomena - such as body language, tone of voice, context etc. - that cannot be pictured by propositional calculus. An entirely new approach to philosophy was the result.

Wittgenstein (PI p.3) writes of how the nature of his philosophical investigations 'compels us to travel criss-cross in every direction over a wide field of thought', so that the book 'is really only an album'. The style of the PI is essential to Wittgenstein's purpose and has evoked 'both high praise and widespread alarm' because of its confessional nature (Cavell, 2000:55). It is the nearest thing possible to sitting in a tutorial with Wittgenstein and it makes great demands on its reader, not least because Wittgenstein is clearly struggling with problems and refuses to give easy solutions, for example, at one point (PI 153) he states: 'I am in a muddle'. Precisely because of the way the PI is written, it is a dangerous practice to quote from it out of context. To use Plato as a counter-example, whilst the Republic, for instance, debates a number of issues and allows different points of view to be heard, Socrates, the central character, advances definite doctrines at certain points: for example, the view that society should be ruled by philosopher-kings (471 ff.); individual sentences can be taken from this section to express what Socrates is trying to teach about authority. Wittgenstein, by contrast, offers a way of doing philosophy. As James Klagge and Alfred Nordmann (1993:viii) assert, much of Wittgenstein's later writing 'appears to exemplify philosophy conceived as an unceasing activity rather than the elaboration of a doctrine'. Perhaps the importance of the style is another reason why Wittgenstein has been read by poets and novelists. Cavell (2001:250) maintains that the style of the PI is not ornamental but essential, as there is no 'aesthetic concern of the text that is separate from its central work', so that the reader needs to make a matching aesthetic effort in order to understand the book. The later work of Wittgenstein accordingly has more affinity with the Vienna in 
which Wittgenstein grew up, of the dramatist Johann Nestroy and the literary satirist Karl Kraus, than it has with the Cambridge of the logician Russell, which is the conclusion of Allan Janik and Stephen Toulmin in Wittgenstein's Vienna (1973). As Beth Savickey (1999:35) asserts, it is possible to see Wittgenstein's later writings beginning where Kraus's writings leave off, in the stress on how language is used in everyday life.

Does the $P I$, then, offer a different theory of language from the $T L-P$ ? It offers no theory at all, which, as McGinn (1997:31) comments, makes the work both difficult to understand and difficult to write about, so that my own discussion of Wittgenstein's thinking in the $P I$ will be developed throughout the thesis rather than being summed up here in the Introduction. In Cambridge lectures given after 1926 when he was at work on what would become the PI, Wittgenstein constantly stressed to his students that he was not offering a philosophical theory but rather the means to escape from theory. The distinction between saying and showing that was made in the $T L-P$ is taken to its logical conclusion. The $P I$ does not tell the reader anything. It shows. ${ }^{7}$

It is a book that offers therapy to its reader, the same sort of therapy that Wittgenstein had gone through since realising that the $T L-P$ was flawed. There is keen debate about how central the therapy is in the PI. Crary (2000a) sees it as essential, and reads Wittgenstein as not putting forward any point of view, but as expressing nonsense in order to make the reader realise that he or she is expressing nonsense. Hacker (2007b), on the other hand, sees therapy as an aspect of Wittgenstein's style, which I also find to be the case. The orthodox interpretation of Hacker and others (Kahane et al., 2007:2) allows the reader to engage with the views put forward by Wittgenstein, rather than being a passive recipient of treatment.

Three analogies can illustrate the therapeutic aspect. Wittgenstein's approach firstly resembles the psychoanalytic approach of Sigmund Freud (1999), which aims to show the patient exactly what is going on in his or her mind, as a means to the end of curing neurosis or psychosis. Secondly, it is like the approach of the Jesus presented by the synoptic Gospels (Matthew, Mark and Luke), whom Don Cupitt and Peter Armstrong (1977:66) describe as not promoting a metaphysic but as using language in such a way that the hearer is brought to an understanding of his or her

\footnotetext{
${ }^{7}$ Such an approach is often seen as fundamental to the art of storytelling (Benjamin, 1999:89).
} 
real situation: 'The reader has understood his teaching when he has been changed by it'. A third analogy comes from considering Wittgenstein's style of writing in the PI, as described in $C V$ p.28: 'philosophy ought really to be written only as one writes a poem'. The analogy is that of the poet, who makes the reader work hard to meet him or her halfway. Poems tend to inspire a variety of readings, because like stories they show rather than tell (Mitchell, 1992:56), which may explain why there are so many radically different readings of Wittgenstein (Kahane et al., 2007). To translate Wittgenstein would similarly involve translating him as if he were a poet. Venuti (1998:107) comments that this is the approach of Anscombe in her rendering of the $P I$, which will be discussed in 3.4. The PI is more reminiscent of the Spiritual Exercises of Ignatius Loyola (2005), a sixteenth-century meditation manual, than of works by Wittgenstein's philosophical contemporaries such as the Logical Positivists (Ayer, 1990). It is an approach adopted in modern philosophy in the seventeenth century by René Descartes in his Meditations (1968) (whom Kerr compares to Ignatius, 1998:50). Other modern philosophers who have written in a similar way include: Søren Kierkegaard (2004); Georg Lichtenberg (1984); Nietzsche (2001); Blaise Pascal (1982).

There are many other later writings by Wittgenstein now available, which address other topics, such as knowledge in On Certainty $(O C)$, or the philosophy of mathematics in Remarks on the Foundations of Mathematics (RFM), as well as the sort of concerns found in the $P I$, for example $P R$. Yet the $P I$ occupies the central place in Wittgenstein's oeuvre. It is the book chiefly studied by philosophy undergraduates and that attracts the most commentary among the published work. As Klagge and Nordmann (1993:ix) assert: 'To understand Wittgenstein as he would want to be understood, we should focus on the works that come closest to passing muster with him'. The PI was the work that he intended to be published after his death to represent his later thinking, which had entered philosophical debate informally through his Cambridge lectures. Can it be applied to other areas of inquiry, such as translation? 


\subsection{Applying Wittgenstein}

In Johann Wolfgang von Goethe's Faust (1972:44), a retelling of the legend of the scholar who sells his soul to the devil, Faust undertakes the translation of the NT into German, beginning with John 1:1. No source language (SL) is specified by Goethe, but in (12) I give the Hellenistic Greek (HG) of the ST, with transliteration and gloss. ${ }^{8}$ The usual translation of this sentence into English is, 'In the beginning was the Word' (cf. New Jerusalem Bible).

'Ev $\dot{\alpha} \rho \chi \tilde{\eta} \quad \hat{\eta} v$ o $\lambda o ́ \gamma o s$
En archê ên ho logos.
in beginning was the word

Faust, clearly a translator who can see beyond linguistic meaning (defined by BoaseBeier and Lodge (2003:12-13) as that which is found in a dictionary) renders the notoriously difficult Greek word $\lambda o ́ \gamma o \varsigma[\operatorname{logos}]^{9}$ in three ways before arriving at the translation that consoles him, which I give as (13).

Im Anfang war die T a t!

in-the beginning was the deed

He rejects the linguistic meaning - Wort ('word') - as well as the more creative renderings Sinn ('sense') and Kraft ('power'), settling on Tat ('deed'), a concept that is emblematic of the striving central to Goethe's dramatic poem, where virtue is identified with ceaseless activity, so that it is fitting to identify the Word of God with the Deed of God.

'Im Anfang war die Tat' ('In the beginning was the deed') is quoted by Wittgenstein in $O C 402^{10}$ and Monk (1990:579) claims that it can stand as the motto not just of $O C$ but of the whole of Wittgenstein's later philosophy, where language is

\footnotetext{
${ }^{8}$ All NT quotations are from Aland et al. (1968).

${ }^{9}$ See Green et al. (1992:481-484) for a discussion of the philosophical and religious connotations of the term in the first century when John was writing.

${ }^{10}$ Wittgenstein misquotes Goethe by not highlighting Tat and omitting the exclamation mark.
} 
seen as an activity, a practice open to investigation, something that human beings do; 'Words are also deeds' (PI 546). Language is dynamic rather than static, it makes things happen, it produces effects in the real world. It has more to do with brushing your chin with your hand than with writing a truth table to analyse a proposition. Faust is performing, through his translation of John, what Wittgenstein (PI 116) identifies as the primary task of the philosopher: to bring back words 'from their metaphysical to their everyday use'. I have accordingly used Goethe's phrase as the motto for this Introduction. How is everyday use to be investigated?

Wittgenstein (PI 90) remarks: 'Our inquiry is therefore a grammatical one'. It is through the grammatical investigation that the philosopher restores the everyday. The grammatical investigation will be analysed further in 2.4 and 4.4, but here an example of the method can be given: how Wittgenstein (PI $66 \mathrm{ff}$.) looks at the concept of a game in order to show that there is no metaphysical common denominator linking the phenomena that we categorise as games. Any search for one runs into difficulties. If (to use my own references) I claim that a game involves a team (such as rugby or cricket), then tennis singles does not fit this category. If I claim that a game is about winning or losing, then the co-operative board game Star Trek: Expeditions has not been included in the definition. If I claim that a game needs set rules, then this does not make sense of the child playing a game in which he or she makes up the rules as he or she goes along. Wittgenstein uses the concept of 'family resemblance' to describe games. All games have some feature in common with at least one other game, but 'it would be foolish to say that all these activities are part of one supergame', as Peter Winch (2008:18) comments. The situation is therefore analogous to that of a family, where the members share various physical characteristics but are not identical. (One member has the same-shaped nose as another, but completely different eyes, which are the same colour and shape as those of a third family member, etc.) Wittgenstein's grammatical investigation shows that the concept of a game is one with 'blurred edges' (PI 71). Confusion is replaced by clarity.

If Wittgenstein is offering philosophy as a tool, a means of solving puzzles that does not interfere with the use of language but describes it (PI 124), then it is possible to apply this philosophical method to other areas of inquiry, which would not be possible with a philosophical theory. The philosopher Charles Taylor, for example, expresses a theory when he relates how we live now to the 'affirmation of 
ordinary life' characteristic of the Reformation (1998:211-223). The reader who is convinced by Taylor's argument cannot go out and affirm ordinary life in his or her existence by applying Taylor's theory, because that is to misunderstand what is a descriptive project. With Wittgenstein, the situation is different, because the $P I$, as argued in 1.3, does not advance a theory as doctrine. Rather it instantiates a number of methods, which can be applied (viewing application as the use of a general framework to aid a particular purpose). Grammatical investigations, in Wittgenstein's sense, can form the basis for applying Wittgenstein to fields outside philosophy. The procedure can be illustrated through an example from a detective story by Arthur Conan Doyle (2005:39), quoted as text (14). The narrator is Doctor Watson and the other speaker is the detective Sherlock Holmes.

'What is your theory, then, as to these footmarks?' I asked eagerly, when we had regained the lower room once more.

'My dear Watson, try a little analysis yourself,' said he, with a touch of impatience. 'You know my methods. Apply them, and it will be instructive to compare results.'

If Holmes were to reveal to Watson his own view of the matter, Watson would not be able to apply it, although he would be able to do tests to show whether his mentor's theory was sound or not. Holmes is asking Watson to try to look at the evidence after the manner of Holmes (considering all possibilities, eliminating the impossible, attempting to see things from the point of view of another etc.) in order to come up with a theory of his own.

In the three examples of applying Wittgenstein I now discuss, changing the way we look at things has potentially radical conclusions for the field in question. In 1.5.1, I describe an episode from Wittgenstein's life when he was involved in medical research, using Monk (1990:449-453), in order to show one specific application of Wittgenstein's methods; in 1.5.2, I examine how Gareth Moore has applied Wittgenstein's methods to theology; in 1.5.3, I look at how Perloff has used Wittgenstein to investigate the translatability of poetry. There are many other areas in the humanities where Wittgenstein is now being applied, such as: human rights (Holt, 1997); law (Patterson, 2004); politics (Lavery \& Read, 2009). The three 
examples used below have been chosen for these reasons: looking at Wittgenstein's life (1.5.1) helps to understand the spirit of his work; theology (1.5.2) is an area in which Wittgenstein has been influential; the use of Wittgenstein in translation studies (1.5.3) makes a suitable bridge into the main body of the thesis.

\subsubsection{Wittgenstein's work in medical research}

During World War Two, Wittgenstein's work as a laboratory assistant took him to a research unit run by Doctors Grant and Reeve in Newcastle, where he played an active role in the investigation of the 'shock' from which many servicemen were diagnosed as suffering. Reeve would comment later that he was influenced by Wittgenstein in two ways: keeping in mind that things are as they are; seeking illuminating comparisons to gain such an understanding. These are both central themes of the PI: Wittgenstein aims to free his reader from misleading pictures by looking at how terms are used in ordinary life, for example, the analysis of pain (PI $281 \mathrm{ff}$.); and he often uses analogies, for example, the investigation of games referred to above becomes an illustration of how language works as a whole (PI 77).

The final report issued by the unit asserted that to use the term 'shock' at all was a misguided strategy, because it was of no practical help as a blanket term. A doctor, called to a wounded person who had been diagnosed with shock, might find a wide variety of symptoms in that patient. Two patients, who had both been diagnosed with shock, might have significantly different symptoms and might need different treatments. An interpretation, as opposed to a description, was being made about a wounded patient by the doctor doing the initial diagnosis. It would be like saying that somebody is suffering from shock and neglecting to mention that he or she has a badly cut hand. The situation is reminiscent of the current use of 'stress' as a term to cover a multitude of problems, ranging from depression to overwork, so that 'stress' effectively becomes useless as an indicator of what is wrong with an individual (Patmore, 2006).

The conclusions of the report were that what was needed was a clear description of a patient's symptoms and that the term 'shock' should be dropped. The Medical Research Council's report for 1939-45, commenting on the unit's work, asserted that it "threw grave doubt upon the value of attacking the "shock" problem 
as if wound "shock" were a single and pathological entity' (Monk, 1990:452). The unit was thus able to turn to detailed observations of injuries sustained in warfare, in an attempt to be able to provide clearer diagnoses.

The Wittgensteinian search for clarity had two practical effects. Firstly, it closed down misguided lines of research, in line with the contention of Wittgenstein (PI 339) that an inappropriate expression 'is a sure means of remaining stuck in confusion'. Secondly, it opened up more positive paths, in line with the emphasis laid by Wittgenstein (PI 115) on 'the value of the discovery' that a picture is holding us captive, so that better ways forward can be found. The search for clarity, involving the rejection of misleading interpretations and the search for correct description, can also be seen in those philosophers of religion who look to Wittgenstein for inspiration, for example, Moore.

\subsubsection{Moore's theological investigations}

In Believing in God (1998), Moore takes what Howard Robinson (2003:353) calls a radically Wittgensteinian approach to the existence of God, for he does not look at theism as a revealed religion but examines the way in which believers in God use language. Moore undertakes a grammatical investigation of God-talk, 'a sketch towards a philosophical understanding of Christianity' (1998:ix). Of the ten works in his bibliography (1998:288), seven are by Wittgenstein, whose methods Moore applies throughout the text. His analysis shows how, for example, the propositions (15) and (16) (my examples) seem to have the same grammatical form, with the pattern of [subject - verb - direct object] in the past tense.

Anna made the table.

God made the world. 
Reflection on the way that these sentences are used, however, shows they are very different. ${ }^{11}$ Anna, the subject of (15), is a young woman with a talent for making tables. In (16), the term 'God' does not refer to a person in the world (even the world of the imagination) in the same way, for God is held by theists to be the reason why there exists anything at all. Moore (1998:34 ff.) calls this "the logical "oddity" of God' and compares God to the term 'equator'. The equator, most people would say, does exist, but not in the way that Anna exists. I can neither touch it nor label it. If I see a sign saying 'EQUATOR' then what I am seeing is only a sign for the equator, not the equator itself. It does, however, make perfect sense to say that I flew over the equator, because of the way that the term 'equator' is used in the language as a whole. Similarly, when I talk of God, my philosophical grammar is different from when I talk of Anna, because God is not a person. Theists do not believe that there is one more thing in the world than atheists think there is (Moore, 1998:20), which means that (16) can be rewritten as (17), which I imagine would be an astonishing conclusion for many practising Christians.

Nobody made the world.

It reflects the 'negative way' found in Christian theology, for example, in PseudoDionysius (1986), who sees religion as an apophatic stripping of metaphysical concepts. It also allows Moore to stress the role of practice in the Christian life (1998:35 ff.) in a way that leads back to the practical ethics of the NT and which avoids the identification of Christianity with the epistemic. Moore takes the concept of serving God, for example, to mean that the Christian should serve nobody, i.e. observe a total freedom (1998:133 ff.).

Moore's conclusion (1998:287) is that people 'do not discover religious truths, they make them', which is reminiscent of the position on the philosophy of mathematics that Wittgenstein defended against the mathematician Alan Turing in a series of Cambridge lectures, Wittgenstein insisting that mathematical truths were invented, Turing that they were discovered. Moore's is a revisionist theology, a

\footnotetext{
${ }^{11}$ Wittgenstein's notions of surface and depth grammar - see 2.4 - would be helpful here, but Moore does not use them.
} 
consistent if controversial position argued from a grammatical investigation of religious language, one which offers the possibility of a non-supernatural religion.

The same objection can be made to Moore that was made by Ayer (1985:92) to the use of Wittgenstein by philosophers of religion: 'I am not myself a religious believer but if I were I doubt if I should be content to be told that I was playing a game in accordance with a canonical set of rules. Rather, I should wish for some assurance that my beliefs were true.' For Ayer, applying Wittgenstein to religion is an application too far. Ayer's conception of belief is that it is something that has to be ultimately testable. He and Moore effectively refer to different things by the concept of faith. Such an objection, whether well-founded or not, cannot be made to the application of Wittgenstein to translation: Wittgenstein is (among other things) a philosopher of language and translation is (among other things) a linguistic undertaking where empirical research is possible.

An important way in which Moore is Wittgensteinian is that he does not constantly refer to Wittgenstein as he writes. Moore moves on from Wittgenstein by applying his methods. I am writing an academic thesis, the text-type of which demands frequent referencing of the subject of my investigation, i.e. Wittgenstein, but it is important to note that Wittgenstein's aim is for his readers to move beyond what he himself wrote. In PI p.4, he asserts: 'I should not like my writing to spare other people the trouble of thinking. But, if possible, to stimulate someone to thoughts of his own.' This later position is reminiscent of the way in which at the end of the $T L-P(6.54)$ he speaks of the need for the reader to throw away the ladder after having climbed it, and the application of Wittgenstein to translation can in its turn be a ladder, allowing translation to be seen more clearly and its practice to be improved, which are the aims of translation studies according to Venuti (2004:13).

\subsubsection{Perloff on Wittgenstein and poetic translatability}

Perloff references PI 215 in the full title of her essay - 'But isn't the same at least the same?": Wittgenstein and the question of poetic translatability' - and I give Wittgenstein's remark as (18), in the revised translation.

But isn't at least the same the same? 
For identity we seem to have an infallible paradigm: namely, in the identity of a thing with itself. I feel like saying: 'Here at any rate there can't be different interpretations. If someone sees a thing, he sees identity too.'

Then are two things the same when they are what one thing is? And how am I to apply what the one thing shows me to the case of two things?

Perloff (2004:34) examines various English translations of the opening line of the first of the German Duineser Elegien (Duino Elegies) by Rainer Maria Rilke, finding them unsatisfactory and asserting that the poetic is that which cannot be fully translated. An analysis follows (2004:35-36) of part of Robert Lowell's poem 'Skunk Hour' and its German translation by Manuel Pfister. Perloff considers that Pfister has lost Lowell's tone and concludes that translation 'inevitably involves ... slippage of meaning, especially in the case of poetry' (2004:36), though the relationship between tone and meaning is not made clear. For those engaged with the translation of poetry, this might be a depressing conclusion, reminiscent of Robert Frost's supposed dictum ${ }^{12}$ that poetry is what is lost in translation, a phrase Perloff herself uses (without referencing Frost) when she claims that Rilke's 'dense sonic network is inevitably lost in translation' (2004:35).

Perloff's use of Wittgenstein does little to improve matters. David Antin's contention (1998:163) is quoted, that Wittgenstein 'is not a poet of the German language or of the English language; he is a poet of thinking through language ... a poet of nearly pure cognition', and Wittgenstein's own assertion ( $C V$ p.24) that his philosophy is written as a form of poetic composition is interpreted as Wittgenstein aiming to provoke awe in his readers (2004:42), rather than as a comment upon the style of his writing. Perloff (2004:37) contrasts denotative language and connotative language: the former is used for establishing meaningful propositions, the latter exhibits literary features, such as rhythmic or sonic qualities. Denotative language is translatable: Perloff refers to Wittgenstein, who in her opinion uses denotative language and who has been successfully translated into many languages. Connotative language is not translatable, which is why poetry is usually lost in translation. Some poems, such as Quelque chose noir (Something Black) by Jacques Roubaud do use denotative language, and therefore here the same can be the same.

\footnotetext{
${ }^{12}$ David Bellos (2011:52) notes that nobody has ever found this phrase in Frost's work, but that it is very commonly used in debates on poetry and translation, with over 15,000 internet references recorded in 2011.
} 
Rilke cannot be translated, but Roubaud can, for example in the renderings by Rosmarie Waldrop that Perloff examines (2004:51).

Perloff does make good points about how Wittgenstein may be used for translation: she notes, for example, that 'meaning can only be established by studying each word group or sentence in the larger context in which it appears' (2004:52) and I refer in 3.2 to her illuminating comments on Georges Perec and his translator Gilbert Adair. Her attempt to apply Wittgenstein, however, seems to me to be nothing short of disastrous. Firstly, Perloff's use of Wittgenstein is chiefly confined to the notebook material collected in $C V$. Use of the PI is minimal. It is mentioned but not applied, so that the article becomes an instance of what John Searle (Magee, 1987:342) complains about when he notes that 'most of the references to Wittgenstein in fields outside philosophy are really a kind of philosophical name-dropping'. There is no problem in referring to $C V$ to expand our knowledge of what Wittgenstein thought about his work, but it seems to me to be a shaky foundation for a theory of how Wittgenstein's philosophy relates to poetic translatability. Secondly, Perloff's division of poetry into either the denotative or the connotative exhibits the essentialism and the dualism against which Wittgenstein's later work fights (Kerr, 1998). The concept (from Antin) of Wittgenstein being a poet of pure cognition is contradicted by the stress in the $P I$ that form and content cannot be divorced: in PI 568 meaning is seen as a physiognomy, because thought cannot be extracted from the form of life in which it is expressed. Thirdly, Perloff's contention that the translation of poetry inevitably involves slippage must be weighed against those translated poems that are held by scholars not to have lost the tone of the ST author, even when the ST is written in highly literary language. Phyllis Gaffney, for example, analyses renderings of Hopkins into French by Pierre Leyris and concludes that Leyris's translation 'not only says what the original poem says, but does what the original poem does' (1999:57). And yet this does not mean that the same is here the same: ST and TT remain different texts. Close attention to PI 215 (which Perloff does not give in full and does not analyse) shows that Wittgenstein is questioning the notion of essentialism, the fact that we impose unity on phenomena when we ought to be describing them. Perloff begins with the conviction that poetry cannot be translated. The need is not to think, but to look, which is the topic of Chapter 2. 


\subsection{Conclusions}

Read (2007a:4) stresses that 'what matters is whether Wittgenstein's chosen methods work ... whether we can learn to go on'. In the following chapters, I go on by examining the phenomenon of translation, asking how it can be illuminated by the story told by Wittgenstein. Chapter 2 examines the reading of the source text (ST) for translation; Chapter 3 examines the writing of the target text (TT); Chapter 4 examines the theorising of the TT. These three aspects reflect the way that a translator must deal with a work that is to be translated, such as a novel: the novel is read for translation, then translated, finally theorised (for example, by an introduction or notes, or by a translation scholar). These stages are not necessarily consecutive. A translator will read and re-read constantly while translating and may form a view of a text, i.e. a theory, during the process of reading for translation. My thesis therefore does not prescribe an order of events, but presents an album where many of the considerations on translation will go criss-cross, as Wittgenstein describes his project (PI p.4). In this sense at least it will resemble Wittgenstein's later work, with its turn to the rough ground (PI 107). As Wittgenstein ( $C V$ p.7) notes about his writing: 'Each of the sentences I write is trying to say the whole thing, i.e. the same thing over and over again; it is as though they were all simply views of one object seen from different angles'.

John Kay (2011:176) argues that good decision making is best done obliquely, relying on 'a toolkit of models and narratives rather than any single account'. The research question of this thesis is whether Wittgenstein can provide such a toolkit of models and narratives.

I mentioned in 1.4 the different readings of Wittgenstein that are available. In 'Translation after Wittgenstein', I offer my own reading with respect to translation, based on extensive reference to the PI. To adapt what Kerr says in Theology after Wittgenstein (1998:190): the reader will be immersed in an anthology of Wittgenstein's texts, many of which will stay in the memory, whatever is to happen, after Wittgenstein, to the practice of translation. 


\section{READING THE SOURCE TEXT FOR TRANSLATION}

I'll teach you differences.

Shakespeare (1972:81) 


\subsection{On not thinking but looking}

Wittgenstein (Teichmann, 2008:1) considered using a quotation from King Lear (Shakespeare, 1972:81) as a motto to the PI: 'I'll teach you differences'. I have chosen to use it as a motto to this chapter - on reading the ST for translation because it illustrates a basic contention of my thesis, i.e. that translation involves looking at the features of a literary work and that Wittgenstein can help us to do this. He can teach us differences by showing us how to look. In PI 66, in a discussion of games in reference to the way we use language to describe phenomena, he offers this advice to his reader: 'don't think, but look!' James Guetti (1993:1) argues that the reason why Wittgenstein provides a valuable access to literary questions - which would include literary translation - is because his philosophy 'privileges nothing above language'. The PI, whilst it has great implications for other issues in philosophy (as I discuss in Chapter 3), is primarily an investigation of language.

Reading is a linguistic practice, related to the status of the human being as a linguistic animal. A dog seems to have emotions, longings, intentions and can be happy or sad, but not, as Wittgenstein (PPF 363) notes, either hypocritical or sincere. A dog cannot speak and cannot express any regret for past misdemeanours or for the fact that the climate of the world is changing. Nor does a dog sit down and peruse a novel before dinner. To read a text is to engage in a peculiarly human undertaking, an everyday activity that forms part of the stream of life investigated by Wittgenstein in his later work.

It is trivially true that nobody can translate the ST that he or she has not read. Parallel to physical necessity is aesthetic necessity, however, because the translator must make decisions in reading about how he or she will render the work. Clive Scott (2008:18) asserts that the translator "who does not integrate [his/her] reading into his/her version of the text is betraying his/her value and destiny as a reader', whilst Michel Deguy (2008) goes as far as to describe his translation of a Seamus Heaney poem as a reading of that poem: 'Pylos: Poème lu par Michel Deguy' ('Pylos: poem read by Michel Deguy'). In PI 164, Wittgenstein shows how the term 'reading' is used for 'a family of cases' so that we are led by the use of the word 'reading' into thinking that the same thing is going on when, say, reading silently or reading aloud, whereas very different criteria apply. As Boase-Beier (2006b:24) points out, 'reading for translation' differs from other types of reading, such as reading for pleasure or reading for information: to sit down and read, say, a poem by 
Goethe with a view to translating it may lead to the translator noting how certain aspects of the poem might be maintained in his or her translation, such as an image or the rhyme scheme. The formulation of a rendering becomes part of the reading process.

The PI offers a series of exercises that can be used by the literary translator to this end. In PI 336, for example, Wittgenstein tells the story of a French politician (probably Louis Le Laboureur, 1669:174) who failed to look outside the constraints of his own language. The remark is given as (19).

[The case when] someone imagines that one could not think a sentence with the curious word order of German or Latin just as it stands. One first has to think it, and then one arranges the words in that strange order. (A French politician once wrote that it was a peculiarity of the French language that in it words occur in the order in which one thinks them.)

A speaker of French may find it 'curious' that in German the main verb is in terminal position in subordinate clauses. The error here is to fail to realise that what we have is a different way of using language, not an encryption of a French pattern. Germans, similarly, are surprised that in French the predicative adjective agrees with the substantive in gender, which it does not in German (PI 538). The French politician has made the error of seeing French as a language that corresponds precisely to the language of thought ${ }^{13}$, an essentialist view that fails to note how language is a dynamic system that can be used in different ways (Lodge, 1998). Seventeenthcentury French, for example, is very different from the French of the Middle Ages. Wittgenstein satirises the view that French is the norm, i.e. the one and only language in which it is not necessary first to think the words and then to arrange them into the curious word order of the language in question. That in the end Wittgenstein chose to preface the $P I$ with a motto from the satirist Nestroy is a clue that satire is one of his intentions (PI p.2). ${ }^{14}$ To adopt the French politician's view of languages would be to adopt a theory of language that is far too complicated. It is hard to believe that Goethe, say, first thought some words and then re-arranged them

\footnotetext{
${ }^{13}$ See Carruthers (2006) for an account of the language of thought.

${ }^{14}$ The significance of the motto is further discussed in 5.3.
} 
mentally according to a number of pre-given rules before speaking them or writing them. Through this story Wittgenstein portrays the tendency that human beings have to see linguistic matters wrongly. German is not a faulty version of French, but a different language. The point seems a trivial one, but corrects a tendency in how we think. An example from literary translation can show how Wittgenstein's point matters.

Helen Lowe-Porter, the first translator of Thomas Mann's German novels into English, believed that the way that Mann wrote German was because of the nature of the German language, rather than because of any particular stylistic genius on his part: for example, she refers to the way that German has longer sentences than English, which must therefore be broken up in English translation so as 'not to produce clumsy English' (Thirlwell, 1966:199), failing to see that Mann's long sentences were a result of choice, and that it is possible to imitate such long sentences in English. Anthea Bell (2011:213), for example, describes how she maintains a sentence of nine pages in her translation of a Sebald text, in order to preserve the way the sentence conveys the mindless haste of a concentration camp being given the appearance of a holiday camp. Lowe-Porter's view, which parallels that attributed by Wittgenstein to the French politician, may help to explain why her translations have been criticised for failing to represent Mann's style (Gledhill, 2007:57).

It is necessary to look at how speakers and writers choose to speak or to write, rather than to begin with a theory of how language directs its speakers, and it is the possibility of choosing to work creatively with language that makes literature possible (Boase-Beier, 2006b:1). In Zettel ${ }^{15}$ (Z) 160, Wittgenstein remarks that a poem is not about giving information, even though it appears to be written in the language of giving information, which is an important lesson to learn. As Severin Schroeder (2001:210) notes, much twentieth-century literary theory, such as Marxist theory, has been ruled by the view that what matters in a work of literature is the message that it is intended to convey, which misrepresents the literary work. A reading of Wittgenstein shows why the trend to look for information has been so dominant: we mistake what goes on in certain cases for what must go on in all cases. Thus, we note that Karl Marx and Friedrich Engels (1970), for example, use the

\footnotetext{
${ }^{15}$ German: Fragments.
} 
language of information to set out their critique of other Young Hegelians, and we (correctly) view their book as a polemical exercise in conveying this message. We then assume that a poem must similarly fulfil an informative function and fail to note that there is a difference. Derek Attridge ${ }^{16}$ (2004:26) argues against the tendency by stating that a literary work does not have a function. In Wittgensteinian terms, a poem (and by implication other literary works) is not about conveying information. It is wrong-headed to sit down to read, say, one of Shakespeare's histories to learn about English history. Attridge uses the concept of the 'singularity' of literature to describe this lack of function. From the point of view of literary translation, it is crucial to see the literary text as literary. Attridge (2004:96) argues that it is possible to read George Eliot's novel Middlemarch, an established text in the canon of English Literature, as fiction 'without at the same time reading it as literature', although it is not possible to read it as literature without reading it as fiction. To read Middlemarch as fiction would involve, perhaps, following the story to see what happens to the characters; whereas to read it as literature might involve responding to the style (as further discussed below). Two translators, both competent linguists, might both translate Eliot's novel into the same TL. In one case, where Middlemarch has not been read as literature, the TT is unlikely to be a literary translation; in the second case, where it has been read as literature, it may be a literary translation (as further discussed in Chapters 3 and 4).

Thus Wittgenstein (PI 531) can speak of understanding a sentence in terms of replacement but points out that such an understanding does not apply to the literary. The remark is given as (20).

We speak of understanding a sentence in the sense in which it can be replaced by another which says the same; but also in the sense in which it cannot be replaced by any other. (Any more than one musical theme can be replaced by another.)

In the one case, the thought in the sentence is what is common to different sentences; in the other, something that is expressed only by these words in these positions. (Understanding a poem.)

\footnotetext{
${ }^{16}$ Attridge (2004:143) states that his views are influenced by his reading of the later Wittgenstein.
} 
In the four examples ${ }^{17}$ (21)-(24), various replacements can be made in terms of getting a point over.

I can walk.

I am able to walk.

I have recovered from the operation on my legs.

I don't want a lift, thank you.

The imagined context is a speaker recently recovered from an operation on her legs, and who can replace (21) with (22) in order to communicate this fact. If offered a lift, which she does not want, she could use any of the four statements to convey her meaning. In other contexts, such as being asked by a visitor how she is, it would make no sense to replace (21) by (24), however. Replacement here is contextdependent, but it can be satisfactorily made. The situation is without clear boundaries. However, the two lines from the sonnet 'The Windhover' by Hopkins (1985:30), given as (25) cannot be replaced by the text I have written as (26), not because (26) does not represent the content of (25), but for the same reason why one theme by Ludwig van Beethoven cannot be replaced by another.

I caught this morning morning's minion, kingdom of daylight's dauphin, dapple-dawn-drawn falcon ...

(26)

This morning I saw a falcon announcing day, silhouetted against the patchy sky of dawn.

${ }^{17}$ Thanks to Marie McGinn for these examples. 
It cannot be replaced at all; otherwise a different event would take place, such as explicating the poem to a student. The work of art, as Wittgenstein stresses, 'does not aim to convey something else, just itself' ( $C V$ p.67). To replace (25) with (26) is a replacement too far.

(Such a position raises the question of whether it is possible to replace a literary text with a translation, which I discuss in 5.2. For the moment I note Wittgenstein's comment in $Z 155$ that a poet's words 'can pierce us' because of 'the use that they have in our life', which suggests that to replace the ST by its TT would mean preserving the use it has in our life. If I substitute one theme by Beethoven for another, I have changed the use, just as if I substitute one poem by Shakespeare for another. But, given that I do not speak Russian, the only way in which I can use a Russian poem in my life will be through a translation. How this might be done is the subject of Chapter 3.)

If I read Goethe's Faust (1972) as a warning not to sell my soul to the devil, then I miss the point, even though this work is about a man who sells his soul to the devil with disastrous consequences. The literary work cannot be divided arbitrarily into content and form, something shown by the depiction by Raymond Queneau (1947) of an incident on a bus in ninety-nine different styles, ranging from Alexandrines to an official letter. Matt Madden, discussing his own graphic imitation of Queneau, in which a domestic story is told in ninety-nine different drawings, concludes that the debate needs to be moved away from the eternal battle between form and content or style and substance to a new model: 'form as content, and substance inseparable from style' (2006:1). Wittgenstein (PI 568) asserts that meaning is 'a physiognomy'. If I want to know what somebody is feeling, then it is a good idea to look at his or her face. David Cockburn (2009:128) notes how much 'of what we learn about others we learn through their emotional expression'. If I want to know what a Hopkins sonnet means, then I similarly need to look at its physiognomy. Thus the poetry of Hopkins differs markedly in style from that of G.K. Chesterton (1994), although both poets share the same Catholic ideology. The physiognomies, i.e. the styles, differ. I need to learn how to read them.

Wittgenstein sees reading as a set of practices that can be taught, in accordance with the general contention of the $P I$ that the mastery of a language is the mastery of a technique (PI 199). Eagleton (2007) devotes a whole book to how to read a poem, stressing that reading a poem is an art, like 'thatching or clog-dancing' 
(2007:1), and Schulte (2004:156) notes, in an essay on a how a reading of Wittgenstein can deepen an appreciation of poetry, that the fact 'that one can take trouble to get the tone exactly right shows that there is something one can try to do well, something which one may fail to do well', which suggests that getting it right is something that can be learned. Instead of seeing a series of lines that are unconventionally aligned when I look at The Windhover, I may come to see a poem. It remains of course true that many poems are left-aligned. Students need to learn that this is only a part of what they are: as Eagleton (2007:3) asserts, it is not the case that the computer got stuck. Wittgenstein notes (PI 156) how the verb 'read' is applied differently in the case of the beginner and what he calls the 'practised reader': there has been a change in behaviour.

Wittgenstein can therefore be used in the training of literary translators. Boase-Beier (1998), addressing how literary translators can be trained, stipulates that attention must be placed on the way in which literary translators read the ST and not on the way in which they translate. She concludes (1998:41): 'What training of translators involves is showing them how language works, above all how literary language works, so that in any individual case they will have at their disposal the means for understanding how the particular text works'. Her method, which is seen in the course structure of the MA in Literary Translation at UEA (2010:np), is to offer students training in stylistics. Not only would Wittgenstein offer support for such a stylistic approach to translation - in $C V$ p.80, he analogously stresses that to learn how to appreciate music begins with learning how music works - but the PI forms a set of exercises on the understanding of how language works that students could work through. To read one of its stories, such as the builders who communicate using only four words (PI 2 ff.), is to be invited to see language in a different way and to deepen one's understanding of it, hence illumining the reading for translation of the ST. In his dramatisation of Wittgenstein's builders, Stoppard (1980:74) has one of the characters realise that language is caught and not taught, for example.

Human beings bring many preconceptions to the understanding of what goes on in reading. If I pick up a piece of paper covered in symbols and read an account written by somebody whom I have never met, detailing events of which I could have had no prior knowledge, then this appears to be very like breaking a code, and the code model of communication, defined by Dan Sperber and Deidre Wilson (1995:2) 
as the belief that 'communication is achieved by encoding and decoding messages', has been very influential in views on reading. It was held by Roman Jakobson (1959), for example, and seems to represent a natural way of viewing language: to read (or to listen, or to translate) is to decode. The young Jude, in Thomas Hardy's Jude the Obscure (2007), has such a code model in his head when he forms the desire to learn Latin and Greek, a task that seems to him to be straightforward: 'He concluded that a grammar of the required tongue would contain, primarily, a rule, a prescription, or clue of the nature of a secret cipher, which, once known, would enable him, by merely applying it, to change at will all words of his own speech into those of the foreign one' (2007:28). Jude's 'childish idea' is to assume that there is a 'law of transmutation' (2007:29) and he is devastated to learn that this is not so and that he will have to learn the necessary vocabulary and grammar.

Jude has a false picture of language. He is freed from it by his research into the classics, but his idea remains emblematic of the human tendency to see meaning in terms of cryptography, by which the reader with a key can crack the code and can find the solution to what was formerly unintelligible (Piper \& Murphy, 2002:2). Language certainly does have a code aspect: to teach a child to read English, it would be necessary to show how certain letters relate to certain sounds, for example, so that the letter ' $b$ ' at the beginning of a word is the signal for a bilabial voiced plosive, as in 'Ben' or 'butter'. But, as Sperber and Wilson (1995:2) argue, a code model is not sufficient to explain human communication, for it ignores context. To use Wittgenstein's own encoded notebooks as an example: there is only one correct way of decoding these, but different ways of understanding them (Monk, 1990:581586). Sperber and Wilson (1995:2) suggest combining the code model with the 'inferential model', which holds that 'communication is achieved by producing and interpreting evidence'. Decoding may be a necessary condition of communication, but it is not a sufficient one. To decode a word is possible in the sense of knowing how to pronounce it or spell it or look it up in a dictionary, but decoding is only about intension. Meaning, as Sperber and Wilson stress, has an extensional aspect and this is where the reading of Wittgenstein is of profit to the translator, because it is a philosophical investigation that broadens our understanding of meaning: we stop looking at language as a code, as a calculus, as a denotation, and see that it is a human practice, which parallels the Wittgensteinian approach to language. 
The code model is not held by contemporary linguists, though writers who did use it, such as Jakobson, still have an influence on contemporary work. It might therefore seem that to turn to Wittgenstein as a way of freeing oneself from the code model is to use the philosopher to fight against a straw man. This is not the case, however, because to see language as a calculus is a psychological rather than a logical compulsion (Bellos, 2011:258), a point made by Wittgenstein in PI 140, and the compulsion has not gone away because of developments in linguistics. Modern manuals on translation therefore still find it necessary to point out to their readers that translation is not about decoding. Douglas Robinson (2003:148), for example, states: 'What we do not do is sit down with a comprehensive set of rules for linguistic equivalence and create a text that conforms to them. That is the image projected by traditional linguists when they have studied translation; the image does not correspond to reality'. The code model lives on as a cognitive tendency that must be resisted. It is alive and well in current writings on literary translation. Franck Miroux, for example, makes the following assertions in an inquiry into verse translation: that poetry relies on a 'highly codified language' (2010:97); that 'poetry and prose rely on different codes' (2010:98); that decoding and recoding is one possible option for the translator of poetry (2010:100). From a Wittgensteinian point of view, this represents a failure in how literature is to be read. It is not that the decoding model is a possible one that can be rejected as part of a strategy, but that the decoding model is wrong per se, by being too narrow and by failing to do justice to what people can do with language. Robinson, following Wittgenstein, stresses that translators 'don't translate words; they translate what people do with words' (2003:142). The $P I$ is a set of exercises that can lead a translator to this conclusion. Again and again Wittgenstein shows our tendency to see language as a code. Again and again he seeks to undermine this tendency, through sustained use of parables, stories, dialogues, analogies etc. in order to change his reader's way of thinking, by encouraging his reader to look.

My thesis is concerned with the translation of literature, the reading of which must also be about more than cryptography. To describe a reading of the long fantasy epic The Lord of the Rings by J. R.R. Tolkien (1968), for example, as an act of decoding misses the point. If a reader were to decode the text as a synopsis of twenty pages and give this to a friend to read, then the friend is missing out on something. Such a synopsis might be of use to those who wanted to see the film or 
who were tired of being left out when in the company of Tolkien fanatics, but for the enthusiastic reader of the book, its length is actually an advantage. Readers of Tolkien exult in the words in their hands. Rob Pope (2005:137), writing about creation myths, stresses that "it is never sufficient merely to "decode" a myth, as though it has some "message" embedded within that is simply waiting to be extracted'. His point holds, I think, for all literature, and it is therefore worth looking at the functions of literature within human life.

Literature is not generally read to gain information (Pilkington 2000:161). Somebody who wants to learn about a certain period in history would usually be better advised to read a work of history than a historical play. ${ }^{18}$ Many people read for entertainment or diversion. A glance at an airport bookshop shows the continued popularity of the so-called 'airport novel', designed to help passengers overcome the fear of flying by offering them lengthy stories about danger and sex. Such novels do not often make it into the literary canon, the body of texts studied as literature (for example, by students taking university courses). For the purpose of this thesis, I hold only those texts to be literary that exhibit literariness, defined by Eagleton (2007:48), following the Russian formalists, as 'language which is peculiarly conscious of itself: that has been "made strange", so that it becomes newly perceptible to the reader or listener'. Eagleton stresses how such 'foregrounding' is not restricted to literary works such as novels and can be found in tabloid headlines as well as in the works of George Orwell. The headline for page one of the Daily Mirror of 23 June 2009, for example, is given as (27).

\section{OUT OF JORDER}

The subsequent article describes offensive behaviour by the model and novelist Jordan (Katie Price). The headline signals this behaviour by blending her name with the noun 'order' to form the neologism 'JORDER', whilst the phase 'OUT OF JORDER' mirrors the phrase 'out of order', an expression that was formerly used only of malfunctioning machines but that in contemporary use can designate a

\footnotetext{
${ }^{18}$ Historians may turn to literature for information about an era, of course.
} 
person behaving badly. The anonymous writer of this headline is trying to do more than simply impart information about Jordan's behaviour: by coining a phrase that is unique to her, the writer also satirises Jordan and indicates that this is abnormal behaviour for her. It is an example of literary language, even if not constitutive of a literary text. Literariness is a necessary condition for the literary, if not a sufficient one (Attridge, 2004). Texts seen as literary similarly ask us to attend to the manner of their telling, as asserted by John Mullan (2011), who views Wolf Hall by Hilary Mantel as a literary novel because of the way in which it is told.

In view of recent developments in cognitive theory, Eagleton's definition of literariness in terms of literary language can be extended to include the effects that such language has on the reader. Adrian Pilkington (2000:189) concludes that literariness can be defined 'in terms of cognitive events triggered in minds/brains by linguistic stimuli'. The question for the critic or the translator then arises of how literary authors are able to write in such a way - for example, by using the sort of foregrounded language that Eagleton describes - as to trigger these poetic effects. The temptation is to give in to what Susan Sontag (1996:653) calls 'the odd vision by which something we have learned to call "form" is separated off from something we have learned to call "content"'. Eagleton (2007:2) makes this point about poetry, but it holds for all language that exhibits literariness: 'People sometimes talk about digging out the ideas "behind" the poem's language, but this spatial metaphor is misleading ... the language of the poem is constitutive of its ideas.' A poem is not a translation from some language of ideas that exists in spiritual purity like one of the Platonic forms and happens to have been instantiated in a particular set of verses, even though there seems to be a natural tendency to believe that this is the case, as Wittgenstein shows. This topic is further discussed in 3.1.

Eagleton (2007) uses the work of formalist critics such as Jakobson to support his points about literariness, which raises an important question: why should we bother with Wittgenstein if other authorities are available? There are certainly important similarities between Wittgenstein and the formalists, such as the stress on what Wittgenstein would call a physiognomy and the formalists would call style, but Jon Cook and Read (2010:473) ask whether there are any differences that make using the Wittgensteinian philosophical investigation worthwhile and conclude that the project is worthwhile because Wittgenstein's work can offer 'a phenomenology of the experience of reading literature'. Such a phenomenology would run parallel to 
other approaches to literature, such as the linguistic or the literary, rather than replacing them, because it is a philosophical inquiry. One way in which a Wittgensteinian approach is valuable is because it avoids the polarities and strict divisions associated with many writings on translation. Jakobson (1959:233), for example, asserts that there are three kinds of translation: intralingual translation or rewording; interlingual translation or translation proper; intersemiotic translation or transmutation. While this is a helpful classification, it makes no allowance for the case where more than one thing is going on. An adaptation of a Leo Tolstoy novel for an English-speaking audience, for example, would be both interlingual and intersemiotic. Beginning with a theoretical perspective, as Jakobson does, can be a straightjacket, running the risk of offering an 'impoverished account' of what it is like to read or to encounter literature (Cook \& Read, 2010:473). Similarly, many translation theorists view translation in terms of polarities (Pym, 2010:33), which can lead to black-and-white thinking, whereas Wittgenstein's account of language allows the literary phenomenon to be seen from many different angles. (I further discuss the way in which theory tends towards polarisation in 4.1.)

It is because of the rich phenomenological experience that they offer that literary works can matter to their readers. Jenefer Robinson (2005:143) asks how it is possible for her to feel compassion for Tolstoy's heroine Anna Karenina (who throws herself under a train when she feels her life to be intolerable), given that she never existed. There is a difference between this case and feeling compassion for the sufferings of, say, the dying Wittgenstein, while reading about his life, given that Wittgenstein's existence was instantiated, and he did die from cancer. But to shed tears for Anna Karenina, or for Shakespeare's Romeo, or for Goethe's Werther: this seems analogous to getting depressed because there are no unicorns to be seen in the local park. Nevertheless, this is what people do. There are even reports of eighteenthcentury young men dressing like Werther and taking a pistol to their own head, so moved were they by his story: Danielle Moyal-Sharrock (2009:180) notes how the term the 'Werther effect' has been invented to designate such copycat suicides and in answering Robinson's question uses Wittgenstein's notion of the surveyable representation (2009:165).

The term 'surveyable representation' (PI 122) renders a German expression that has caused some difficulties for translators, i.e. 'übersichtliche Darstellung' ('overseeing representation'), which Wittgenstein describes as the attempt to form an 
overview in which one is enabled to see connections. Anscombe (2001) translates it as 'perspicuous representation'; Raymond Hargreaves and Roger White translate it as 'bird's eye view' in $P R$ 5; Wittgenstein himself spoke of a 'synoptic representation' in his Cambridge lectures (Ambrose, 1979:43). Much of the secondary literature on Wittgenstein in English uses Anscombe's rendering, as does Moyal-Sharrock, but I shall use the translation 'surveyable representation' by Hacker and Schulte in their revision of Anscombe's translation, because I follow their edition as the most scholarly available in English and because I accept their argument that 'surveyable representation' preserves 'the reference to view and survey in translating Übersicht [overview] and its cognates' (PI, p.252). (I further explore the notion of the surveyable representation in 4.3.) Moyal-Sharrock's response is that literature is able to engage our emotions through its surveyable representations of emotional (and other) concepts and the cognitive pleasure that such representations evoke.

It is important for the translator as reader to identify the key elements of a surveyable representation by not seeing the text as something to be decoded. To read for translation involves accounting for the vividness of the text by paying attention to its stylistic elements, as Moyal-Sharrock (2009:171) notes. In Table 1, I sum up her discussion of how a writer can evoke vividness in the writing of a literary text.

\section{TABLE 1: STYLISTIC EFFECTS ACCORDING TO MOYAL-SHARROCK}

\begin{tabular}{|l|l|}
\hline STYLISTIC FEATURES & EXAMPLES \\
\hline Presentation of material & $\begin{array}{l}\text { Dialogue, narrative, description, meditation, } \\
\text { stream of consciousness }\end{array}$ \\
\hline Literary devices used & $\begin{array}{l}\text { Metaphor, symbolism, vocabulary, syntax, } \\
\text { tone, cadence, silence }\end{array}$ \\
\hline Other elements & $\begin{array}{l}\text { Irony, suggestion, psychological acuity, } \\
\text { action, timing, juxtaposition, tension, mood, } \\
\text { plot }\end{array}$ \\
\hline
\end{tabular}

Moyal-Sharrock takes the view that it is this vividness that enables the reader to engage with a text, so that he or she may come to shed tears for a woman who never existed. Literature is something more than an expression of the intellect. It is something physical, something that affects the mind, something suitable for the 
linguistic animal that reads. Richard Pevear and Larissa Volokhonsky (2000:xx-xxi), commenting on their translation of Anna Karenina, state that to apply 'general notions of natural, idiomatic English and good prose style to Tolstoy's writing is to risk blunting the sharpness of its internal dialogisation'; previous translations of the novel have frequently toned down narratorial interventions, or omitted them, a strategy that Pevear and Volokhonsky reject. Narratorial interventions are one of the ways in which Tolstoy presents his material in order to give a surveyable representation of the story of Anna Karenina.

Wittgenstein, in PPF 118, introduces the concept of 'the dawning of an aspect' which can be helpful in analysing how people may approach the literary. He distinguishes the dawning of an aspect from 'the continuous seeing of an aspect' and uses Robert Jastrow's 'duck-rabbit' as an illustration, to show the difference between 'seeing' and 'seeing as'. The duck-rabbit is reproduced as Figure 1.

\section{FIGURE 1: THE DUCK-RABBIT}

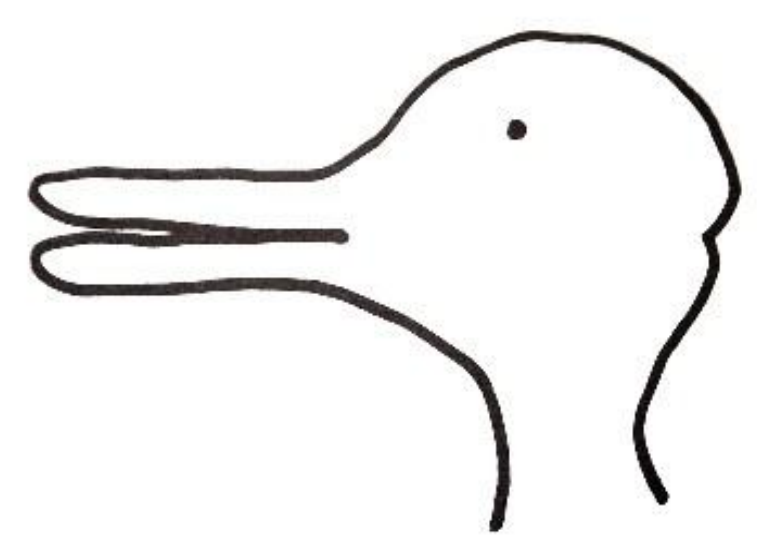

It is an image that may be consistently described as a duck or as a rabbit. Somebody may see the figure as a duck, until suddenly a new aspect dawns and he or she sees it as a rabbit. Neither view of the duck-rabbit is exclusively correct, hence its blended name.

The experience of seeing things differently is a common one. Anna may perceive a cloud as a castle and describe it as such to Chris, who is unable to see what Anna is talking about, until he suddenly says, 'Oh yes!' With respect to the 
duck-rabbit, Wittgenstein stresses that it is not a question of interpretation but of reporting what one sees: 'I should simply have described my perception'. On a walk, I may see a passing rabbit and think what a great pet it would make, while my dog thinks it would be a tasty snack. Catholics believe that bread and wine are transubstantiated into the real presence of Christ during the Mass, and will show this by bowing, genuflecting etc., which can be puzzling behaviour to a guest who knows nothing of Eucharistic theology. Similarly, somebody may come to see a page of what were once meaningless symbols in a new way, if he or she learns Greek, and may come to see a poem in a new way if he or she is taught about metaphor and other such devices as those listed in Table 1. Failure to see other aspects is referred to by Wittgenstein as 'aspect-blindness', akin to the lack of a musical ear ( $P P F$ 260) and the project of the $P I$ can be described as an attempt to overcome aspectblindness. Wittgenstein (PPF 263) describes a code that uses the word 'tower' to mean 'bank', so that a command to go to the tower can be de-coded as a command to go to the bank: this, he argues, would be felt by somebody to be strange, because he or she would not yet have absorbed the meaning. The term 'tower' is being used artificially, outside the way that a native speaker will have learned it. By contrast (PPF 264), it is possible to be trained to read a poem with feeling, by paying particular attention to the intonation, so that the poem is being read in a different way from how it would be read if scanned for information. The reading of a poem with feeling is a practice: 'I can also give a word an intonation which makes its meaning stand out from the rest, almost as if the word were a portrait of the whole thing'.

Hopkins (1985:xv) referred to the obscure elements in his poems 'exploding into meaning' to a sensitive reader prepared to spend time with the verse. The writer creates a text that is completed by the reader. Wittgenstein, in Lectures and Conversations on Aesthetics, Psychology and Religious Belief (LA) p.4, uses his own reading of the German poet Friedrich Klopstock (who wrote unrhymed verse with intricate metrical patterns) to illustrate the phenomenon, describing how, when he finally read Klopstock with a stress on the metre, he was able to say, 'A-ha, now I know why he did this'. Such an experience, what Wittgenstein refers to as 'A-ha', is the coming to be aware of the style, of seeing that form and content are inseparable. Previously Wittgenstein had felt bored by Klopstock, but was now able to appreciate the poetry by seeing it in a new way. 
The $P I$ (in contrast to the $T-L P$ ) has an approach to truth based on coherence rather than on correspondence. Wittgenstein (PI $201 \mathrm{ff}$.) stresses the practice of following a rule. When people play cricket, for example, what makes the game function is that all the players agree on how to behave. Cricketers are not discovering an arcane metaphysics of cricket that dictates how the game must be played. From time to time new rules are introduced and old ones modified and abolished. Cricketers today dress very differently from those of the past, and women's cricket has been introduced into what was an all-male world. The term 'Owzat!' (a contraction of 'How's that?') makes sense when shouted out during a game of cricket because it is an agreed way of appealing to the umpire to have a player dismissed, but it is not usually an acceptable replacement for 'How's that?' outside cricket. There is a carefully managed coherence within the game of cricket. As Wittgenstein (PI 202) notes, following a rule is a practice, and it is not possible to follow a rule privately. We look at what people do, and speak of rules. The same would be true of literary practices, such as translation: rules do not determine what we do. It is a question of coherence.

John Gibson (2004:117) calls such coherence 'the wonder of agreement', citing Wittgenstein's example in PI 50 of the standard metre in a Paris archive, held to be the measure for making rulers etc. There is again nothing arcane about this metre-rule, which has 'no extraordinary properties'. It is simply used by those who need it, under the proviso that, wherever the metrical system is established, it should be taken as standard: we can neither state that it is one metre long nor not one metre long. Gibson (2004:121) argues that literature itself can be seen as an archive, so that the existence of literature becomes something with which to measure our distinctively human ways of seeing and behaving. Similarly, custom decrees that the word 'dog' in English means what it does in the contexts where it is used. A word has an agreed application within a context. Words can therefore change or expand their meaning, for example, the noun 'mouse' has taken on a new meaning as a piece of computer hardware. Philosophy, for Wittgenstein, does not offer any metaphysics of meaning, as is seen in PI 126, given as (28). What is astonishing about this remark is how it contrasts with the received idea of philosophy as a quasi-mystical quest for metaphysical reality. 
Philosophy simply puts everything before us, and neither explains nor deduces anything. - Since everything lies open to view, there is nothing to explain. For whatever may be hidden is of no interest to us.

Philosophy is a matter of description rather than of discovery. A Wittgensteinian approach to literature would similarly involve the formation of the surveyable representation. The task of the translator reading the ST for translation is not to think, but to look (PI 66). 


\subsection{Language-games}

For the reflective practitioner of translation, Wittgenstein's notion of the language-game can provide both a way of describing the ST and a way of translating it. In this section, I introduce the language-game, which is at the heart of the philosophy of the later Wittgenstein.

At the beginning of the PI, Wittgenstein cites a passage from Augustine's Confessions in Latin, giving his own German translation. The Confessions (1961) is regarded by many as one of the most significant texts in western civilisation (Brown, 1967:158), Wittgenstein himself referring to it as the most important book ever written (Rhees, 1984:90). Georg Henrik von Wright (1958:21) has noted that Wittgenstein's own way of philosophising owes a lot to the philosophical parts of the Confessions. Augustine describes his conversion to Catholic Christianity in the Confessions, effectively writing the first autobiography, and the passage that Wittgenstein quotes contains reflections on how Augustine came to learn language as a child. It is given as text (29), translated from Wittgenstein's German (PI 1).

When grown-ups named some object and at the same time turned towards it, I perceived this, and I grasped that the thing was signified by the sound that they uttered, since they meant to point it out. This, however, I gathered from their gestures, the natural language of all peoples, the language that by means of facial expression and the play of eyes, of the movements of the limbs and the tone of voice, indicates the affections of the soul when it desires, or clings to, or rejects, or recoils from, something. In this way, little by little, I learnt to understand what things the words, which I heard uttered in their respective places in various sentences, signified. And once I got my tongue round these signs, I used them to express my wishes.

Here is a story of how language is learned. I shall refer to it as 'the Augustinian paradigm', to distinguish it from Augustine's theory of language (Kerr, 1988:56), which lies outside the scope of this thesis and to which Wittgenstein does not refer. The Augustinian paradigm describes learning language as a process of denotation, of ostensive definition. If I want to show a child what a dog is, I point at the dog: the word 'dog' denotes the fuzzy thing sleeping in the corner of the room and the child learns how to recognise and then apply the term. The theme of the $P I$ has been introduced, i.e. the investigation of the human person as linguistic. As Hacker 
(2001:68) comments on the project of the later Wittgenstein: 'The behaviour of man has to be understood, and something interpreted, in the sense in which the behaviour of inanimate nature and much of animal behaviour do not. This is obvious in the case of human linguistic behaviour.'

Wittgenstein, in the opening sections of the $P I$, takes his reader through a series of scenarios designed to show that the Augustinian paradigm is too narrow. It offers a code model of language, a picture theory not unlike that of his early work, in which terms were held to stand for things in the world (T-LP 2.161). Wittgenstein shows the limitations of this view. For example, he tells the story of the two builders, $\mathrm{A}$ and B (PI 2), as an instance of where 'the description given by Augustine is right', which I give as (30).

A is building with building stones: there are blocks, pillars, slabs and beams. B has to pass him the stones and to do so in the order in which A needs them. For this purpose they make use of a language consisting of the words 'block', 'pillar', 'slab', 'beam'. A calls them out; B brings the stone which he has learnt to bring at suchand-such a call. - Conceive of this as a complete primitive language.

At this very basic level, A and B function as builders who successfully communicate, in the sense that things get built, so that Augustine 'does describe a system of communication' (PI 3). It is too limited, however, to fit the way that people live outside the story of the builders. The Augustinian paradigm shows how nouns might be learned: 'Someone who describes the learning of language like this is, I believe, thinking primarily of nouns like "table", "chair", "bread", and of people's names, and only secondarily of the names of certain actions and properties; and of the remaining kinds of word as something that will take care of itself'. Wittgenstein sets against this the story of the shopping trip (which I discuss in 3.1) and shows how the primitive language used by the builders in PI 2 would have to be expanded beyond ostensive definition if it is expanded to include more than nouns: the builders function according to the Augustinian paradigm when they only need to use the four nouns for different types of building materials, but once other elements are introduced, such as numbers or demonstratives (PI 8 ff.) then the paradigm 
collapses, not because it is wrong as such, but because it is too restricted. ${ }^{19}$ The significance of the paradigm lies in the way that it exemplifies a common way of and indeed natural way of looking at language (Bellos, 2011:83), but which is more like an account of how people learn a second foreign language than a first language, as Wittgenstein points out in PI 32; it is as if the child Augustine had come into a foreign country, already able to think and already having a language, but not the language of the new country. Things in the world as we find it are more complicated. For a start, there are many different types of utterances. In PI 23, Wittgenstein attacks the traditional view in logic (fundamental to the $T-L P$ ) that there are three types of proposition: the statement, the question and the command, represented here by (31), (32) and (33) respectively.

Ben is in the kitchen.

Is Ben in the kitchen?

Go into the kitchen, Ben!

Language is seen as propositional, as representing reality through pictures. Text (31), for example, is a proposition that can be true or false, depending on whether Ben is in the kitchen or not, and depicts a certain dog in a certain room.

Against his earlier picture theory of language, Wittgenstein advances the position that the meaning of a proposition is shown by its use, both in the language as a whole and in its immediate context. He introduces the concept of the 'languagegame' to explain this: 'We can think of the whole process of using words ... as one of those games by means of which children learn their native language. I will call these games "language-games" and will sometimes speak of a primitive language as a language-game. ... I shall also call the whole, consisting of language and the actions into which it is woven, a "language-game" (PI 23). He indicates a

\footnotetext{
${ }^{19}$ Even the initial situation is more flexible than the paradigm suggests, as discussed in 3.1.
} 
multiplicity of linguistic activities that can be categorised as language-games, given as (34).

Giving orders, and acting on them -

Describing an object by its appearance, or by its measurements -

Constructing an object from a description (a drawing) -

Reporting an event -

Speculating about the event -

Forming and testing a hypothesis -

Presenting the results of an experiment in tables and diagrams -

Making up a story; and reading one -

Acting in a play -

Singing rounds -

Guessing riddles -

Cracking a joke; telling one -

Solving a problem in applied arithmetic -

Translating from one language into another -

Requesting, thanking, cursing, greeting, praying.

Instead of three types of linguistic activity, there are many: the list could in fact be extended indefinitely. ${ }^{20}$ As Wittgenstein (PI 108) notes, to ask 'What is a word really?' is like asking 'What is a piece in chess?' I take this to mean that a piece in chess has a set move that it can make according to agreed rules but that there exists a vast number of positions in which it might end up, a vast number of ways in which it can be used, especially when it is recalled that no chess piece operates in isolation. The mistake would be to describe its physical appearance and to think that here was an end of it. Something similar is true of words. To say that 'dog' is a noun of three letters may be an important observation, but there is a lot more that can be said about how the word can be used (for example, as a noun or as a verb: this is discussed further in 2.3).

Such an approach is of use to the translator, who can be brought to see that reading is not a scientific procedure but a language-game, an activity carried out by people, in which we engage with language-games played in a text, rather than dealing with denotation. Wittgenstein, in Philosophical Grammar $(P G)$ I 5, describes how a sentence from a story may make complete sense in isolation, so that a context

\footnotetext{
${ }^{20}$ The significance of translation as a language-game is discussed in 3.1.
} 
may be invented, but that 'I do not understand it in the sense in which I should understand it if I had read the story.'

As Hacker (2007a:46) comments, meaning is not a matter of scientific discovery. It is much more than denotation, than the Augustinian paradigm of the child pointing at the fuzzy thing in the corner and working out that it is Ben the dog. In PI 43, given as (35), Wittgenstein advances a different way of looking at meaning.

For a large class of cases of the employment of the word 'meaning' - though not for all - this word can be explained in this way: the meaning of a word is its use in the language.

This remark is probably the most celebrated in the PI (Hacker, 2010b). Wittgenstein is careful to stress that exceptions do arise, because there are cases when the Augustinian paradigm is correct, i.e. when the meaning can be explained by 'pointing to its bearer' (PI 43), as in the case of the primitive language employed by the builders in PI 2 ff (but not when expanded). In most cases, however, meaning is best explained by looking at use.

An example of how this Wittgensteinian epistemological tool can be applied to everyday language is given by Duncan Richter (2009:198), who examines the concept of happiness, showing that it is a 'blurry and elusive' concept: when a City banker and a Buddhist say they are happy, they may be playing different languagegames, confusing psychologists by their employment of the same adjective, so that it is wrongly assumed that they are referring to the same phenomenon. To understand the difference between the two individuals would involve looking at a wide range of examples from their respective lives, which may, for example, lead to a conclusion that the happy banker is talking about hedonism and the happy Buddhist is talking about spirituality. What matters is what they are doing with the word 'happy'. There is one word but two uses. It is not as if there were some mystical meaning attached to 'happy', so that we have both word and meaning as separate entities. Wittgenstein (PI 120) gives this parable to illustrate the point: we do not have both the money and the cow that we can buy with it; we have only the money, which means that we can do certain things, such as buy a cow. It is therefore important, as Hacker (2010b:32- 
33) asserts, to distinguish between a meaningful sentence and the meaningful use of a sentence. The sentence given as (36) is meaningful: it is well formed according to rules given by English grammars and would be readily understood by a competent speaker of English.

I am happy.

To establish its meaningful use, however, a number of other criteria are relevant, such as: who says it; when it was said; in what circumstances it was said; how it contributes to a move in a language-game etc. If I am told that it was said by a banker to her boss after receiving her bonus, then I have a meaningful use of (36). I can see how a language-game is being played.

Literary texts can be seen in terms of the language-games that they play. Queneau (1947), as discussed in 2.1, is playing different language-games, not giving his readers one story in many encryptions. James Joyce's novel Ulysses (1992), which tells of one day in Dublin, uses a variety of narrative approaches that can be seen as language-games, for example: drama (1992:561-703); catechism (1992:776871); interior monologue (1992:871-933). Looking at language-games enables the translator reading for translation to be aware that an infinite number of things may go on in the literary text. It enables him or her to be aware that language is a 'spatial and temporal phenomenon' rather than 'some non-spatial, atemporal non-entity' (PI 108). The Augustinian paradigm of language as labelling is too limited but is a common one. As McGinn (2008:62) notes, 'we are focusing on one central case the case of naming people or things - and overlooking the complexity that is inherent in our language-games; it is only when we turn our attention to language in use that we begin to see our original picture as a misleading over-simplification'. McGinn's use of the first person plural is significant. By turning our attention away from the denotative, we realise how much more complicated matters are, for, as Wittgenstein (PI 6) notes, even the simplest form of language-game admits of variation. Hence Queneau (1947) can play the language-game of telling a story about a man on a bus in ninety-nine different ways, each of which is an individual language-game. The teacher holding up the flashcard of a dog may expect his or her students to do any of 
the following: to listen silently; to repeat what they hear; to tick a picture of a dog in a series of animal pictures in their workbooks; to give a picture of a dog to a neighbour etc. Learning language involves using many types of language-game. As Savickey (1999:76) comments, Wittgenstein's ideas on language-learning and language-use, the examples he uses and the analogies he gives, are all influenced by his work and experiences as a schoolteacher, of having seen how language is used by learners. $^{21}$

Wittgenstein (PI 28) shows how problematic the notion of ostensive definition is by the example of trying to define the notion of 'two' by showing somebody two nuts. There is a danger that the student may think that he or she is learning the word for a particular group of nuts. The contrary can also happen, when the student mistakes the name of a particular group of nuts for the number two. Wittgenstein concludes: 'an ostensive definition can be variously interpreted in any case'. I recall showing a slide, part of the Nuffield Foundation course, to classes learning German. The slide depicted two boys armed with guns going into a wood. An accompanying tape gave the commentary in text (37).

Sie gehen auf die Jagd. they go onto the hunt

It was not uncommon for students to infer that the German phrase meant, 'They are going into the wood', rather than, 'They are going hunting'. The teacher would know that the phrase had been misunderstood by the application made of it: some students might choose the wrong answer in a multiple choice exercise in their workbook; others might give a wrong translation when asked what the phrase meant; others might write the phrase in an essay when no hunting was involved. A form of triangulation is necessary to become aware of meaning: the context in teaching must be larger than a single slide with a single sentence. Similarly nobody can learn Finnish only by tuning in to Finnish radio when driving. A third point of reference is necessary, such as: a dictionary; a transcript; a tutor; a crib; interaction with Finnish speakers; all of these. There comes a point when even pointing at places and things

${ }^{21}$ See the discussion of $W F V$ in 1.4 . 
will only work when the pointing 'occurs in the use of the words too and not merely in learning the use' (PI 9).

The relevance of language-games to reading for translation is illustrated by the dialogues in (38) and (39).

$\begin{array}{ll}\text { Anna: } & \text { Let me test you on your history. } \\ \text { Richard: } & \text { Fine. } \\ \text { Anna: } & \text { When was the Battle of Waterloo? } \\ \text { Richard: } & 1815 . \\ \text { Anna: } & \text { Who commanded the Prussian forces at Waterloo? } \\ \text { Richard: } & \text { Blücher. } \\ \text { Anna: } & \text { Well done. To where was Napoleon exiled after the battle? } \\ \text { Richard: } & \text { Elba. } \\ \text { Anna: } & \text { You've really worked hard on this. } \\ \text { Richard: } & \text { Thank you. }\end{array}$

Anna: $\quad$ Let me test you on your history.

Chris: $\quad$ Fine.

Anna: When was the Battle of Waterloo?

Chris: $\quad 1812$.

Anna: Who commanded the Prussian forces at Waterloo?

Chris: Ney.

Anna: Well done. To where was Napoleon exiled after the battle?

Chris: Who?

Anna: $\quad$ You've really worked hard on this.

Chris: Thank you.

These two sketches are almost identical. A reader who shares Anna's knowledge that the Battle of Waterloo was in 1815, that Blücher commanded the Prussian troops at that battle, and that Napoleon was then exiled to Elba - will be aware that Chris did badly in his test, unlike Richard. Therefore it is a reasonable inference that Anna's remark, 'You've really worked hard on this', expresses a compliment to Richard but a reprimand to Chris, possibly spoken in a sarcastic tone. When Anna says this to Chris, she is neither mistaken nor lying but expressing disapproval. The same holds for her comment, 'Well done', whilst it may be reasonable to infer that Chris's remarks, 'Fine' and 'Thank you', are spoken in a tone of defiance. There is no core meaning that can be extracted from even such a simple phrase as, "Thank you', as the circumstances in which the phrase is uttered need to be taken into 
account. ${ }^{22}$ I am not suggesting that the translator should necessarily translate the common phrases in text (38) differently from text (39), but that it is necessary for the translator to be aware of what is going on, that the meaning is in the use.

Wittgenstein's distinction between surface grammar and depth grammar is useful here. In PI 664, there is the remark given as (40).

In the use of words, one might distinguish 'surface grammar' from 'depth grammar'. What immediately impresses itself upon us about the use of a word is the way that it is used in the sentence structure, the part of its use - one might say - that can be taken in by the ear. - And now compare the depth grammar, say of the verb 'to mean', with what its surface grammar would lead us to presume. No wonder one finds it difficult to know one's way about.

The distinction between surface grammar and depth grammar does not contradict Wittgenstein's stress in PI 126 that everything of interest is on the surface and that nothing of interest is hidden, because we can only understand depth grammar by a careful reading of surface grammar. Nothing arcane is involved. Surface grammar is what the grammatical form of a statement seems to offer; depth grammar is how the statement is used, something indicated by the context. Anna in (38) and (39) uses the same surface grammar but the depth grammar is different. The translator of (38) and (39) might choose to find phrases that would represent the depth grammar in both cases. Boase-Beier (2011:17), for example, notes that translation is not only about transferring the surface features of the ST onto the TT.

When language is not given a context, then - according to Wittgenstein - it idles, it 'goes on holiday' (PI 38). ${ }^{23}$ Hacker (2010b:31), for example, compares the utterances given as (41) and (42).

I don't know what he means.

\footnotetext{
${ }^{22}$ It does not follow that no words have a core meaning if the term is understood as signifying a single meaning. The German word drei can be safely rendered as 'three' without too much hesitation, unless in a literary context (where it rhymed, for example).

${ }^{23}$ Anscombe's translation is discussed in 3.4.
} 
I don't know what I want.

The two sentences are very similar in terms of surface grammar. They both begin with 'I don't know what', followed by subject and main verb in the simple present indicative active. In terms of depth grammar, they are different, however, because the respective use is different: (41) is a confession of ignorance while (42) is a confession of indecision. (And the situation may become more complicated if the context is stipulated.) As Hacker comments, in craving uniformity we overlook the 'fluidity, flexibility, forms of context-variability and distinctive uses of our language and its instruments'. It is a critical lesson for a literary translator to learn: how to see differences, to refer again to the quotation from Shakespeare (1972:81) that Wittgenstein considered using as a motto to the $P I$.

If I am faced with a sentence such as that in (43), then the surface grammar is clear enough.

Anna went to the library.

However, the depth grammar is here not clear without more contextual information. The sentence in (43), in isolation, is on holiday. It cannot do any work because it lacks specificity. To reference Wittgenstein's list of language-games in PI 23, given as (34) above, (43) could be any of the following: an event being reported; a hypothesis being formulated; a story being made up; a story being read; a joke being told; a translation being made from another language. When reading for translation, it would be important to be aware of these possibilities and to form a view of the depth grammar, seen in the language-game, as can be shown by a literary example.

Geoffrey Chaucer's Middle English account of a pilgrimage to Canterbury, The Canterbury Tales, includes a description of a Benedictine monk who is very fond of hunting (1965:56), given as (44). 
He yaf nat of that text a pulled hen, he gave not of that text a plucked hen That seith that hunters ben nat hooly men, that says that hunters be not holy men $\mathrm{Ne}$ that a monk, when he is reccheless, nor that a monk when he is irresponsible Is likened til a fissh that is waterlees, is like to a fish that is waterless This is to seyn, a monk out of his cloister. this is to say a monk out of his cloister But thilke text heeled he nat worth an oyster; but this text held he not worth an oyster And I seyde his opinion was good. and I said his opinion was good

The last line seems, on a reading of its surface grammar, to be expressing approval of the monk, for Chaucer says that the monk's opinion was good. As James Winny comments, however, in his note on this text (Chaucer 1965:91), the line is ironic, a 'pretence of approval ... a straight-faced joke which caps the outrageousness of the monk's argument'. The monk is praised for virtues that have nothing to do with his monastic vocation. The translator who fails to note this would have problems not just with this line but with the whole portrayal of the hunting monk, whom Chaucer satirises by contrasting his worldly way of life with the ascetic ideals that drove the rule-givers of western monasticism, Augustine and Benedict. Chaucer never tells the reader that he does not approve of the monk, but writes in such a way as to trigger a response in his reader. As Pilkington (2000:47) asserts: 'The literary writer attempts to articulate her feelings and experiences: the critic and reader do the same with the writer's assistance'. Wittgenstein's concept of the language-game is a philosophical way of describing this literary phenomenon. The narrator in (44) is playing several language-games: describing somebody; reporting what was said; narrating a story; satirising a cleric. The final language-game is the key one to note when reading the final line. It is the point of Chaucer's description of the monk, making it an exercise in humour, not hagiography. For the trained reader, this is language at work, not on holiday, and it is part of the task of the literary translator to read (and eventually render) the depth grammar. As Tim Parks (2007:246) asserts, the ideal is the translator who has done everything in his or her power 'to understand the deeper sense of the author's text and to find a way of recreating that in translation'. The 
writing of the TT is the topic of Chapter 3, but Parks is right to see it as based on an understanding of what, in a Wittgensteinian sense, can be seen as the depth grammar of the ST. As I remarked in 2.1, reading the ST for translation is not only a physical necessity but also an aesthetic one. In translating the final line of (44), a translator might therefore choose to find a phrase that maintained both surface and depth grammar. (A translation that explicitly stated that the monk was a hypocrite would lose the surface grammar.) In this reading of (44), there has been nothing arcane, no discovery of a secret lurking behind Chaucer's text. Meaning remains a physiognomy (PI 568). The genius of Chaucer is shown by how he can use a phrase that in another context would indicate fulsome praise in order to undermine everything that this particular monk stands for and to allow the reader to interact with the ST in a certain way. It would be possible to read the description of the monk as documentation only, not as a satire, just as it is possible to read Middlemarch for the story and not for the literature (Attridge 2004:96), but this is only possible for the reader who ignores the depth grammar. Wittgenstein shows how the literary reading of Middlemarch could take place, which would in turn facilitate literary translation.

Wittgenstein's presentation of the Augustinian paradigm is not meant to dismiss as stupid the way that we instinctively operate: 'the difficulty is to remove the prejudice which stands in the way ... It is not a stupid prejudice' (PI 340). Malcolm (1984:59) records that Wittgenstein's decision to use Augustine came about "not because he could not find the conception expressed in that quotation stated as well by other philosophers, but because the conception must be important if so great a mind held it'. The Augustinian paradigm shows the way that we naturally tend to think about language, one that is not easy to shift, hence the lengthy treatment that follows Augustine's story in PI 1. The aim is to bring about clarity in the reader, as Wittgenstein points out in PI 81, given as (45).

All this, however, can appear in the right light only when one has attained greater clarity about the concepts of understanding, meaning something, and thinking. For it will then also become clear what may mislead us (and did mislead me) into thinking that if anyone utters a sentence and means or understands it, he is thereby operating a calculus according to definite rules. 
Wittgenstein refers here, I assume, to his own early work in the $T$ - $L P$, which puts forward a theory of language as calculus. In contrast, the PI puts forward no theory (PI 109); we need to be wary of our forms of expression, which send us 'in pursuit of chimeras' when really 'nothing extraordinary is involved' (PI 94). Wittgenstein (PI 109) sees philosophy as a battle against 'the bewitchment of our understanding by the resources of our language'. Does the battle against bewitchment also hold for the reading of literature? Does literature threaten us with bewitchment, as suggested by Plato (Republic 595a ff.)?

Schroeder (2006:156-7) analyses the contention by the pre-Socratic philosopher Heraclitus (Plato, Cratylus 402a) that one cannot step into the same river twice. By applying the methods of the $P I$, he concludes that this is an example of the philosophical misuse of language, because it ignores how the term 'river' is used. We are bewitched by the use of an expression into ignoring facts about rivers, i.e. that they are not lakes. Schroeder then questions whether this would apply to the literary use of language, which would also then be a misuse. He refers to Goethe's poem 'Dauer im Wechsel' ('Permanence in Change') (Goethe, 1967:136), of which I give the second stanza as (46). An unacknowledged reference to Heraclitus is in lines 7-8.

Willst du nach den Früchten greifen, want you after the fruits to-grasp Eilig nimm dein Teil davon! quickly take your part of-it Diese fangen an zu reifen, these begin to ripen Und die andern keimen schon; and the others germinate already Gleich mit jedem Regengusse even with every rain-downpour Ändert sich dein holdes Tal, changes itself your lovely valley Ach, und in demselben Flusse alas and in the-same river Schwimmst du nicht zum Zweitenmal. swim you not for-a second-time 
Schroeder argues that the use of Heraclitus is here legitimate because it is 'a figurative expression of a feeling or a hyperbolical way of emphasising a certain aspect of the world' (2006:157) and I think that this is an important point. Wittgenstein's strictures against hyperbolical language in philosophy do not apply to literature, for different language-games are played in literature from philosophy. Literary features cannot be explained away and are there to be seen. As Wittgenstein ( $P P F$ 79) remarks, it is not so surprising that the same expression is used in different games. The key is to identify the game. To translate (46) whilst omitting or changing the lament that we cannot swim in the same river twice, on the grounds that this view is philosophically incoherent, cannot be justified on Wittgensteinian grounds.

By identifying literary language-games, we facilitate reading for translation. As Attridge (2004:75) notes, formal features in literature are so significant that they can be imitated in translation, so that asking questions such as 'Which languagegame is being played here?' or 'What is the depth grammar of this sentence?' can become an important part of the task of translation and help the translator to get down to work. That Wittgenstein can indicate what Cook and Read (2010:473) call the 'phenomenology of the experience of reading literature' shows that it is possible for the literary translator to enter into this phenomenology. As Wittgenstein ( $P P F 7)$ remarks: 'If someone says, "When I heard this word, it meant ... to me", he is referring to a point in time and to a way of using the word. (Of course, it is this combination that we fail to grasp.)' A reading of the PI can help the literary translator to grasp this combination as a prelude to translation.

If literature can be seen in terms of language-games, is there anything that can account for the language-games? In 2.3, I investigate Wittgenstein's notion of the 'form of life' and its use for the literary translator. 


\subsection{Forms of life}

Wittgenstein argues that human beings agree not in opinions but in form of life (PI 241), i.e. the way they live, so that language becomes 'the conversation that is carried on with the characteristic activities of a form of life' (Kerr, 1988:30). To go shopping involves playing the language-game associated with that activity, to have a store of set phrases, expressions of politeness, items of vocabulary, transactional structures etc. A game of football is played according to a certain kit of expressions. An item such as 'hand ball' is meaningless outside the form of life that is football, where players apart from goalkeepers may not use their hand to touch the ball, whereas in many other sports, such as netball or rugby (or in everyday life) there is no offence in doing this. Wittgenstein (PI 23) stresses that he uses the term 'language-game' in order to emphasise that 'the speaking of language is part of an activity, or of a form of life', thus linking the two concepts through his characteristic emphasis on practice. In this section, I argue that to explore the concept of the form of life can help the translator who is reading for translation.

There is some controversy about how big a form of life can be (Kerr 1998:31), but some writers on Wittgenstein have taken large-scale phenomena such as Christianity to be forms of life with their own language-games (Malcolm, 1977:212). I similarly see any activity that has its own distinct language-game as a form of life, accepting a range from shopping to Christianity. In terms of literature, forms of life can be seen in many texts. The description of the monk by Chaucer in (31), for example, is set against the form of life of the pilgrimage and depicts the form of life of decadent Benedictine monasticism.

The meaning of words can similarly be related to forms of life, e.g. 'dog' can be used in different language-games depending on the form of life in question. For Wittgenstein, as Guetti (1993:3) asserts, use of language is 'not a mere saying of words; it is an application of words ... that is both purposive and consequential'. Thus 'dog' can be used conventionally as a concrete noun or as a verb, but not as an adjective or as an adverb. A reader who was confused by its occurrence in a sentence could look it up in a dictionary, but would need to recall the context in which the word occurred in order to find a fitting definition, so that care would have to be taken as to whether the ST used 'dog' as a verb or as a noun: it would be an error to look up the adjective when the noun was implied, for example. In Table 2, a number of examples are given, all including the word 'dog'. Each example consists of two 
sentences, in order to make the context clear. There is an explanation in the righthand column. (It follows from what was said in 2.1 that the explanations would be unsatisfactory as literary translations.)

\section{TABLE 2: THE WORD IN CONTEXT}

\begin{tabular}{|l|l|}
\hline EXAMPLE & EXPLANATION \\
\hline $\begin{array}{l}\text { There is a dog in the kitchen. He is called } \\
\text { Ben. }\end{array}$ & $\begin{array}{l}\text { A barking domestic quadruped, i.e. a } \\
\text { member of the genus canis and subspecies } \\
\text { canis lupus familiaris, is in the kitchen. }\end{array}$ \\
\hline $\begin{array}{l}\text { Bad luck seems to dog me. I lost at cards last } \\
\text { night again. }\end{array}$ & I always seem to be unlucky. \\
\hline You lucky dog. You won at cards, so I hear. & You were so fortunate. \\
\hline He was as sick as a dog. Too much brandy. & He vomited in a degrading way. \\
\hline $\begin{array}{l}\text { This choir is going to the dogs. The last } \\
\text { concert was terrible. }\end{array}$ & This choir is in decline. \\
\hline
\end{tabular}

The one word 'dog' has many uses. Wittgenstein (PI 77) advises his reader, when puzzled about a meaning, to think of how he or she learned the meaning of a word, from what sort of examples, and in what sort of language-games, in order to see that a word (his example is 'good') must have a family of meanings. There is no single ideal of exactness (PI 88), because language is a labyrinth of paths (PI 203).

In inviting his reader to think in this way, Wittgenstein points beyond pragmatics to a rich picture of speaker interaction. The point of talking about language-games is not merely to clear up cases of ambiguity. It is of course important to know, when Anna refers to 'a mouse', whether she is talking about a rodent or a piece of computer hardware, but Wittgenstein takes his reader much further than this, as is made clear by his linking of the language-game with the form of life. Searle (Magee, 1987:339) sums up: 'For the later Wittgenstein, all the criteria of meaning are ultimately social, not personal, and still less private. Words derive their meaning from the contexts in which they are used, and these in turn depend on social practices and thus ultimately on forms of living, forms of life'. The word 'dog' in the examples in Table 2 is ultimately bound up with forms of life, with the fuzzy way that we use the word in so many more ways than to designate the fuzzy thing in 
the corner, as is illustrated in Table 3, using the same examples as Table 2 in the lefthand column and indicating the form of life in the right-hand column.

\section{TABLE 3: FORMS OF LIFE IN TABLE 2}

\begin{tabular}{|l|l|}
\hline EXAMPLE & FORM OF LIFE \\
\hline $\begin{array}{l}\text { There is a dog in the kitchen. He is called } \\
\text { Ben. }\end{array}$ & $\begin{array}{l}\text { Dogs are kept as pets and treated as family } \\
\text { members, given names (often human ones, } \\
\text { as here) and referred to by a } \\
\text { masculine/feminine personal pronoun. }\end{array}$ \\
\hline $\begin{array}{l}\text { Bad luck seems to dog me. I lost at cards last } \\
\text { night again. }\end{array}$ & $\begin{array}{l}\text { Bad luck is given an animate form as a dog, } \\
\text { an animal with tracking abilities. We tend to } \\
\text { think in metaphors. }\end{array}$ \\
\hline You lucky dog. You won at cards, so I hear. & $\begin{array}{l}\text { My envy leads me to dehumanise you, } \\
\text { though the choice of a domesticated animal } \\
\text { stops the image being too offensive. }\end{array}$ \\
\hline He was as sick as a dog. Too much brandy. & $\begin{array}{l}\text { The mores of this society prohibit being sick } \\
\text { in public and expect a self-control that we do } \\
\text { not expect of dogs. }\end{array}$ \\
\hline $\begin{array}{l}\text { This choir is going to the dogs. The last } \\
\text { concert was terrible. }\end{array}$ & $\begin{array}{l}\text { Dogs are regarded by most people as } \\
\text { ontologically inferior to humans. A choir of } \\
\text { dogs is unlikely to be a success. }\end{array}$ \\
\hline
\end{tabular}

The examples in Tables 2 and 3 are typical of the sort of issue that translators face in their work. A translator would have to pay particular attention to the sentence, 'This choir is going to the dogs', for example, as this could mean either that the choir was in decline or that the choristers were going off to the greyhound races. The sentence that follows - 'The last concert was terrible' - makes it clear which language-game is being played here. Published translations often exhibit presumably unintended shifts in meaning when translators fail to look at context. Gill Paul (2009:54) records how Hanan al Shaykh was puzzled when, reading an Arabic translation of the Austrian writer Stefan Zweig, she read of a cat going to the fridge for a glass of milk, an activity alien to the form of life of cats. She later discovered that 'cat' was a mistranslation for 'man'. The translator had confused the German word Herr ('gentleman') for a similar-sounding word in Arabic for 'cat'. The context of the sentence in the TT makes it clear to a careful reader that something has gone wrong, 
given that we know from other textual and biographical evidence that Zweig is not a writer of feline fantasy and given what we know about how cats live. Using the concept of language-games and forms of life can prevent the translator from making such error shifts, something addressed further in Chapter 4.

The notion of the form of life explains why translators who themselves have different forms of life may translate differently, which is most clearly illustrated by looking at different translations of the same text. An eighteenth-century translation of Homer's Iliad has a very different look to a contemporary one: the 1715 rendering by Alexander Pope (1931) is in rhymed couplets of iambic pentameter, for example, which was a common verse form when Pope was writing (and in which most of his other work is written), but this strategy is unlikely to be used by a contemporary translator, because the form is no longer fashionable and also bears no direct relationship to the hexameters of the Greek ST. Robert Fagles (1990:x), for example, writes that the aim of his translation is to find a middle ground between Homer's aesthetic and the expectations of readers in the late twentieth century.

Forms of life imply that there are factors to account for the production of any text. In 2.2, I argued that the meaning of a literary work lies in its physiognomy rather than in any notion of meaning outside the text, accessible through decoding. However, an edition of any work will normally make reference to key facts in the author's background and to the times in which he lived. In a Wittgensteinian sense, just as a word or a phrase has to be seen in context, so a person has to be seen in context. In order to read, describe or translate a text, it is of use to have information about forms of life. Books in the Penguin Classics series, for example, begin with an introduction in which an editor gives background about the text in question. The Penguin Jacques the Fatalist, a translation of a Denis Diderot novel by Michael Henry (1986), begins with an introduction by Martin Hall (1986:7-18) that gives information on the following topics: Diderot; fiction and reality; stories and storytelling; thematic organisation; servant and master. The last concept, for example, is a topos with a long history in European literature. Hall shows what links Diderot to the tradition and also how he subverts it, which can aid the reader, especially in a case (such as Diderot) where many details about forms of life are only available through scholarship, because the ST was written over two hundred years ago.

Does not this emphasis on what can account for a text contradict the earlier emphasis on meaning as a physiognomy in 2.1 ? I do not think so, because the reader 
also brings his or her own form of life to the reading of a text. In the case of Diderot, many readers of the Penguin Classic who come to the text for the first time will have little idea of its background, the French Enlightenment. Appreciating a form of life is a necessary condition for meaning to function as a physiognomy. It is analogous to being in a foreign country, where knowledge of social mores may be of great help to a visitor, even to one who can speak the language, by facilitating communication (Lewis, 1999). To appreciate music, according to Wittgenstein, it is necessary to learn the rules of music: 'Learning the rules actually changes your judgement' (LA p.5). The same is true of poetry. To appreciate a sonnet, say, it is necessary to learn the conventions by which sonnets are written. The form of life and the languagegame are mutually enlightening. The reader - here the translator as reader, for whom this chapter is written - is now in a position to make a philosophical description, a surveyable representation, of the text.

What can go wrong if a translator fails to take forms of life into account when making such a description is shown by Daniel Raveh (2008), who, in a discussion of translations of the Indian mystic Patañjali's Yogasūtra, notes how many translators of this sacred text into English have failed to recognise that translation is not just an 'interlinguistic phenomenon' but something that involves 'transpositions of culture and thought' (2008:169). Raveh (2008:179) concludes that most contemporary translators of Patañjali 'have suppressed or even defused the world-renunciation directives of this ancient philosophical text in their eagerness to project more moderate, palatable images of yoga to their anticipated audience in the west'. What begins in the ST as a life-transforming activity ends in the TT as a manual on how to pass the time on a wet afternoon. What begins in the ST as yoga ends up in the TT as Yoda: Raveh (2008:174) describes how one translation relates the ST to Jedi Master Yoda from the Star Wars science fiction films of George Lukas.

It should be stressed that a form of life may refer not just to a culture but also to a language. Different languages provide different ways of viewing the world. Contemporary English, for example, has a very large vocabulary. According to Crystal (2003:119), a conservative estimate of the number of lexemes in English would be around one million, whereas a more radical account (including scientific terminology) would double that figure. The very size of English vocabulary raises a problem for a translator from, say, the HG of the NT, where the extant vocabulary is 
much smaller: the dictionary by Newman (1993), for example, contains about 8000 lexemes. Any one word in some HG ST may therefore suggest multiple English possibilities. English also does not have gendered articles, unlike other European languages. In German, for example, a noun is masculine, feminine or neuter and shows this by the form of its article, so that 'the fir-tree' is masculine, i.e. der Fichtenbaum, and 'the palm-tree' is feminine, i.e. die Palme. Heinrich Heine is able to use the genders of these trees to suggest the notion of their being in love, in his poem 'Ein Fichtenbaum steht einsam' ('A Fir-tree Stands Lonely’) (Heine 1976:36), in a way unavailable to a writer of English. Gender is one way in which some languages must say certain things, as Jakobson notes (1959:236). That this may make speakers of language perceive reality differently has been associated with the Sapir-Whorf hypothesis (Whorf, 1956); most current thinking rejects the hard determinism sometimes associated with the hypothesis, but admits that language is one way in which we form reality (Deutscher, 2010). The language I use is part of my form of life.

Such awareness of how language forms reality is similarly a useful intercultural skill for business travellers. Richard Lewis (1999:15), for example, describes how different languages make people see cultural interaction differently, so that for an English-speaker to demand 'fair play' is meaningless if he or she addresses somebody whose culture has no tradition of organised games and has no term for 'fair play' in his or her language. The point can be extended to the translator who is reading for translation, because awareness of forms of life - which are varied yet ultimately human practices - can make the translator aware of both the difficulties yet also of the possibilities of translation. Searle (2011:122) asserts that it is local cultural factors that make activities such as translation difficult, whilst the shared Deep Background we have as human beings makes them possible. (He refers to 'the Deep Background', where Wittgenstein would use 'form of life', as that which is necessary for human beings to function socially: to do something like attending an academic conference depends on a lot of shared know-how.) In an aside when the paper was given at the Second Annual Conference of the British Wittgenstein Society, June 2009, Searle told the story of a contemporary American translator, who has never been to France, translating a description by the French novelist Marcel Proust of a formal French dinner of the early twentieth century, which is very different from any dinner she has ever attended in the United States. 
Her task is therefore far from straightforward. It is manageable, however, because she can make certain assumptions about the Background, such as that Proust's diners will be placing the food in their mouths and not in their ears. ${ }^{24}$

People can understand forms of life because of the nature of the human body, which means that there is a common human form of life, as Searle notes: this is the view on which cognitive linguistics is based (Lakoff \& Johnson, 2003), and gives us a further reason for looking at Wittgenstein, who offers support for and elucidation of such views. According to Wittgenstein, if a lion could talk, we would not be able to understand it (PPF 327). The reason for this, as Gordon Baker and Hacker (2009:73) point out, is not because a lion would not speak clearly but because the form of life accessible to lions is too far removed from our form of life for anything that a lion said to count as sense: talking lions in fantasy, such as the cowardly lion in the film The Wizard of $O z$ (Le Roy 1939), are blends of the human and the leonine. Lions as they really are do not speak, of course: the phenomenon of language, and its investigation in the $P I$, is necessarily both anthropological and anthropic. When this insight is applied to literature, it becomes clear (Pilkington, 2000:12) that literariness as a phenomenon is universal, while the forms it takes vary according to form of life, so that literature itself is a cultural notion. The works of Proust are of their time (such as the clothes and customs depicted or the vocabulary available to Proust), but the poetic effects that a reading of Proust can trigger (such as regret) are of all times. Literature itself is a language-game, played in different ways at different times and places. Wittgenstein's list of language-games quoted above as (34) includes 'making up a story', but the number of stories that people can tell is potentially limitless, even though there may be constraints on the way a story is structured (such that it needs a beginning).

Current research from linguistics and neuroscience supports Wittgenstein's approach. Anna Wierzbicza (1999), writing in linguistics, notes that cultures differ markedly in the vocabularies they employ, but that there exist lexical universals that allow them to be compared in the first place. David Robson (2011), writing in neuroscience, notes that recent research has overturned the view of the body as a vehicle driven by the brain, replacing it with a view of a partnership between brain

${ }^{24}$ This example is not in the published paper and I rely on my notes made at the conference. 
and body. Such support is further warrant for using Wittgenstein's philosophy in translation studies to describe what translators do and as a tool for working. 


\subsection{Philosophical descriptions}

In the German review Das Magazin, June 2009, is a cartoon by Adam on page 83 depicting three men sitting in a room. One man is speaking and his words are cited as (47) followed by my translation as (48).

Hallo, ich bin Tom und ich freue mich so sehr, hier zu sein. hello I am Tom and I rejoice myself so much here to be

Hello, I am Tom and I am so very pleased to be here.

What makes Tom's words at least potentially funny is the clash between his conventionally polite speech, which expresses pleasure at where he is, and its context, as shown visually in the cartoon. His body language is that of a man resigned to a terrible fate. Of the other two men in the image, one seems bored and the other seems irritated. On the open door are the words ANONYME SARKASTEN ('anonymous sarcastics' or 'Sarcastics Anonymous'), a play on the names of such organisations as Alcoholics Anonymous that help those with addictions. The context makes the meaning clear. Sarcasm is a language-game, just as Wittgenstein (PI 249) holds that lying is a language-game. The form of life is that of the contemporary west where addiction to drugs, alcohol etc. has become common, so that self-help groups proliferate, and Adam is playing with the fantasy of a self-help group for those addicted to sarcasm. In context, the words of the speaker, precisely through their surface-grammar of formal politeness, perfectly express the depth grammar, i.e. the language-game of the addict who is far from over addiction. Such insights would be of use to anybody engaged in translating Adam's cartoon, who might choose, for example, to reference vocabulary associated with self-help groups in the target culture.

The use of Wittgensteinian terms can therefore elucidate a text, in this case a cartoon. Both 'language-game' and 'form of life' are tools that can be used. The end to which they are used is that of the philosophical description. In PI 109, Wittgenstein asserts that the task of philosophy is one of description, and this should 
be seen in the greater context of how Wittgenstein approached phenomena, i.e. through the grammatical investigation: 'our inquiry is therefore a grammatical one' (PI 90). The grammatical investigation is a tool in Wittgenstein's battle against what he sees as our bewitchment by language (PI 109) and he undertakes grammatical investigations of terms such as: expectation (PI 434-445); negation (PI 446-448); meaning (PI 449-468). As McGinn (2008:14) asserts, his method has two purposes. Firstly, he shows the dichotomy between our idea of how we believe that a concept works and the way that it works in practice. Secondly, he shows the many different ways in which a concept can be used. In his investigation of 'expectation', for example, he presents the term as a linguistic rather than as an essentialist function (PI 445) and also as something that has various uses in the ways that people speak (PI 444). Concepts are examined as to how they function. The goal is the description, the surveyable representation (PI 122). Wittgenstein's method can be used to gain a philosophical way of understanding literature. He does not address literature directly, but an application of his work to literature suggests a focus on language rather than on such literary tropes as characterisation, plot etc. As Huemer (2004:5) notes, on reading literature through Wittgenstein: 'in literary texts language itself becomes the topic'. For the literary translator reading for translation, this is a valuable insight.

An example of what would count as a surveyable representation is the way Goethe (2008:349) views the Middle High German epic the Nibelungenlied (The Nibelung Song) (1972). His summary is given as (49), with my translation as (50).

Die beyden Theile unterscheiden sich von einander. the two parts differentiate themselves from each-other Der erste hat mehr Prunk. the first has more splendour Der zweite mehr Kraft. the second moreforce

Two parts can be discerned in the work. The first has more splendour.

The second more force. 
Goethe avoids the common but misleading tendency to view the poem in terms of a dichotomy between the courtly and the heroic (Müller, 2007:426). His summary represents the way in which the author organises material in two halves, the first depicting the Burgundian court and the second a massacre in Hungary, but it does not try to relate the text to issues of ethos. To see a contrast between the courtly and the heroic is to ignore the fact that the narrator's (and the characters') fatalistic view of death and suffering does not vary throughout the text. Goethe remains at the level of description and I consider what he says to be a surveyable representation. Is it therefore an objective description?

It may be argued that there can be no such thing as an objective description of any text. Goethe's view of the Nibelungenlied can be seen as just as much an interpretation as the view that there is a dichotomy between the courtly and the heroic. Eliot Weinberger stresses: 'As no individual reader remains the same, each reading becomes a different - not merely another - reading' (Paz \& Weinberger, 1987:43). Similarly, in an attack on what he sees as the pseudo-scientific pretensions of stylistics, Stanley Fish (1996:110), whose reader-response theory of literature sees meaning as a process in the mind of the reader, claims that every act of description is an act of interpretation. To ask two people to describe a work of art may result in two very different descriptions, and the situation may become even more complicated if an aesthetic evaluation is called for. Would the duck-rabbit (Figure 1) mean anything to somebody who had never seen a duck? What would it mean to somebody who loves rabbits but hates ducks, or vice-versa?

I find it to be true, however, that a rigorous description of a text can be attempted, because facts can be given on which observers can agree. In his work on the archaeology of the mind, for example, Steven Mithen frequently disagrees with the interpretations of other scientists. For example, he argues that chimpanzees' use of tools indicates only a general intelligence, not a technical intelligence (1996:8384). Both sides of the debate nonetheless agree on the core facts about how chimpanzees use tools, because they accept descriptions recorded by primatologists. Similarly, Jean Jacques Weber (1996:3) describes how pedagogical stylistics stresses that 'stylistic analysis may not be objective and scientific but ... it can be rigorous, systematic and replicable, and hence achieve intersubjective validity and pedagogical usefulness' by pointing to facts about a literary work, such as a poem's metre. Such, I think, would be the sense of a Wittgensteinian philosophical description: it is 
rigorous, systematic and replicable and points to facts, so that reading for translation after Wittgenstein means putting the ST first, adopting what Weinberger (Weinberger \& Paz, 1987:17) calls 'an absolute humility towards the text', which dissolves the translator's ego.

Wittgenstein's methods of grammatical investigation can be applied to show that there is more than one sense of using the term 'interpretation', which is a highly contested term (Ricoeur, 2006:25). In $Z$ 235, for example, given as (51), Wittgenstein shows the complexities surrounding an everyday activity such as reading a timetable.

If I see the thought symbol 'from outside', I become conscious that it could be interpreted thus or thus; if it is a step in the course of my thoughts, then it is a stopping place that is natural for me, and its further interpretability does not occupy (or trouble) me. As I have a time-table and use it without being concerned with the fact that a table is susceptible to various interpretations.

A future historian may read a bus time-table as a source of information about twentyfirst century way of life, whilst a local councillor may analyse it in order to back up an argument about the need for better services. A student, however, may use it to work out when the next bus to the university is due, without worrying about these possibilities. Wittgenstein shows how it comes down to use. The literary translator uses the ST as a basis for translation, even though it is susceptible to various interpretations.

To interpret (in the narrow sense) when I should be describing is dangerous, as Weinberger shows through analyses of various English translations of a poem by the eighth-century Chinese poet Wang Wei. He argues, for example, that a bad translation allows the reader to hear only the translator and not the poet, offering as evidence a translation by Chang Yin-nan and Lewis C. Walmsley that bears 'little resemblance' to the ST, because the translators see a need to improve on it: thus they reverse its couplets (Weinberger \& Paz, 1987:17). Wittgenstein (PPF 234) similarly notes how the subject can see any phenomenon 'in various aspects according to the fiction I surround it with'. The stress on description, on striving for a surveyable representation, involves attempting to look at the text and its context free from such 
fictions. The mind is capable of making highly sophisticated connections, so that Fish (1996) is right to say that we often interpret before we describe. He goes too far, however, in his claim that the mind is unable to isolate facts. The key issue is the distinction between description and interpretation. As Wittgenstein ( $Z$ 234) notes, if we do not interpret, it is because we feel at home with a picture, whilst to interpret is to step from one level to another. Interpretations can also be shown to exist in a net of family resemblance and can be distinguished from associations and descriptions through grammatical investigation.

Reading Wittgenstein enables the translator to be aware of when he or she is describing and when he or she is interpreting, as Sonia Sedivy (2004:168) notes. A reading of Wittgenstein can enable the translator, by paying attention to physiognomy, to avoid the pitfall of imposing interpretation. Wittgensteinian description is akin to what Heidegger (2010:144) understands by 'Auslegung', a term usually translated as 'interpretation', but which Heidegger sees as 'the development of understanding', by laying out the facts of a situation, playing on its etymology, 'laying-out'. (An example of such laying-out is in the study of Jesus by E.P. Sanders (1993:10-11), which gives a list of established facts about Jesus's life, such as his baptism.) For Heidegger (2010:144), interpretation as the working out of what the author meant - for which he uses another German noun for interpretation, 'Deutung ${ }^{25}$ - follows on from this initial laying out of facts, even though there is inevitably an issue of choice in 'Auslegung'. As Wittgenstein (Z 234) notes, we have stepped to a different level when we interpret in the sense of 'Deutung'.

The $P I$ is about human practices, one of which is the reading of the work of literature. Wittgenstein addresses this in PI 652, given as (52).

'He sized him up with a hostile glance and said ...' The reader of the story understands this; and he has no doubt in his mind. Now you say: 'Very well, he supplies the meaning, he guesses it.' - Generally speaking, he supplies nothing, guesses nothing.

Wittgenstein is not saying that the cited words have to be taken as the final statement on what is happening in the story - he goes on to note that the character's hostility

${ }^{25}$ The noun used by Wittgenstein. 
may be a pretence - nor does he (I assume) want to stop readers of detective fiction, say, guessing who committed the murder. As Sedivy (2004:166) asserts, he shows that 'a text presents an immediate meaning just as a face presents an immediate expression'. The literary translator can concentrate on identifying this immediate meaning (which may of course be puzzling or ambiguous) and considering how it may be rendered for the reader who does not command the SL.

Certain followers of Wittgenstein have used his work in order to oppose interpretation completely: Phil Hutchinson et al. (2008) argue that interpretation has no place in the social sciences; Guetti (1993) claims that Wittgenstein shows that we must move away from the stress on literary interpretation because it suggests that we are decoding a hidden meaning. As usual in philosophy, it depends what is meant by interpretation. It seems to me that this position goes too far if the literary activity known as interpretation is banned, but that it is sound if a narrow view of interpretation is in question, which would pin the reader down to one view of a text. Gaps, implicatures and ambiguity, which often feature in literary texts, form part of such texts, and would be part of a description. Interpretation is a human activity and follows from facts. John Berger (1977:8) argues that the sight of fire had a different meaning in the European Middle Ages because of the prevailing belief in hell, but goes on to maintain that the belief itself 'owed a lot to the sight of burns'. Most contemporary Europeans may not think of hell when they see a flame, but an image of fire will still evoke feelings of danger, memories of pain suffered etc.

From a Wittgensteinian point of view, interpretations are not private: they follow on from descriptions of public phenomena, of facts. It would be very odd, when asked why he or she held a particular interpretation of a text, for a critic to say: 'I just do'. In reading the ST, the translator can note the facts that might give rise to later interpretation. For example, in the poem 'Selige Sehnsucht' ('Blessed Longing') by Goethe (2005:183), the image of the flame burning up the moth is crucial to the lyric's effect: even if the reader does not share the anagogical worldview of the narratorial voice, he or she will react to the 'Flammentod' ('flamedeath'). As Sedivy (2004:182) notes, Wittgenstein's work helps us 'regain our sense that the meanings and facts of a text are immediately present to us - for the most part, depending on the forms of life that "grow" the text and the reader'. The Wittgensteinian method allows the reader to follow the benign route of interpretation rather than the malign route, and this route may vary from case to case. It is against 
the spirit of Wittgenstein to use interpretation as if it were a doctrine, i.e. as if there were only one way of going about it.

Mistakes can be made both in description and in interpretation. It would be an error to state that text (44) by Chaucer is a depiction of a Christian saint. Chaucer's intention in describing the Benedictine has been taken to be satirical on textual evidence. How then can we proceed? Wittgenstein's approach is summed up in PI 79, given as (53).

Should it be said that I'm using a word whose meaning I don't know, and so am talking nonsense? - Say what you please, so long as it does not prevent you seeing how things are. (And when you see that, there will be some things that you won't say.)

We are constrained by the facts, but within this constraint we have great freedom. A dictionary is a good example of what Wittgenstein meant. We define $\mathrm{X}$ in terms of $\mathrm{Y}$ and $\mathrm{Y}$ in terms of $\mathrm{X}$. It is a matter of coherence but also of pragmatism, for the word 'dog' can certainly refer to a barking domestic quadruped. It is just that it can do so much more, because there is no central meaning to be extracted. But its use is limited by forms of life and by language-games. Brian Magee (1987:335) refers to the misconception of Wittgenstein as adopting an 'anything goes' attitude: 'He did not think we can use language how we like and then claim meaning or validity for our utterances on equal terms with anyone else's'. In (53), Wittgenstein insists that if we look at the facts then there will be certain things that we will not say: for example, that dogs and cats can be usefully categorised by the same noun. The meaning of the word (or of the sentence or of the text) is to be looked for in the utterance, e.g. the literary text, and in the human practices that sustain it. Facts are established by philosophical investigation, which is a descriptive activity. Hence good teaching of literary appreciation stresses that reference always has to be made to the text and that any assertion always needs support from that text (Eagleton, 2007). It is also why consensus can show what is a sound interpretation and what is not. Any attempt to 
read the mind of the author must be based on agreed facts. ${ }^{26}$ Hence good practice in academic writing will use published work to support assertions made (Fish, 1980).

Wittgenstein opposed what Monk (1990:416) calls the 'idolisation of science'. In terms of philosophy, as stressed in 1.4, this led him to a stance against theory in the sense of systemisation. His position is exemplified by Simon Blackburn's attack on theory (1999:119): 'Theorists and gurus like to make a pattern: people are all selfish; people are only influenced by class interests; people hate their parents; people can be conditioned; men are aggressive; women are gentle; people cannot help themselves, and so on. But this is not so much a matter of following the evidence as of imposing an interpretation on it.' For Wittgenstein, the investigation of the particular case has to come first - in terms of logical priority if not in terms of temporal priority - and to perform such an investigation is the limited but demanding task of philosophy. Interpretation is inherently anthropic, not objective.

Readings of a text can change over time because of this anthropic aspect, for example, the different readings that have been brought to Plato's Republic (1998). Annas (2000:28 ff.) asserts that the dominant status of the Republic within the work of Plato is a post-Enlightenment construct rather than one that can be attributed on available evidence to what Plato thought of the work, and she describes three stages in the reception of this text in the English-speaking intellectual community: the Romantic; the Utilitarian; the Victorian. Each of these intellectual trends was able to find in the text the merits it was looking for, i.e. respectively: mystical reality; rationality; education for the common good. Every generation has a tendency to read a text through its own concerns. If reading, like translation, is seen as anthropic, then this variety of interpretation should not be a cause of surprise or of distress, for the measurement of what people believe will always be relative to a human community. Fish (1980) uses Wittgenstein's notion of form of life to speak of 'interpretative communities'. The difficulty of arriving at a consensus is inevitable and it helps the reader for translation if he or she is aware from where he or she is coming.

I have argued in this chapter that a reading of Wittgenstein can lead to a philosophical description, i.e. a surveyable representation based on a text's

\footnotetext{
${ }^{26}$ Post-structuralism would say that the attempt to read the mind of the author is a category error, but recent critical work refutes this (Burke, 1998).
} 
physiognomy, which can form a basis for the translation of the ST. In 2.5, I show how such a description can be made, by presenting two case studies. 


\subsection{Case studies}

Here I present two case studies of reading the ST for translation: in 2.5.1, the German poetry of Mörike, which I also examine in 3.5 as a case study on writing the TT; in 2.5.2, the HG NT, which I also examine in 4.5 as a case study on theorising the TT. I offer two case studies in order to illustrate two genres, poetry and prose: as Antoine Berman (2004:279) stresses, it is easy to forget that literary translation applies as much to prose as to poetry. Both forms have considerable expressive potential (Scott, 2000:159). In investigating Mörike, I show how the consideration of forms of life and language-games can help the reflective practitioner of translation; in investigating the NT, I show how the consideration of surface grammar and depth grammar can help the reflective practitioner of translation, in line with Wittgenstein's epistemological instruction (PI 45) that meaning can be found by examining use. This separation is artificial and is a result of constraints of space, and there will be overlap, because any Wittgensteinian investigation is necessarily crisscross (PI p.3).

In making use of Wittgenstein's terms, there is a danger of falling into what Read (2004:85) calls the 'technicalisation and jargonalisation of what ... must above all be an activity, a set of methods'. I hope to avoid this danger, though the genre of the academic thesis involves a necessary referencing of Wittgensteinian tools, more than would be the case in an inquiry outside a thesis. The Danger of Words by Maurice Drury (1973), for example, has been described by Monk (1990:264) as 'perhaps, in its tone and concerns, the most truly Wittgensteinian work ever published by any of Wittgenstein's students'. What is noteworthy is that Wittgenstein is rarely referred to in Drury's essays (although the intellectual debt is fully acknowledged in the Preface). Drury simply submits psychological terms to grammatical analysis by examining how they are used and showing how this use causes confusion in the practice of psychiatry. I think that translation after Wittgenstein can proceed in a similar way. Wittgenstein would be mentioned as a source and then applied. The ladder is thrown away ( $T L-P$ 6.54). Therefore the case studies in this thesis will not constantly make specific reference to Wittgenstein for support, although his terms will be used and the overall perspective will be Wittgensteinian. As Laura Cook (2007:xv) notes, applying Wittgenstein is not to muse in the abstract over how his terms work: the terms are instructions for procedure rather than abstract theories. 


\subsubsection{The poetry of Mörike}

Wittgenstein, in a letter to Russell in 1914, asserts that Mörike 'really is a great poet and his poems are among the best things we have' (McGuinness 2008:65). In line with what has been argued in this chapter, it is possible to state a number of facts about Mörike and his verse: Mörike lived between 1804 and 1875 in Swabia, Germany; his work is part of the canon of German Literature; he was a Lutheran minister by profession who completed his studies in Tübingen; he found his vocation to be a difficult one, eventually taking early retirement to eke out a living from writing, journalism and teaching; his poems have become popular through their settings by Hugo Wolf (1926); there is an immense variety in his verse, both in form and in voice, as shown in Table 4.

\section{TABLE 4: MÖRIKE'S POETRY}

\begin{tabular}{|l|l|l|}
\hline ST & FORM & VOICE \\
\hline $\begin{array}{l}\text { 'Abschied' } \\
\text { ('Departure') }\end{array}$ & $\begin{array}{l}\text { Rhymed couplets and } \\
\text { tercets with free rhythm }\end{array}$ & $\begin{array}{l}\text { A poet kicks a reviewer } \\
\text { downstairs with burlesque } \\
\text { abandon. }\end{array}$ \\
\hline $\begin{array}{l}\text { 'Auf ein altes Bild' (1975:46) } \\
\text { ('On an Old Picture') }\end{array}$ & $\begin{array}{l}\text { Rhyming couplets with } \\
\text { four line stress } \\
\text { (Knittelvers): } 6 \text { lines }\end{array}$ & $\begin{array}{l}\text { An image of the nativity of } \\
\text { Jesus foreshadows his death. }\end{array}$ \\
\hline $\begin{array}{l}\text { 'Bilder aus Bebenhausen' } \\
\text { ('Pictures from Bebenhausen') }\end{array}$ & Unrhymed elegiac couplets & $\begin{array}{l}\text { Pictures of a ruined } \\
\text { monastery are given. }\end{array}$ \\
\hline $\begin{array}{l}\text { 'Der alte Turmhahn' } \\
\text { ('Th75:16-25) }\end{array}$ & Knittelvers: 306 lines & $\begin{array}{l}\text { A self-styled idyll in which a } \\
\text { weathercock describes the } \\
\text { wonders of parsonage life. }\end{array}$ \\
\hline $\begin{array}{l}\text { 'Ein Stündlein wohl vor Tag' } \\
\text { (1975:31) } \\
\text { ('One Small Hour Before } \\
\text { Day') }\end{array}$ & $\begin{array}{l}\text { Folk song (see below for } \\
\text { more detailed comment) }\end{array}$ & $\begin{array}{l}\text { A young woman is told by a } \\
\text { swallow that her lover is } \\
\text { unfaithful. }\end{array}$ \\
\hline $\begin{array}{l}\text { 'Im Frühling' } \\
\text { (1975:3) } \\
\text { ('In Spring') }\end{array}$ & $\begin{array}{l}\text { Use of rhyme to no scheme } \\
\text { and with free meter }\end{array}$ & $\begin{array}{l}\text { The lyric 'I' muses on spring } \\
\text { and contemplates the } \\
\text { unknowable past. }\end{array}$ \\
\hline $\begin{array}{l}\text { 'Rat einer Alten' } \\
\text { (1975:37) } \\
\text { ('Advice of an Old Woman') } \\
\text { syllables }\end{array}$ & $\begin{array}{l}\text { An old woman advises } \\
\text { young people on life. }\end{array}$ \\
\hline
\end{tabular}


This laying-out of facts is in line with Wittgenstein's stress on description (PI 124). The seven poems play seven different language-games. Whereas 'Im Frühling' portrays the lyric voice introduced to German Literature by the poetry of Goethe, 'Auf ein altes Bild' shows a more Christian sensibility, while 'Der alte Turmhahn' celebrates a particular bourgeois form of life etc. A number of tropes can be seen in the images that dominate his poetry, making manifest the transitory nature of a beautiful world: rivers flow; animals announce betrayal; the sun disperses the mist; signs of death are everywhere, even when everything seems to be going well, so that even the old weathercock realises that its days are numbered.

These are typical of the facts of which a reader needs to be informed (Fish, 1996) and therefore central to reading for translation. I see in the variety of mood in Mörike's verse the same tensions he exhibited in his failure to follow his pastoral vocation. The reader encounters the voice of a Romantic poet with a bad conscience in one poem (e.g. 'Im Frühling') and the voice of a bourgeois poet with unfulfilled longings in the next (e.g. 'Der alte Turmhahn'). The portrayal of a fractured self possibly accounts for his continued popularity in an age where questions of identity and self-definition proliferate. His work is a blend of conflicting drives, each poem articulating this blend in a different way. The poems were also written for a particular reading community, i.e. bourgeois readers prepared to look back to the Romantic vision.

The 1837 poem 'Ein Stündlein wohl vor Tag' (1975:31) is given as text (54).

$$
\begin{aligned}
& \text { EIN STÜNDLEIN WOHL VOR TAG } \\
& a \text { small-hour well before day }
\end{aligned}
$$

Derweil ich schlafend lag, while I sleeping lay

Ein Stündlein wohl vor Tag, a small-hour well before day

Sang vor dem Fenster auf dem Baum sang before the window on the tree Ein Schwälblein mir, ich hört' es kaum, a small-swallow to-me I heard it hardly Ein Stündlein wohl vor Tag. a small-hour well before day

'Hör an, was ich dir sag! hear on what I to-you say 


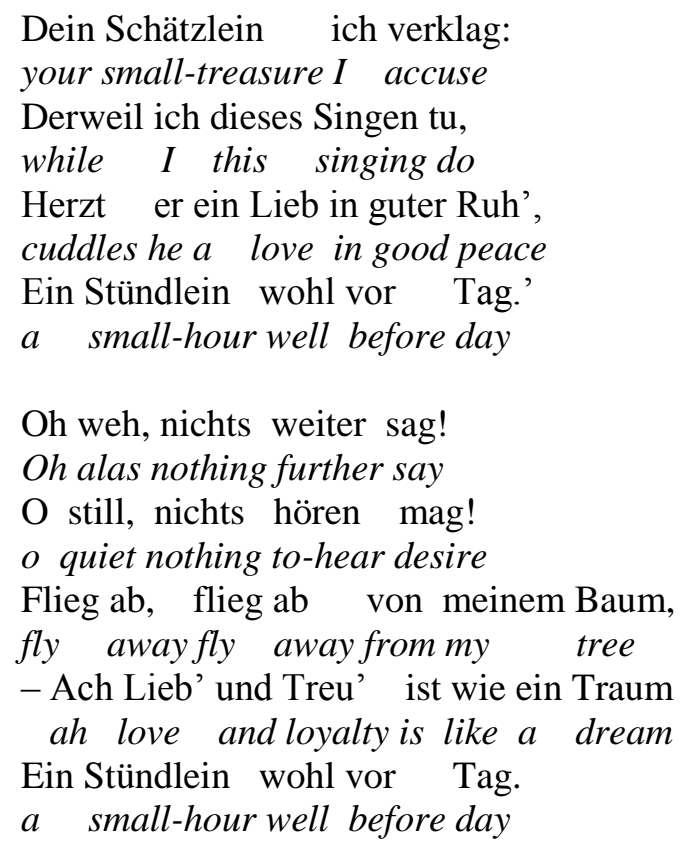

There are facts about the poem's physiognomy that can be agreed upon: it plays with the Volkslied ('folk song') tradition, exhibiting elements of that tradition, e.g. the refrain, the use of diminutives, the talking bird and the theme of disappointed love; it is a Rollengedicht ('role-poem'), in which the lyric poet adopts a persona, i.e. that of the betrayed lover; it uses full rhyme to the scheme of $\left[\left(\mathrm{aA}^{1} \mathrm{BbA}^{1}\right)\left(\mathrm{A}^{2} \mathrm{acc}^{1}\right)\right.$ $\left.\left(\mathrm{A}^{2} \mathrm{aBbA} \mathrm{A}^{1}\right)\right]$; within three stanzas the narrator is brought from being secure in love to total disillusionment with a faithless lover; the blend of the talking swallow sets the poem in the world of the fairy tale; it is influenced by the Tagelied ('dawn-song') tradition (in which lovers part at dawn), on which it is an ironic take.

The language-game played is that of the human person in love who finds that love betrayed. In a comparison of Minnesang (Middle High German love lyric) with the sweet lyric of the 1930s (the work of such songwriters as Cole Porter), Ruth Harvey shows how both traditions manifest the same patterns, with the same themes and techniques appearing in lyrics from both traditions, so that sweet lyric can be described as 'an art form ... preserving many of the essential features of a long and glorious tradition' (1963:15). It could be said that the two forms play the same language-games. Similarly, 'Ein Stündlein wohl vor Tag' plays the same languagegames found in many contemporary pop songs, e.g. its guiding metaphor LOVE IS 
A TRAP ${ }^{27}$ is also seen in the song 'Womanizer' by Britney Spears (2008). The particular form of life portrayed (the intricate verse form; the use of full rhyme; the fantasy of the talking bird) makes the poem difficult to translate, but that the form of life is human makes translation possible (Searle, 2011). Writing in 2011, I therefore find myself wondering what contemporary singers such as Spears, Werner Güra or Katherine Jenkins would make of this lyric. How about the contemporary Symphonic Metal band Within Temptation? How could the poem be written to make it performable by any of these? Could the rhyme scheme be preserved without descending into bathos? Are multiple translations possible? If this is a surveyable representation of the human being in love, which retains its poetic effects some two hundred years after its composition, is it possible to replace it by a surveyable representation in English? Could the same language-games be played? Such questions indicate a turn from reading the ST for translation to writing the TT, the topic of Chapter 3.

\subsubsection{The New Testament}

Most people who read the NT do so in translation (Boase-Beier \& Holman, 1999:3), a point further considered in 4.5.1. To recognise that the NT is a translation and to look at the HG of its first-century writers is to investigate the stylistic and lexical choices made by these writers, which may indicate that opportunities open to them are not open to a writer of contemporary English, French, German etc. Julian Barnes (2012:np), reviewing translations of Gustave Flaubert's novel Madame Bovary, points out that English grammar is not French grammar, which seems an obvious enough remark, but one that, he claims, has escaped a recent translator of Flaubert, Lydia Davis, who imports a clunkiness to her version that is not in the ST by trying to imitate French grammar in her rendering. Noting the differences between languages is an essential task of the translator. Jakobson (1959:236), for example, asserts that languages differ not in what they may say but in what they must say, which is supported by the insistence in the PI that meaning is on the surface, that we should look at the form of what is said etc.

The NT is a collection of 27 texts written in the first century and accepted as canonical by most Christians. Can a Wittgensteinian reading, which puts the ST first,

${ }^{27}$ The use of capitals is a convention to indicate a conceptual as opposed to a textual metaphor. 
shed any light on a work that has been studied intensely for two thousand years? To put the ST first involves acknowledging that it lacks any easy categorisation. The Gospels (traditionally ascribed to Matthew, Mark, Luke and John), for example, which tell the life of Jesus, are not biographies in the contemporary sense of the word: Mark omits material that would be expected in a contemporary biography, such as any description of Jesus or details of his life before his ministry. There has been a recent trend in scholarship, however, to read the NT as literature, and this would fit in, I think, with a Wittgensteinian stress on the primacy of practice and of use. Thus the Gospels do fit the criteria of first-century Greek and Roman lives that combine ‘folklore, gossip, praise and literary invention' (Keefer, 2008:19). We can bring a literary reading to the NT, which would allow readers 'to understand content through close engagement with form' (Keefer, 2008:7), to be part of the text, to engage with it, to use it to change his or her mind or life. A grammatical investigation of Mark, for example, can show how the style is integral to the presentation. Keefer (2008:29) notes that Mark presents Jesus as a lonely and misunderstood figure, an enigmatic portrait supported by the 'sparseness of the narrative', so that in 'the same way that the narrative isolates the character of Jesus, thus also the syntax of the Gospel isolates the reader'. An instance of this is the iconic way that chapters 8,9 and 10 of Mark all end with a prediction by Jesus that he must suffer and die, a prediction that the disciples meet with incomprehension, making the reader ask himself or herself if he or she is prepared to follow Jesus no matter what it takes.

Looking at how the ST uses words can enable us to see how an author has chosen to write in a particular way in order to create a particular effect. In Mark 9:2, for example, a past occurrence is described in the present tense. The ST is given as (55).

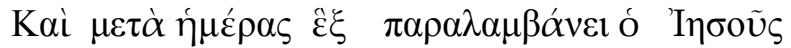
Kai meta hêmeras hex paralambanei ho Iesous and after days six takes-away the Jesus 
The use of the present tense heightens the tension for dramatic effect. Jesus interrupts his journey, in order to take three of the disciples up a high mountain. It seems that something significant will happen, especially as the Old Testament frequently sets important events on mountains, such as Moses receiving the Covenant from God on Mount Sinai (Exodus 19:20). In Mark, Jesus will be transfigured before his disciples. Most translations of this episode (e.g. the $\mathrm{New}$ Jerusalem Bible) choose to use the past tense for rendering the text, but Nick King (2004) uses the simple present, maintaining the note of the unexpected: 'And six days later Jesus takes aside ...'

I use texts (56) and (57) to show how surface grammar relates to depth grammar, following PI 664. The texts represent John 20:27 and John 21:19 respectively.

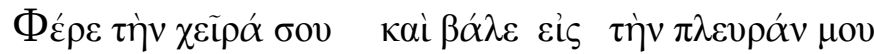
Phere tên cheira sou kai bale eis tên pleuran mou take the hand of-you and place into the side of-me

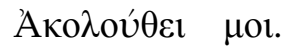

Akolouthei moi.

be-following to- me

The aorist imperatives in (56) indicate that a single action is commanded: Jesus demands that Thomas should place his hand into his side on this occasion only. The present imperative in (57) indicates that an ongoing action is commanded: Jesus commands Peter to follow him forever, not just for the next few minutes. To look at the grammar of the ST in this way is useful for the translator, who can see how the meaning of the HG depends on the use, viewing each sentence as an instrument 'and its sense as its employment' (PI 421). By analysing the grammatical choices made by ST authors, by working out why an author made a particular choice, a way in to a translation can be found as a translator writes commands in his or her TL that would maintain the distinction. 
Text (58) represents Mark 1:15 and shows how the choice of lexis instantiates meaning.

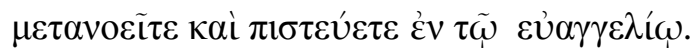

metanoiete kai pisteuete en tô euangeliô.

repent and believe in the good-news

The initial verb, $\mu \varepsilon \tau \alpha v o \varepsilon ́ \omega$ [metanoeô] ('I repent') in the present active imperative indicative, second person plural, has the implication of turning round one's entire life, not simply giving up sweets for Lent. In translating this term, therefore, a translator might choose to find ways of maintaining the radical nature of the message preached, as in the rendering in Die Bibel in gerechter Sprache (The Bible in Just Language) (2006), cited as (59).

Kehrt zum Leben um und vertraut dem Evangelium! turn to-the life round and trust to-the gospel

The notion of turning one's life round is maintained and faith is construed as trust rather than assent, though the noun 'Evangelium' retains a scholastic rather than an everyday connotation.

Text (60) is the description of Jesus's death by crucifixion in John 19:30. ${ }^{28} \mathrm{I}$ use the analysis by University of London BD examiners (2004:13) in my discussion.

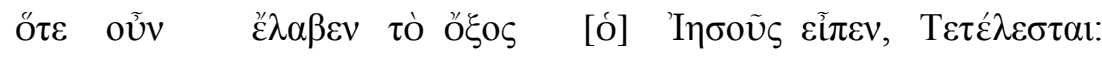

hote oun elaben to oxos [ho] Iesous eipen, Tetelestai:

when therefore received the vinegar [the] Jesus he-said it-has-been-finished

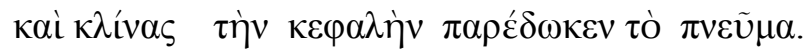

kai klinas tên kephalên paredôken to pneuma.

and reclining the head he-gave-up the spirit

${ }^{28}$ The square brackets indicate that not all manuscripts have the definite article here. 
The surface grammar is a simple narrative account of four actions: Jesus drank vinegar that had been offered to him by a Roman soldier; he said that it was over; he bowed his head; he died. My translation in (61) therefore seems to be satisfactory, because it represents these actions.

So when Jesus had taken the vinegar, he said: 'It is finished'. And, bowing his head, he died.

Or should the final clause be translated as 'he gave up the ghost', in order to retain the Greek idiom (which has become a standard if now somewhat archaic - and potentially facetious - form in English, because it was the rendering of this expression by the translators of the King James Bible)? The question seems to be one of stylistic choice and nothing more.

Attention to the way in which the Greek is written, however, shows that other factors have not been taken into account in this reading, i.e. the implications of the

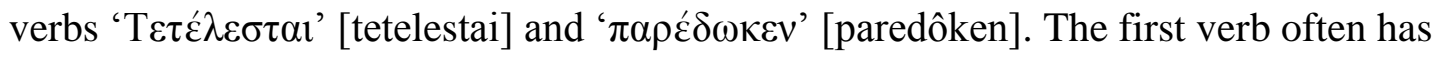
a purposive sense, a sense of fulfilment, consonant with the stress throughout the whole Gospel on how Jesus, as Word of God, is in control of events. The second verb can also mean 'hand over', so that Jesus could be said here to be handing over the Holy Spirit to the Church. The Examiners (2004:13) comment that this understanding of John's words 'is not necessarily refuted by the observation that Jesus gave the Spirit only at Easter (John 20:22), since John tends to merge Jesus's death and glorification'. It is a question of reading the text with a view to the form of life that produced it, what King (2004:12) calls 'the kind of life that lurks beneath the text of the NT'. (King has told me in personal correspondence that he believes a reading of Wittgenstein has influenced his approach to translation.) His rendering of this verse brings out the theological implications and is given as text (62) and enables the reader to construct the depth grammar beneath the surface grammar.

And when he had taken the vinegar, Jesus said, 'It is perfected'. And inclining his head, he handed over the Spirit. 
In PI 373, Wittgenstein notes: 'Grammar tells us what kind of object anything is. (Theology as grammar.)' By reading the NT grammatically, we encounter its theology, which may allow in turn the theology to be translated. 


\subsection{Conclusions}

'How should I translate?' The correct answer to this question is to point out that translation is a practice and that this practice begins with reading, i.e. reading for translation. If Berger (1977:8) is right to assert that what we see is affected by what we know, then it follows that a knowledge of Wittgenstein will enable a reader to see the text as physiognomy and to be freed from the (possibly unconscious) paradigm of decoding. In the Big Typescript (BT) p.314, Wittgenstein notes that we encounter philosophical problems in practical life when we are guided by 'certain analogies within language', rather than by practical purpose, an insight that supports work by George Lakoff and Mark Johnson on cognitive metaphor showing how certain cognitive metaphors can mislead us into thinking that meaning has an existence independent of words, as in the container metaphor: when somebody says, for example, that it is difficult to put his or her thoughts into words (Lakoff \& Johnson, 2003:11). False analogies are embedded in our language.

That it is possible to link Wittgenstein to theorists such as Lakoff and Johnson strengthens the case for looking at his work. Wittgenstein supports and is supported by relevance theory (Sperber \& Wilson, 1995), for example, where the stress on reading the mind of the speaker parallels Wittgenstein's notion of the form of life. Similarly, Michael Burke (2003) uses the concept of the cognitive scenario (following Lakoff, 1987) as a tool to facilitate the understanding of love poetry, giving the example of the pub (after Stockwell, 2002:77). Most people know the sort of things to expect when they enter a pub: drinks and food for sale; quiz machines; tables at which to sit; a bar etc. Somebody is unlikely to be surprised to hear that a pub is serving food, but might be very surprised to be told that food is being served by a dog, because this is not typically part of the cognitive scenario outside a joke or a fantasy narrative. Similarly, a number of features might be expected by the reader who opens a volume of love poetry: the intense expression of emotion; the use of metaphor; the use of the first person singular etc. Wittgenstein's methods offer a link to the cognitive scenario, a short-cut for getting there, a set of methods for describing it. The attentive reader of the PI is offered tools to allow him or her to become adept at seeing what is instantiated in a literary text, at becoming at home there. For the translator, this means to be in a better position to translate, by seeing the text's physiognomy and responding to it, just as one might note differences between a German pub and an English pub. 
My claim is not that a reading of Wittgenstein will produce perfect translators and perfect translations. Any such claim would view translation as a scientific procedure analogous to propositional calculus, a view alien to the spirit of the later Wittgenstein. Pilkington (2000:49) asserts that there is no single theory or method that can unlock a meaning within literary texts, so that they can be read correctly by the reader who happens to have come across that theory or method. If that were the case, then the vast majority of readers would have no hope of ever understanding literature. Pilkington's view is correct because the concept of a hidden meaning in a text, waiting to be unlocked, is a chimera, as shown by my reading of Wittgenstein. To use Wittgenstein is a philosophical way of describing the process of reading for translation. There are other ways available: the sociological; the cognitive; the literary; the psychological etc. And any way of describing a process is bound in turn to become part of that process. Boase-Beier (2006b:147) argues that knowledge of a theory can be 'a pair of spectacles through which we see the world differently', quoting the philosopher Mary Midgeley (2001:26).

Wittgenstein, in Remarks on the Philosophy of Psychology (RPP) I 94, similarly recommends the need for 'new conceptual glasses' in order to see with clarity. The tools in the PI can provide such glasses, which is not to suggest that to use Wittgenstein is necessary for literary translation. The number of acclaimed literary translations written before the publication of the $P I$ in 1953 is sufficient to dismiss that notion. My claim is rather that the story told by Wittgenstein in his later work is too important for the reflective practitioner of translation to ignore, because he offers a perspective on language that can enable the task of reading for translation to be approached with clarity: 'the clarity we are aiming at is indeed complete clarity' (PI 133). 


\section{WRITING THE TARGET TEXT}

In the elder days of art

Builders wrought with greatest care

Each minute and unseen part,

For the Gods see everywhere.

Longfellow (1904:186) 


\subsection{The translator and the fly-bottle}

In this chapter, I address the translator, the writer of the TT, and ask how the account of Wittgenstein that I have built up can be of use to him or her. For the practising translator, the later philosophy of Wittgenstein can offer a philosophical turn that can improve practice. In PI 309, Wittgenstein states that his aim in philosophy is to show the fly the way out of the fly-bottle (a simple form of trap). This image has been taken (for example, by Kerr, 1998:55 ff.) as a metaphor for Wittgenstein's project of subverting a metaphysical way of thinking that has been highly influential in the west. The destruction of a false paradigm can make it possible for the world to be seen clearly. Drawing on insights from the translation theorist Berman, I argue that the metaphysical tradition critiqued by Wittgenstein has been responsible for an approach to translating that deforms literary translation, and I claim that a reading of Wittgenstein can be used to tell a different story that opposes the metaphysical: Read (2010:605) notes that for Wittgenstein the opposing term to 'ordinary' is not 'extraordinary' but 'metaphysical' or 'nonsensical'. The translator is freed from the fly-bottle. Literary translation becomes possible.

The activity of translating is frequently divided into literary and non-literary, as discussed in 1.1. Chesterman and Wagner (2002:5) give the example of Ted Hughes' translation of Aeschylus from Greek to English (1999) as an example of literary translation, and the translation into English of the label on a packet of white powder in a Greek supermarket as an example of non-literary translation. This example is a straightforward way of categorising translation, which reflects a division in the way that the discipline is organised in the academic world: UEA (2010), for example, offers an MA in Applied Translation Studies in the School of Language and Communication Studies and an MA in Literary Translation in the School of Literature, Drama and Creative Writing. The aspiring translator is directed to a school of study depending on the sort of texts that he or she wishes to translate. Theo Hermans (2007a:77), commenting on how Chesterman and Wagner refer to literary and non-literary translation as the 'top' and 'bottom' ends of the range, respectively, notes how 'value enters the picture as well'. The plays of Aeschylus (on account of their literariness) are valued more highly than works of popular fiction and advertisements, even though advertisements, for example, can exhibit literariness and can be very difficult to translate. Hughes' translations (on account of 
their literariness) have in turn been valued more highly than translations of popular fiction and of advertisements.

In a 1985 essay, Berman (2004:277) addresses the 'great split' between literary and non-literary translation. He defines literary translation as being concerned with works 'so bound to their language that the translating act inevitably becomes a manipulation of signifiers', and non-literary translation as being about 'semantic transfer'. These definitions are themselves problematic, for they seem to suggest that literary translation does not involve replacing a text in one language with a text in another language, but they can be used to explain the examples given by Chesterman and Wagner. Hughes manipulates the signifiers of the Greek text of Aeschylus for literary effect, producing a creative work that is itself literary, so that it can be read in its own right or performed on the stage; his translation involves more than the competent use of a dictionary, because he is concerned with maintaining the poetic effects of the ST. By contrast, the main thing that matters about the translation of the label of the white powder is that the English-speaking tourist should not mistake rat poison for sugar and meet an untimely end while on holiday. Here, only semantic transfer is the issue, which might well involve the competent use of a bilingual dictionary and nothing more. This raises a crucial question: can the literariness of the ST go missing? ${ }^{29}$

Berman's core assertion (2004:288) is that there has been a tendency in western translation to translate literary texts as if they were non-literary by prioritising the restitution of meaning, so that translators have attempted to produce works that are (paradoxically), more clear, more elegant and more fluent than the ST, by ignoring the ST's literariness and attempting to producing a TT that is easily understood. His critique is similar to that of Ezra Pound (2004:93), who notes how translators often engage in the self-defeating task of writing for the linguistically lazy reader. Berman refers to this tendency as a 'deforming' method of translation. Works of literature have been translated as if they were technical manuals, without regard to matters of style or to the production of literary effects, only to easy comprehension. This pessimistic view of the history of literary translation is shared by other translation theorists. I use Berman to exemplify a common perception. Venuti (1998 $\&$ 2008), for example, sums up the history of literary translation as a succession of

${ }^{29}$ See 4.3 for further discussion of quality in literary translation. 
scandals, in which translators attempt to make themselves invisible by normalising the ST in their rendering, whilst Barnstone (1993:35) warns against the 'mindless imposition of standards for information transfer onto the translation of aesthetic texts'. The normalising of the ST in translation is a recognised tendency in translation that Bellos even sees in the translations of Edgar Allen Poe by the great French poet Charles Baudelaire (2011:199). Similarly, Berman's view that literary translation is not a matter of searching for semantic equivalences (2004:287) is common to many translation theorists, for example, Paz \& Weinberger (1987) or Hermans (2007b).

In that Berman was writing to expose a scandal, understood as a misrepresentation of the literary task of the translator, and to propose ways of reforming it, it might be hoped that the situation is different in the twenty-first century. However, this does not seem to be the case. I give two examples. Firstly, in a recent article Sarah Lawson (2009) describes how translations she produced for the Foundation for the Production and Translation of Dutch Literature were rejected solely because the style of her English was perceived to be insufficiently elegant and insufficiently easy to read, a rejection made without any reference to the style of the ST and how this might have been echoed in the writing of the TT. Lawson argues that one of the most important tasks of the translator is to bring out the voice of the ST author, which is a central claim of Berman, so that in her opinion the experts from the Foundation confused translation and translator. I find this to be true: if I were to translate Simone de Beauvoir on Monday, Albert Camus on Tuesday and André Gide on Wednesday, it would be odd if I rendered them in the same elegant English style, because these authors have very different French styles. To look solely towards the TT is to ignore the physiognomy of the ST (PI 568). As Berman (2004:279) notes, literary masterpieces - he cites François Rabelais and Jean Paul are often characterised by "a kind of "bad writing", a certain "lack of control" in their texture'. To aim to render a novel by Rabelais into elegant English is to be engaged in the same sort of exercise as translating the label on the bottle, for all the surface differences. It is to fail to be aware of the novel's depth grammar, to use the term from PI 664 discussed in 2.2. In Wittgensteinian terms, the difference between literary translation and non-literary translation can be described as the difference between the translation of depth grammar and surface grammar, a description that has the advantage of criss-crossing genres and avoids the problems in Berman's 
definitions. Secondly, Eliza Handyani (2011:34) notes that many literary translators into Indonesian produce the TT by rendering the ST word for word, instead of looking for creative solutions, a situation she explains by lack of SL competency and literary skills, both of which would seem to be necessary to produce a literary translation in Berman's sense.

Value judgement is crucial to Berman's argument. He identifies exceptions to the deforming trend, for example, the Sophocles renderings carried out by Hölderlin (1952), which he sees as 'one of the great moments of western translation' (2004:276). Such exceptions, however, only confirm the rule. He details twelve 'deforming tendencies' in translation: rationalisation, clarification, expansion etc. Yet to see these as 'deforming' involves a value-judgement that is presumably not shared by those who use strategies such as clarification in the first place. There is no reason per se why to produce a rationalising translation should be seen as deforming. Every translation is in one sense deforming because the writing of the TT inevitably changes the form in which a reader encounters the work: Berman's contention is that the manner in which reformulation has taken place has frequently been detrimental.

Berman would need to show why the situation he describes has arisen and then to show why it is wrong. I think that he addresses the first of these two points but fails to address the second. My reading of Wittgenstein can be used both to support and to complete Berman's argument. ${ }^{30}$ It supports the argument by showing that Berman has identified the correct target in the metaphysical tradition. It completes the argument by offering a way of subverting this tradition: methods from Wittgenstein can be used to show other ways of approaching literary translation, so that the work of Wittgenstein can offer a set of tools to be used in the training of the translator. In Chapter 2, I argued that Wittgenstein can be used to help the translator read the ST. In this chapter, my point is that he can be used to help the translator become clear about the nature of literary translation. The translator is introduced not to a single method, but to methods, like 'different therapies' (PI 133). Using Wittgenstein in this way, I am in line with what Pym (2007:24) sees as one of the three main interactions between philosophy and translation studies, i.e. the use of philosophical discourses by translation theorists and practitioners for support and authority for their ideas, as discussed in 1.2.

\footnotetext{
${ }^{30}$ Arrojo (2010) similarly sees Platonic thought as responsible for a wrong picture of translation as transference and uses Nietzsche's thought as a tool to argue against it.
} 
Berman (2004:288) traces the deforming tendency in literary translation to the (largely unconscious) influence of Plato and the 'typically Platonic separation between spirit and letter, sense and word, content and form, the sensible and the nonsensible', so that all translation becomes the translation of surface grammar, which is seen as bad writing, and tidied up. It would never be possible to prove whether Plato has caused the deforming tendency in translation. The views attributed to him are in any case those expressed by Socrates, the main character in Plato's dialogues, whose views do not necessarily represent those of Plato. There are also many different ways in which Plato has been interpreted. Berman's perception of how Platonic dualism has formed and dominated western thought is, however, not isolated. Mark Edmundson (1995), Kerr (1998) and Sontag (1996) describe how Platonic dualism has influenced the following fields respectively: literary criticism; philosophy and theology; aesthetics. I now examine the views that Plato expresses through Socrates on art.

In Plato's most widely-read dialogue, The Republic (1988), Socrates attempts to sketch an ideal society, one ruled by philosophers, and maintains that artists would have no place in it. He sees the activity of art as corrupting for citizens, so that if a dramatic poet visited the Republic, he or she would be taken politely to the border (514a). Murdoch (1997) relates this view to the parable of the cave (514 ff.), in which Socrates describes prisoners who lie shackled in an underground cave lit by a fire, to which they have their backs. They watch shadows cast on the wall, as events take place behind them, and mistake these shadows for reality. Socrates asserts that philosophical activity can allow the prisoner to leave the cave and to see the true world in the light of the sun. He advances the doctrine of the Forms, which are ultimate instances of the qualities that we dimly discern. The good qualities that we ascribe to phenomena - for example, when we describe a wine or an action as good are caused by the eternal, immutable Form of the Good, for example. Philosophy enables human beings to perceive the Forms, which is why Socrates expresses hostility to art. The artist makes copies of the material world, itself a copy of the spiritual world. The artist mistakes the fire for the sun. Art therefore 'apes the spiritual and subtly disguises and trivialises it' (Murdoch 1997:433) and must be banned.

With respect to literature, the Republic would accept the Greek legends if and only if they have an improving moral. Stories that do not have such a moral would 
be rejected, and even stories that are morally praiseworthy would be stripped of their style. Socrates (393d) analyses Homer's account in The Iliad of Chryses the priest appealing to the Greeks on behalf of his daughter. Socrates decodes the episode, stripping away the style in order to find 'the pure narrative, which is free from representation': signifier and signified are separated in the same way that Platonic dualism separates body and spirit. The story of Chryses is narrated as somebody might describe a film that he or she has just seen to a friend who had missed it. Style is seen as decorative, not as structural. Even Homer would be led to the border. If Socrates would banish the artists because they copy a copy, he would presumably also banish the translators for making a copy of a copy of a copy and thus committing the same metaphysical crime as the artist.

The tendency to take an essentialist view of language, i.e. postulating a oneto-one correspondence between words and their meanings, can also be traced back to Plato. Socrates, in the Cratylus (338A), defends the view that 'everything has a right name of its own, which comes by nature ... a name is not whatever people call a thing by agreement ... there is a kind of inherent correctness in names'. Socrates also attacks this view, but it can be taken to represent a way that people construe meaning, and is the construal found in the Augustinian paradigm in PI 1.

In contrast to Berman, who both argues against the dualist tradition and names Plato as its source, Wittgenstein generally avoids individual targets in the PI. As McGinn (2008:20) asserts: 'The philosophical doctrines and pictures of how language works that Wittgenstein looks at, some of which may be identified with the views of particular philosophers, are really of interest to him insofar as they represent a style of thought which he believes makes misunderstanding and confusion inevitable'. He is not attacking Plato, but what Nassim Nicholas Taleb (2007:xxv) calls 'Platonicity', which Taleb defines as 'our tendency to mistake the map for the territory, to focus on pure and defined "forms"". The mind attempts to deny the body. The translating mind attempts to deny the words on the page and looks towards the Forms not the forms. The target that Berman identifies can be broadened from Plato to Platonicity.

What is missing in Berman is any foundation for his argument. There is assertion and example and illustration, but no reason why his essay should not be seen as just a passionately-held opinion. There is no appeal to anything outside for support. Socrates, in other words, might be right. Berman (2004:288) specifically 
states: 'this Platonic figure of translation is not something "false" that can be criticised theoretically or ideologically'. The implication of this is that Berman's own counter-argument is similarly beyond criticism. The situation becomes one of the assertion of intuitions, or of emotions, of trying to scream the loudest. There is a logical gap here that a reading of Wittgenstein can fill, for the PI can be seen as an extended criticism of the phenomenon of the dualism that Plato is taken by Berman to represent. Many other influential figures in the western tradition can be described as dualists: Augustine, Meister Eckhart, Martin Luther, Descartes, Franz Kafka, etc. What is at stake is a whole metaphysical tradition, which Kerr (1998:136) defines as 'the age-long refusal to acknowledge the bodiliness of meaning and mind', so that life becomes a quest for objectivity. This metaphysical tradition can be seen as implying that there is a language of ideas that lies behind reality, to which an individual can gain access by introspection. A work of literature is accordingly seen as a translation into ordinary language from this ideal language. William James (1981:185) describes, for example, how we can discover 'states of consciousness' through introspection, positing what McGinn (2008:117) calls 'a pure psychological language ... free of any objective reference'.

Wittgenstein $(P R 3)$ points out: 'How strange if logic were concerned with an "ideal" language and not with ours. For what would this ideal language express? Presumably, what we now express in our ordinary language; in that case, this is the language logic must investigate'. To look for an ideal language remains, however, a very human temptation. Read (2010:595) argues that PI 243-275, usually categorised as the private language argument, depicts 'the reader's (and the author's) inclination to fantasise that a "private" language will satisfy his desires, giving him certainty, the kind of foundation that he philosophised in order to obtain'. The desire for a private language can frequently be seen in the view held of translation. Will Stone (2005:14), for example, introducing his translations of the Austrian poet Georg Trakl, refers to 'trying to absorb and filter that more elusive language lying just beyond, a language which the German is privileged to carry'. It is the 'pure language' described by Walter Benjamin (2004:80), which the translator is seen as striving to release. By contrast, a reading of Wittgenstein suggests that meaning is found in the forms, not in the Forms.

The search for an ideal language is seen in the way that the process of translation is often described. In a discussion of machine translation, for example, 
Wagner (Chesterman \& Wagner, 2002:124) asserts that translation is a process in three stages. Step 1 is the analysis of the ST. Step 2 involves 'visualising the abstract non-linguistic sense of the language'. Step 3 is the synthesis, the writing of the TT. In the context of machine translation, it is unsurprising that her model is a mechanistic one, but it seems to me to make no sense to talk about a non-linguistic sense of the linguistic. I am not denying that thought can take place without language. Steven Pinker (1994:70), for example, notes how many creative people report thinking in mental images not words when they are inspired, citing Samuel Taylor Coleridge's account of how he composed the poem 'Kubla Khan', while Temple Grandin and Catherine Johnson (2005:241ff.) argue that recent research shows that many animals can think, although they cannot use language. My denial is that it makes no sense to look at a linguistic string and to try to work out its nonlinguistic sense. To do so is to fall into the trap of decoding. It is not the case that we have a non-linguistic meaning that we turn into linguistic meaning by making some sort of mental act (PI 120).

This view of language is one of the major targets of the PI. The Augustinian paradigm sees meaning as ostensive, as a mental activity. Kerr (1998:57) describes the paradigm with the metaphor 'the hermit in the head'. The mind is viewed as something isolated and distinct from the body. Knowledge is conceived as mental and individual and meaning is seen as hidden, which is the view of the early Wittgenstein $(T-L P)$, for whom the task of the philosopher as logician is to excavate meaning by formalisation. For the later Wittgenstein, the case is different, as shown by his attack on the Augustinian paradigm, which can be linked both to the picture theory of the $T$-LP and to the metaphysical tradition described above. In PI 1, Wittgenstein tells a story to show how the mentalist view of the world is absurd, how there cannot be a hermit in the head. I quote it as (63).

Now think of the following use of language: I send someone shopping. I give him a slip of paper marked 'five red apples'. He takes the slip to the shopkeeper, who opens the drawer marked 'apples'; then he looks up the word 'red' in a chart and finds a colour sample next to it; then he says the series of elementary number-words - I assume he knows them by heart - up to the word 'five', and for each numberword he takes an apple of the same colour as the sample out of the drawer. - It is in this and similar ways that one operates with words. 
The key point is in the final sentence: 'one operates with words'. The shopper is involved in a transaction, where what matters is the use of language in order to obtain the five red apples, and the behaviour of the shopkeeper is similarly transactional. Counting, for example, is not a mysterious mental activity, but a technique, in which somebody (here the shopkeeper) can be trained. If I have been taught how to count, then I can give somebody five apples, five oranges, five bananas etc. Wittgenstein comments: "But what is the meaning of the word "five"? No such thing was in question here, only how the word "five" is used". To find the meaning of a word it is necessary to look at its use (PI 43), not to try to relate the word to an internal concept. Wittgenstein attends to practice. For him, language is about doing things, so that learning a language is about learning to do things.

The rest of the PI can be seen as Wittgenstein's working-out of this thought. All the key Wittgensteinian concerns follow from it: the language-game; the form of life; the surveyable representation; the impossibility of a private language; the way in which rules are followed etc. Wittgenstein offers methods that allow the grammatical investigation of terms, what he calls the occasions on which 'we call to mind the kinds of statement that we make about phenomena' (PI 90).

The metaphysical tradition is a picture that holds us captive because of the bewitching nature of language: ‘And we couldn't get outside it, for it lay in our language, and language only seemed to repeat it to us inexorably' (PI 115). Berman sees this as true but cannot offer a theoretical or an ideological critique. Translation studies, unaided, cannot offer a theoretical or ideological critique. Translation after Wittgenstein, however, can justify through Wittgensteinian methods how the practice of taking meaning as something to be extracted and conveyed can be replaced by looking at the use of a word and moving on from there (PI 340). This is the central contention of my thesis. As with his presentation of the Augustinian paradigm, Wittgenstein's criticism does not dismiss as stupid the way that we instinctively operate (PI 340).

One of the key ways in which Wittgenstein attempts to free his reader from the false picture is through offering other pictures. Images are central to the PI: Wittgenstein compares words to different tools in a tool-box, in order to bring out the diverse functions of words (PI 11); he describes looking into the cabin of a locomotive, where the similar-looking handles must be manipulated in different ways, in order to show how words must be used differently (PI 12); he describes the 
language-games of the builders, quoted as (30), in order to show how the meaning of a word can be found by looking at its use in the language: any of their four words could be used in different ways to get different transactions to take place (PI 2, $7 \mathrm{ff}$.); he uses the urban image quoted as (64), in order to describe language as a whole (PI 18).

Our language can be regarded as an ancient city: a maze of little streets and squares, of old and new houses, of houses with extensions from various periods; and all this surrounded by a multitude of new suburbs with straight and regular streets and uniform houses.

The point of this image is to subvert any inclination to impose a unified view onto language. As Kerr (1998:31) notes, it contrasts with the enthusiasm for 'orderly towns' planned by an engineer, as opposed to 'badly proportioned' old cities, expressed by the dualist Descartes (1968:35). Every person is born into a language community with a history, into the traditions and techniques of which he or she must be trained. To see language as an ancient city (as opposed to a planned town) will make a difference to how one conceives of language and accordingly will have consequences for how one translates.

Berman describes a situation in which a truth about one kind of translation, i.e. translation as transfer, has been taken to be the whole truth about every kind of translation. As Bellos (2011:25) argues, it is easy for English speakers to be misled by the word's etymology of 'carrying-across', from the Latin trans, 'across', and latum, supine of ferre, 'to carry'. ${ }^{31}$ The etymology suggests and supports the idea of translation being summed up by the conceit of the ferryman or trucker moving something from A to B. As Barnstone (1993:15) notes, Greek vans often bear on their sides the $\log 0 \mu \varepsilon \tau \alpha \varphi \rho \rho \alpha$ [metafora] ('carrying across') to signify 'transportation': the noun signifies the transference of a word to another sense as well as the movement of goods. Etymology is a valuable tool, but Wittgenstein's advice to seek meaning in use shows that it is dangerous to equate etymology with meaning. As Bellos (2011:26) notes, knowing that the noun 'divorce' comes from the Latin divortium, ('watershed' or 'fork in the road'), does not tell us what the

${ }^{31}$ The etymology is common to many European languages, as in the Greek example that follows. 
word means now, i.e. how it is used to designate the legal end of a marriage. In 'carrying-across', we have a metaphor of one way of seeing translation. By applying it to all translation, it becomes a prejudice.

It is not a stupid prejudice and is understandable in view of the human need to generalise, but it has been a disastrous prejudice. As I noted in 2.6, my claim is not that literary translation only becomes possible after Wittgenstein: the existence of great literary translations that pre-date his work invalidates any such claim. As mentioned above, Berman cites Hölderlin's translations with unqualified approval, renderings described by Steiner (1998:340) as being 'of the first importance'. What Wittgenstein offers is a short-cut for the translator, who is shown both the existence of the fly-bottle and the way out. The short-cut begins with the realisation that translation has more to do with shopping than with mental processes. An example from literature can illustrate this.

Language has many more uses than denotation. In Kafka's German story 'Ein Landarzt' (1963) ('A Country Doctor'), the eponymous protagonist's maid is called Rosa, a name that connotes the adjective rosa, 'pink', and the feminine noun Rose, 'rose'. Kafka's choice of name for the maid relates to both connotations. After watching with apparent helplessness as a mysterious servant breaks into his house in order to rape Rosa (1963:55), the doctor rides away to treat a patient, whose wound he describes as 'Rosa' (1963:58). The foregrounded adjective, capitalised at the beginning of the sentence, is now identical to the maid's name. Not only does it describe an injury but it also links the wound to the maid, and hence to sexual crime. The revolting wound (it is crawling with worms) blends sex, guilt and violence, contrasting with the positive associations of the rose: Adele Nozedar (2010:309) comments that the rose is a sacred flower that symbolises love, beauty, perfection and purity. A literary translation of the story would have to address the different ways in which language is being used by Kafka. In 3.3, I examine two translations of this example, and note here that to reach for a dictionary to translate the word in Kafka's story and not to go further is to remain within the fly-bottle.

Both Socrates and Wittgenstein use images of freeing the captive. Socrates wants to release the prisoner from a cave by introducing him or her to philosophy. Wittgenstein wants to set the fly free from the fly-bottle by dispelling confusion. The crucial difference is that the prisoner has been born in the cave whereas the fly has flown into the fly-bottle. Socrates describes a situation that is metaphysical and 
demands a change in the whole human condition by looking beyond to the Forms; Wittgenstein looks at the world as we find it and demands a change in our way of thinking about language. Socrates contributes to one of the great myths of the west; Wittgenstein, as Kerr (1998:75) notes, has 'written a text that enables the reader, with patience and luck, to become suspicious of the power the myth still wields'.

One further conclusion follows. The background to Berman's essay is the split within the field of literary criticism between the literary and the linguistic (Boase-Beier, 2006b:6-12), a split reflected in his insistence that literary translation has nothing at all to do with semantic transfer (2004:277). Whereas traditional language studies looked at both language and literature, a division opened between those following the literary path, using ideas taken from structuralism, poststructuralism and postmodernism, and those following the linguistic path, taking their cue from the generative linguistics of Noam Chomsky. As Jakobson (1960:351) notes, aiming to forestall the split: "The separation of the two fields [poetics and linguistics] is based on a current but erroneous interpretation of the contrast between the structure of poetry and other types of verbal structure'. The bridge between the two fields has now been built in literary studies by the growth of stylistics, but it is a bridge that has not yet been fully constructed in translation studies. Current work on stylistic approaches to translation may be seen as making a start, for example, BoaseBeier (2006b), and the work of Wittgenstein is here of potential importance. Firstly, he gives a rich picture of communication, thus helping the translation theorist restore what Elżbieta Tabakowska (1993:10) calls the 'human factor in communication'. Secondly, he shows that if communication is based on language-games then it is not possible to split language into the linguistic and the literary. Wittgenstein (PI 23) notes the following as being language-games: reporting an event; making up a story and reading one; translating. One list includes both the literary and the linguistic. The bridge is built in the PI. It can now be constructed by the translator, who can write the TT while responding to the style of the ST. How this might be done is the topic of 3.2. 


\subsection{The language-game of translation}

As Edith Grossman (2010:63) remarks, literary translation 'is an occupation that many critics agree is impossible at best, a betrayal at worst, and on average probably not much more than the accumulated result of a diligent, even slavish familiarity with dictionaries'. The impossibility of translation is due to the demand for perfect equivalence: Barnstone (1993:18) argues that if 'truly literalist assumptions' prevailed, translation would indeed be impossible, because in translation ' $\mathrm{A}=\mathrm{A}$ is impossible'. The work of linguistic determinists such as Benjamin Whorf could also be used to support the view that literary translation is impossible, for linguistic determinism would suggest that no form of translation could be successful if (and only if) this view is taken to its extreme. Whorf (1956:215), for example, argues that Hopi and English cannot be 'calibrated' against each other because they embody different metaphysics, different ways of looking at the world. If we think that we can translate from Hopi into English then we deceive ourselves. Donald Davidson (2001:128), however, remarks that Whorf's position is self-destructive because Whorf does use English to show the contents of sample Hopi sentences. It does not follow that because one language cannot be calibrated against another that it cannot be translated. One argument against those who believe that translation is impossible is to take them into a bookshop. How, though, can we know that the works on sale there are genuine translations? How can we know that translation is possible?

I take Wittgenstein's later account of language to show that translation is possible once meaning is recognised as not being something private, i.e. when it is seen as inter-subjective, not objective. Meaning in the $P I$ is to be understood by looking at interaction: between individuals; between communities; between the individual and the community. As Wittgenstein (PI 265) notes: 'justification consists in appealing to an independent authority'. It would not be possible for a totally isolated person to look up words in a mental table for this would be like buying several copies of the morning paper to assure oneself that what is in it is true. What a dictionary does is to 'justify the translation of a word $\mathrm{X}$ by a word $\mathrm{Y}$ '. It would be impossible to translate a newly discovered language, for example, without some form of independent reference. The 196 Rosetta Stone, discovered in 1799, displays a text in Ancient Egyptian, a language that had proved impossible to translate. That the Stone also contains the text in Ancient Greek, which could be translated by 
scholars, enabled linguists both to translate the Ancient Egyptian and to form a basis for understanding the entire language, as a result of triangulation (Parkinson, 2005). Where no triangulation has to date been possible, nor has translation, as in the case of Linear A (Davidson, 2011:256). Wittgenstein stresses that there can be no such thing as a private language ( $P I$ 256-314), and translation is similarly a shared language-game (PI 23). Linear A is not in principle untranslatable.

The description of translation as a language-game is convincing because translation is an activity already practised within the communities into which we are born, one that pre-exists the individual, so that a person can in turn be trained to translate. Cultures have professional translators. If I want to read the latest crime bestseller from Sweden, I do not have to learn Swedish, because I can buy an English translation. If I have a meeting with a Swede who does not speak English, I can employ an interpreter. There is a heuristic aspect to translation, to which Wittgenstein appeals by naming it a language-game, an activity that can be carried out by the child learning a second language and by the academic working on a new version of a play by Goethe. Translation has history and traditions. A constantly growing body of texts has been produced by translators, describing what they have done, giving advice, justifying strategies etc., from Herodotus's fifth-century BC comments in his Histories (1963) to the translator's notes in any recently published edition of a translated work, for example, Constantine (2005). Wittgenstein (PI 23) sees the language-game of translation as analogous to such activities as: giving orders; presenting the results of an experiment in tables and diagrams; guessing riddles; thanking.

Wittgenstein advises his reader to look for the meaning of a word in its use (PI 43). For the practising translator, this is a way into playing the language-game of translation. He or she can look at the ST and decide what use is being made of words. Charles Travis (2011:np), for example, gives the example of dining in France with a companion who does not speak French. The waiter announces: 'Les oursins sont arrivés' ('The sea urchins have arrived'). Travis translates the sentence as 'They have sea urchins', and asserts that his is an acceptable translation because the games he plays in English make the same demands on the correctness of words and their use as do the games played by the waiter in French. In PI 20, Wittgenstein asserts that sentences can have the same sense because they can have the same use, illustrating this by Russian having 'Stone red', whereas German (or English) has 
'The stone is red'. He notes that the copula is not missing: it does not have to be attached 'in thought' by speakers of Russian. To refer again to the example of nonliterary translation quoted from Chesterman and Wagner (2002:5) in 3.1: when translating the label on the packet of white powder, the translator needs to be aware that the use of the Greek term is to impart information in order to make sure that nobody dies, and he or she will therefore make sure that the choice of words will signify to an English-speaking tourist that this is, say, rat poison, not something to be added to coffee. An iconic sign like the skull and crossbones could be used, in order to make matters absolutely clear, and not only to Anglophone tourists (cf. Davidson, 2011:325). Chesterman (1997:9) is therefore right to call equivalence 'a red herring, in that it is virtually unattainable, and hence not a useful concept in translation theory', pointing to Wittgenstein's notion of family resemblances (PI 67) as a more fruitful way of examining meaning. As Travis (2008:70) notes, Wittgenstein shows there is 'a gap between what words mean and what is said in them on occasion'. The slipperiness of meaning is something often noted by translation scholars. Grossman (2010:71), for example, asserts that translators need to avoid the literalist trap, because 'words do not mean in isolation' but are part of a 'contextual whole' (such as emotional tone or literary antecedents), so that good translators can be said to translate context.

Gledhill (2007:1) asserts that Wittgenstein's concept of the language-game can be used as a means of translating: 'The translator needs first to identify the nature of the "game", and then to use the translation strategy most appropriate for the particular language-game'. Wittgenstein's way of describing language becomes a method of translating. It is the refusal to play the game, the insistence on seeing literary translation as objective transference, which accounts for bad translations in Berman's sense of the deforming translation. It is not just that stylistically difficult texts such as Finnegans Wake by Joyce (1950) are untranslatable if there is a search for equivalence: all literary texts are untranslatable if there is a search for equivalence. If the search is dropped, then possibilities open up, which supports the assertion by Berman (2004:287) that the task of the literary translator 'is not to search for equivalences', and offers a strategy both practical and based on the literary way in which we may read literary texts. Wittgenstein can be used to support translation theory and literary theory, which strengthens the case for introducing his work to translation studies, as can be shown by three examples in which scholars 
express Wittgensteinian insights. Firstly, Grossman (2010:10) sees good literary translators as proceeding 'by analogy - that is, by finding comparable, not identical, characteristics, vagaries, quirks, and stylistic peculiarities in the second language'. Secondly, Attridge (2004:76) sees literary works as translatable because their singularity can be imitated in the TT. Thirdly, Bellos (2011:78) urges that translators should translate the genres in the text, by which he means something very close to language-games, so that a good translator will not translate a Chinese kitchen recipe into English but into a kitchen recipe.

To develop a strategy based on the language-games in the ST is coherent in the way that another frequently-advocated strategy is not, i.e. translating for the same effect. David Constantine (2005:xxxix), for example, describing his translation of Goethe's Faust, asserts that he aims to attain 'equivalence of effect'. As Chesterman (1997:35) notes, however, trying to reproduce effect is inconsistent, because no two readers can ever approach the same text with the same set of cognitive assumptions. There will be a variety of effects associated with a text such as Faust, because many different readers read it at different times. A twenty-first-century reader cannot possibly experience the same effects as an eighteenth-century reader. The notion of playing the same language-game in the TT avoids the problem, for the (extremely important) effects can look after themselves if the language-games are imitated.

Literary translation is more about playing games than breaking a code, something that good literary translators have always known. As Weinberger (Paz \& Weinberger, 1987:34) puts it: 'The point is that translation is more than a leap from dictionary to dictionary; it is a reimagining'. A reimagining has many possibilities, just as a game can be played in many ways. If the later Wittgenstein is right, it means that the literary translator cannot extract a meaning from a text that he or she can move somewhere else, as a mechanical operation. It offers support for the notion that even a single word has to be seen in context (Bellos, 2011:75). An example of a translator dealing with the problem of context is Bell (2009b:xxix), who, in her note to Kafka's The Castle, explains the problems of terminology she faced in translating this unfinished and unedited novel, giving as one instance the Bauern (plural form) whom the protagonist K. meets when he first arrives at the Bridge Inn. Bell notes that a bi-lingual dictionary would offer the alternatives 'peasant' or 'farmer' for Bauer (singular form), but that neither possibility appealed to her, the first sounding too medieval and the second suggesting the modern National Farmers' Union of the 
British Isles, many of those described by Kafka as Bauern not being farmers anyway. Her translation choice, 'the local rustics', indicates how literary translation is not a search for equivalents. Later uses of the same word by Kafka are given different renderings by Bell depending on context: 'the local rustics' when applicable; 'the locals'; 'the rustics'; 'the villagers'.

In $Z 698^{32}$, Wittgenstein asks the question given as (65).

How is this joke (e.g.) to be translated (i.e. replaced) ...?

The description of translation as replacement is significant. ${ }^{33}$ Wittgenstein sees no quasi-mystical procedure by which one text is transformed into another. One text is, rather, simply replaced by another. Instead of Goethe's Faust in German, I pick up an English translation to read, a TT that replaces the German ST in my form of life. That is all: but the implications are important. The text that replaces the ST can be a surveyable representation or can fail to be one (a topic discussed further in Chapter 4). There is no single way of solving the problem of replacement because there is no systematic method to which appeal can be made ( $Z$ 698), which opens out the possibilities of translation and also ought to enhance the status of translators, which are the twin aims of Tymoczko's Wittgensteinian book on translation (2007). To aim to produce a replacement rather than a perfect rendering of the ST into pure language should remove any need to apologise. The translator becomes an author, a solver of problems, a creator, not just a cipher, and although a problem in translation can be solved, e.g. a joke can be replaced, there is no systematic method of solving it ( $Z$ 698), as discussed in 3.4. Steiner (1998:290) notes the importance of the distinction that Wittgenstein puts forward of how a solution can coexist with the absence of any systematic method of solution and sees it as being true not only of translation itself but also of the descriptions and judgements made of it.

There would seem to be a contradiction here of my argument in 2.1 that it is not possible to replace the literary text, when I quoted Wittgenstein in (20) on how

\footnotetext{
${ }^{32}$ The remark is also in $R P P$ I 778.

${ }^{33}$ It is similar to the definition of translation by J.C. Catford (1965:20), but without Catford's appeal to equivalence.
} 
certain sentences (such as poems) cannot be replaced by another sentence any more than one musical theme can be replaced by another (PI 251). It is the description of translation as a language-game, as part of the human form of life, which saves the contradiction. Wittgenstein notes that a poet's words 'can pierce us' and that this is connected with the 'use that they have in our life' ( $Z$ 155). Translations can be written that have an analogous use in our lives. The literary translator can choose to write in such a way as to respond to the literariness of the ST by playing the same language-games, just as Milton's translation of Horace was a response to the Latin poet's 'specific verbal arrangement', according to Attridge (2004:74). Reading and applying Wittgenstein would enable the translator to do this consciously. It makes no sense for me, as a speaker of English, to read a decoding of an English literary text under the illusion that I am reading the text, but it makes a great deal of sense for me to read a translation of, say, a Japanese literary text, as long as I am aware that I am playing a certain game. For the game of literary translation to be played, the translator must be responding to a literary reading. I noted in 2.1 , following Attridge (2004:96), that it is possible to read Middlemarch as literature or not as literature, so that it would be possible to translate the novel in a literary way or in a non-literary way. Translation after Wittgenstein stresses both the form of life of the work and the language-games played in it, just as stylistics stresses the cognitive state of the reader and the style of the text (Boase-Beier, 2006b).

I began this section with the comment by Grossman (2010:63) on how literary translation is often perceived as an impossible task. Scott (2000:2) similarly notes how translation theorists continue to speak about 'the translator's lack of literary credibility, about the translator's invisibility, about the impossibility of any translation worth the name', but goes on to assert that this is not the end of the story: 'All these symptoms of a condemned condition can ... be turned round, if we are prepared to change our expectations and our prejudices'. His use of the word 'prejudice' can be linked to Wittgenstein's remark that it is prejudice that keeps us in thrall to the correspondence theory of meaning, but that it is not a stupid prejudice (PI 340). We need to change both the way we see meaning and - this follows logically - the way that we see translation. Wittgenstein can be a tool to this end, a tool employed in the forms of life of the literary translator. 


\subsection{The forms of life of the literary translator}

Nikolaou and Kyritsi (2008:3), noting the frustration that has accompanied experiments with machine translation, assert that human consciousness remains central to the task of translation and quote Wittgenstein to explain why: 'Language is a part of our organism and no less complicated than it' (NB p.48). It is impossible to divorce the self of the translator from the text, for language is a part of being human, not a faculty that can be practically isolated. ${ }^{34}$

Rachel May (1994:9), in a review of Russian Literature in translation, identifies what she calls 'a sort of translator-consciousness', translational tendencies that persist across cultures and across time. One example is the trend to alter the structures of the ST in order to assert 'a more objective, more authoritative literary stance', an empirical finding (based on the analysis of a large corpus of translated novels) in line with Berman's identification of deforming tendencies in translation (2004:288). If translators act not only on the text but in it, i.e. if there is a translatorconsciousness, then this consciousness must be something that can be formed, for which a reading of the $P I$, described by Read (2007:1) as a 'philosophical self-help text', can be used. One of the central drives of the PI is to show that language and behaviour are products of how we are trained. Wittgenstein's ideas can be applied to the training of the translator in order to suggest how a translator-consciousness could be produced that does not lead to the deformation identified by Berman and May. In 2.1, I argued that Wittgenstein's philosophy can help train the translator as reader of the ST. In this section, I investigate the language-game of writing the TT as found in the forms of life of the literary translator, in order to examine how a translatorconsciousness can be formed that moves beyond intuition. As Wittgenstein asserts: 'Instinct comes first, reasoning second. Not until there is a language-game are there reasons' (RPP II 678). Grossman (2010:72) cites Gregory Rabassa, whose main concern as translator of the Colombian novelist Gabriel García Márquez was whether his English was up to the task, not his Spanish. It would be absurd to suggest that reading Wittgenstein can make a great stylist out of a translator, but reading Wittgenstein can suggest reasons for writing so as to create a languagegame. It may help the translator's TL to be up to the task.

\footnotetext{
${ }^{34}$ Chomsky (2000) and his followers argue that there is a language faculty, but Wittgenstein's inquiry is different, coming out of philosophy, not cognitive science. See the discussion in 5.3.
} 
I use the form of life in three ways: to describe a way of living that the translator takes on, i.e. a vocation; to refer to the way of life of the writer of the ST, a particular form of life that has produced a particular work of literature; to refer to the forms of life depicted in the ST and the TT. Wittgenstein's term, while often used in the singular, is frequently to be understood as plural, because every person is involved in many forms of life. Chris has the distinctive form of life connected with having a human body, so that he needs to eat, keep warm etc., but he can be viewed in other ways, such as having the form of life of a computer specialist.

Translation as vocation is a way of living, often a way of earning a living, and it begins in a way of reading, as described in Chapter 2. Scott (2008:17) sees a translator as 'someone who reads in order to write'. One becomes a translator, however, by producing translations: writing must follow reading, as Scott notes. It is a practice into which one can be trained, in which one can become qualified, for example, by taking a professional qualification. To read accounts by practising translators of their work, whether in the paratextual material attached to a particular translation or in theoretical works about translation, is to find a form of life with its own language-games, involving concepts such as: source-target; equivalence; untranslatability; free-vs-literal; all-writing-is-translating etc. These are the five translation supermemes identified by Chesterman (1997:7-14), who sees them as themes that have occurred throughout the history of translation. The grammatical investigation of such concepts is something that a reading of Wittgenstein can bring to translation studies, as exemplified in 4.4.1. The form of life of translation includes: reading of literature and literary theory; translation studies; one's own past translations; reading translated literature; drafting; delivering the TT etc. These are practices.

Although translation is a profession that has often been characterised by its invisibility (Venuti 2008), the translator appears as the hero of novels. In Gaudi Afternoon (1991) by Barbara Wilson, for example, the central character is the translator Cassandra Reilly, who takes on a job as a private detective, but for whom being a translator is at the heart of her self-definition. In a work where nothing is ever quite as it seems, Cassandra is involved in the dialogue quoted as (66), (Wilson, 1991:74). 
'My name is Carmen', Carmen said in English. 'I am woman. Please, what are you? Woman or man?'

'Neither,' I said in English then in Spanish. 'I am a translator.'

Perhaps this is to say no more than that translators are professionals, but that is to say a lot. The sociologist Pierre Bourdieu (2003), influenced by Wittgenstein, advances the theory of 'field' and 'habitus' to explain cultural phenomena such as professions. A field is defined as the domain in which somebody acts: Cassandra works in the field of literary translation, being currently engaged on the translation of a South American novel. Habitus is defined as the set of aptitudes that somebody must develop if he or she is to flourish in a certain field: what Bella Brodzki (2007:45) refers to as the 'shrewd critical skills and opinions that Cassandra has honed as a practising translator, cosmopolitan traveller, and social critic' (and which incidentally help her in her new role as detective). Field and habitus can be seen as an extension into sociology of the concepts of form of life and language-game developed in philosophy by Wittgenstein. From a Wittgensteinian point of view, Cassandra's work as a translator involves her in a form of life, which results from her competence at playing the language-game of translation. Certain English texts (that represent certain Spanish texts) exist because of her aptitude, which is a further reason why the invisibility of the translator in western culture described by Venuti (2008) is offensive to the translator, not only professionally but also personally. Françoise Wuilmart (2009:40), for example, describes being ignored in a radio discussion about a book she had recently translated from German. She refers to " "my" words that were being broadcast, or rather the words of the anonymous German woman that my labour had transposed into French', and laments that nobody on the radio programme thought to reference them as such. The identification of the translator with texts that he or she has translated - Wuilmart insists that the words being broadcast are not those of the ST writer - shows why Cassandra can define herself as a translator rather than as a man or a woman. That she may be trying to dodge the question is irrelevant to this argument. People tend to identify themselves with what they do. 
Patricia Clancy (2006) describes her work as the translator of the detective novels of the French writer Pierre Magnan, identifying two main challenges, the translation of lexis and the translation of style. Lexis is an acute problem when translating an author such as Magnan, whose novels contain a wealth of detail from Provence, e.g. Clancy wonders if Le Blayeul is a village, a mountain, a range or a river (2006:7). Such questions send her to: the internet; long out-of-print French dictionaries and encyclopaedias; contacts in Provence; the ST author. The meaning of the term Le Blayeul can be found by looking at its use in the language, Wittgenstein would advise (PI 43), and Clancy found that it was used by Magnan to designate a mountain. The translator, professionally concerned with meaning, must address the issue of contextualisation, because all expressions, not just this one, must be seen in context and the ST must be referenced to the form of life that produces it: 'after nine years in Magnan's company, I feel as if I have lived there' (Clancy, 2006:7). Yet the translator translates texts, not just words, and the meaning of a literary text cannot be separated from its style, ${ }^{35}$ as argued in Chapter 2, so that the rendering of style is also the concern of the literary translator, which is why Clancy (2006:11-12) describes Magnan's novels as a challenge not only linguistically but also stylistically. She gives an example of one image that caused her particular difficulties, only resolved after consultation with Magnan. The ST image, a description of Le Blayeul, is quoted as (67), with Clancy's translation as (68).

vertement vêtu de sa consonance d'arbre à tisane greenly dressed of its harmony of tree to tisane

robed in green resonance with le tilleul, the lime tree, which its name always evoked.

Magnan explained that he was trying to evoke the similarity in sound between the name of the mountain and the name of the lime-tree, le tilleul, and Clancy notes that she has been able to retain the alliteration and some of 'the unusual poetic

\footnotetext{
${ }^{35}$ Clancy (2006: 7) categorises Magnan's novels as too literary to be classed as thrillers and too close to genre fiction to be classed as literature. In my opinion they do exhibit literariness.
} 
juxtapositions of sound and sight', and writes of 'the ability and the tenacity of translators who, once the allusions in the image have been teased out, will work to create something that still conveys something of the original expression'. Yet (68) exhibits the drive for objectivity that May criticises, because Clancy leaves little room for any imaginative play on behalf of the reader. She interprets, where Magnan implies, and has moved to a different level ( $Z$ 234, as discussed in 2.4). She has allowed her attention to the form of life depicted in the ST to distract from the form of the ST, so that (68) could be described as a Platonising translation. It would seem that attention to the form of life of the ST, whilst a necessary condition of literary translation, is not a sufficient one. The language-games must also be considered.

The literary translator stands between ST and TT. I offer two contrasting translations of the description of the patient's wound in the story 'Ein Landarzt' ('A Country Doctor') by Kafka (1963:58), referred to in 3.1. The doctor's maid is called Rosa and the wound is described by Kafka in the sentence quoted as (69), the first word referring the colour pink and recalling the German noun Rose ('rose') but also representing the maid herself, because its initial and capitalised position make it a possible proper noun.

Rosa, in vielen Schattierungen, dunkel in der Tiefe, hellwerdend zu den pink in many shadows dark in the depth brightening to the Rändern, zartkörnig mit ungleichmäßig sich aufsammelndem Blut, offen wie ein edges tender with irregularly itself collecting blood open like a Bergwerk obertags.

mine to-the-air

Malcolm Pasley (1963:22) draws attention to the text's repetition of the word 'Rosa' in his editorial introduction to the story: 'His [the doctor's] two new-found concerns, erotic and spiritual, are linked together. The wound is "rosa"".

One translation, by Richard Stokes (2005:81), is quoted as (70).

Pink, in many shades, dark in the depths, paler towards the edges, soft-grained, the blood welling unevenly, gaping like the surface of a mine. 
Stokes has preserved in his translation the name of the maid as Rosa, but by keeping the name and by rendering the colour of the wound as 'pink', he does not show how Kafka foregrounds the blend of name and adjective. His rendering can be contrasted with that of Pasley, given as (71), which illustrates how a close reading by the translator (1963:22) can be traced in the writing of a translation (1990:159). Pasley (1992:157) changes the name of the maid from Rosa to 'Rose', which in English has a multiple resonance that echoes that of the ST word, and that is picked up in the first word of (71).

Rose-red, in various shades, dark in the depths, paler towards the edges, finely grained, with blood welling unevenly, open like a mine at the surface.

Pasley both conveys the use of multiple connotations typical of Kafka's style (Crick 2009:xxxv) and the linking of the erotic and the spiritual central to the story's meaning. It is neither a Platonising translation nor the rendering of meaning alone, but a translation that maintains meaning as a physiognomy (PI 568): a literary translation. I argue in this thesis that the work of the later Wittgenstein provides ways of looking at language (Chapter 2) and using language (Chapter 3) that open up new possibilities for the translator. Using Wittgenstein is a short-cut, a way of attaining clarity, of moving out of the Platonic paradigm. The story told by Wittgenstein becomes a part of how we see translation and this new way of seeing can in turn drive translation by changing what we expect from it. Of the three examples quoted in this section, only Pasley provides a literary translation of the ST. Stokes renders meaning but fails to maintain a key aspect of Kafka's style. Clancy writes an English that is literary but that deforms the ST by doing too much work for the reader.

One becomes a translator, as evidenced both in the title and the content of Robinson's Becoming a Translator (2003), where he examines field and habitus. Discussing the translator's experience, he cites a foundational statement on translation from Jerome (2003:106). I give Jerome's text, written in 395, as (72) (1997:25). 
Now I not only admit but freely announce that in translating from the Greek except of course in the case of Holy Scripture, where even the syntax contains a mystery - I render, not word for word, but sense for sense.

Robinson (2003:107) comments that this is what 'translation instructors have been telling their students for decades' and recommends that students be told this early in their careers to save them the problem of working it out for themselves. We therefore have an influential current work on translation, recommended, for example, to candidates for the examinations of the Chartered Institute of Linguists (2010:np), which activates the oldest debate in translation studies and advocates translating sense not words.

The work of Wittgenstein shows that such a dichotomy between sense and word is a false one, reliant on a Platonic paradigm, as argued in 3.1. We have no access to meaning outside language and it is on forms that we must rely, not on the Forms. Otherwise translation becomes a process of attempting to discover the correct answers, which may be an acceptable procedure for translating the label on a packet of white powder but not for translating Aeschylus (Chesterman \& Wagner, 2002:5). Eugene Nida and Charles Taber (1969:12) define translation as 'reproducing in the receptor's language the closest natural equivalent of the source-language message', which is to see translation as a science. Again the notion of equivalence is the conceptual hinge.

It is easy to set up equivalence as a straw man. It is obvious, for example, that Brot and pain (French and German nouns respectively for 'bread' ${ }^{36}$ ) are not equivalents in the sense of being identical, because a long list of differences can be compiled, such as different acoustic values or different cultural connotations. Therefore there is the risk that my thesis could be accused of using Wittgenstein in order to win a debate that has been won in translation studies without his work: Berman, for example, writing in 1985, insists that literary translation cannot be a search for equivalences (2004:287). My contention, however, is that any translator who sits down to translate a literary text will still be tempted by the same sort of dualism seen in Jerome. Why should this be so?

\footnotetext{
${ }^{36}$ The example is from Benjamin (2004:78) and is discussed further in 3.4.
} 
In $B T$ 423, Wittgenstein comments on his later method, quoted as (73).

One keeps hearing the remark that philosophy really makes no progress, that the same philosophical problems that had occurred to the Greeks are still occupying us. ... The reason is that our language has remained the same and seduces us into asking the same questions over and over. As long as there is a verb 'to be' which seems to function like 'to eat' and 'to drink', as long as there are adjectives like 'identical', 'true', 'false', 'possible', as long as one talks about a flow of time and an expanse of space, etc., etc., humans will continue to bump up against the same mysterious difficulties.

That we are bewitched by our language may be because of the way the mind works. Pinker (2007:83 ff.) suggests that the mind's settings were fixed in the remote past and describes what he calls 'cognitive quirks' i.e. mental habits that worked well once but do not fit the modern world, for example, the conduit metaphor, similar to the container metaphor discussed in 2.6, which suggests that it is possible to know something and to send it on to others in a package. This scenario can explain why we are in thrall to a model of translation based on transference (Tymockzo, 2007), which is itself based on a split between sense and word (Berman, 2004) and which can be changed by changing our view of language by reading Wittgenstein, who can show that the sense is in the word.

The semantic model lying behind equivalence, according to Pym (2010:18), is that of the "tertium comparationis ${ }^{, 37}$, which involves deverbalising the ST in order to listen to the sense, which is then translated. A twentieth-century advocate of this is Danica Seleskovitch (Seleskovitch \& Lederer, 1984). Pym (2010:20) comments that her theory is in many ways naïve and idealistic, because it seems to be impossible to make sense of a sense that is deverbalised; but he maintains, writing twenty-five years after Seleskovitch, that the operational values of her approach 'correspond to some very widespread ideas about what translation is (or should be)'. Translators, from a Wittgensteinian perspective, keep flying into the fly-bottle and are unaware that they are doing so (PI 309). Pym re-asserts the equivalence model (2010:38), despite the numerous difficulties he sees associated with it, as shown in text (74).

${ }^{37}$ Latin: 'third of comparison'. 
Equivalence might appear to be dead, except for the occasional deconstructionist who has read little translation theory and needs a straw man. Then again, history has not finished.

Equivalence is not a straw man. Our dilemma lies in the fact that we think that it is. Pym admits that his defence of the equivalence paradigm will be unpopular but maintains that the paradigm underlies all thinking about translation (2010:6 ff.) and that it is still the 'dominant paradigm' underlying many approaches (2010:91).

My reading of Wittgenstein can offer several ways forward. Firstly, it shows that the equivalence paradigm is misleading, as was argued in 3.1 and as will be taken up again in 4.2. Secondly, it focuses on the forms of life of literary translation, so that the translator can be seen as a reader of literary forms and as a re-writer of them as literary forms. Thirdly, the use of Wittgenstein offers insights into the way that language works, insights that can free us from false paradigms and that can offer clarity.

Winch (2008) argues that the humanities do not function through correspondence to objective facts, but through agreement on what could be held to be true. We agree to call something a translation, just as we agree to call something a theory in literature. The translations that are written are to be located within a tradition. Baker (2004:48) notes that the criteria for judging the correctness of a description are 'as indeterminate as the criteria for judging the correctness of the description of a painting', and something similar must apply to judging translations. What can be formed is an educated judgement, however, an awareness of what one is doing and of what one might do in translation. For Wittgenstein, educated judgement is a result of work on oneself, as asserted in $C V$ p.24, quoted as (75).

Work on philosophy - like work in architecture in many respects - is really more work on oneself. On one's own conception. On how one sees these things. (And what one expects from them.) 
This remark shows how one becomes a translator: through work on oneself. One works at how one sees things (in the ST), and on what one expects from them (in the TT). Wittgenstein (RFM III-85) asks who it is who says that a poem can be translated to our satisfaction. For the literary translator, the answer is to look in the mirror and then to work on himself or herself. The ideal I am putting forward is the one described by Johann Gottfried von Herder (1997:207), who wonders: 'Where is the translator who is at once philosopher, philologist, and poet?' Such a translator, as Herder puts it, would be a bright morning star. 


\subsection{Translating a play on words}

In this thesis, I aim to offer a picture of Wittgenstein's relevance to literary translation, not, as stated in 2.6, to show that literary translation is only possible after Wittgenstein. My position is analogous to that of Read (2010), who argues that the PI, although not overtly a political book, can be used to show how Wittgenstein's thinking can inform the ways in which philosophers approach politics. In this section, I examine one of the deforming tendencies in translation identified by Berman (2004) - i.e. how idioms (such as plays on words) are translated - in order to show how Wittgenstein's line of thinking can feed the ways the literary translator approaches his or her task.

How do you translate a play on words? It is an important question because it cuts to the heart of translation. Jokes, proverbs, puns and plays on words bring in a cluster of problems at both cultural and communicative levels. As anybody who has ever tried to translate a pun knows, to transfer its meaning through conscientious word-by-word rendering is often to come up with something that will only puzzle the addressee. An example of this is the English joke given as (76).

What do you do if an elephant takes a gate?

Nothing: he might take offence.

The humour here lies in two things. Firstly, there is the homophony of 'offence' and 'a fence', so that the reply to the question can also be construed as 'Nothing: he might take a fence', which is both a mondegreen and a blend: the elephant is not only easily hurt but also liable to run off with a second artefact. Secondly, there is a zeugma implied in the use of 'take', which is used concretely in the question and abstractly in the answer.

Berman attacks translators' 'destruction of expressions and idioms' (2004:286), prescribing that these should be rendered literally i.e. word for word, a consequence of his view that translation 'is not to search for equivalences' (2004:287). He gives examples from André Gide's French translation of Joseph Conrad's novel Typhoon, which are rendered word for word by Gide instead of being 
given a so-called equivalent. I give the English as (77) and Gide's translations as (78) (from Berman, 2004:286-287).

\section{(77)}

He did not care a tinker's curse

Damme, if this ship isn't worse than Bedlam!

Il s' en fichait comme du juron d' un étameur he himself of-it was-indifferent as of-the curse of a tinker

Que diable m'emporte si l'on ne se croirait pas à Bedlam! that devil me take if one not oneself would-believe not at Bedlam

As Berman (2004:287) notes, there is a common French expression that would convey the same idea as that of not caring a tinker's curse, while the mention of Bedlam is potentially confusing for a French reader because it was an English institution for the mentally ill, so that a translator might have gone for a relocation, such as Charenton (a similar French institution).

But does abandoning the search for equivalences necessarily imply that the way forward is literal translation? To suggest that this is the only strategy is to fail to grasp the nature of the difference between languages and to be still in thrall to the longing for pure language discussed in 3.1. Benjamin, for example, sees the interlineal version of the Scriptures as the ideal translation, a position following logically from his belief in a pure language (2004:83). Glossing is increasingly a part of good practice in translation studies, as a type of surveyable representation of the ST; but to remain at the level of the gloss or of the literal translation is to fail to look at the physiognomy of the text. To take the two nouns pain and Brot, which signify 'bread' in French and German respectively, it is basic to note that they are different both in form and connotation, as Benjamin does: "The words Brot and pain "intend" the same object, but the modes of this intention are not the same. It is owing to these modes that the word Brot means something different to a German than the word pain to a Frenchman, that these words are not interchangeable for them, that, in fact, they strive to exclude each other' (2004:78). So far, so good. But Benjamin then looks 
towards the pure language that supposedly hides behind the languages of the world, quoting Stéphane Mallarmé as support: 'The imperfection of languages consists of their plurality' (2004:80). It is against this sort of dissatisfaction with the world as we find it that the Wittgensteinian project is aimed. As Kerr (1998:50) comments, it is difficult to see what is obvious because of the desire to see something metaphysical beyond. For the translator, what is obvious is the text: the word pain or the word Brot, i.e. their physiognomy (PI 568). And yet we so much want to see something beyond the text, as if there were an eternal immutable Form of the Bread, whereas Wittgenstein, through his stress on practice, shows that nothing extraordinary is involved (PI 94).

There is a tension in Berman (2004:288) between his assertion that 'literal translation' is to be defined as attention to the stylistic qualities of a text (2004:121) and the word-for-word rendering he praises in the examples from Gide, which conforms to the more common understanding of the notion of literal translation (cf. Nabakov, 2004:121). A proverb, for Berman, must be kept as it is in the ST in order to respect the source culture, rather than being translated as what would be said in the target culture in those circumstances. Such translation is certainly a possibility, but to think that it is the only possibility is still to be trapped in the fly-bottle, still to see literary meaning as a quality that can be transferred mechanically. It may be possible to calibrate an English TT against a German ST, but this is because German and English have many similarities, belonging to the same language family. Calibrated translation is not possible between languages that do not themselves calibrate, such as Hopi and English, which are from different language families (Whorf, 1956). Berman is still locked in the extreme Augustinian picture, of language as code, which Wittgenstein attacks: despite Berman's insistence that translation is not about equivalence, he implies that for translation to be possible there must be perfect correspondence, perfect equivalence. By contrast, the Augustinian paradigm is shown by Wittgenstein ( $P I 1 \mathrm{ff}$.) to be untenable, so that it follows that the search for perfect equivalence must also be dropped. Berman identifies the problem, but his prescriptive solution must be rejected as the sole option.

To use my own example of translating a proverb: in (79) I give an example of a German proverb, with two possible renderings as (80) and (81). 
Besser einen Spatz in der Hand als eine Taube auf dem Dach. better a sparrow in the hand than a dove on the roof

Better to have a sparrow in your hand than a dove on the roof.

A bird in the hand is worth two in the bush.

Translation (80) follows Berman's demand (2004:287) that a parallel expression should not be used, because it would be an ethnocentrism implying that ST characters express themselves in TL images. Berman would therefore have problems with (81), the parallel English phrase to the German. (A German speaker and an English speaker might say (79) and (81) respectively if they were, say, trying to console themselves about not being able to partake in a particular venture.) Berman (2004:287) insists that reproducing idioms in translation, as in (80), will enrich the TL. His prescription is ethically praiseworthy, but is based on the view that characters in an English novel in French translation should be shown to be speaking English, whereas they are speaking French. The translated novel is a special case of what Coleridge (1975:169) calls 'that willing suspension of disbelief for the moment which constitutes poetic faith'. That the reader is required to believe that SL characters are speaking the TL is the contradiction at the heart of all literary translation, part of its language-game.

Following Wittgenstein's stress on the importance of the use of the literary work in our form of life ( $Z$ 155), a proverb can be translated in various ways depending on its use in a particular ST. If a particular acoustic or phonaesthetic effect is desired, for example, then a complete recasting is required. Text (82), for example, is an anapaestic tetrameter and therefore uses 'bird' instead of 'sparrow', in order to create this metrical pattern. It is a rendering that might be offered by a translator seeking a poetic effect. Text (83) relocates the proverb to the twenty-firstcentury against an implied backstory of marital breakdown, perhaps as part of a drama. 
For a bird in the hand's worth a dove on the roof.

A Renault in your drive is worth a BMW in your husband's.

And other translations are possible, because the question of how to translate the play on words cannot be considered apart from the context. The canonical translation that Berman praises, that of Hölderlin (1952), itself moves beyond literal translation: as Wolfgang Schadewaldt (1970:119) comments, while the intermediate versions Hölderlin made of the Antigone of Sophocles can be described as literal in the sense of word for word, the final versions represent what Schadewaldt calls 'erneuerndes Nachgestalten' ('renewing post-shaping', or transformation).

In Last Writings on Philosophical Psychology (LWPP I 278), Wittgenstein asks: 'What is the correct German translation of an English play on words? Maybe a completely different play on words'. The remark shows how the concept of playing the same language-game allows the translator a great deal of freedom. If I need to translate a joke in a novel, the key factor may be that a joke is being told, rather than that somebody is making a pun on a certain verb, so that the best choice may be to write an entirely different joke. An example is the way that Bell translates the characters' names in the world of Asterix the Gaul, the cartoon creation of René Goscinny and Albert Uderzo: 'Names: the books to date contain some four hundred proper names of people ... nearly all of which have had to be changed in translation, since they are not really names, but comic spoofs on names made up out of French words in the original. For instance the village bard Assurancetourix = assurance tous risques, "comprehensive insurance". As with all the Gauls, his name ends in the suffix -ix, to echo the genuine Vercingetorix. But translated straight the phrase sounds nothing like a name of any kind. In English he becomes Cacofonix because he is tone-deaf and sings and plays so badly out of tune that his music is mere cacophony' (Bell 2009a:np). Bell's key realisation is that Goscinny and Uderzo are playing more than the language-game of naming when they invent terms such as 'Assurancetourix'. By translating it as 'Cacofonix', a strategy appropriate for the 
language-game (of punning) has been chosen, with reference to the form of life of the character in question.

It is the stress on formalism (correctly viewing form and content as inseparable) that makes translation seem impossible. Jakobson (1959:239) argues that poetry cannot be translated, that only 'creative transposition' is possible. The Wittgensteinian surveyable representation (PI 122) is, I think, a more coherent concept than the creative transposition, because Jakobson's term is too broad: all sorts of things can count as transpositions, whereas a representation keeps the ST always in mind. The translation of Magnan by Clancy cited in 3.3 as (68) is a creative transposition, but I do not think it is a literary translation, because it does not represent the ST. I now examine three translations, of Ernst Jandl, Perec and Wittgenstein, which in my opinion function as surveyable representations.

Scott (2008:27), describing German poems and their English translations in Waldrop's edition of Jandl (2000), asserts that the translations are 'maybe not translations so much as imitations, using the same creative principle'. Scott's notion of the creative principle is analogous to the language-game. The ST 'reihe' ('series') (Jandl, 2000:19) is given as (84). It is a creative mishearing of the numbers one to ten in German, ${ }^{38}$ as if written down by somebody who does not know them and is trying to find German words that match what is heard; (84) is not glossed because my translation in (85) functions as a gloss.

reihe

eis

zweig

dreist

vieh

füllf

ächz

silben

ach

neu

zink

${ }^{38}$ These are: eins, zwei, drei, vier, fün, sechs, sieben, acht, neun, zehn. 
The poem works because many readers will spot the intertextual reference to German cardinals. Text (85), however, will only baffle any English-speaking reader, although it is a word-for-word rendering of a list, something that at first sight appears to be the easiest translation task in the world, that of words without context.

(85)
ice
branch
brazen
cattle
fill
groan
syllables
alas
new
zinc

Unless the intention is in fact to baffle the reader, this is unsatisfactory, because the ST does have a context, i.e. the language-game of counting. Jandl's translators have come up with various solutions, and I reference two. Martine Bellen (Jandl, 2000:20) writes a string of words based on the English cardinals, while Julie Patton's (untitled) rendering (Jandl 2000:21) is based on the German cardinals. I give their translations as (86) and (87) respectively.

series

wand

toot

tree

fort

fry

sex

servin'

eh

none

$\tan$

hind

size 

wire
fear
fund
sexy
bent
act
anoint
zen

Both Wittgenstein (LWPP I 278) and Scott (2008:27) use the word 'maybe' in the comments cited. We are talking about possible ways of translation, which is seen by Scott as transferring the energy of the ST, just as Robert Lowell (1971:xi) speaks of trying to retain 'the fire and finish' of the poems he translates, a task that paradoxically necessitates 'considerable re-writing'. Bellen and Patton have produced possible surveyable representations, based on the use Jandl makes of German cardinals.

What does a translator do, however, when he or she is faced with translating not a single play on words but an entire novel playing on words? Perec's $L a$ disparition (The Disappearance) is a product of Oulipo $^{39}$, the literary movement that seeks to evoke creativity by imposing constraint on authors. Perec's novel is lipogrammatic, for the letter 'e' does not appear, a considerable creative feat given that many common French words use 'e', such as elle ('she'), je ('I'), le ('the': masculine definite article). Perec's opening (1969:17) is quoted as (88).

Anton Voyl n' arrivait pas à dormir. Il alluma. Son Jaz marquait Anton Voyl not was-arriving not to sleep he lit-up his Jazwas-showing minuit vingt. Il poussa un profond soupir, s' assit sur son lit, midnight twenty he pushed a deep sigh himself seated on his bed s' appuyant sur son polochon. Il prit un roman, il 1' ouvrit, il lut; mais il himself leaning on his bolster he took a novel he it opened he read but he n' y saisissait qu' un imbrolglio confus, il butait à tout instant sur not there was-seizing only an imbroglio confused he was-hitting at each instant on un mot dont il ignorait la signification.

a word of-which he was-not-knowing the signification

\footnotetext{
${ }^{39}$ Oulipo (French) signifies Ouvroir de littérature potentielle ('workshop of potential literature').
} 
Referring to the English translation by Adair (1995), Perloff (2004:45) comments that Oulipo 'seems to have exerted as powerful a force in translation as in the original', so that 'the central motive and its working out are wholly translatable, whatever the surface details'. Adair translates under the same constraint as Perec. His opening (1995:3) is given as (89).

Incurably insomniac, Anton Vowl turns on a light. According to his watch it's only 12.20. With a loud and languorous sigh Vowl sits up, stuffs a pillow at his back, draws his quilt up around his chin, picks up his whodunit and idly scans a paragraph or two; but, judging its plot impossibly difficult to follow in his condition, its vocabulary too whimsically multisyllabic for comfort, throws it away in disgust.

The challenge facing Adair is indicated by how the gloss of (88) uses 'e' 28 times, with 'he' occurring eight times for $i l$ in the ST. To work within the constraint demands rewriting, such as translating un roman ('a novel') as 'his whodunit', even though all translation can be said to be an act of rewriting, because no TT is in the same language as the ST: the word 'rewriting' is understood here as showing that the task of the translator is more than the transference of meaning. There is even a play on words in Adair's translation of the title, because A Void both conveys the title's reference to disappearance and also shows what Adair is attempting: it reinforces acoustically that he must try to avoid something, i.e. the vowel 'e'. As Perloff (2004:45) comments: 'The Wittgensteinian language-game paves the way for some of the most interesting poetic experiments of our own moment ... To translate texts like ... La disparition is to subordinate oneself to the original'. The Castilian translation (Arbués et al., 1997) similarly subordinates itself by avoiding the letter ' $a$ ', not 'e', because ' $a$ ' is the most common vowel in Castilian.

The Oulipo methodology itself introduces explicit constraints to the writing of the literary text. Constraint, as Boase-Beier and Michael Holman (1999) argue, is a fact of all literary production and can be viewed as facilitating creativity rather than stifling it. They see the same being true of translation: 'if translation is indeed more constrained than original writing, then, by virtue of the ability of constraint to engender creativity, it at least has the potential to be more creative, though of course an excessive burden of constraint can be crippling' (1999:13). The qualification is an 
important one. Deforming translation occurs when the translator is constrained by the Platonic or scientific paradigm, which results in the destruction of the literary. By contrast, the radical rewriting of Sophocles by Hölderlin (1952) is not deforming because it is creatively constrained by the ST.

The initial decision about what is the most important language-game in the ST will itself have ramifications. By choosing to write a lipogrammatic TT, certain moves are closed to Adair. He cannot reproduce the repetition of $i l$ ('he') in Perec, for example. Translation is analogous to a series of 'moves, as in a game', as Jiří Levý (2000:148) asserts, where 'every single move is influenced by the knowledge of previous decisions' (2000:149). It is noteworthy that Levý, like Wittgenstein, sees translation as a game.

Bellen, Patton and Adair cannot be said to have been influenced by Wittgenstein, unlike Anscombe, his pupil and first translator of the PI, the 2009 edition of which is still based on her rendering, its cover announcing that the English translation is 'by G.E.M. Anscombe, P.M.S. Hacker and Joachim Schulte', i.e. effectively a revision of her work by Hacker and Schulte. (Anscombe died in 2001.) They refer to her translation as 'an impressive achievement' (2009:viii).

Wittgenstein demands an aesthetic effort from his readers (Cavell, 2001:250) and Anscombe writes a translation that replicates this demand. Venuti (1998:108) examines her rendering of Wittgenstein's explanation of why philosophical arguments arise. In (90), I give the German ST from PI 38.

Denn die philosophischen Probleme entstehen, wenn die Sprache feiert. for the philosophical problems arise when the language celebrates idles stops-work

As shown by the gloss, the translator faces a problem with the final verb, which has three senses in German. Anscombe's translation, quoted as (91) from the 2001 edition of the $P I$, is what Venuti (1998:109) calls a choice 'that goes beyond any equivalence based on lexicography'. 
For philosophical problems arise when language goes on holiday.

This expression has become part of English-speaking Wittgensteinian terminology. Read (2007b:109), for example, writing on politics, remarks that we need to look at the 'illusions (not simple falsehoods) that are perpetrated upon us (and that we perpetrate upon ourselves and others) when language goes on holiday'. The reference to Wittgenstein (via Anscombe) is not referenced. Anscombe's rendering preserves both the positive and the negative implicatures of Wittgenstein's remark. When Anna goes on holiday, for example, she looks forward to it and is pleased to be going, but it does mean that she will not be around to do any work. The 2009 revision of the PI maintains Anscombe's rendering of this and most other key expressions.

As Venuti (1998:109) comments: 'Anscombe's translation can be said to have communicated Wittgenstein's ideas, even to have mimicked his style of writing'. To use Wittgensteinian terminology, she has identified the language-games in the text and has adopted strategies to play them in her own rendering. The translation is a surveyable representation, which is reinforced by the edition being bilingual, with the German on the left page and the English on the right, which enables the reader to follow the German, so that even the reader without any German can keep track of key terms. The example of 'feiert' again shows a play on words being translated by a completely different play on words, as does the way in which Anscombe renders the pun by Wittgenstein ( $P P F 15$ ), quoted as (92) in German and as (93) in her translation.

Wenn ich sage 'Herr Schweizer ist kein Schweizer', so meine ich das erste if I say $\mathrm{Mr}$ Schweizer is not-a Swiss so mean I the first 'Schweizer' als Eigenname, das zweite als Gattungsname.

'Schweizer' as proper-name the second as common-name

If I say 'Mr Scot is not a Scot', I mean the first 'Scot' as a proper name, the second one as a common name. 
Wittgenstein's pun rests on the fact that 'Schweizer' means 'Swiss man' but is also frequently found as a surname. By translating 'Schweizer' as 'Scot', Anscombe avoids the English translation becoming an example of the sort of confusion that Wittgenstein was aiming to clear away ( $C V$ p.9). To write, 'If I say Mr Schweizer is not a Swiss, I mean the first "Schweizer" as a proper name, the second one as a common name', is confusing. The use of notes could support the translator who chose this rendering, but would add paratextual material not in the ST and would interrupt the flow of the text. Anscombe's rendering solves the problem and also imitates Wittgenstein's use of a nation apart from Germany where German is spoken (i.e. Switzerland) by the use of a nation apart from England where English is spoken (i.e. Scotland).

In 3.2, referring to how some works of literature are viewed as untranslatable, I cited Finnegans Wake by Joyce (1950), in view of its stylistic difficulty. Yet translations of Finnegans Wake do exist, Joyce himself (with Nino Frank) translating parts of it into Italian (1979). Gledhill (2007:118), discussing this translation, concludes: 'To translate like Joyce, you have to write like Joyce, or at the very least be a brilliant imitator of his style'. In $C V$ p.28, Wittgenstein remarks that philosophy should only be written 'as one writes a poem'. The same is true of literary translation, which begins with recognising the poetry in a text - with seeing the literary text as literary - and ends with writing in a way that maintains the poetry, by writing a translation as one writes a poem. Texts such as Jandl or Perec or Wittgenstein are not exceptions in foregrounding a play on words. They are typical. All literature is a play on words. Most of the time we fail to notice this. The translators of these texts have noticed it. What is the correct translation of a literary work? Maybe a completely different literary work. 


\subsection{Case study: translating the poetry of Mörike}

The purpose of this case study, which relates to the description of Mörike's poetry in 2.5.1, is to show how a reading of Wittgenstein can influence the process of translation by opening up possibilities. In 2.5.1, I offered an account of Mörike influenced by Wittgenstein's stress on description. Here I use Wittgenstein's accounts of language and the tools of the PI to show how being reflective about practice can change practice. As Baker (2004:34) has noted: 'Conscious analogies and comparisons are useful tools for curing diseases of the intellect, whereas unconscious ones generate insoluble problems by exercising an imperceptible tyranny over our thinking'. Wittgenstein writes to change the way that people think, by making things clear (PI p.4) and - given that translation involves thinking - his work can change the way that people translate. His method involves suggesting analogies that allow the reader to realise that if something is true of one situation then it may be true of others, thus undermining preconceived ideas (PI 1) and giving us conscious analogies and comparisons. What I write here is also analogical, because I trace a link between the grammatical investigations of Wittgenstein and the task of the translator. If Wittgenstein is right about language, then this has consequences for the translator: the story told in the $P I$ enables him or her to find different ways of expression, as Kerr (1988:170) claims is the case for the theologian who reads Wittgenstein. Wittgenstein's philosophy becomes a useful translation tool - and his notions become useful translation tools - through direct application.

A reading of Wittgenstein shows that words are things with which we operate (PI 1) rather than entities to which meaning adheres, which allows interesting questions to be asked about translation, in a way that may be unlikely outside a reading of Wittgenstein. How could a German poem written in the nineteenth century be expressed in the voice of a contemporary English-speaker? How could it be rewritten as a song, using rhythm and rhyme for poetic effect? How could it be placed in dialogue with other poems, songs, figures? What happens if Wittgenstein's contention that meaning is a physiognomy (PI 568) is taken seriously? Translation becomes an exercise in anthropology, forsaking the crystalline beauty of the linguistic transfer of meaning ( T-LP 3.343) for the rough ground of the everyday world of transaction (PI 107). Robinson (2003:112), discussing Wittgenstein's instruction to look for meaning in use (PI 43), asserts that a 'person-centred approach to any text, language or culture will always be more productive than a 
focus on abstract linguistic structures or cultural conventions'. What would the people in Mörike's poems - both the characters and the narratorial voices - say in translation? How could Mörike still speak through them? Bell (2011:215) describes how 'the literary translator is always, as it were, playing a part like an actor, trying his or her hardest to become the author of the original'. Wittgensteinian notions, such as the language-game, may help the translator do this. Above all, they offer a rationale for doing this. As argued in Chapter 1, the rationale for practices comes from outside the practice.

I give ten remarks derived from my own translations of the poem discussed as (54) in 2.5.1, 'Ein Stündlein wohl vor Tag' (Mörike 1975:31). The translations are part of a larger project of translating Mörike's poetry for a projected anthology, using Wittgenstein to drive the renderings. Considerations of space prevent the use of other material from this project.

(i)

I take Wittgenstein's account of language to indicate that the language-game of translation is possible, because meaning is not just something that goes on in the head (PI 693) but is to be understood by looking at interaction: between individuals, between communities, between the individual and the community. As discussed in 3.2, we can translate because justification consists in appealing to something independent (PI 265). At the very least, for example, the ST can be glossed, as in (54), providing what Scott $(2000: 149)$ calls the 'negative function' of signalling to the reader which sense of a word is meant where one or more semantic renderings are available: the word 'weh' in line 11 of (54), for example, is glossed to signify 'alas' rather than 'hurt'. Glosses are a valuable aid to study, but fall short of literary translation, where I take it as axiomatic that the TT must be able to stand by itself, so that it can play a similar role in the TL to the one the ST plays in the SL ( $Z 155)$. Literary translation involves playing a game with the gloss, so that use can be maintained (PI 43) by seeking strategies to enable the same language-games to be played in the TT as in the ST (Gledhill 2007:5). Text (94) represents one translation of (54). 


\author{
AN HOUR BEFORE THE DAY \\ In deepest sleep I lay, \\ an hour before the day: \\ and, as I slept, from the nearby tree \\ a swallow sang a song to me, \\ an hour before the day. \\ 'Now listen to what I say! \\ Your love has gone astray. \\ And while I sing, as swallows do, \\ he holds a girl who is not you, \\ an hour before the day.' \\ Oh no, what's that you say? \\ My swallow, go away! \\ Before your singing from the tree \\ I'd dreamed of love and loyalty, \\ an hour before the day.
}

I was interested in seeing whether the formalism of the ST could be recreated in translation. I therefore decided to use full rhyme and the iambic metre and complex rhyme scheme of the ST, i.e. $\left[\left(\mathrm{aA}^{1} \mathrm{BbA}^{1}\right)\left(\mathrm{A}^{2} \mathrm{acc}^{1}\right)\left(\mathrm{A}^{2} \mathrm{aBbA} \mathrm{A}^{1}\right)\right]$. Within this constraint, which preserves the song form (such as the refrain), I chose to write an English that did not twist itself to produce rhymed line endings, and that evoked the form of life of somebody moving from security to disillusionment before day has even begun. What I did not maintain were the three diminutives in the ST formed by the use of the suffix -lein, because using an analogous technique seemed archaic in English, such as adding the suffix '-let'; so Schwäblein, 'the little swallow' in line 4 of the ST becomes 'swallow', not 'swallowlet', although I was able to compensate by having the protagonist call it 'my swallow'. It is a poem that I intend to be able to work by itself through its poetic effects, without the ST necessarily being placed alongside it, a poem that could be set to music and sung by a contemporary singer such as Jenkins, as discussed in 2.5.1.

(ii)

The PI shows that there are many ways of approaching problems: hence its warning against doctrine (PI 109) and its stress on the particular case (PI 66). Many translators do, however, translate according to a single strategy that precedes looking 
at the text (cf. Jerome, 2004). An approach to translation after Wittgenstein would by contrast examine the ST's meaning by looking at its form and responding to that. A translator might therefore bring a variety of strategies to his or her rendering. In line 11 , for example, I refrain from translating ' $\mathrm{O}$ weh' as 'alas' or 'oh woe', and use the expression 'oh no', which seems to me to be what somebody would say in the twenty-first century when faced with the collapse of his or her world. I do, however, retain the refrain (in contrast to (96) below) because of the song form: people may not speak with refrains, but they still sing with them.

(iii)

Using Wittgenstein frees the translator from the dualistic paradigm identified by Berman (2004:237) as a cause of failed literary translation, as discussed in 3.1. Raleigh Whitinger (2005:xix), for example, describing his translation of Mörike, writes of being in the 'uncomfortable position' of 'having to produce English equivalents of German verse'. His renderings in my opinion parody the ST, and it is hard not to see the search for perfect transfer at all costs as the cause of this. An example is (96), which renders the opening of Mörike's poem 'Der Feuerreiter' ('The Fire Rider') (2005:19), with the ST as (95) (Mörike 1975:62).

Sehet ihr am Fensterlein see you at-the small-window

Dort die rote Mütze wieder?

there the red cap again

Nicht geheuer muß es sein,

not normal must it be

Denn er geht schon auf und nieder.

for he goes already up and down

See you at yon window small

There again, the red cap gleaming?

See it rise, now see it fall,

Like an omen ill, 'tis seeming. 
Whitinger's translation deforms the English language - the expression ''tis seeming' in line 4 , for example, is ungrammatical. It is therefore impossible to see it as a representation of the ST, which does not deform the German language.

Translation after Wittgenstein is not a matter of seeking equivalences but a literary activity. The fly is freed from the fly-bottle (PI 309) when the translator is liberated from the false picture of translation being about moving meaning from one place to another. I am not transferring Mörike to English. If that were what was desired, it might be better to read English poetry contemporary with Mörike, such as Wordsworth, following Douglas Hofstadter (1979:380). To translate Mörike involves recreating the $\mathrm{ST}$, not attempting to clone it.

(iv)

A translation, to be identified as such, must be taken as standing in some sort of a relationship to the ST. In Wittgenstein's terms, this relationship is that the TT must be a surveyable representation of the ST. The surveyable representation (PI 122), as discussed in 2.1, clarifies something to an audience by making connections. Moyal-Sharrock (2009:165) views literary works as surveyable representations and her theory can be extended to literary translations. The TT (94) was written to be a surveyable representation of the ST (54), a relationship that could be made clear by the way the poem is presented, for example, in a bilingual edition, as considered further in 4.3. Here I note that by writing in order to produce a surveyable representation, Wittgenstein's notion becomes a tool.

(v)

The speaking of a language 'is part of an activity, or of a form of life' (PI 23), which implies that the translator after Wittgenstein would see himself or herself as a translator of texts, rather than of meaning, because meaning does not exist outside the text as a form of life. Sentences, words and paragraphs must be seen in context, both the immediate context and the context of the whole language. The translator, like Wittgenstein, is engaged in a series of grammatical investigations, looking at the pragmatics of the ST and the pragmatics of what he or she writes in response, without having to translate out of a language of ideas. The poem given as (97), for example, can be taken as a translation of (54) because it maintains key aspects of the ST, such as the betrayed lover or the perceived dawning of day; as 
well as formal aspects such as rhyme, although to a different scheme; the swallow is referred to in the title and its prophetic role is paralleled in the figure of Mike. The setting is contemporary - for example, the reference to getting a lift in line 1 , or to the spiking of drinks in line 9.

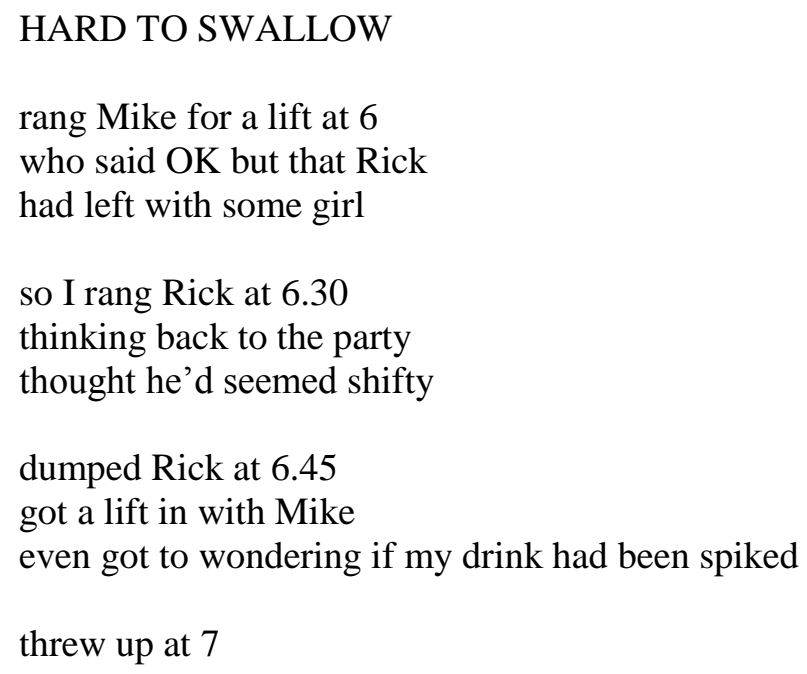

(vi)

Because the translator after Wittgenstein is not attempting to find equivalences, many different translations of any text are possible. Baker (2004:34) sees any surveyable representation as 'one of many possible orders, not the order'. (The consequence is not, however, that anything goes, given Wittgenstein's insistence in PI 9 that we must respect how things are.) Text (98) is another possible order, which places the ST in dialogue with the world of contemporary Symphonic Metal, as considered in 2.5.1.

\section{WHAT THE RAVEN SANG}

You'll call it cliché if I say there was a raven listening to Within Temptation from outside the window as I lay in bed getting round to wondering if the undead have to leave for work at seven.

You'll call it cliché if I say that the raven 
began to sing along to Within Temptation

about somebody slipping away. You didn't text back,

an hour before I left for work.

I wish I could believe in heaven.

Why does fate make us suffer? At seven

I left for work, gave in to temptation

and called on you. You were still in the park.

You'll be in the park forever. I came back.

Couldn't you resist this temptation?

Symphonic Metal is suggested by the referencing in lines 2, 7 and 11 of the song 'What Have You Done' by Within Temptation (2007), and by the intertextual reference in the title and lines 1 and 6 to the talking raven in the poem 'The Raven' by Poe (2003:69-76); the talking swallow, a bird that symbolises the world of the fairy-story, becomes a symbol of the Gothic world of Within Temptation. The TT is a poem in dialogue, just as the ST is in dialogue with the Volkslied and the Tagelied.

(vii)

For Wittgenstein, meaning is a physiognomy (PI 586); it is in the form not in the Forms. Translation is therefore not a scientific activity. My translation of Mörike is my Mörike, not an equivalent of Mörike or the definitive Mörike, just as Meredith McKinney (2005:59), discussing her translation of Sei Shônagon's The Pillow Book, refers to 'my Sei Shônagon', recognising that other Sei Shônagons exist. Winch (2008) applies Wittgensteinian methods to show that the humanities do not function through correspondence to objective facts, but through agreement on what could be held to be true. We agree to call something a translation, just as we agree to call something a theory in literature. The translations I write are to be located within a tradition of writing TL poems that replace SL poems (Z 698).

Text (99) is a free verse translation of the very formal ST.

\section{JUST ONE HOUR BEFORE DAWN}

after Mörike

While I lay asleep, 
just one hour before dawn,

I thought I heard a small swallow sing to me

from the tree outside my window.

'Listen to what I have to say:

I bring a charge against your lover.

For while I am singing this song to you

he is having his way with another.'

Ah, that was too much for me

and I awoke into a bad dream

where there was neither love nor loyalty.

And the swallow flew away.

Here, in another attempt at expressing my Mörike, the rhythms of ordinary speech take precedence over any imposed rhythm. The intricate sound patterns of the ST are echoed in half rhymes ('asleep' and 'me' in lines 1 and 3 etc.) and assonance ('swallow' and 'window' in lines 3 and 4 etc.), but there is no attempt to reproduce the refrain. The translation therefore has a different shape from the ST, because it has only four lines per stanza, not five, but my contention is that it can be regarded as a translation because I have rendered it as part of the public practice of translation - as seen in the subtitle 'after Mörike' - while paying attention to the physiognomy of the ST.

(viii)

As argued in 3.3, applying Wittgenstein to translation involves linking the activity of translation to the forms of life of the literary translator, cf. $C V$ p.75. In my own case, being a reader of Mörike has involved: studying his poems; reading his biography; researching secondary literature; visiting places associated with him; translating over thirty of his poems. The translator is involved in a public, not a private language (PI $243 \mathrm{ff}$.) and this is extended if and when translated poems themselves become part of the form of life of literature, e.g. through publication. The greatness of what anybody does, for Wittgenstein, depends on everything else that he or she does ( $C V$ p.75). Even the decision to use lower case at the beginning of lines, in contrast to the ST, can be related to a form of life, here the conventions of twentyfirst-century English versification. 
(ix)

Just as Cook and Read (2010:473) ask whether Wittgenstein makes a worthwhile difference to how we read a text (as discussed in 2.1) and conclude that he offers 'a phenomenology of the experience of reading literature', I argue here that using Wittgenstein offers a phenomenology of writing literature, a practical method of translating that takes a translator into the heart of how the ST may be rendered. Trying to imitate the features of the ST makes more sense than trying to write to provoke effects. As argued in 3.2, attempting to replicate effects is too indeterminate a task.

(x)

Wittgenstein's project is a descriptive one (PI 109). In remarks (i) to (ix) above, I have described my Wittgensteinian translation work on a German ST. Given that I have completed the work, it might be asserted that the description is now of no use to me. However, as Boase-Beier (2011:77) argues, a description of any practice will in turn affect practice because it affects the way that people see things. Therefore my description of my practice will affect my future practice, as well as the practice of those who read the description, not by offering a methodology, but in the way that Richard Rorty understands the Wittgensteinian language-game as related to 'practices, traditions, the kind of things that people pick up without learning any rules but just by "know-how" (Rorty \& Vattimo, 2005:59). Wittgenstein's philosophy becomes a useful translation tool - and his notions become useful translation tools - through indirect application. 


\subsection{Conclusions}

Wittgenstein ( $C V$ p.39) cites a quatrain from the poem 'The Builders' by Henry Wadsworth Longfellow (1904:186) as a possible motto for his work. I give his citation as (100). ${ }^{40}$

(100)

In the elder days of art

Builders wrought with greatest care

Each minute and unseen part,

For the Gods are everywhere.

I have in turn used the verse as the motto for this chapter because it sums up an attitude towards language found in Wittgenstein, who asserts in $C V$ p.40 that language, music and architecture all contain 'significant irregularities'. In Chapter 2, I showed how a reading of Wittgenstein can help the literary translator discern significant irregularities in the ST; in this chapter, I have shown how a reading of Wittgenstein can help the literary translator recreate significant irregularities in the TT, by working with greatest care on each minute and unseen part, in a process more akin to art than science. The thoughtful activity of Longfellow's builders in the elder days may be contrasted with the form of life of Wittgenstein's builders of PI 2, who play very limited language-games, as discussed in 2.2. William James DeAngelis (2007:88) describes their activities as pointless, claiming that Wittgenstein's text implies that genuine building is something that should be done reflectively and not regarded as an end in itself.

Wittgenstein's philosophy can play a dual role for the practising translator. Firstly, it can help him or her realise that literary translation is more than transfer, despite what our intuitions may tell us. Samuel Johnson's seminal 1755 Dictionary of the English Language (1820), for example, defines linguistic translation as 'to change into another language retaining the sense', which matches the Platonic contention that form and content can be divided (Plato, 514a ff.). Wittgenstein's methods undermine this dualistic intuition, as if by various therapies (PI 133), and allow the translator to avoid the deforming translations that Berman (2004) links with Platonic dualism. Secondly, Wittgenstein supports the contrary intuition, often

${ }^{40}$ Wittgenstein misquotes Longfellow, whose final line reads: 'For the Gods see everywhere'. 
put forward by creative writers (the builders of literary works) that literary translation is about more than transfer. The poets Matthew Sweeney and John Hartley Williams, for example, advise that the goal of translating poetry is to come up with a poem that 'lives in the new language', so that 'a poem that's ragged in the original needs to be ragged in the translation' (2005:156). Their instruction is reminiscent of Wittgenstein's remark, 'What's ragged should be left ragged', though Wittgenstein is here addressing religion, not translation ( $C V$ p.51). Wittgenstein offers a set of tools, such as the language-game, to support those who choose to translate this way.

With respect to the academic study of translation, a correlative of my reading of Wittgenstein is that his methods oppose work on language and translation that assumes a code model of language or that stresses equivalence, such as the positions taken by Davidson (2001) in philosophy and by Pym (2010) in translation studies. His methods, by contrast, support an occasion-sensitive approach to language in philosophy (Travis, 2008) and a stylistic approach in translation studies (BoaseBeier, 2006b).

As stressed in 2.6, there is no single Wittgensteinian method to be applied to the process of translation, just as there is no single way of building a house. Wittgenstein (PI p.4) claims that his aim is 'not to spare other people the trouble of thinking' but 'to stimulate someone to thoughts of his own'. Similarly, the literary translator may be provoked by reading the $P I$ to produce translations of his or her own. Wittgenstein asserts - in Anscombe's translation - that philosophical problems arise when language goes on holiday (PI 38), i.e. when it idles, divorces itself from context. The same is true of translational problems and Wittgenstein can help us to see this - and therefore to translate - with clarity. 


\section{THEORISING THE TARGET TEXT}

Do not look for a theory behind the phenomena: they themselves are the theory.

Goethe (1901:261) ${ }^{41}$

${ }^{41}$ Translation by Luckhardt \& Aue (RPP I 889). 


\subsection{The beetle in the box}

Translation studies attempts to account for both the practice and product of translation, that is, the activity and its artefacts. Theorising has been a response to phenomena. As Tymoczko (2007:5) notes, the development of translation studies in its current form was influenced by historical events, including the importance attached to translation by the Allies during the Second World War and the decision of the European Union to recognise the official languages of all member states as official languages of the Union. From the Wittgensteinian point of view, it is always advisable to start with the phenomenon, not the theorising, as in the approach to the study of literature advanced by Attridge (2004:1): 'I do not wish to begin ... as many theoretical accounts of literature do, with the various philosophical projects that have largely determined our approach to these issues and the vocabulary we use, but rather with the observable phenomena themselves'. Philosophy, for Wittgenstein, likewise begins with looking, not with a doctrine (PI 66). Attridge (2004:143), as noted in 2.1, acknowledges the influence of the later Wittgenstein on his work, particularly in making him 'cautious about the search for closed definitions'. And this is what is at stake in this chapter on the theorising of the TT: that the investigation should not be a search for a closed definition.

As discussed in Chapter 1, the later Wittgenstein takes a radical position on theory, given his assertion in PI 109 that 'we may not advance any kind of theory', which has led some commentators to advocate a total rejection of theory (Cook, 2009). This position, however, does not seem to be justified by the German ST, given as (101).

Und wir dürfen keinerlei Theorie aufstellen. and we may absolutely-no theory put-up

The verb aufstellen implies that we should not start with a theory, in line with Attridge's position, not that theory is to be banned. The refusal to advance theory and to avoid the hypothetical involves a stress on the concrete and examples from the everyday, which contrasts with the theoretical approach of much traditional western philosophy, such as the continental tradition, or the traditions of philosophical 
theology. As Searle (Magee, 1987:143) asserts, however, just because Wittgenstein did not advance a theory does not mean that his readers cannot have a theory about anything. As I argued in Chapter 1, to advance a view about something is not the same as to advance a doctrine. With respect to literary translation, the temptation to begin with the theoretical, with the closed definition, is strong, given the existence of a bewildering variety of theories that are on offer in the academic market place of the humanities: Iser's book (2006) on how to do theory lists twelve theoretical approaches that can be taken to the analysis of literature. ${ }^{42}$ But the Wittgensteinian quest always begins with the concrete.

Much of what was said about reading the ST in Chapter 2 will also apply to theorising the TT. A translated literary text will, for example, similarly be written in the language of information but will do more than give information (Wittgenstein, $Z$ 160). Is there any point to writing this present chapter, then? Would it not be simpler to state that what went on in Chapter 2 still applies, and to leave it at that? That the present chapter is necessary is because the language-game of translation has been played in writing the TT: in PI 23, Wittgenstein notes how translating from one language into another is a language-game, and this makes the TT a different sort of text from the ST. As Attridge (2004:73) notes, a translated text evokes a more complicated response from readers, who see the TT as 'both original and translation'. Constantine (2005:xl), introducing his translation of Goethe's Faust I, states that his aim 'is always to write an English verse which, whilst conveying the whole freight of sense and implication of the original, will be readable with pleasure as English verse'. There are two aspects to that aim. When Constantine (2009) writes his own verse, only the second aspect is relevant.

It is necessary to examine translation both as practice and as product. Confusion can be avoided from the start by being clear how the same word is being used to describe these different phenomena, and is then used in different ways in those descriptions. ${ }^{43}$ By using Wittgenstein in an investigation of translation theory, I can clear up conceptual confusion and open the way to clarity, by showing that there is no one meta-practice involved, but a variety of practices that results in a variety of outcomes. In this section, I refer to the work of Tymoczko (2007), who has applied

\footnotetext{
${ }^{42}$ These theories are, in chapter order: phenomenological; hermeneutical; Gestalt; reception; semiotic; psychoanalytical; Marxist; deconstructionist; anthropological; the theoretical approaches of John Dewey, Elaine Showalter and Edward Said.

${ }^{43}$ This is a characteristic of language, not just of the language used to describe translation (PI 5).
} 
Wittgenstein to the study of translation; in 4.2, I look at how a TT may be described; in 4.3, I consider how a translation practice or a TT might be evaluated; in 4.4, I examine aspects of the theorisation of the practice of translation from a Wittgensteinian perspective; in 4.5, I give a case study of NT translation.

In PI 293, Wittgenstein tells the story of the beetle in the box, quoted as (102).

Suppose that everyone had a box with something in it which we call a 'beetle'. No one can ever look into anyone else's box, and everyone says he knows what a beetle is only by looking at his beetle. - Here it would be quite possible for everyone to have something different in his box. One might even imagine such a thing constantly changing. - But what if the word 'beetle' had a use nonetheless? - If so it would not be the name of a thing. The thing in the box doesn't belong to the language-game at all; not even as a Something: for the box might even be empty. No, one can 'divide through' by the thing in the box; it cancels out, whatever it is.

The example is about the public and the private, about the impossibility of knowing something only according to internal criteria. It illustrates Wittgenstein's previous discussion in PI 293 about whether it is possible to know what pain is 'only from my own case', and should be seen in the context of the remarks about the possibility of a private language, PI 256-314. There is no way of knowing what somebody else has in their box within the constraints set out by Wittgenstein. A box could even be empty. As long as we look inwards for the meaning of the word 'beetle', it remains meaningless. The beetle would have to be shown for the term to be meaningful.

Wittgenstein's beetle in the box has received a vast amount of exegesis, as detailed by David Stern (2007). It has usually been taken as 'a reductio ad absurdum of Cartesian dualism' (Stern 2007:249) but has been interpreted in many other ways, e.g. Malcolm (1966) reads it as proving that there is no link between the learning of words for sensations and private objects. Martin Cohen (2005:109) describes it being 'too sparse and too ambiguous to lead to any conclusion' and this is perhaps the point: it is not designed to lead to a conclusion, because it is a literary artefact. Cohen himself misses that point by seeing the ambiguity as a fault, rather than as a sign of literariness, referring to the story as a 'thought experiment' and pushing its boundaries (2005:106 ff.) in an analytic way contrary to its spirit. To read the story 
analytically is to take it in a fashion that makes it appear that Wittgenstein's writings are 'assimilable into the very intellectual background they were largely a warning against' (Drury 1984:101). Stern (2007:249) describes it as a parable, with its own afterlife, like Plato's cave (Plato 514 ff.), within the context of the PI, a work he views as 'a distinctly literary achievement that invites the reader to take part in the debate it presents'. This seems a much more profitable way of looking at the beetle in the box. If Wittgenstein had wanted to make assertions about the nature of mind, he was quite capable of doing so (as in the dogmatic statements that characterise the $T-L P)$.

I propose to take part in the debate by using the story of the beetle in the box as a parable for translation, so that its afterlife can enter the world of translation studies. My re-writing of the parable is given as (103).

Suppose that everyone had a box with something in it which we call a 'translation'. No one can look into anyone else's box, and everyone says he or she knows what a translation is only by looking at his or her translation. - Here it would be quite possible for everyone to have something different in his or her box. One might even imagine such a thing constantly changing.

By looking at what people mean by translation, at the use of the term, we can fulfil the anti-essentialist project at the heart of the $P I$, illustrated by $P I 116$, given as (104).

When philosophers use a word - 'knowledge', 'being', 'object', 'I', 'proposition/sentence', 'name' - and try to grasp the essence of the thing, one must always ask oneself: is the word ever actually used in this way in the language in which it is at home? -

What we do is to bring words back from their metaphysical to their everyday use.

The metaphysical is rejected in favour of the everyday. Instead of trying to define the phenomenon and then looking for examples, the correct process is to pay attention to how the term is used in everyday discourse. To expect a single answer to the 
question, 'What is translation?' is to fail to recognise that the meaning of the term 'translation' is complex. Translation, whether as practice or as product, only makes sense when I show my translation practice or product to others and tell them what I mean by it. Considerations of time, place and context all apply. Thus the drive of the rewritten parable in (103) is anti-essentialist.

An example of how translation might be shown to others is through the use of the dictionary. Although it is frequently commented that literary translation is about more than competent use of a dictionary (cf. Weinberger \& Paz, 1987:43), it would be an unusual translator who did not have a dictionary to hand. The sort of errors that make people laugh in translation can often be ascribed to poor use of a dictionary. Robinson (2003:187), for example, gives the example of the slogan (of the scotch tape 3M) 'It sticks like crazy' being given in Japanese as 'It sticks foolishly'. That this is wrong can be discovered by the reaction of the English person who reads it in back-translation, which would typically be amusement. Meaning is a communal activity and the dictionary is a guarantee of how that meaning is constituted through use, for example the historical quotations given in the Oxford English Dictionary to show the various uses of words now and in the past. There are other guarantees, such as those cited from Clancy (2006:7) in 3.3: the internet; encyclopaedias; consulting the ST author etc. The competent use of the dictionary and other forms of checking can be seen as a necessary if not sufficient condition of literary translation.

With reference to products, the term 'translation' is used to refer to very different outcomes. Clarity is attained by comparing the phenomena under investigation (PI 50). It is, for example, all too easy to see translation solely from a western perspective, forgetting that non-western traditions instantiate different approaches (Tymockzo, 2006). Anuvad (Spivak, 2007:274) is a Sanskrit and Hindi term for written translation that means 'repeating' or 'saying later', so that translation in this context can be seen as a process of 'updating and elaborating, rather than as some kind of physical movement across cultures' (Pym 2010:2). Different western translation practices have also dominated in the past: for example, the notion of foreignisation is very different in the nineteenth-century writings of Schleiermacher (2004) from what it is in the contemporary writings of Venuti (1998, 2008). 
The term 'translation' can be seen to be controversial, and it has often proved impossible for scholars and writers to agree on what it means, as can be shown by three examples. Firstly, Don Paterson (2006:73 ff.) asserts that his rendering of a sonnet cycle by Rilke is not a translation but a version. He defines 'translations' as works that aim to be 'true to the original words and their relations', and 'versions' as works that are 'trying to be poems in their own right'. His contention is that there are two types of rendering available to the literary translator and that the version is the better option. Secondly, the writers of the canonical Middle High German romances and legends, by contrast, stress their status as translator and their trueness to the ST, so that Hartmann von Aue (1972:61), for example, maintains that his role in the production of the Gregorius was to bring it into German poetry out of Old French. Today, however, his work is studied as literature in its own right, with little reference to any ST used (Jackson, 1994), which shows that the distinction between translation and version has been much more fluid in the reception of texts than Paterson's definitions would suggest. Thirdly, in his analysis of film and translation, Michael Cronin (2009:81) investigates interpretation as well as translation. He analyses, for example, Sophia Coppola's presentation of the Japanese interpreter in her film Lost in Translation (2003). His study assumes that the practice of translation is wider than often recognised and can refer to oral as well as to written work. The difficulty of the term, as seen in these examples, has led translation theorists to attempt classification.

As discussed in 2.1, Jakobson proposes a tripartite classification: intralingual translation or rewording; interlingual translation or translation proper; intersemiotic translation or transmutation (2004:139). Although influential, his definitions are too broad to allow certain texts to be satisfactorily categorised. A relocation, for example, involves a very specific strategy on the part of the translator: the translation of Frédéric Beigbeder's novel 99 francs (2000) by Hunter (2002a), £9.99, moves the setting of the ST from Paris to London, yet it can only be classified as interlingual translation according to Jakobson's system, which would not differentiate it from translations that do not relocate, for example, Hunter's translation (2002b) of Catherine Millet's erotic memoir.

Munday (2009:8) gives the more detailed classification represented in (105), which he refers to as a 'cline of strategies' that contrasts the derivative with the primary and enables any translation to be located at a point along the cline. Hunter's relocation of Beigbeder can thus be mapped on the right hand side of the cline as a 
'translocation'. The cline represents an advance on Jakobson's classification, because it includes more categories and allows texts to be placed along a line, rather than given a designation.

\author{
More derivative \\ phonological translation \\ word for word \\ literal
}

formal

\author{
More primary \\ creative/primary
}

translocation

free - adaptation

functional

The problem is that the cline offers a two-dimensional view of any given strategy, whereas the solution that is called for is at least three-dimensional. The cline opposes the phonological and the creative, for example, but there is no reason why a phonological translation should not be creative, as is the case with the English edition of the Latin poet Catullus by Celia and Louis Zukofsky, who aim to follow 'the sound, rhythm, and syntax of [Catullus's] Latin ... to breathe the "literal" meaning with him' (1969:np); theirs is both a creative and a derivative project.

To map a translation on Munday's cline is too restrictive, a false dilemma. It is analogous to saying that if I take after my mother then I cannot bear any resemblance to my father at all. Tymoczko (2007:83-90) uses Wittgenstein's notion of family resemblance, discussed in 3.2 , to avoid the sort of problems of classification that arise in systems such as those of Jakobson and Munday (too broad in the first case, too narrow in the second). Just as the search for any one characteristic, found in all members of a family, is typically fruitless, so Tymoczko argues that trying to apply all-encompassing categories to the variety of phenomena addressed in translation studies is futile. She uses the term 'cluster concept' to designate a concept that includes different aspects, and proposes translation as a cluster concept, being, like 'game', a concept with 'blurred edges' (PI 71). The term 
is brought back from a metaphysical to an everyday use, as part of an antiessentialist project.

Seeing translation as a cluster concept can clarify the use made of the term. To return to the three examples given above: Paterson (2006) is playing with words when he tries to seek an essentialist difference between a translation and a version, rather than spelling out clearly his own aims as translator, possibly deflecting attention from how he has rendered the ST; the case of the writers of German mediaeval courtly romances shows that the concept of originality in creative work is more flexible than often thought (Boase-Beier \& Holman, 1999:2 ff.), so that translations are acts of creative writing; the Japanese interpreter in Coppola (2003) is as much a translator as Faust in his vaulted study. The meaning of the term chosen to describe individual acts of translation depends upon its use (cf. PI 43). The opera Faust by Charles Gounod (1962), for example, can be described as a translation of Goethe's Faust (Goethe, 1972), but I should probably cause frustration if I were to bring back the score if my friend asked me to get a translation of Faust when I was in town. I should have failed to carry out a grammatical investigation of what my friend wanted.

Tymoczko, as part of her grammatical investigation of the phenomena of translation, accordingly writes the term with an asterisk, i.e. '*translation', in order to signal to the reader that it is a cluster concept that can include different practices of translation and hence signify 'the cross-cultural understanding that translation studies must move towards' (2007:59). An advantage of seeing translation in this way is that it allows overlap between different types of translation and different types of translating. The translation of Beigbeder by Hunter (2002a) for example, can be analysed from several angles: the purpose of the relocation; the consistency of the relocation; the way that her style echoes the style of the ST; the accuracy of the rendering of French expressions etc. ${ }^{44}$ All are part of the cluster.

The description of any TT will involve its identification as a translation. This point will be elaborated in 4.2. Here it is important to note the variety of words that are used to describe translations and to use Wittgenstein to show that terms such as 'adaptation', 'literal translation', 'version' etc. only have sense in the way they are used. There is no essence behind a concept to which appeal may be made, just as the

\footnotetext{
${ }^{44}$ Such was my strategy when I used this novel as a case study for an essay for the MA in Literary Translation at UEA, 2007-8.
} 
box may not even contain a beetle in Wittgenstein's story. In a review (2008:76) of Gordon Pirie's Fables (2008), a translation of poems by the seventeenth-century poet Jean de la Fontaine, for example, Maya Slater makes this comment: 'None of the poems is a complete and faithful translation: he always adds something of his own. He takes so many liberties that his poems are versions rather than translations.' The word 'version', as in Paterson above, is used to indicate a certain type of translation. Here it is based on the fidelity debate in translation (which I shall review in 4.4), and it is implied that a version is inferior to a translation, in contrast to Paterson. Slater does define her term so that the reader can understand what she means by a version, i.e. a free translation as opposed to a supposedly faithful one. But she fails to recognise that translation is a cluster concept. There are many ways of translating la Fontaine and it is not possible to formulate essentialist categorisation, although her review at least indicates what sort of rendering a purchaser of Pirie's text might expect. La Fontaine is in any case a much-translated author whose opus allows comparison of different renderings. His own work can itself be described as a set of 'translations going back to the semi-mythical Aesop' (Barnstone, 1993:93). The cluster is more complicated than Slater implies.

By referring to *translation, Tymoczko is able to challenge what she sees as the predominant western paradigm of translation, i.e. the transference of meaning (analogous to a scientific process), as discussed in 3.1. She regards this paradigm as too narrow, principally because it excludes non-western ways of engaging with the ST. She quotes the Chinese fanyi (or 'turning over') as an example of such a way, and it would also apply to the Sanskrit/Hindi anuvad mentioned above. Her call (2006:20) is for the broadening of the term 'translation' in critical and scholarly discourse, to include such non-western methods, in order to move away from a situation that is ethically unacceptable because it assumes the superiority of western paradigms. Munday (2009:19) predicts that the response to Tymoczko's call will be of immense importance, possibly involving a radical change in the whole discipline of translation studies, 'a new "turn”, detour, byway or complete translocation'. As with Wittgenstein's laboratory work on shock, described in 1.5.1 as an example of how the insights of his philosophy can be applied, what begins as a look at how a term is used ends by threatening to change everything (Monk, 1990:533).

Faced with a cluster, there is a tendency for the critic to oversimplify. Freud (2006:59) points out that to recognise that something is a cluster is to make a start, 
not a finish: "The only way that we can give an account of complex clusters is to describe their various elements one by one. And consequently, all our explanations are initially guilty of being one-sided simplifications, and wait to be filled out, added to and thereby corrected.' Tymoczko (2007:90) quotes with approval the assertion by Peter Fawcett that it is a mystery 'why theorists are so determined to defuzz the discipline' of translation studies. Defuzzing ignores the 'rough ground' of linguistic practices ( $P I$ 107), by seeing language as an artefact of 'crystalline purity', a preconceived ideal that 'can only be removed by turning our whole inquiry around' (PI 108). An example of the defuzzing tendency is the way that translation is often viewed in polarities. It is possible to read many classic statements from translation practitioners and translation theorists in terms of polarity, where one method of translating or viewing a translation is contrasted exclusively with another. In Table 5, I give examples of nine translation polarities, based on the summary by Pym (2010:33), with the sources in chronological order of composition.

\section{TABLE 5: TRANSLATION POLARITIES}

\begin{tabular}{|l|l|l|}
\hline SOURCE & POLE 1 & POLE 2 \\
\hline Cicero (1997) & As an interpreter & As an orator \\
\hline Schleiermacher (2004) & Foreignising & Domesticating \\
\hline Nida (1969) & Formal & Dynamic \\
\hline Newmark (1988) & Semantic & Communicative \\
\hline Levý (2000) & Anti-illusory & Illusory \\
\hline House (1997) & Overt & Covert \\
\hline Nord (1997) & Documentary & Instrumental \\
\hline Toury (1980) & Adequate & Acceptable \\
\hline Venuti (1998) & Resistant & Fluent \\
\hline
\end{tabular}

There are two problems. Firstly, the polarities differ in kind, whereas their tabulation suggests that they do not. Cicero (1997), for example, addresses how a translator deals with the ST, whereas Toury (1980) is interested in how the TT is perceived in 
the target culture. The polarities are similar, of course, and are linked in family resemblance, but not in type. Secondly, to rely on polarities is to use an intellectual shorthand that ignores how most descriptions are not exclusive (Austin, 1962:83). To refer to the terminology of Christiane Nord (1997), for example: a translation may be documentary in one sentence and instrumental in another; or documentary in one part of a sentence and instrumental in another part; or both documentary and instrumental at once (Boase-Beier, 2006:27). Anscombe's translation of a sentence in PI 38, discussed in 3.4, can serve as an example; ST and TT are given again as (106) and (107) respectively.

(106)

Denn die philosophischen Probleme entstehen, wenn die Sprache feiert. for the philosophical problems arise when the language celebrates idles stops-work

For philosophical problems arise when language goes on holiday.

The first six words of (107) can be described as documentary translation because they instantiate dictionary meaning; whereas the final three words can be described as instrumental, because they go beyond dictionary meaning. To attempt to describe the whole sentence as either documentary or instrumental oversimplifies. As with Munday's cline in (105), the solution offered is two-dimensional, whereas the ideal solution would be at least three-dimensional, just as Wittgenstein (PR 51-52) uses the colour octahedron (as opposed to a colour wheel) as an example of a surveyable representation. An example of translation as a cluster, of translation as *translation, is to be seen in the work of Hughes (2006), not just in the sense that Hughes translates many different types of ST, ranging from Classical Greek tragedy to contemporary Hungarian verse, but in the sense that he translates in different ways. Daniel Weissbort (2006:vii) asserts that Hughes often translates in a way that 'suggests a belief in the intrinsic ability of poetry to cross linguistic frontiers, provided the translator does not interpose himself overmuch', as seen in his practice of reworking a gloss provided by an SL speaker, as described by Gaia Servadio 
(Hughes, 2006:218). I give part of an Italian poem by Lorenzo de' Medici (ibid.) as (108) with Hughes' translation (2006:100) as (109).

Quanto sia vana ogni speranza nostra,

how is vain every hope our quanto fallace ciaschedun disegno, how whimsical each design

(109)

How futile every hope is, that we have, How illusory, all our designs,

This translation illustrates the advocacy by Hughes and Weissbort (Hughes 2004:200) for 'translations that can be described as literal, though not literal in a strict or pedantic sense'. In his translations from Ovid, however, there is a different approach, as can be seen in his rendering (1997:81) of the description in the Metamorphoses of Narcissus falling in love with his reflection (2004:81). The Latin ST is given as (110) and the TT as (111).

Quisquis es, huc exi! quid me, puer unice fallis whoever you-are to-here come why me boy unique beguile quove petitus abis? certe nec forma ne aetas to-where sought you-go certainly not from-form nor from-age est mea quam fugias, et amarunt me quoque nymphae. is mine which you-flee and loved me also nymphs

Who are you? Come out. Come up

Onto the land. I never saw beauty

To compare with yours. Oh why do you always

Dodge away at the last moment

And leave me with my arms full of nothing

But water and the memory of an image.

It cannot be my ugliness

Or my age that repels you,

If all the nymphs are so crazy about me. 
As Raphael Lyne (2002:263) points out, Hughes 'discovers Hughesian moments in the Metamorphoses'. Thus: the idiom in the final line is distinctly colloquial; there is no attempt to convey the dactylic hexameter of the ST, three lines of Ovid becoming six lines in Hughes; the interjection ' $O h$ ' is used in line 3 to heighten dramatic tension etc.

Hughes can in turn be seen as part of a cluster of translations that have appeared around Ovid, as shown in Table 6.

TABLE 6: OVID AS A CLUSTER OF TRANSLATIONS

\begin{tabular}{|l|l|}
\hline TT & DESCRIPTION \\
\hline $\begin{array}{l}\text { Tales from Ovid (Hughes (tr), Supple \& } \\
\text { Reade (eds), 1999) }\end{array}$ & $\begin{array}{l}\text { A working of Hughes (1997) for the stage by } \\
\text { Tim Supple and Simon Reade. }\end{array}$ \\
\hline Ovid Metamorphosed (Terry (ed), 2000) & A collection of 19 stories based on Ovid. \\
\hline Ovid in English (Martin (ed), 1998) & $\begin{array}{l}\text { An anthology of translations of Ovid into } \\
\text { English from Chaucer to the twentieth } \\
\text { century, representing 76 translators. }\end{array}$ \\
\hline $\begin{array}{l}\text { After Ovid: New Metamorphoses (Hoffman } \\
\text { \& Lasdun (eds), 1994) }\end{array}$ & $\begin{array}{l}\text { An anthology of poetry inspired by Ovid's } \\
\text { Metamorphoses, representing 42 translators. }\end{array}$ \\
\hline
\end{tabular}

Michael Hoffman and James Lasdun (1994:xii) discuss their practice as editors: 'We invited each contributor "to translate, reinterpret, reflect on or completely re-imagine the narratives" and got the full gamut', i.e. the resulting book manifests a cluster both of practice and of product. In Martin's anthology (1998:183), there is James Shirley’s 1646 translation, given as (112), of text (110).

What e'er thou art, come forth, and meet me here He cries; why dost deceive me with a look?

What meanes that imitation? come neare,

Leape from the depth of thy imprisoning brook. Fold not thy arms like mine, or smile on me, Unlesse I may enjoy thy company. 
This poem is formally very different from the translation by Hughes given as (111). The Venus and Adonis stanza of Shirley contrasts with Hughes' free verse, for example. Both forms reflect their time in their poetic form of life. And yet both translators can, I think, be said to be playing the language-games of Ovid. To detail how they do this is to move towards describing the TT, which is the subject of 4.2.

In this section, I have argued that Tymoczko, following Wittgenstein, is right to view translation as a cluster concept. We should attempt to see clusters and not to impose clines. The beetles, as opposed to the beetle, must be brought out of the box and described. After all, more than 4,000 different species of beetle have been categorised in Britain alone (Cooter \& Barclay, 2006:xiv), and the taxonomy of translation may likewise be a demanding task. 


\subsection{Describing the surface}

For Wittgenstein, meaning is on the surface, as argued in 2.1. To grasp meaning involves looking at form, as Nietzsche (2001:8) puts it in his praise of classical Greek culture: 'Oh, those Greeks! They knew how to live. What is required for that is to stop courageously at the surface, the fold, the skin, to adore appearance, to believe in forms, tones, words, in the whole Olympus of appearance. Those Greeks were superficial - out of profundity!' In this section, I show how the surface can be described in order to produce a theory of the text. Following discussion in Chapter 1, I use the term theory to mean 'view of' rather than 'doctrine about'. I begin by considering Wittgenstein's application of his methods to mathematics, a subject outside philosophy, which may suggest by analogy how his methods may be applied to translation.

Wittgenstein wrote at length on the problems of mathematics, chiefly in $R F M$, stressing not the subject-matter taught in schools or universities but the use of mathematics in ordinary life, what he calls its use 'outside mathematics ... the meaning of the signs, that makes the sign-game into mathematics' (RFM V-2). Parallel to the language-game (the central concept in Wittgenstein's later work on language, PI 7) is the 'sign-game' (such as a sum), which only makes sense in context, in how mathematics is carried out. As Monk (2007:287) comments, for Wittgenstein mathematics is 'first and foremost the motley of techniques and practices we employ that use mathematical signs; we count out the money we give to the bus driver, we calculate how much money we will need to save to afford a holiday, we estimate how fast a car was going when it hit a pedestrian etc. etc.': mathematics is viewed as a human practice, like language.

This unconventional view of mathematics explains what Wittgenstein means by the comment on translation $\left(Z 698^{45}\right)$ quoted as (113).

Translating from one language into another is a mathematical task, and the translation of a lyrical poem, for example, into a foreign language is quite analogous to a mathematical problem. For one may well frame the problem 'How is this joke (e.g.) to be translated (i.e. replaced) by a joke in the other language?' and this problem can be solved; but there was no systematic method of solving it.

\footnotetext{
${ }^{45}$ The question about replacing the joke was discussed in 3.2 .
} 
The first sentence might suggest to somebody unacquainted with Wittgenstein's views on mathematics that translating a poem is a mechanical task following a preset procedure. Barnstone (1993:19), in my opinion, misleads his readers by giving only this first sentence as a motto for a subchapter, ignoring Wittgenstein's description of mathematics as a process of agreeing practices rather than discovering truths. I may use a mechanical application if I want to work out the product of, say, (49 x 49), but there is no mechanical procedure involved if I am trying to work out how to save up for a holiday, but rather such considerations as: where I would like to go; other projects I wish to undertake; how long I want to be away for; how much money I have saved etc. The example from Wittgenstein in (113) is of translating a joke (cf. his remark in LWPP I 278 on how the correct translation of an English play on words may be a completely different play on words, as discussed in 3.4). Wittgenstein stresses that the problem can be solved, i.e. that translation is possible, but that there is no systematic formula for solving it. The same joke may be translated differently on different occasions, depending on the context, just as there are many ways of arranging my finances so I can go on holiday. Neither the signgame nor the language-game can be divorced from the form of life. Translation is by implication first and foremost the motley of techniques and practices we employ that use linguistic signs when we replace one text with another in a different language.

This later approach contrasts with the view of translation given in the $T-L P$, where the picture theory of meaning (the natural way we view language) implies a 'pictorial internal relation, which holds between language and the world', which gives 'a rule of translation' ( $T-L P$ 4.014). The later Wittgenstein abandons the search for foundations in philosophy, i.e. absolutely certain premises from which to proceed, such as the Cartesian conviction that the thinking subject exists (Descartes, 1968). Instead, Wittgenstein maintains that philosophy cannot give any foundation and stresses instead looking at practices (PI 124). Monk (2007:278) accordingly describes him as a 'methodological anarchist'. It would analogously be an error to search for a rule to enable me to translate this joke into German. What is possible, however, is to describe the ways that people do translate a joke (a poem, a play, a novel) into German, descriptions that may in turn suggest to me ways of translating, as I learn from practices and am trained in techniques.

In PI 109, quoted as (114), Wittgenstein shows the consequences his position has for explanation. 
All explanation must disappear, and description alone must take its place. And this description gets its light - that is to say, its purpose - from the philosophical problems. These are, of course, not empirical problems; but they are solved through an insight into the workings of our language, and that in such a way that these workings are recognised - despite an urge to misunderstand them.

The stress is on looking rather than on thinking, on considering phenomena rather than on imposing doctrine onto phenomena. The approach leads to the surveyable representation of phenomena (PI 122), just as a dictionary will show how a language is used, rather than prescribing use.

In Chapter 1, I argued that Wittgenstein's work has had limited impact on translation studies, with certain exceptions such as DTS, to which I now turn. DTS is associated with the work of Toury, who cites Wittgenstein as a source (1980:17-18). Edwin Gentzler (2001:126) describes Toury's project in the passage cited as (115).

Toury suggests a different theoretical framework in which to conceptualise phenomena regarded as translation. Borrowing from Ludwig Wittgenstein the concept of family resemblances, Toury now views 'original' texts as containing clusters of properties, meanings, possibilities. All translations privilege certain properties/meanings at the expense of others, and the concept of a 'correct' translation ceases to be a possibility.

Family resemblance, as discussed in 4.1 , is a way of showing that such common notions of translation as transference or of translation as equivalence are wrongheaded, because they oversimplify complicated phenomena. Because translation is a human activity (PI 23) and a cluster-concept (as argued in 4.1, following Tymoczko, 2007), there are many ways of approaching it. The translation theorist can show his or her reader what is going on in the TT, while avoiding any suggestion of a correct model of translation underlying the process like a Platonic form. DTS represents a refusal to impose a paradigm onto the phenomenon of translation and its products: for example, by seeing translation as either instrumental or documentary (as discussed in 4.1), as if there were only two ways in which it could be described. The existence of many different sorts of polarities in the field of translation theory - 
shown in Table 5 - is itself an indication that different people choose to describe things in different ways, and that things can in fact be described in different ways.

Toury (1995:10) presents a map of translation studies, based on the outline of Holmes (2004). There is an initial division between pure and applied translation studies; pure translation studies is then divided into the theoretical and the descriptive (DTS); DTS is further divided into three approaches: product-oriented approaches; process-oriented approaches; function-oriented approaches. Toury's map is a surveyable representation of the outline offered by Holmes and shows that translation theory is itself a cluster concept, because there are many different types of theory found in the field, ranging from the descriptive (Toury, 1995) to the mystical (Benjamin, 2004).

Any attempt to describe translation from a Wittgensteinian point of view will investigate the language-games played by ST and TT as well as the "particular historical and cultural context of any translator, any translation event, and any translation movement' (Tymoczko 2007:41), i.e. the form of life that produces the artefact. I again use the translation of Homer's Iliad by Pope (1931) as an example, as in 2.3. Unlike the ST, which is written in unrhymed dactylic hexameter, Pope uses rhyming couplets in iambic pentameter. My last sentence is a description, not an explanation. This description can be extended by showing how the iambic pentameter was the dominant verse form of the eighteenth century, when Pope was writing. At this point we do have a partial explanation of what Pope was doing, for it is an error to assume that explanation and description are exclusive terms. Any description will contribute to our understanding. If I describe how a man fell from a window, for example, this may explain his broken leg, though there may be other causes, such as that he was pushed by his boss, who was angry with him etc. Wittgenstein places the phenomenon first and I do not think it is possible to ban explanation in the way an initial reading of PI 114 may suggest. Rather the insistence is on how we talk about things - the grammatical aspect, not the empirical as such - and on placing phenomena in context. Wittgenstein's own work contains explanation: the story of the shopping trip in PI 1, for example, is elucidated. To return to Pope, there can be no question of a total explanation of why Pope wrote as he did, because style is a result of choice, 'the perceived manner of expression' as Katie Wales defines it (2001:371), and so for a total explanation we should need a total explanation of Pope's mind. It is in this way that explanations 'come to an end 
somewhere' (PI 1), as we turn to look at how we use words, expressions and texts. The concept of a total explanation remains illusory (Keil \& Wilson, 2000). The more descriptions we can offer, however, the fuller our picture of any phenomenon may become and the more we may understand it, which is why Bertolt Brecht maintains that a person with only one theory is lost and that we should stuff many theories 'in our pockets like newspapers' (Makaryk, 1993:vii).

The stress on description, rather than the putting forward of a doctrine, is typical of many of the classical texts of translation studies. As Barnstone (1993:61) asserts: 'Before the second decade of our century translation theory, despite the name, was not so much theory as a history of the practice of translation'. The texts anthologised by Robinson (1977) illustrate this. His collection of pre-twentiethcentury texts from ninety authors is not theoretical in the way that, say, the writings of Benjamin (2004) are theoretical. Many of the texts are by practising translators who comment on their work or the work of others and justify strategies, as shown in Table 6, where I give five examples from Robinson (1997). The first four examples are of practising translators. The final example, Nietzsche, is of a philosopher examining the phenomenon of translation.

\section{TABLE 6: PRE-TWENTIETH-CENTURY TRANSLATION THEORY}

\begin{tabular}{|l|l|}
\hline AUTHOR, TEXT, YEAR & DESCRIPTION \\
\hline $\begin{array}{l}\text { Jerome (23-30), 'Letter to } \\
\text { Pammachius', 395 }\end{array}$ & $\begin{array}{l}\text { A justification of sense-for-sense as opposed to word-for- } \\
\text { word translation. Jerome refers to the practice of the Gospel } \\
\text { writers. }\end{array}$ \\
\hline $\begin{array}{l}\text { Luther (84-89), from } \\
\text { Circular Letter on } \\
\text { Translation, 1530 }\end{array}$ & $\begin{array}{l}\text { A justification of the sense-for-sense approach of his recent } \\
\text { translation of the NT into German. Luther aims to write } \\
\text { German as spoken in his place and time. }\end{array}$ \\
\hline $\begin{array}{l}\text { Dryden (172-174), from } \\
\text { 'Preface to Ovid's Epistles', } \\
\text { 1680 }\end{array}$ & $\begin{array}{l}\text { A meditation on three possibilities available to the literary } \\
\text { translator: 'metaphrase' (literal rendering); 'imitation' (free } \\
\text { rendering); 'paraphrase' (middle way). }\end{array}$ \\
\hline $\begin{array}{l}\text { Pope (193-195), 'Preface to } \\
\text { the Iliad', 1715 }\end{array}$ & $\begin{array}{l}\text { A description of his aim, when translating Homer, of } \\
\text { preserving 'that spirit and style which makes [Homer's] chief } \\
\text { character' (1997:195). }\end{array}$ \\
\hline $\begin{array}{l}\text { Nietzsche (262), from The } \\
\text { Gay Science, 1882 }\end{array}$ & $\begin{array}{l}\text { A description of the translation of Greek texts by Roman } \\
\text { writers as a form of conquest. }\end{array}$ \\
\hline
\end{tabular}


The authors' statements describe what is done in particular cases. Dryden, for example, puts forward possibilities of practice, rather than stating laws. It is analogous to putting forward possibilities open to somebody who wishes to go on holiday. Wittgenstein's own stress on practice supports the value of such an approach.

The descriptive tradition continues in the paratextual material often found accompanying the TT. The translation of Theodor Fontane's German novel Effi Briest by Hugh Rorrison and Helen Chambers, for example, includes a Translators' Note (2000:xxi-xxii), in which a number of points are made about their practice. In Table 7 , I describe the main points paragraph by paragraph.

\section{TABLE 7: TRANSLATORS' NOTE TO EFFI BRIEST}

\begin{tabular}{|c|c|}
\hline PARAGRAPH & FUNCTION \\
\hline 1 (2000:xxi) & $\begin{array}{l}\text { Justification of the need for a new translation and setting out of the overall } \\
\text { strategy: to retain the effect of the ST without anachronism. }\end{array}$ \\
\hline 2 (2000: xxi) & $\begin{array}{l}\text { Description of the translation of style: to retain 'echoes and patterns', } \\
\text { whilst producing a version with 'a rhythmical flow and dynamic of its } \\
\text { own'. }\end{array}$ \\
\hline 3 (2000: xxi) & $\begin{array}{l}\text { Description of the translation of forms of address: some left in German, } \\
\text { others translated by terms from Fontane's English contemporary, Oscar } \\
\text { Wilde. }\end{array}$ \\
\hline 4 (2000: xxii) & Description of how the translation aims to be both readable and reliable. \\
\hline 5 (2000: xxii) & $\begin{array}{l}\text { Description of how translating Fontane has given the translators new } \\
\text { insights into his work. The hope is expressed that the TT may bring new } \\
\text { English-speaking readers to Fontane. }\end{array}$ \\
\hline
\end{tabular}

In each paragraph, a problem is identified and a solution described in an approach reminiscent of that of the texts in Robinson (1997).

Central to DTS is the case study. Toury (1995:113 ff.) offers an 'assortment of case studies' from Hebrew translation to illustrate a variety of genres and translation approaches: renderings of Shakespeare's sonnets; indirect translation; mediation in translation; literary translation; interim solutions; translations of Shakespeare's Hamlet; translation of lexis; experimental translation; bilingualism and translation. Such stress on examples is a Wittgensteinian approach. The $P I$ is 
memorable for the stories Wittgenstein uses to illustrate his philosophy: the shopping trip (PI 1); the labourers (PI 2 ff.); the beetle in the box (PI 293) etc. In a 1935 letter to Wittgenstein, C.L. Stevenson comments: 'I have learned over again what you often said, and practised in your classes - that clarity is almost all a matter of giving examples' (McGuinness 2008:182). The use of a spectrum of cases avoids blackand-white thinking. The case study can be used to train translators, e.g. the MA in Literary Translation at UEA (2010:np) introduces students to a variety of case studies and asks them to write one.

In his study of Hebrew translation of Shakespeare's sonnets (1995:114-128), Toury surveys work done between 1916 and 1993 in order to describe the evolution of translators' attitudes. His strategy is to present the salient features of the translation under discussion. Historical facts are given, such as the author of a rendering and the circumstances in which it was written, followed by a presentation of those features of the translation that can be identified as 'conspicuous characteristics' (1995:123), a phrase paralleling Wittgenstein's 'surveyable representation'. For example, in discussing a 1929 translation by Avraham Shlonsky (1995:123-124), Toury first describes how it appeared and then discusses four stylistic features: form; title; rhyme scheme; language. The description focuses on the sonnet as translation, rather than as literature in its own right. Toury shows how Shlonsky's work is a modernist rendering of Shakespeare: it does not set the poem out formally as a sonnet, for example. His description shows 'another possible point of departure for translating Shakespeare's sonnets into Hebrew' (1995:124).

To produce a description of a literary work is not straightforward, as discussed in Chapter 2. As Attridge (2004:156) asserts: 'To engage in the process of "accurate description" is to make decisions about which of the myriad features of the work merit description - the use of archaic words? the use of polysyllabic words? the use of five letter words? the typeface? the colour of the ink? The list is potentially endless, and the choices made in any description will reflect a prior theory of what is relevant to an explanation of the work's meaningfulness and power.' One answer to the problem is to look at the context in which a description is made. The literary critic writing about the characterisation in a work may choose not to refer to the typeface. The scholar in book studies assessing the impact of a first edition on the reading public may choose to describe it in detail. Similarly, the description relevant in translation studies is that made by the translation theorist, whose primary 
responsibility is to describe the text as translated. My case study of NT translation in 4.5.2 is such a description.

Translated texts are often described without being seen as translations, for example, in book reviews. Lasdun (2009), writing on the The Kindly Ones, fails to mention that it is a translation of Jonathan Littell's French novel Les Bienveillantes (2006) by Charlotte Mandell (2009). His review is an exercise in literary criticism, dealing with Mandell's translation as if it were a non-translated work in English. Within DTS, by contrast, the description can only be a surveyable representation if it describes the TT as translation. As Chesterman (1997:62) comments: 'The minimum requirement is simply that a text is claimed to be a translation, and that it is accepted (by the client and/or the readers) as a translation in the target culture ... the boundaries of the concept "translation" are not set by something intrinsic to the concept itself, but by the ways in which members of a culture use the concept'. To describe things in reference to other criteria is Wittgensteinian in its anti-essentialism (cf. PI 190). The way Chesterman references Wittgenstein frequently in the book from which this quotation is taken gives a rationale for his theorising on translation. As I have argued throughout this thesis, the possibility of using Wittgenstein for support in this way is the main justification for researching his relevance to translation.

Many texts in translation studies aim to do much more than to describe. Toury (1995:259 ff.), for example, moves on from description to his theory of norms, the 'laws of translational behaviour' he discerns operating in his case studies, such as the 'law of growing standardisation' (1995:265), which states that textual relations in the ST are often ignored in translation, in favour of target culture relations. Whether this is a law, however, seems to me debatable. It is certainly not a law in the sense that scientists speak of laws. Textual relations in the ST are often modified, according to Toury: if this were a law, they would always be modified. To speak of laws is to attempt to give an explanation when what is at stake is interpretation. Toury's laws are not laws in the sense of hardcore theory (Iser, 2006:5), because they have no predictive power. If I buy a new translation of Faust, I cannot use the law of growing standardisation to predict that the translation will modify ST textual relations. It is an error to force the study of literary translation into scientific patterns. What is worthwhile is to describe literary translation and then to interpret the description, because this approach may have an influence on practice. 
Soft theories do not predict, but they indicate how things are done and they form a way in which practitioners can reflect on what they do, thus changing, confirming or refining the way they translate.

Twentieth-century translation theory is often seen as moving away from practice into obscure realms of no help to the practising translator. Benjamin's essay 'The Task of the Translator' (2004), for example, was written as the introduction to his own translation into German of the French of Baudelaire's Tableaux parisiens, but does not reference the ST. Barnstone (1993:4) comments that the essay is 'a little world made cunningly of theory, literary translation and language' and that the German translations of Baudelaire 'do not seem to be written by the same man who discusses theory and method in the prefatory essay': there is 'an absolute split between theory and practice' (1993:61). The perception of this split perhaps explains why many practising translators are wary of theory. In dialogue with Chesterman (Chesterman and Wagner 2002:1 ff.), Wagner comments that most translators encounter theory as students and later forget it as they get to grip with practical work; she sees a gap between theory and practice greater than in other professions. For her, theory is useless because it fails to offer concrete advice, guidelines and doctrines. Chesterman's response is to express sympathy with her complaint but to state that she has misunderstood the theoretical project. He makes an analogy with literary criticism, which is not expected to be used as a tool to produce creative writers, and claims that her desire for prescriptive theory misses the point, because to prescribe would be to ignore practice. Translation theory is primarily a descriptive project in which, as Pym points out, 'scholars have set out to describe what translations are, rather than just prescribe how they should be' (2010:65). In 3.1, for example, I argued that Berman (2004), whilst correctly diagnosing certain problems that have dogged literary translation throughout its history, is wrong to move on to prescribe ways of translating, because this is to ignore the context of any translation. The strategy he advocates, 'literalism in translation' (Berman, 2004:287), may only be suitable for certain contexts or certain functions. The descriptive project is a reaction against the prescriptive approach and against theory divorced from practice, and it represents a turn in translation studies, described by Tymoczko (2007:16) as a move away from a positivist, quasi-scientific position.

Wittgenstein's refusal to advance any kind of theory (PI 109) should be seen in the context of his own work and not taken as a ban on theory in other areas, 
including translation studies. Using Wittgenstein ought not to be a case of appealing to a philosophical police officer. In PI 123, he remarks: 'A philosophical problem has the form: "I don't know my way about". My contention is that his work provides tools for the translation theorist, who is enabled to find his or her way about by describing the TT, adopting a theory in the sense of taking a view of a text, not in the sense of forming a doctrine of what translation is. The project of theorising the TT after Wittgenstein would be anti-essentialist and anti-prescriptive. It would work through examples and case studies. It would aim at giving a surveyable representation of the TT as translated rather than as a work in its own right, which would be the task of literary studies. It would provide tools for analysing existing translation theories. It would enable the theorist to relate the TT to the form of life of the ST and of the translator. And it would be 'bottom-up analysis' (beginning with the text) rather than 'top-down analysis' (beginning with a theory), following Pym (2010:66). Refusing to advance theory is an insistence that the phenomenon precedes any intellectualising of it, and that looking precedes thinking.

The phenomenon of literary translation itself can also be described, as well as individual texts. As Toury (1995:168) asserts, the term 'literary translation' is subject to 'systematic ambiguity', because it may refer to two different things: firstly, 'the translation of texts regarded as literary in the source culture'; secondly, 'the translation of a text (in principle, at least, any text, of any type whatever) in such a way that the product be acceptable as literary to the recipient culture'. Sophocles is translated out of Greek because of his recognised dramatic and poetic genius, which is an example of the first phenomenon. The translations of Sophocles by Hölderlin (1952) are highly regarded because of the poetic genius of Hölderlin, not of Sophocles, and have even been translated into English (Constantine, 2001), which is an example of the second phenomenon. And both phenomena are clusters, a conclusion reached through description, not a priori theorisation. In addition, the practice of translation can be literary even when non-literary works such as advertisements are being translated (Boase-Beier, 2011:21), as discussed in 3.1.

Theorising the TT begins with describing it as translation, which then allows work on that description. DTS, associated with the work of Toury, is an example of this approach, but the descriptive paradigm is wider; as Pym (2010:64) stresses, it has roots in texts from the history of translation studies and is now the dominant model of theorising about translation. Profundity can be attained by describing the 
surface. Other paradigms of translation theory, such as polysystem theory or skopos theory, are similarly descriptive paradigms. The project of the humanities is itself descriptive (Winch, 2008), so that it is to be expected that theorists working within the humanities should have produced descriptive theories.

As Boase-Beier (1998:33) asserts: 'we still do not know how translation works. On the other hand, anyone who can speak more than one language - and that applies to the vast majority of people in the world - can, and does translate'. To explain translation, it would be necessary to know a great deal more about the mind than is currently the case. It would be a project in cognitive science. ${ }^{46}$ Wittgenstein's insistence in PI 1 that explanations come to an end avoids infinite regression as every explanation demands another explanation. A hardcore theory involves description, interpretation, explanation and prediction. A soft theory involves description, partial explanation and interpretation. How could translation ever be explained? How could translation ever be predicted?

Can description lead to the evaluation of the TT or of theories that have been produced to describe the TT? In 3.1, I referred to the use by Chesterman and Wagner (2002:5) of Hughes' translation of Aeschylus from Greek to English (1999) as an example of literary translation, and the translation into English of the label on a packet of white powder in a Greek supermarket as an example of non-literary translation. By referring to these as the top and bottom ends of the market respectively, Chesterman and Wagner include value as part of the distinction, as Hermans (2007:77) notes. Value is customarily an element of how we describe something. It would be an odd description of a car that did not say whether it was a good car or not. It would similarly be odd for somebody to describe a work of art and not say whether they liked it or not, although it is not inconsistent to recognise that Klee, say, is a painter of genius while not being attracted to his work. Wittgenstein is anti-essentialist but not anti-evaluative, as can be seen from reading his life or his letters. He was fulsome in his praise of musicians, for example, referring to Wolfgang Amadeus Mozart and Beethoven as the 'true sons of God' (Monk 1990:13). In 4.3, I turn to the project of the evaluation of texts, proceeding to the evaluation of theories in 4.4 .

${ }^{46}$ Whether or not such a project could be successful is beyond the remit of this thesis. 


\subsection{Translated to our satisfaction}

The evaluation of translation can help the practice of translation, because to establish criteria about what makes a good translation (if there is any such thing) can help the translator who is trying to do this. It is of benefit to know what you are aiming for. What sort of issues arise when we evaluate translation? Can translation in fact be evaluated? My contention is that the work of Wittgenstein offers ways of representing translation that in turn facilitate evaluation and hence illuminate and influence practice, because to have a notion of what makes a good translation will make a translator choose strategies towards that end.

In 1945, Wittgenstein wrote to Malcolm: 'My landlord has a modern American translation of the Bible. I dislike the translation of the NT (by a man E.J. Goodspeed) but the translation of the $\mathrm{OT}^{47}$ (by a group of people) makes a lot clearer to me and seems to be well worth reading' (McGuinness, 2008:385). The latter is the sort of effect most translators hope their work will have: that readers will find it well worth reading. It is significant that Wittgenstein was drawn to the translation because it made things clearer for him. He saw it as a surveyable representation, something that he recognised as a translation and that made clearer to him (because he could not read Hebrew) aspects of the network of Bible translation, presumably by his crossreferencing it to other translations he had read. By contrast, the Icelandic novelist Halldór Laxness made the following complaint in a letter written to Johannes Lindberg in the same year: 'I had the misfortune of being introduced in Sweden ... by a rotten translation from the Danish of my novel Salka Valka' (Ringmar, 2009:262). This condemnation is stronger than Wittgenstein's expression of dislike for the NT translation, because Laxness expresses a judgement that there is something qualitatively wrong with the translation of his work.

The examples from the letters of Wittgenstein and Laxness make clear that the evaluation of translation is itself a practice that can be related to the Wittgensteinian notion of the form of life. How we evaluate is based on: other works we have read; evaluations made by other people; literary norms etc. As Wittgenstein remarks in RFM III-85, quoted as (116), people want to know that the translation they read is in some sense reliable.

${ }^{47}$ Old Testament. 
(Who says that this English poem can be translated into German to our satisfaction?!)

There are two issues here, of authority and of judgement. I begin with the question of judgement. If a literary translation is a surveyable representation, as argued in Chapter 3, then the surveyable representation itself must be seen as such, that is, it must be shown.

For something to be a surveyable representation depends on the context. Wittgenstein's exemplar, the colour octahedron ( $P R$ 51-52), can be categorised as a surveyable representation because it can be related to something we know from everyday life, i.e. colours, of which it is one possible scheme. Wittgenstein categorises it as a grammatical representation (PR1). In translation, the form of life of the TT may surveyably represent the ST. Catullus, for example, wrote a poem in homage to the Greek poet Sappho (Jay \& Lewis, 1996:30). His lyric signals itself as translation both through the use of the same Sapphic verse form and through the lyric being addressed to Lesbia. (There is no named addressee in the ST, but Sappho came from Lesbos.) The community in which Catullus's poem was circulated was aware of the poetry of Sappho and would have recognised the homage (Wheeler, 1934:112). Contemporary translations often signal themselves through the use of paratextual material, such as: the name of the translator; a translator's introduction; translator's notes. The translation of Fontane by Rorrison and Chambers (2000), discussed in 4.2, has all three. Wittgenstein (McGuinness 2008:385) was aware that he was reading a translation of the Bible (which is not always the case with Bible readers, as will be discussed in 4.5) and paratextual material can make the position clear to readers. Many introductions by translators, however, fail to show the strategies of translation used. Rorrison and Chambers (2000:xxi-xxii) give only one German example (of the translation of a title) in their translators' note, so that the reader is not shown how their translational strategies on rendering style, for example, are worked out in practice. By contrast, Joyce Crick's note on her translation of Kafka gives a detailed discussion with examples of how she has approached the problem of translating Kafka's complex style (2009). 
Venuti (2008) identifies resistance to translation as endemic in the Anglophone literary field, where many TTs are effectively disguised as original work, both in how they are written and how they are presented. The story told in the $P I$ is one that can break down this resistance. By undermining the dualist view of the self, Wittgenstein militates against an atomised view of the individual living in his or her monolingual world. It is significant that Wittgenstein came from a multi-lingual Vienna and served in a multi-lingual army in the First World War (Eagleton, 2008). Many people in the world live at some sort of linguistic interface, for example, India, Luxembourg or Quebec, and most people speak more than one language (BoaseBeier, 1998:33). The typical linguistic situation is dynamic and not static. The organisation of translation in Anglophone cultures may be based on an incorrect, atomised mind-set. Wittgenstein insists that justification consists in appealing to something independent, which is why there is no point buying several copies of the morning paper to check that what it says is true (PI 265). He shows that people constitute each other linguistically and that language forms a human practice. His view in turn has implications for how the presentation of translation can be organised. The view we take of language therefore influences practice.

At the very least, a reading of the later Wittgenstein supports the bilingual edition as opposed to the monolingual, as discussed in 3.3 , so that the reader may compare ST and TT, as in the Visible Poets series from Arc Publications (e.g. Stone, 2005). The Wittgensteinian view pushes further to support more ambitious presentations, such as that by David Luke (1997:105) of Mörike's poem 'Das verlassene Mägdlein' ('The Abandoned Maid'), which offers ST, Luke's English translation and a Scots translation by Gilbert McKay. The whole is a surveyable representation that shows, through its layout, two of the many ways of translation that are available. As Bell (2000:972) comments, it provides 'an interesting and valuable insight into the comparative opportunities for translation offered by different but related idioms and vocabularies'. Influenced by Luke, I offer a similar surveyable representation on page 184 of the poem by Mörike discussed in the case study in 2.5, 'Ein Stündlein wohl vor Tag'. My representation, text (117), combines: ST (top left); gloss (bottom left); poetic translation (top right); relocation (bottom right). ${ }^{48}$

${ }^{48}$ The gloss was given earlier as text (54); the poetic translation as text (94). 


\section{EIN STÜNDLEIN WOHL VOR TAG}

Derweil ich schlafend lag,

Ein Stündlein wohl vor Tag,

Sang vor dem Fenster auf dem Baum

Ein Schwälblein mir, ich hört' es kaum,

Ein Stündlein wohl vor Tag.

'Hör an, was ich dir sag!

Dein Schätzlein ich verklag:

Derweil ich dieses Singen tu,

Herzt er ein Lieb in guter Ruh,

Ein Stündlein wohl vor Tag.'

Oh weh, nichts weiter sag!

O still, nichts hören mag!

Flieg ab, flieg ab von meinem Baum,

Ach Lieb und Treu ist wie ein Traum

Ein Stündlein wohl vor Tag.

\section{EIN STÜNDLEIN WOHL VOR TAG \\ a small-hour well beforeday}

Derweil ich schlafend lag,

while I sleeping lay

Ein Stündlein wohl vor Tag,

a small-hour well before day

Sang vor dem Fenster auf dem Baum

sang before the window on the tree

Ein Schwälblein mir, ich hört' es kaum,

a small-swallow to-me I heard it hardly

Ein Stündlein wohl vor Tag.

a small-hour well before day

'Hör an, was ich dir sag!

hear on what I to-you say

Dein Schätzlein ich verklag:

your small-treasure I accuse

Derweil ich dieses Singen tu,

while $I$ this singing do

Herzt er ein Lieb in guter Ruh',

cuddles he a love in good peace

Ein Stündlein wohl vor Tag.'

a small-hour well before day

Oh weh, nichts weiter sag!

oh alas nothing further say

O still, nichts hören mag!

$o$ quiet nothing to-hear desire

Flieg $a b$, flieg ab von meinem Baum

fly awayfly awayfrom my tree

- Ach Lieb' und Treu' ist wie ein Traum

ah love and loyalty is like a dream

Ein Stündlein wohl vor Tag.

a small-hour well before day

\section{AN HOUR BEFORE THE DAY}

In deepest sleep I lay,

an hour before the day:

and, as I slept, from the nearby tree

a swallow sang a song to me,

an hour before the day.

'Now listen to what I say!

Your love has gone astray.

And while I sing, as swallows do, he holds a girl who is not you,

an hour before the day.'

Oh no, what's that you say?

My swallow, go away!

Before your singing from the tree

I'd dreamed of love and loyalty, an hour before the day.

\section{AN HOUR BEFORE I LEFT FOR WORK}

I was listening to Britney Spears,

a singer I really can't stand,

just too tired to drag myself from bed

to turn the fucking radio off

an hour before I left for work.

'Hey,' she sang in a voice so fucking dreary,

are you really so sure of your man?

He said he was ill? Well, he's in bed with a girl from his firm. The truth is rough,

an hour before you leave for work.'

And a day can start in tears.

They ought to have a fucking ban on Britney Spears. I stayed in bed with a glut of Friends and a packet of stuff

for an hour before leaving for work. 
Such a representation seems to me to be a successful way of presenting literary translations of poems, because the reader is enabled to see what is going on in the ST - by being presented with the ST and a means of accessing it through the gloss - and is given two renderings of it in translation.

A similar representation on a larger scale is by Peter Jay and Caroline Lewis

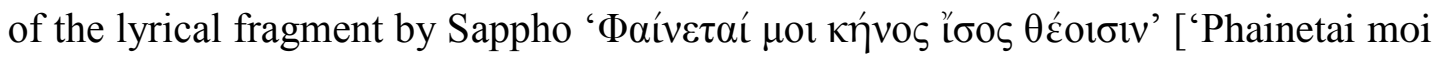
kênos isos theoisin'] ('That man seems to me to be level to the gods') (1996:28 ff.). They include: the ST; the transliterated glossed ST; a selection of translations of the lyric, including Catullus (referred to above). The internet also raises numerous possibilities for the surveyable representation of texts. The website Classic

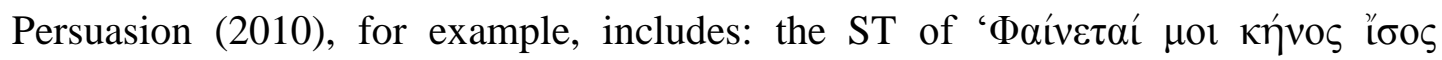
$\theta$ Éoıøıv'; a plain prose translation; renderings by different translators; links to other sites of interest on Sappho. The internet has a number of advantages over a book: it can be updated, as new translations are written; it can be linked to other sites; there are no constraints on space; it is interactive, so that readers can contribute their own translations or translations they have discovered. Translation after Wittgenstein may come to flourish online, with the internet as a space for multiple translations.

With respect to the printed word, however, practical considerations bring limitations for bilingual editions. Even though many publications of translated poetry are available in bilingual editions, as well as some prose works where the reader may want to check the ST (such as the English editions of Wittgenstein), it is unrealistic to expect publishers of prose works to bring out bilingual editions, due to considerations of cost and bulk. One possibility is to include at least some of the ST alongside the TT, which is the approach of Joseph Wright (1917:200ff) in his Grammar of the Gothic Language, who appends excerpts of the fourth-century translation of the NT into Gothic by Wulfila ${ }^{49}$, together with some pages of the HG $\mathrm{ST}$, in what is a surveyable representation. The interested reader can easily obtain the NT in HG to match those Gothic sections with no facing ST. Another solution is to link printed translations with online material, to enable translators to write at greater length about their work, which might not be possible in printed notes due to lack of space. The Italian website La nota del traduttore (The Note of the Translator) (2011), for example, offers such an opportunity.

\footnotetext{
${ }^{49}$ Wulfila (Gothic) is sometimes referred to as Ulfilas (Latin).
} 
In terms of organisation, the surveyable representation could also influence how books are marketed. The design of TT and bibliography can fight against the invisibility of the translator, just as the colour octahedron can make people see the grammar of the spectrum in one particular way, other views being possible. In my translation of Wuilmart (Wilson, 2009:40), I used a translator's note to reference: Wuilmart's anonymous ST; Wuilmart's French TT; the English TT by Philip Boehm. The bibliography to this thesis credits all translators where possible. ${ }^{50}$ The practice of reviewing, similarly, can reference the translator. In 4.2, I referred to a review by Lasdun (2009), in which he never mentions that the novel under review is a translation (by Mandell of Littell). By contrast, Anthony Beevor (2009), in his review of the same work, comments that it is a translation and discusses Mandel's translation of style, even if at an uninformed level: 'This Anglo-American translation, which is certainly faithful, cannot quite capture the stunning use of language in the French original, in which harsh-sounding German ranks and technical terms strike the ear like the crack of a whip'. The ideal, to which Beevor's review is at least a step, would be the review that acknowledges a work as translated and goes on to discuss it in an informed way.

There are therefore ways of presenting translation so as to facilitate evaluation. The existence of a surveyable representation may show that the TT is designed to function as a literary text, but does not in itself make the TT literary. There is an analogy here with the contrast between surface and deep grammar discussed in Chapter 2. It is fitting to organise the surface grammar of the TT so as to alert the reader that what is aimed for is the deep grammar of literary translation. But the deep grammar will only be literary if two conditions are fulfilled: that the TT produces literary effects on the reader and that these effects result from a TT that is a surveyable representation of the ST. Twm Morys (Minhinnick, 2003:xi) comments that whenever he has seen translations of his cynhanedd, the formal Welsh verse he writes, he has 'only dimly recognised them, like friends who've been in some terrible accident'. In Wittgensteinian terms, a translation that fails to play the same language-games as the ST will not be a literary translation, no matter how much paratextual material accompanies it offline or online, or no matter how skilfully written it is. Literary translation, as discussed in 3.1 with respect to the claims of

\footnotetext{
${ }^{50}$ See note on referencing, page 9.
} 
Berman (2004), can fail, a situation captured by Wittgenstein's image in PI 430: 'It is as if we had imagined that the essential thing about a living human being was the outward form. Then we made a lump of wood into that form and were abashed to see the lifeless block, lacking any similarity to a living creature'.

That such wooden blocks exist in translation is often asserted (Berman, 2004), which leads some to advocate against the very practice of literary translation. Morys (Minhinnick 2003:xi) vetoes any translation of his verse, while Scott (2008:16) argues that literary translation 'designs a text to be read by someone in no position to judge either its reliability or its quality', so that it aligns itself 'with the arts of forgery, a logic borne out by the lure of pseudo-translations'. The aptness of the term 'forgery' is disputable, because the translator of a novel does not set out with the intention of deceiving his or her readers in the way that a forger of, say, a Klee painting hopes to deceive a prospective purchaser. Translations do usually advertise themselves as such in some way. ${ }^{51}$ Scott's point addresses the fact that the TT has a different author from the ST, a fact that often goes unremarked in everyday life. When Chris buys the Penguin Classics translation of Jacques le fataliste, he may believe he is about to read a literary work by the great eighteenth-century philosopher Diderot; in fact he will read a work by Henry (1986). If a poem cannot be decoded, as argued in Chapter 2, it seems to follow that a poem cannot be translated, either. Literary translators may as well give up. The logical conclusion of Scott's position is that Chris needs to learn French if he wants to read Diderot. Untranslatability becomes an integral aspect of the literary text.

Scott's position seems reasonable because surveying the relationship between ST and TT is only possible for somebody who can read both. (Outside academia such a person might moreover be unlikely to be reading both.) Louis Sass (1994:28) notes, for example, how Daniel Paul Schreber's memoirs of his mental illness have a 'tentative, non-literal quality' more apparent in the German ST (Schreber, 2003) than in the English TT (MacAlpine \& Hunter, 2000), where the translators omit 'many frequently used phrases and particles that would have been translated in English as "in part", "on the other hand", "so to speak", "up to a point" and "in a way". Their strategy has the effect of making Schreber seem less aware that he is mentally ill in the TT than in the ST, and hence deforms a significant account of mental illness; it

\footnotetext{
${ }^{51}$ Of over 70 translations used for this thesis, for example, only one did not indicate a translator: Marx \& Engels (1970). This is shown in the Bibliography.
} 
shows the typical Platonising transference of meaning and consequent failure to render style that was discussed in 3.1. Sass accordingly questions the value of the $\mathrm{TT}$, arguing that to ignore phrases and particles is a reasonable strategy if the only concern is with the content of Schreber's delusional world, but that it is unsatisfactory if one wishes to grasp the form of that world. Having read Schreber in English and German, I agree with Sass, but am only in a position to do so because I can read the ST. If Scott's implicit stipulation is accepted that every reader must be in a position to judge every ST, then the practice of literary translation is questionable, hence the analogy with pseudo-translation. The eighteenth-century poems by James Macpherson (2003), for example, were believed by most contemporary readers to be translations from an earlier Gaelic ST by the poet Ossian, yet are now known to be forgeries, Ossian never having existed: hence their status as pseudo-translations (Bate, 2011:45). Only scholarly work was able to establish whether Macpherson's texts bore relation to any ST or not. The poetry is by no means without literary merit: Fiona Stafford (2003:vii) refers to its 'extraordinary power', for example. As a translation, however, it fails to be a surveyable representation because there is nothing to represent. When Matthew Arnold (1960:99) argues that Pope's translation of the Iliad is not Homer, despite its 'power and attractiveness', he is making a similar point, although there is no doubt that Pope (1931) worked from the ST.

The readers who evaluate translations, as Chesterman points out, are therefore 'not general ones, but a particular subset of them: scholars, critics and teachers', unrepresentative of 'the wider readership for whom a translation is intended' (Chesterman \& Wagner, 2002:83). Arnold asserts that 'all the poetic feeling in the world will not enable a man who is not a scholar to judge [the translator] truly' (1960:117). But does this matter, given the role translated texts play in our lives? Wittgenstein $(O C 471)$ comments that it is difficult to know where to start with an inquiry: "it is difficult to begin at the beginning. And not to try to go further back.' To speak of literary translation as forgery is to go back too far, to try to reach the land before Babel, before translation. As is stressed by Steiner (1998) in both the title and the text of After Babel, this is not possible. We live in a world where certain translations have been accepted as literary, where, to use Wittgenstein's notion of family resemblance, certain translations resemble others in a literary way. The discipline of translation studies produces experts whose 
pronouncements will change the field. Tymoczko (2007) aims at reformulating the way we look at translation so as to include non-western perspectives, for example. Such transformation can come about through description rather than through prescription. Wittgenstein stresses that philosophy leaves everything as it is (PI 124): but what is changed totally is the way the philosopher sees things. To leave everything as it is, is therefore to change everything (Monk 1990:533). A translation of the literary will fail to be a literary translation when it does not display literary features itself, i.e. when it has been translated as if it were a non-literary text (as discussed in 3.1), or when it fails to represent a text (as with Macpherson), despite displaying literary features. The reading of Wittgenstein is one means by which the translation theorist can be trained to make such judgements. It is again a question of work on oneself ( $C V$ p.24), as discussed in 3.3 with respect to the translator. To change the field will change the way translation is presented, criticised, written.

Wittgenstein (RFM III-85) asks who can say that the poem has been translated to our satisfaction. The answer is the translation theorist, a blurred term that can be extended to include the poet, the literary scholar, the academic, the critic, the ordinary reader. Where does authority come from? For Wittgenstein, as discussed in 3.3 with respect to the form of life of the literary translator, it comes from the form of life of the translation theorist, from the practice of the evaluation of literary translation: in this sense, anybody who has a view of a translation. The translation critic (for example, the reviewer) is rarely a translation theorist in the sense of being an academic teaching or researching translation studies. The field includes poets, literary scholars and academic specialists. In 4.2 and in this section, I have referred to reviews by Lasdun (2009) and Beevor (2009) of a translation by Mandel (2009): Lasdun is a professional poet and Beevor is a professional historian. The crucial point is that critics be informed readers, in the sense used by Fish (1996), which Lasdun does not seem to be. When the ordinary reader is in turn enabled to make judgements - for example, by being offered a bilingual edition - he or she is no longer an ordinary reader, which is the rationale for including paratextual material: to make informed readers. The field of translation is a complicated cluster: any rules are generated from forms of life - of texts, of translators, of theorists, of readers (cf. PI 202). To argue like this is to respond to Scott's criticism and, I think, to overcome it. 
By evaluating translation, we move beyond description. As Malmkjaer (2004) argues, the TT-oriented philosophy of DTS makes it difficult to justify evaluation theoretically, because any translation choice may have been the result of following a norm, however bizarre. Malmkjaer distinguishes between identifying patterns of manipulation and identifying errors, and appeals to the notion of semantic fields as a way of doing this (2004:142), just as Wittgenstein describes how the metrical system can only function when appeal is made to the standard metre in Paris (PI 50). We have to look outside the text to understand it. Appeal to semantic fields is one way of doing this, as is the appeal to language-games, and they are not exclusive.

In 4.4, I examine how translation theories can be evaluated from a Wittgensteinian point of view. Here I examine how one text can exemplify the evaluation of translation: the commentary by Weinberger (Weinberger \& Paz, 1987:2 ff.) on the translation of the poem 'Lù Zhái' ('Deer Grove') by Wang Wei. How this can be read as Wittgensteinian is represented in Table 8 .

TABLE 8: READING WEINBERGER AS WITTGENSTEINIAN

\begin{tabular}{|l|l|}
\hline WITTGENSTEINIAN FEATURE & EXAMPLE (Weinberger \& Paz, 1987) \\
\hline The stress is on practice. & $\begin{array}{l}12 \text { renderings of the ST are given with } \\
\text { descriptions (8-31). }\end{array}$ \\
\hline $\begin{array}{l}\text { There is a surveyable representation of the } \\
\text { ST. }\end{array}$ & $\begin{array}{l}\text { The ST is given in Chinese, transliteration } \\
\text { and gloss (2-7). }\end{array}$ \\
\hline There is close reading of the ST. & $\begin{array}{l}\text { An 'absolute humility towards the text' (17) } \\
\text { is demanded. }\end{array}$ \\
\hline Literary translation is not about transfer. & $\begin{array}{l}\text { Translation 'is more than a leap from } \\
\text { dictionary to dictionary; it is a reimagining } \\
\text { of the poem' (43). }\end{array}$ \\
\hline $\begin{array}{l}\text { Deforming tendencies in translation are } \\
\text { noted and condemned. }\end{array}$ & $\begin{array}{l}\text { It is shown how translators tend to feel they } \\
\text { must improve on the ST (9). }\end{array}$ \\
\hline There is evaluation of translation. & $\begin{array}{l}\text { Weinberger (29) comments on the } \\
\text { translation by G.W. Robinson (28) that it is } \\
\text { 'unhappily' widely available. (Robinson } \\
\text { introduces a group of people to the TT } \\
\text { where there is none in the ST, which } \\
\text { Weinberger sees as a deformation.) }\end{array}$ \\
\hline
\end{tabular}


Description of texts, description of translation practice and evaluation of texts are linked, criss-cross. The practice is Wittgensteinian without being Wittgenstein. Cook and Read (2010:482) similarly offer a reading of the poet Wallace Stevens 'as "a Wittgensteinian", because Stevens is "making, through his "strong-grammared" poetry, a set of moves that invite the reader to learn almost exactly the kinds of thing about themselves and about their tendencies to mire themselves in misunderstanding and delusion that Wittgenstein invites his reader to learn, through his therapeutic writing, his philosophy of delusion and its overcomings'. Here, I offer a reading of Weinberger as a Wittgensteinian, using Wittgenstein to confirm my intuitive positive reaction to Weinberger's work. My reading of Wittgenstein becomes a way of evaluating texts on translation and also a way in which my own views on translation can be formulated as the result of philosophical deliberation and not solely as the result of intuition, which recent research shows to be unreliable (Chabris \& Simons, 2011). Following Cook and Read, there is a crucial difference between reading an author as a Wittgensteinian and giving a Wittgensteinian reading of a text. The latter can be done of any text; the former only of certain texts.

The question of reliability, of whether one can trust the translated words on the page or whether a certain TT makes anything clearer, also raises the question of accuracy. In the 2009 AQA foundation reading test for GCSE French, for example, candidates were asked the question given as (119) about the text given as (118) (AQA, 2010). The text was not glossed for the candidates, who were not allowed a dictionary.

C'est au premier étage. it is at-the first floor.

On which floor is the flat?

No matter how imaginative the guesswork, no matter how poetic the candidate's answer, a candidate who does not know that au premier étage is French for 'on the first floor' is going to lose the mark (cf. Arnold, 1960:117). It was stressed in 
Chapter 3 that literary translation is not about transfer, but it is problematic to see how a literary translation can be produced at all where the translator has failed to understand the text. Barnstone (1993:118) discusses a Spanish translation of a poem by Dylan Thomas, in which the Argentine translator renders 'she bore angels' as 'ella aburrió a los angeles', which means 'she bored angels' and he concludes that this is not free interpretation of the English verb 'to bear' but a mistake, caused by ignorance of English. Again, as with the case of failed literary translation and pseudo-translation, such discoveries are the privilege of informed readers. Here, in contrast to my comments above on Sass, I am reliant on Barnstone as scholar, because I cannot read Spanish. Barnstone (1993:121) notes that translations will have howlers, just as typographical errors are found in printed books, but that this does not necessarily destroy the worth of a translation: 'Better a magnificent translation by a Borges or a Camus with a few mistakes than an "accurate", ponderous translation unredeemed by art' $(1993: 121){ }^{52}$ In his translation of Sophocles (1994:34), Hölderlin (1952:219), for example, translates the dative noun oí $\mu \alpha \sigma l v$ [oidmasin] ('swellings') as Häusern ('houses'), possibly mistaking it for a similar Greek word with this meaning, for example, oikalৎ [oikais]. This and many other howlers do not prevent the translation being highly regarded, even though (to use Malmkjaer's terms) we seem to be identifying error not manipulation. Berman (2004:276), for example, praises Hölderlin's work for the way in which it 'reveals the strangeness of the Greek tragic Word ${ }^{53}$, whereas most "classic" translations tend to accentuate it or cancel it'. In contrast, the translations of Thomas Mann by LowePorter show many misunderstandings of the SL that contribute to the overall failure to represent the texts creatively (Gledhill, 2007). It is a question of judgement.

Creative translations such as Hölderlin's can also be valued because they form part of a cluster and do not stand as the sole representation of the ST. The Loeb classical texts (e.g. Lloyd-Jones, 1994) place a Greek or Latin ST opposite a plain prose English translation. By contrast, Christopher Logue (2001) makes significant deviations in his translation of the Iliad: anachronistic referencing, such as helicopters (2001:230); quotation from English literature, such as from Shakespeare

\footnotetext{
52 Barnstone's comment is reminiscent of the adage of Edward FitzGerald (1980:335) about translation, that it is better to have 'a live Sparrow than a stuffed Eagle', which is itself another variation on the proverb considered in 3.4 .

${ }^{53}$ In the sense of the $\lambda$ ó $o$ s [logos], the creative word.
} 
(2001:23); a stress overall on Homer's depiction of warfare, playing down the redemptive aspects of the ST (Naffis-Sahely, 2011:59). We can, however, accept Logue within the field because there are other translations - Fagles (1990), for example - that render style and content without anachronism etc. The cluster is part of the context. The attack on Logue by André Naffis-Sahely (2011) is written as if Logue were the only English translation. As George Szirtes (forthcoming) notes, if no other translation is available, a translator has an obligation to produce 'a kind of inspired imitation', whereas with better known authors (such as, in this case, Homer) there is 'more scope' for free play.

By contrast, Mandell (2010:i) stresses that her translation of Littell (2006) is the 'sole English language version', which will presumably remain the case for some time because of copyright law. There are inevitably more English language renderings of older classics, for which copyright has run out, than of modern classics. However, even a relatively recent work such as the 1953 PI was republished in 2009 with a revised English translation in order to maintain the English edition as a surveyable representation. Hacker and Schulte (2009) describe how the new translation was necessary in order to: correct misprints; standardise terminology and punctuation; correct translation errors etc.

The notion of representation explains why Matthew Sweney (2010) takes issue with the translation of a collection by the Czech poet Vítězlav Nezval by Ewald Osers (2009), noting among other things: misprints; omitted dedications; unacknowledged abridgement; omission of ST poems. He concludes that the reader is being offered a 'botched job' due to poor editing, because there has been no comparison of input and output (2010:98). An anecdote about Wittgenstein comes to mind here. Fania Pascal (1984:28-29) recounts how Wittgenstein was disgusted with her for saying (after an operation) that she felt like a dog that had been run over, Wittgenstein commenting that she had no way of knowing what a dog that has been run over feels like. In a discussion of this incident, Harry Frankfurt suggests that Pascal's Wittgenstein is angry not because she is lying but because she offers a description of a state of affairs without submitting to the constraints imposed by the attempt to describe reality accurately: 'Her fault is not that she fails to get things right, but that she is not even trying' (2005:32). Similarly, the apparently unedited edition of Nezval is not even trying. 
Advocating a Wittgensteinian approach is not intended to turn the translation theorist into a literary inquisitor, finding and accusing bad translations. Tymoczko (2007), for example, uses her reading of Wittgenstein as a means of broadening the scope and possibilities of translation and of empowering translators. To demonstrate that non-literary translation of any ST is a possibility is potentially liberating, in the way that the Wittgensteinian therapy of the $P I$ is liberating, because the fact that things can be done badly is the concomitant of the fact that they can be done well. Sedivy (2004) uses her reading of the PI to argue that Patricia Rozema (1999) goes too far in her filming of Jane Austen's Mansfield Park by modifying aspects of that novel in order to make points about the slave trade, a view in line with general reception of the film (Walker, 2006:708). However, this does imply that a successful intersemiotic translation of the novel could be done.

Wittgenstein's comments on translation are not dogmatic. His remark (LWPP I 278) on the correct German translation of an English play on words being "maybe a completely different play on words' is qualified by the use of 'maybe', for example. There is no prescription. It is worth noting again his advice: 'Say what you please, so long as it does not prevent you from seeing how things are' (PI 79). Within constraints, within the views put forward in the PI of how language actually works, there is the freedom that comes from clarity. So where does this leave evaluation?

Chesterman (Chesterman \& Wagner, 1995:83-84) states that there are four basic approaches to the evaluation of translation quality in translation studies. I sum these up in Table 9, together with the support that could be offered to each from my reading of Wittgenstein.

TABLE 9: THE EVALUATION OF QUALITY IN TRANSLATION STUDIES

\begin{tabular}{|l|l|}
\hline APPROACH & WITTGENSTEINIAN SUPPORT \\
\hline Comparing the TT with the ST. & $\begin{array}{l}\text { The notion of the surveyable representation } \\
\text { is based on comparison, contextualisation } \\
\text { and family resemblance. }\end{array}$ \\
\hline Comparing the TT with parallel texts. & $\begin{array}{l}\text { The notion of the cluster concept recognises } \\
\text { there is no one definitive translation or way } \\
\text { of translating. }\end{array}$ \\
\hline $\begin{array}{l}\text { Measuring the reactions of general, typical } \\
\text { readers. }\end{array}$ & $\begin{array}{l}\text { The reader's form of life can be described. } \\
\text { The reader can become informed. }\end{array}$ \\
\hline
\end{tabular}


There is an analogy with the practice of law. Kerr (2008: 92-3) notes how law courts reach judgements that do not match the standards of proof and verification that are expected in science, such as in engineering, but that it does not follow that such judgements should be regarded as flawed. Similarly, the translation theorist approaching literary translation will use a variety of strategies in what is not a scientific procedure. Wittgenstein, as noted in Chapter 2, offers 'a phenomenology of the experience of reading literature' (Cook \& Read, 2010:473), which can be extended to a phenomenology of the experience of reading translated literature. By asking if a poem can be translated 'to our satisfaction', Wittgenstein (RFM III-85) implies that there is no objective criterion here, but rather criteria determined by our forms of life. The surveyable representation of Sappho by Jay and Lewis (1996), for example, shows that this is the case. Some literary translations have been done to our satisfaction, such as Hölderlin (1952), praised by Steiner (1998:340). Other works have the appearance of literary translations and yet fail to be such because there is no ST (pseudo-translations), such as Macpherson (2003). Others claim to be literary translations yet fail to be such, because they fail to work as literature: Benjamin (2004:75) asserts that ' $\ldots$ any translation which intends to perform a transmitting function cannot transmit anything but information - hence, something inessential' and that this is the 'hallmark of bad translations', like the targets identified by Berman (2004). Wittgenstein's work supports such judgements.

It also indicates a further move that can be made in evaluation. Robinson (2003) stresses that translation is about people, not least at the level of the project. The TT on sale in a bookshop is a collaborative product that has been commissioned, translated and edited. Translation scholars often write as if the translator alone is responsible for the decisions in the TT, some of which may have been taken at the editorial level, as anybody who has ever translated a text is aware. The recent translation of Clemens Meyer by Katy Derbyshire (2011:243) credits the whole team behind the book, including the editors, which is a move that Wittgenstein's work, which stresses how we constitute each other, would demand. 
Throughout this chapter I address primarily the translation theorist and show how a reading of Wittgenstein may place him or her in a better position to comment on why and how we evaluate translations and to evaluate translations in his or her turn. He or she will be able to decide whether a Bible translation is well worth reading or not (cf. Wittgenstein, McGuinness, 2008:385), and to investigate whether Laxness (Ringmar, 2009:262) was right to say that he had been represented in Swedish by a rotten translation. He or she will be able to describe why people make such comments. It is a question of clarity and one that in turn affects practice. 


\subsection{Grammatical investigations}

The grammatical investigation is fundamental to Wittgenstein's approach to philosophy (PI 90), a tool in his battle against what he sees as our bewitchment by language (PI 109), as discussed in 2.4, where it was shown how the method is used to show both the dichotomy between our idea of how we believe that a concept works and the way that it works in practice, as well as the many different ways in which a concept can be used (McGinn, 2008:14).

In this section, I look at how the grammatical investigation can make issues clearer in the field of translation studies. I begin with an example from Schroeder (2006:157) of how this Wittgensteinian tool can be applied. Schroeder postulates that the grammatical investigation is a philosophical and not a linguistic exercise (such as compiling a dictionary) and investigates a text from F.H. Bradley (1893:1920), in which the apparent paradox is advanced that sugar is white but is not identical with white, so that we can say, 'Sugar is white', but cannot say, 'White is in the bowl', whereas to say that 'Sugar is sugar' is uninformative. Bradley sees a dilemma here: 'If you predicate what is different, you ascribe to the subject what it is not; and if you predicate what is not different, you say nothing at all'. For Schroeder (2006:157), the paradox is easily dissolved 'by recognising that a word is used in two different ways'. There is a fundamental difference between the deep grammar of examples (120) and (121), despite the similarity of surface grammar.

George Orwell is Eric Blair.

Sugar is white.

In (120), we use the word 'is' to mean 'is the same as', because the novelist Eric Blair published under the pseudonym George Orwell. In (121), the verb ascribes only a property or a relation. As Wittgenstein puts it, philosophical problems disappear under correct analysis (PI 122). My intention in 4.4.1 is to investigate grammatically some common terms in translation studies, in order to see whether such an investigation can lead to any conclusions about how the terms are used. I then look in 4.4.2 at translation theories after Wittgenstein. 


\subsubsection{Investigating the supermemes}

I have chosen five terms from Chesterman (1997:7-14), referred to in 3.3, which he has identified as 'translation supermemes' because of the regularity with which they appear in translation studies, from the earliest writings to the present day, ideas 'of such pervasive influence that they come up again and again in the history of the subject, albeit in slightly different guises'. The term supermeme is adapted from the coinage 'meme' of Richard Dawkins (1976:5) to indicate a 'unit of cultural transmission'. The five translation supermemes identified by Chesterman are: source-target; equivalence; untranslatability; free-versus-literal; all-writing-istranslation. What follows is not intended to be a commentary on Chesterman. While I use some points he makes, I do so only when they represent a Wittgensteinian stance. The aim is to conduct a grammatical investigation of the terms.

\subsubsection{Source-target}

Chesterman defines source-target as 'the idea that the translation is directional, going from somewhere to somewhere' (1997:8). We see the twenty-firstcentury translation of Faust by Constantine (2005) as coming from the eighteenthcentury work by Goethe (1972), for example, so that the direction is from Goethe to Constantine, from the earlier text to the later, from ST to TT, which seems to be common sense, as it is difficult to refer to translation in any other way in ordinary usage. The meme may either indicate that source-target relationships resemble others or that people have tended to see a source-target relation as always present in translation.

However, the metaphor of direction implies that the ST moves, which is not the case. As Chesterman (1997:8) notes, a text does not vanish from the source culture when it appears in the target culture. The supermeme also fails to recognise that translation is a cluster concept. There are many English translations of Faust on the market, for example, and Goethe's Faust itself is part of a cluster. Gledhill (2007:111) describes the numerous portrayals of the Faust legend that exist in various genres, of which Goethe's work is one. The portrayals exist in a relationship of family resemblance, a relationship that is multidirectional. A child is often said to resemble a parent, for example, but a parent may be described as resembling a child. The supermeme 'source-target' has the effect of devaluing the translation by privileging the source. Toury (1995) counters this by his Wittgensteinian descriptive 
approach, because his analysis begins with the TT. Furthermore, it is possible to approach a text through its translation, something that second language learners frequently do, which reverses the direction of this supermeme. Parks (2007), for example, uses translations to show aspects of the style of literary works, in a translation approach to literature.

The source-target supermeme implies there is an essential relation between source and target, rather than one constructed for the sake of convenience. The relation is furthermore implicitly directional, because of the semantics of 'source' and 'target': something comes from a source and aims at a target. Grammatical investigation prevents the theorist being held captive by a picture and enables him or her to use a term with clarity. I am not suggesting that the terms source and target be abolished - unlike Barnstone (1993:228), who advocates replacing 'target' with the less belligerent 'receptor' - simply that we become aware that there are consequences in choosing to use them. A grammatical investigation, by taking in the meaning of the words used, can show us what these consequences are.

\subsubsection{Equivalence}

Chesterman defines equivalence as the expectation that 'a translation is, or must be, equivalent to the source, in some sense at least' (1997:9). This definition is circular, because it begs the question of what is meant by equivalence, which is a problematic term, as discussed in 3.3. In mathematics, for example, it makes sense to say that $(2+2)$ is equivalent to 4 , because the two expressions can be interchanged. In language, however, even a single word may have its own form of life, which means that an equivalent may not be found automatically. Raymond van den Broeck (1978:36) argues that if 'we take into account the fact that expressions in context not only have conceptual meanings but also convey connotative, stylistic, affective, reflected and collocative meanings, it will in fact be difficult to discover any pair of expressions in actual speech which are really equivalent'. The point applies within a language and, by extension, across languages, and is both Wittgensteinian and in line with contemporary linguistics (Malmkjaer, 2005:24). The same is true when viewing things at the level of whole works. It would be misleading to assert that, say, Constantine's Faust (2005) is the English equivalent of Goethe's Faust (1972), in virtue of being its translation, or that Christopher Marlowe's play Doctor Faustus (1986) is the English equivalent, in virtue of being an English dramatisation of the 
Faust legend. Constantine cannot be equivalent because, as Parks (2007:244) notes, even the best translation 'is a total transformation'. Marlowe cannot be equivalent because the two poets treat the legend in very different ways, Marlowe linking it to a Renaissance form of life and Goethe to an Enlightenment form of life.

Does this mean that the concept of equivalence should be banned from translation studies? Not necessarily, as long as care is taken with what is meant when using the term, following Wittgenstein's notion that meaning is use (PI 43). As Wittgenstein notes in PI 79, meaning is not fixed, as quoted in (122).

And this can be expressed as follows: I use the name ' $\mathrm{N}$ ' without a fixed meaning. (But that impairs its use as little as the use of a table is impaired by the fact that it stands on four legs instead of three and so sometimes wobbles.)

Chesterman (1997:9) uses Wittgenstein's family resemblance to see equivalence in terms of similarity, following Toury (1980:9). The two sentences 'Il pleut' (French, 'it rains') and 'It is raining' can be said to be similar, and therefore equivalent because they can often be used to the same purpose. There are important differences, however: the English is present continuous, a tense that does not exist in French; there are more syllables in the English etc. To speak of similarity does not rule out difference. If I say that Anna is similar to Chris, this makes sense, even if it is pointed out that Anna is female and Chris is male, because it can be presumed that I am referring to one particular aspect of their character or of their appearance. Constantine's Faust can be said to be similar to Goethe's, even though the former is written in English and the latter in German, whereas Marlowe's Dr Faustus is, I think, a very different work from Goethe's Faust, despite both being part of the cluster of creative work around the Faust legend. There are things that you will not say, as Wittgenstein notes (PI 79). Barnstone uses the notion of similarity within constraints as a description of the activity of translation: 'creating related difference' (1993:18).

Tymoczko (2007:41), following Wittgenstein, asserts that equivalence is best seen as 'a relation constructed by the translator ... a similarity relationship involving both likeness and difference - and as such ... contingent on many cultural 
factors', having 'an a posteriori value, rather than a positivist or absolutist value'. Thus many translations are possible of any ST. As was argued in Chapter 3, one of the most misleading pictures that face a translator is that there is a decoding process to be gone through in literary translation in order to establish an a priori equivalence. Equivalence is in any case a concept that has come out of a western view of the world, due to the rise of the printing press making it possible to have stable texts, and it comes from a form of life that does not apply in other cultures (Pym, 2010:22).

The supermeme is misleading because of its use in the language-games of mathematics and science, which tends to be taken over into ordinary language and then used in translation studies, where it can suggest an essentialist function of carrying meaning across, linked to the view of 'translation' as 'carrying-across' suggested by its etymology (as discussed in 3.1), and it therefore demands careful definition in context by writers who choose to use it. It would only make sense to speak of one translation being equivalent to another in a legal context. Hermans (2007b:12), for example, describes how the French, German and Dutch versions of the Belgian constitution are deemed by Belgian law to be equally authoritative. In a Belgian court, a lawyer cannot appeal to, say, the Dutch version of the constitution as expressing a meaning not found in the German and French versions. It is not possible to play that language-game. In the language-game of the Belgian court, these three texts have been authenticated as equivalent. And this illustrates Wittgenstein's case. A term such as equivalence makes sense in certain languagegames and not in others, unless re-defined. As Hermans (2007b: 24) concludes: 'Rather than being an inherent feature of relations between texts, equivalence is declared'.

\subsubsection{Untranslatablity}

Chesterman defines untranslatability by referring to equivalence: 'if translation is defined in terms of equivalence, and ... equivalence is impossible, translation must be impossible' (1997:10). However, as argued above in 4.4.1.2, if the term equivalence is used with clarity and care (as by Tymoczko, 2007:41), then the idea of the perfect translation becomes untenable and with it the notion of untranslatability, as argued in 3.2. There is no more a perfect translation that there is a perfect literary work (cf. Ricoeur, 2006:5). The Wittgensteinian stress on practice 
is a useful counterweight to any insistence on the impossibility of translation, because people do translate and there exists a documented history of translation (Bellos, 2011:34). It is also the case that texts are not avoided by translators because of being untranslatable. Difficult texts, such as the lipogrammatic novel by Perec (1969), discussed in 3.4, seem to inspire rather than confound their translators. There is a form of life of translation. If equivalence is no longer seen as Platonic form, then translation can take place. Whether it will always be done well is, of course, a different question, but ridding oneself of the notion that literature is untranslatable is, is seems to me, a necessary concomitant of literary translation.

The supermeme may be used to try to show that what passes as a literary translation is in fact a forgery, to cite Scott (2008:16), as discussed in 4.3. The reader who picks up Constantine (2005) is being duped into thinking that he or she is reading Goethe (1975), whereas he or she is reading Constantine: if he or she wishes to read Goethe, then the only course of action is to learn German. There are a number of issues here: Constantine is not trying to dupe anybody, for he advertises his work as a translation; it is trivially true that to read Constantine is not to read Goethe; and anybody who is passionate about Goethe would benefit from learning German. But to maintain that Goethe is untranslatable in the sense that there is a metaphysical core in Goethe that cannot be recreated in English is again to be in thrall to the Platonic myth. Translation is a language-game according to Wittgenstein (PI 23), who sees meaning as part of the way we interact as humans, not as something that is found outside the human form of life, whether in the Platonic Forms or in the canonical writings of Goethe. The reader has to be willing to play the game. It remains a possibility to refuse to play, but one that goes against the best of human practice.

\subsubsection{Free-vs-literal}

Chesterman refers to the 'binary opposition between free and literal translation' (1997:12). Such an opposition is found in Jerome (1977:25), who opposes translation as 'sense for sense' (i.e. free) and 'word for word' (i.e. literal). Grammatical investigation questions the tendency to think in polarities, as argued in 4.1, because even a single translated sentence can display different styles of translation. There are problems of definition at the level of the text, also. If all translation is transformative, then all translation is free. If all translation is about 
letters, then all translation is literal. The problem with this polarity, as with many polarities, is that it presents a three-dimensional cluster as something twodimensional, and hence fails to be a surveyable representation. Grammatical investigation can also clarify the different uses of terms such as 'literal'. Berman (2004:288), for example, uses it to signify 'attached to the letter (of works)', i.e. the restoration of 'the particular signifying process of works (which is more than their meaning)', which contrasts with the sense of literal as 'word for word' as used, for example, by Vladimir Nabakov (2004:121). To assert that both Berman and Nabakov recommend literal translation is therefore both true and, without explanation, highly misleading.

Behind this supermeme is the notion of fidelity. As Louis Kelly (1977:24) notes, by the seventeenth century, translation was being assessed by the faithfulness of the translator to the spirit of the ST author. The Translators Association still sees fidelity to the ST as the golden rule of translation (Society of Authors, 2011:np). There seems to be a misuse of a word here. One can be faithful to one's partner but not to one's ST. The wrong language-game is being played. The Penguin translation of Thomas Mann's Doctor Faustus, for example, includes Lowe-Porter's translator's note that begins with the French proverb that translations are like women: when they are beautiful, they are not faithful, and when they are faithful they are not beautiful (Lowe-Porter, 1992:xxxix). It does not make sense to speak of translations as being unfaithful in the same way that a woman is unfaithful, because the issues are completely different: two separate language-games are being mixed-up. Pushing this further, the proverb can be seen as offensive to women. When the feminist critic Susanne de Lotbinière-Harwood (1991) attacks the related image of 'les belles infidèles' ('the beautiful unfaithful-women'), she is performing a Wittgensteinian task: the image is degrading because of the patriarchal form of life that it evokes.

Translation after Wittgenstein shows the sterility of continuing the "word for word' versus 'sense for sense' debate in translation that Jerome (1977) raised in 395, that still trapped Luther (1977) in 1530, and that lives on as a supermeme, for example, in Lowe-Porter (1992). A reading of Wittgenstein shows that it is a false dichotomy and supports calls by translation theorists for an ending to the conflict (Bellos, 2011:114). The sense of literature is in the words. The meaning of literature is in the style. To set out to do either a free or a literal translation is to be bewitched 
by our language. Wittgenstein can offer tools, so that we can look at the use of the words and evaluate the consequences of that use.

\subsubsection{All-writing-is-translation}

Chesterman defines this supermeme as follows: 'Semiotically speaking, all writing, including translating, is the mapping of signifieds onto signifiers' (1997:13). The supermeme therefore opposes the view (categorised as Platonic in 3.1) that meanings are somewhere 'out there', and supports the view that 'meaning is something that is negotiated instead' (Chesterman 1997:14), which harmonises with the story told of language in the $P I$, where meaning comes about through transactions within forms of life, so that a language is mastered in the same way that somebody can be said to have mastered the rules of chess (PI 31). When I play chess, I do not look outside the practice of chess to make my next move, but rather look at the position of the pieces on the board and at the possibilities that I have for moving my own pieces according to the rules agreed over more than a thousand years. To speak of all writing being translation is to stress the transactional. It also shows, as noted above, that the cluster of reference is huge. It is impossible to sit down and write something original in the sense of being without influence or constraint of any kind (Boase-Beier \& Holman, 1999), and in this sense all writing can be seen to be translation.

On the other hand, the supermeme invites misunderstanding in everyday usage. To label Fontane's novel Effi Briest (2000) as a translation is to invite a question about the identity of its ST, and there is none. Therefore Ossian (Macpherson, 1807) has been categorised as a pseudo-translation rather than as a translation: it advertises itself as a translation but has no ST, as discussed in 4.3. The word 'translation' is itself dangerous unless defined. A film can be seen as a translation of a book (Cronin, 2009) and a relocation of a novel can be seen as being as much a translation as a TT that does not relocate (Hunter, 2000a, 2000b). Context is crucial, which is one of the key points of the PI. It comes down to how things are seen, how they are represented, and how that representation is shown. As Wittgenstein (PI 66) recommends: 'don't think, but look!'

The semiotic notion of mapping the signifier onto the signified is ultimately a formulation of the Augustinian paradigm criticised by Wittgenstein (PI 1-8). Language is more complex. The scenario described by Wittgenstein to represent an 
Augustinian language depicts builders who only know four terms, and Wittgenstein argues that for them to construct anything, they would have to have an extended vocabulary that would no longer be merely ostensive but one in which there would be many different kinds of word, the classification of which would depend upon their use in context. Translation after Wittgenstein would similarly stress physiognomy rather than mapping.

\subsubsection{Conclusions about the supermemes}

Any term can be a source of confusion unless clearly defined. To assert this is not to argue against concepts being blurred (PI 71); but once we are aware that they are blurred, that there is no essentialist nature to any term, we can use them carefully. Malcolm (1984:63) comments that Wittgenstein's conception that words are used without fixed meanings produced in some of his students the tendency to assume that 'precision and thoroughness were not required in their own thinking, which led to philosophical work of poor quality'. Care must be taken when importing terms into translation studies - and as an interdisciplinary activity, translation studies will always be in the business of importing - because the meaning of any term is found in a cluster of options and, as Malcolm notes, failure to be precise will result in slovenly work. The correct process is described in $C V$ p.44: expressions sometimes need to be withdrawn from language and given a cleaning before being returned to circulation. It is a contention of this thesis that 'translation' is one such term and that the writings of the later Wittgenstein provide one set of tools with which the process can be undertaken.

There is a tendency to use Wittgenstein's philosophy 'to police the borders between sense and nonsense, issuing tickets to those philosophers, psychologists and linguists' who transgress 'the bounds of sense' (Baker, 2004:1). Hacker (2010a:np), for example, advocates setting up 'a Tribunal of Reason, before which scientists and mathematicians may be arraigned for their transgressions'. My own view is that to set up a Tribunal of Reason for translation studies would be to go too far and would be against the spirit in which Wittgenstein wrote. Wittgenstein claimed that his project was descriptive and did not involve interfering with the actual use of language (PI 124). Words are brought back from their metaphysical to their everyday use as part of the anti-essentialist project, as discussed in 3.1, and are not to be treated as having an inherent meaning. To do that is the flaw Wittgenstein 
discerns in Augustine (PI 1 ff.). Words have an everyday use, which is blurred and not fixed, but that can become clear when care is taken. The project is one of restoration. It also furthers dialogue, because clarity can ensure that terms are used in such a way that confusion is avoided, so that both sides in a debate are speaking about the same thing. Berman (2004), for example, facilitates dialogue in translation studies by showing how the term 'translation' functions differently when used for literary texts than when used for non-literary texts. The metaphysical is rejected for the everyday, which is to be understood as how things are done in practice. Wittgenstein destroys the concept of the hermit in the head, for example, by describing a shopping trip (PI 1ff.).

Robinson (1991:259) concludes that equivalence, the second of the supermemes, is 'an interpretive fiction that helps the translator work toward the true goal of translation, a working TL text - and is only one of many such fictions'. I find this to be true. The account of meaning in the PI shows that terms such as 'expectation' are indeed fictions, and have their meaning in the context in which the fictions are told. As Wittgenstein states in PI 307: 'If I do speak of a fiction, then it is of a grammatical fiction'. The same applies to the terms used in translation theory, such as the five supermemes. The method of Wittgenstein enables these fictions to be handled with care, so that they are not assumed to be objective realities. They may, if the theorist chooses, become useful fictions, such as source-target, equivalence and all-writing-is-translation; or they may be rejected as harmful fictions, such as untranslatability or free-versus-literal. The story can then have a happy ending. But it matters that we know that it is a story. Similarly it matters that one knows that one is playing a language-game if one is to play it well. This chapter is written from the point of the translation theorist. The form of life of the translation theorist is a broad one. As well as academics who theorise about the phenomenon, it also includes practising translators. The fields are not exclusive. Every translator inevitably theorises his or her own text, simply by having a view about it, as BoaseBeier (2010a:xii) notes: 'Translators almost always tell you their theory - perhaps without realising - in the introductions to their translations'. To be clear about our use of terminology and to be exact in description will ultimately affect and improve practice, because how we see things changes how we do things. 


\subsubsection{Translation theories after Wittgenstein}

In contrast to the description of individual practice that characterises texts on translation produced before the twentieth century, the twentieth century itself saw the production of various theories about translation as a phenomenon (Barnstone, 1993:1997). What happens to these theories after Wittgenstein? Given Wittgenstein's hostility to theory (PI 109), should they be escorted to the border and shown on their way, following Plato's treatment of the artists (514a)? I do not think so, for three reasons. Firstly, to take such as attitude is again to turn Wittgenstein into a police officer, which I argued above to be against the spirit in which he wrote. Secondly, the major theories are descriptive, being soft theories, not hardcore theories, as argued in 1.3, and can be aligned with the Wittgensteinian project of description, even if they address large-scale phenomena rather than particular cases. Thirdly, they operate in ways that differ from Wittgenstein's philosophical approach. Skopos theory, for example, sees the dominant factor of any translation as its purpose (Reiss \& Vermeer, 1984:100), and can be seen as an attempt to explain translation sociologically. It is not possible to sit down and to write a skopos translation. Skopos theory is not a tool, but an explanation. It operates at a different level from a tool. As Wittgenstein ( $Z$ 234) asserts, when we interpret, we step from one level to another. It is an error to condemn a non-philosophical theory for not being philosophy.

The major translation theories can be supported by Wittgensteinian tools, in line with the second relation between philosophy and translation studies identified by Pym (2007:24) and discussed in 1.2: translation theorists can refer to philosophical discourses for support and authority for their ideas. To apply Wittgenstein's work to translation theories in detail would go beyond the scope of this thesis, but in Table 10 I offer a sketch of how such an inquiry might proceed, giving an example of a theory in the first column, a brief description of it in the second and an example in the third column of a Wittgensteinian tool that could be used in support.

TABLE 10: A SAMPLE OF MAJOR TRANSLATION THEORIES

\begin{tabular}{|l|l|l|}
\hline THEORY & DESCRIPTION & $\begin{array}{l}\text { WITTGENSTEINIAN } \\
\text { TOOL }\end{array}$ \\
\hline DTS (Toury, 1980) & $\begin{array}{l}\text { Translations are described, } \\
\text { rather than the process of } \\
\text { translation being analysed. }\end{array}$ & $\begin{array}{l}\text { DTS is influenced by the } \\
\text { Wittgensteinian contention } \\
\text { that the task of philosophy is }\end{array}$ \\
\hline
\end{tabular}




\begin{tabular}{|c|c|c|}
\hline & & to describe (PI 40). \\
\hline $\begin{array}{l}\text { Linguistic theories } \\
\text { (Malmkjaer, 2005) }\end{array}$ & $\begin{array}{l}\text { Linguistics is seen as a } \\
\text { source for modelling } \\
\text { translation. }\end{array}$ & $\begin{array}{l}\text { The } P I \text { is a philosophical } \\
\text { investigation of how } \\
\text { everyday language works ( } P I \\
1 \mathrm{ff}) \text {. }\end{array}$ \\
\hline $\begin{array}{l}\text { Equivalence theories (Nida } \\
\& \text { Taber, 1969) }\end{array}$ & $\begin{array}{l}\text { Translation is viewed as a } \\
\text { process of finding } \\
\text { equivalences. }\end{array}$ & $\begin{array}{l}\text { Meaning is seen as use (PI } \\
43 \text { ), so that equivalence can } \\
\text { be seen as something that is } \\
\text { constructed. }\end{array}$ \\
\hline $\begin{array}{l}\text { Skopos theory (Reiss \& } \\
\text { Vermeer, 1984) }\end{array}$ & $\begin{array}{l}\text { Translations are analysed } \\
\text { according to their role. }\end{array}$ & $\begin{array}{l}\text { The form of life (PI 19) in } \\
\text { which a translation is used } \\
\text { can be discussed. }\end{array}$ \\
\hline $\begin{array}{l}\text { Polysystem theory (Evan- } \\
\text { Zohar, 1990) }\end{array}$ & $\begin{array}{l}\text { Translations are placed } \\
\text { within literary systems. }\end{array}$ & $\begin{array}{l}\text { Family resemblance and the } \\
\text { cluster-concept (PI 67) can } \\
\text { be used to describe systems. }\end{array}$ \\
\hline $\begin{array}{l}\text { Feminist theory (Simon, } \\
\text { 1996) }\end{array}$ & $\begin{array}{l}\text { Insights from feminist theory } \\
\text { can describe translation. }\end{array}$ & $\begin{array}{l}\text { Wittgensteinian tools can } \\
\text { facilitate feminist analysis } \\
\text { (Scheman \& O'Connor, } \\
\text { 2002)'. }\end{array}$ \\
\hline $\begin{array}{l}\text { Post-colonial theory } \\
\text { (Bassnett \& Trivedi, 1999) }\end{array}$ & $\begin{array}{l}\text { Insights from post-colonial } \\
\text { theory can describe } \\
\text { translation. }\end{array}$ & $\begin{array}{l}\text { Wittgensteinian tools can } \\
\text { facilitate political analysis } \\
\text { (Holt, 1977). }\end{array}$ \\
\hline $\begin{array}{l}\text { Relevance theory (Gutt, } \\
\text { 2000) }\end{array}$ & $\begin{array}{l}\text { Translation is related to what } \\
\text { is relevant in } \\
\text { communication. }\end{array}$ & $\begin{array}{l}\text { Communication (PI } 1 \mathrm{ff} .) \text { is } \\
\text { described as a practice. }\end{array}$ \\
\hline $\begin{array}{l}\text { Stylistics (Boase-Beier, } \\
\text { 2006b) }\end{array}$ & $\begin{array}{l}\text { Literary meaning is viewed } \\
\text { as being in the style of a } \\
\text { work. }\end{array}$ & $\begin{array}{l}\text { Meaning is seen as a } \\
\text { physiognomy (PI 128). }\end{array}$ \\
\hline
\end{tabular}

Nobody would suggest, for example, that Wittgenstein would be a primary resource for a feminist theory of translation, but the articles collected by Naomi Scheman and Peg O’Connor (2002) show how his work can sharpen feminist analysis, because 'Wittgenstein and feminist theorists have mutually illuminating and substantively constructive things to say to each other' (Scheman, 2002:1). The role of philosophy becomes dialogical, rather than autocratic, in line with the call by Antoinette Fawcett and Karla Guadarrama García (2010:13) for a dialogue between models of translation rather than a replacement of one model by another. 
Readers of literature in translation encounter theory in the form of paratextual material by translators in published translations, as noted by Boase-Beier (2010:xiii). Such material is frequently apologetic in nature (Fawcett \& Guadarrama García, 2010:10): when Lowe-Porter (1992:xxxix), for example, prefaces the ST with the proverb about the impossibility of beautiful women being faithful and vice-versa, she immediately sounds a note of apology for what she is doing. The tools of the PI offer support not only for formal theories of translation such as polysystem theory but also for theories expressed informally in paratextual material, and can help theorists (in all contexts) to write with confidence about the practice of translation and to stop apologising for what they are doing. 


\subsection{Case study: New Testament translation}

The aim of this case study is to show how Wittgensteinian methods can be brought to the study of NT translation. How can Wittgenstein's work clarify aspects of the project? I argue that tools from the PI can be used by the theorist who wishes to survey the field of NT translation or to describe an individual translation. The case study, following the arguments of 4.1 and 4.2 , is primarily descriptive and can be seen as an exercise in DTS, which links it to translation theory.

\subsubsection{New Testament translation: a cluster concept}

There exist a vast number of translations of the NT, usually as part of a translation of the whole Bible (Barnstone, 1993:153 ff.). The issue of what is meant by translation here is complex: as Boase-Beier and Holman (1999:3) assert, the Bible 'is a text that blurs the distinction between original and translation in that it available to the vast majority of its readers worldwide only in translation, but rarely regarded as anything other than an original work in the particular language of the individual reader in question'. This assertion can be supported by Wittgenstein's notion of how concepts are often blurred rather than sharp: in PI 71, he notes that 'game' is a concept with blurred edges, as discussed in 1.5, so that it is very difficult to define a game without excluding certain activities definitely held to be games, and asks: 'Is it even always an advantage to replace an indistinct picture by a sharp one? Isn't the indistinct one often exactly what we need?' In PI 19, he argues that use has to be seen within a form of life. Thus for many Christians, the Bible is a holy text in the sense of being a foundational document and is original in the sense of how it functions, of how it is used in their lives. Within translation studies, it can be shown that the NT is situated within a complex web of translation, and a task of the translation theorist is to describe the web. To this end, the work of Wittgenstein offers useful tools.

In PI 77, Wittgenstein extends his investigation of the blurred concept, as cited in (123).

In such a difficulty always ask yourself: How did we learn the meaning of this word ...? From what sort of examples? in what language-games? Then it will be easier to see that the word must have a family of meanings. 
Wittgenstein's investigation can be applied to our understanding of what a translation is. We meet translations within forms of life. We learn how to read them, how to use them and how to recognise them (or else we fail to recognise them). A translation can be done in many different ways, for there are many different forms of life, and this in turn results in many different types of TT (Bellos, 2011:182). As Wittgenstein (PI 68) notes, there are no rules in tennis about how high one should throw the ball when serving or how hard one should hit the ball, but this does not mean that tennis cannot be played. Similarly, a translator works within certain constraints, such as: the TL specified in a commission; the expectations of a particular market; the range of meanings attached to a particular word. Such working practices can be described as 'rules', but there are no rules that determine just how a particular word - and, by extension, a particular text - must be translated, and translation is none the worse for that. Rules emerge in so far as they are useful; they are not imposed. They are practices.

The cluster concept, discussed in 4.1, can be used to describe the situation in NT translation, following Tymoczko (2007) and drawing on the Wittgensteinian notion of family resemblance. In Table 11, I offer a selection of ten NT translations that can be linked in family resemblance, despite considerable differences. The table begins with three editions of the HG NT and then lists seven translations in chronological order of composition. The choice of texts has been made specifically to illustrate variety, and the table could be extended.

TABLE 11: SOME NT TRANSLATIONS

\begin{tabular}{|l|l|}
\hline TEXT & DESCRIPTION \\
\hline $\begin{array}{l}\text { The Greek New Testament (Aland et al., } \\
\text { 1968) }\end{array}$ & $\begin{array}{l}\text { An edition of the earliest surviving Christian } \\
\text { scriptures accepted as canonical, written in } \\
\text { HG in the first century and used by many } \\
\text { translators as the ST (e.g. King, 2004). }\end{array}$ \\
\hline $\begin{array}{l}\text { The New Greek-English Interlinear New } \\
\text { Testament (Brown \& Comfort, 1990) }\end{array}$ & $\begin{array}{l}\text { An example of what Barnstone (2009:1289) } \\
\text { calls 'the Rosetta Stone of Bible } \\
\text { translations': an interlinear gloss of the ST } \\
\text { with a marginal English translation to enable } \\
\text { the reader to cross-reference meanings. }\end{array}$ \\
\hline NT Gateway (2012) & $\begin{array}{l}\text { This internet site includes the HG ST: words } \\
\text { can be clicked on to show their English } \\
\text { meaning, including the grammar of nouns }\end{array}$ \\
\hline
\end{tabular}




\begin{tabular}{|c|c|}
\hline & $\begin{array}{l}\text { and verbs where applicable. A virtual } \\
\text { interactive extension of the interlinear } \\
\text { translation. }\end{array}$ \\
\hline $\begin{array}{l}\text { Nouum testamentum latine (New Testament } \\
\text { in Latin) (Jerome, 1911) }\end{array}$ & $\begin{array}{l}\text { The fourth/fifth-century Latin translation by } \\
\text { Jerome that acquired great prestige and } \\
\text { canonical authority in the Catholic Church as } \\
\text { the Vulgate (from the Latin versio vulgata, } \\
\text { 'version commonly-used'). }\end{array}$ \\
\hline Die Bibel (The Bible) (Luther, 1999) & $\begin{array}{l}\text { The } 1522 \text { German translation by Luther, } \\
\text { which he describes as an attempt to render } \\
\text { German as commonly spoken (Luther, } \\
\text { 1987:87). }\end{array}$ \\
\hline Rheims-Douai (1582) & $\begin{array}{l}\text { A Counter-Reformation English translation } \\
\text { of the NT by exiled English Catholics in } \\
1582 \text { that helped to formalise the identity of } \\
\text { the Catholic community in Reformation } \\
\text { England. }\end{array}$ \\
\hline $\begin{array}{l}\text { The Bible: Authorized King James Version } \\
\text { (2008) }\end{array}$ & $\begin{array}{l}\text { Published in } 1611 \text { under the authority of the } \\
\text { Church of England as a Bible in English for } \\
\text { use in Anglican worship. }\end{array}$ \\
\hline The New Testament (King, 2004) & $\begin{array}{l}\text { A modern translation that can be described } \\
\text { as a surveyable representation because it } \\
\text { contains an interactive study guide, in the } \\
\text { form of commentary and questions } \\
\text { addressed to the reader, interspersed with the } \\
\text { NT text. The work is designed to be used as } \\
\text { a devotional tool. }\end{array}$ \\
\hline Die Bibel in gerechter Sprache (2006) & $\begin{array}{l}\text { A German translation that aims to avoid } \\
\text { exclusive or offensive language, e.g. the } \\
\text { masculine nominative plural noun in John } \\
20: 19 \text {, 'oi } \mu \alpha \theta \eta \tau \alpha i \text { ' [hoi mathêtai] ('the } \\
\text { disciples') is rendered as 'Die Jüngerinnen } \\
\text { und Jünger' ('the female-disciples and male- } \\
\text { disciples'). }\end{array}$ \\
\hline $\begin{array}{l}\text { The Restored New Testament (Barnstone, } \\
\text { 2009) }\end{array}$ & $\begin{array}{l}\text { A modern translation that includes non- } \\
\text { canonical Gnostic writings and aims to } \\
\text { convey the poetic style of the NT. }\end{array}$ \\
\hline
\end{tabular}

All of these texts can be described as translations. The HG NT, on investigation, is no more original than any other translation, because at some point the words of Jesus must have been translated from Aramaic to HG, probably by Mark, whose Gospel is described by Maurice Casey (2010:63) as 'an unrevised translation of an Aramaic 
source'. No ST for the NT has yet been discovered and Barnstone (1993:157) argues that a better title for the NT would be 'Scriptures in Greek translation'.

The texts in Table 11 are therefore orphans. There is no common denominator and they can be seen as exhibiting family resemblance. Even if the HG is taken to be the ST, certain texts here were not translated from it. The Authorised King James Version, for example, is best described as a revision of previous translations into English, as is stated in its Preface: 'wee never thought from the beginning, that we should neede to make a new Translation, nor yet to make of a bad one a good one ... but to make a good one better, or out of many good ones, one principall good one' (2008:12). Or the Rheims-Douai was translated from the Latin Vulgate of Saint Jerome, because of the prestige in which Jerome was held by the Catholic Church in the sixteenth century, as shown in the sub-title: The Nevv Testament of Iesvs Christ, Translated Faithfvlly into English, out of the Authentical Latin. Jerome himself did not translate the NT from the HG, his translation being 'chiefly a revision of an existing Latin text of the NT with occasional corrections based on Greek manuscripts' (Bratton, 1967:230). Yet each text links to others in the table by family resemblance.

As indicated in the descriptions in Table 11, each translation has a form of life that lies behind it and each translation cannot be described without reference to this form of life. The texts can often be described along confessional lines: the Catholic Rheims-Douai places itself in the tradition of Jerome, patron saint of translation, whose rendering was seen as authoritative, whereas Luther's translation is from HG in deliberate reaction against Catholic tradition. Luther's translation remains in print (in updated German) because it has in its turn acquired canonical status within the German-speaking Lutheran Church. Non-confessional factors are also involved, however: Luther's attempt to write the German of ordinary people is typical of the affirmation of ordinary life that characterises the early modern world (Taylor, 1989:211 ff.). Die Bibel in gerechter Sprache (2006), while produced by a team of Lutheran theologians and translators, aims to accommodate the sensibilities of modern liberal democracies where such issues as inclusive language are taken very seriously, and breaks with the received Lutheran tradition (whilst following Luther's example) by translating from the HG, rather than merely making a politically correct revision of Luther's German. 
The cluster can be extended to include radical translations as well as nontextual adaptations, i.e. what Jakobson (1959:233) calls intersemiotic translations or 'the interpretation of verbal signs by means of nonverbal sign systems'. The extension is shown in Table 12. The texts are listed in chronological order of composition.

\section{TABLE 12: EXTENDING THE CLUSTER}

\begin{tabular}{|c|c|}
\hline TEXT & DESCRIPTION \\
\hline The Woman's Bible (Stanton (ed), 1985) & $\begin{array}{l}\text { An edition of the Bible published in } 1895 \\
\text { that includes only passages of interest from a } \\
\text { Christian feminist point of view. Scriptural } \\
\text { texts are followed by commentary by the } \\
\text { editor, Elizabeth Cady Stanton. }\end{array}$ \\
\hline The Gospel in Brief (Tolstoy, 1997) & $\begin{array}{l}\text { A Russian Gospel harmony written by } \\
\text { Tolstoy in the early twentieth century with } \\
\text { all supernatural events (such as the miracles } \\
\text { or the Resurrection) omitted. }\end{array}$ \\
\hline $\begin{array}{l}\text { Il Vangelo secondo Mattheo (The Gospel } \\
\text { According to Saint Matthew) (Pasolini (dir), } \\
\text { 1964) }\end{array}$ & $\begin{array}{l}\text { An Italian filmic version of Matthew's } \\
\text { Gospel, which preserves the narrative. }\end{array}$ \\
\hline $\begin{array}{l}\text { The Last Temptation of Christ (Scorsese } \\
\text { (dir), 1988) }\end{array}$ & $\begin{array}{l}\text { A film based on the } 1960 \text { novel by Nikos } \\
\text { Kazantzakis (1975), in which the dying } \\
\text { Christ wonders if his life was a dream, and } \\
\text { which introduces the Nietzschean possibility } \\
\text { that Christianity is the invention of Paul. }\end{array}$ \\
\hline $\begin{array}{l}\text { The Illustrated Children's Bible: The New } \\
\text { Testament (Hastings, 1994) }\end{array}$ & $\begin{array}{l}\text { Illustrated stories retold in simple language } \\
\text { for children whose reading age would form } \\
\text { an obstacle to reading translations in } \\
\text { common use. }\end{array}$ \\
\hline Ee By Gum, Lord! (Kellett, 1996) & $\begin{array}{l}\text { Retelling of key Gospel texts in Yorkshire } \\
\text { dialect, aiming to combat the declining use } \\
\text { of Yorkshire dialect. }\end{array}$ \\
\hline The Tabloid Bible (Page, 1998) & $\begin{array}{l}\text { Bible narratives as front pages from the } \\
\text { British popular tabloid press, e.g. the Sun. }\end{array}$ \\
\hline $\begin{array}{l}\text { L'Évangile de Jésus-Christ (The Gospel of } \\
\text { Jesus Christ) (Berthier et al., 2004) }\end{array}$ & $\begin{array}{l}\text { A French } B D \text { (graphic novel) harmonising } \\
\text { all four Gospels to give a presentation of the } \\
\text { life of Jesus, aimed at fans of the } B D \text { genre. }\end{array}$ \\
\hline $\begin{array}{l}\text { Christ the Lord: The Road to Cana (Rice, } \\
\text { 2006) }\end{array}$ & $\begin{array}{l}\text { A novelisation of part of Christ's life by } \\
\text { Anne Rice, author of popular Gothic novels. }\end{array}$ \\
\hline
\end{tabular}


These very disparate works are surveyable representations of the NT that aim to make aspects of the NT phenomenon clearer to readers, a phenomenon that is wider than any single ST, because the NT is a cluster of translation, a blurred concept. We are dealing with the Christian story as represented in the HG translation of a lost Aramaic collection of sayings and stories that has come to exist in a family relationship of texts in translation and accompanying commentary and tradition over two thousand years. The cluster would still remain, even in the unlikely event of the finding of an Aramaic ST. The film by Martin Scorsese (1988) depicts scenes not in the NT but it addresses theological problems about the nature of Christ, and is in turn based on a novel (Kazantzakis, 1975). To attempt to understand the ST of Scorsese, it would be necessary to refer to: the translation that is the NT; the novel by Kazantzakis; other films made on the life of Christ (e.g. Pasolini, 1964); Christological traditions; the life and philosophy of the director; criticism written about his work. Everything is multidirectional.

The Green Bible (2008) can similarly be seen as a surveyable representation. It is not a new translation, because it uses the text of a published and widely-read translation (The Bible: New Revised Standard Version, $2007^{54}$ ), but it presents this text in such a way as to make a theological case for environmentalism: it is the first English Bible to be printed on environmentally sustainable FSC paper; its cover is made from renewable cotton linen; it includes paratextual material on the theological theme of justice and the integrity of creation; it highlights in green soy-based ink those passages that have a creation theme, for example, the story of Jesus's baptism (Mark 1:10).

The issue is what can be held to be a translation. It is a question of the use of the term. It is possible to refer to these texts as translations, because, as Wittgenstein notes, there are countless kinds of use for many expressions, and 'new types of language, new language-games ... come into existence, and others become obsolete and get forgotten' (PI 23). As discussed in 4.4 with respect to the supermeme of allwriting-is-translation, it is important not to use terms indiscriminately. The fact that

${ }^{54}$ Itself a revision, as indicated by the title. 
some concepts are blurred is not an excuse for blurred thinking. It would be absurd to buy somebody the DVD of Pasolini (1964), for example, if he or she wanted a translation of Matthew into Italian, but this film can be said to be a translation of the Gospel because it uses Matthew's words in Italian translation and follows the highlyplanned structure of that Gospel. It can be said to play the same language-games as the ST that warns of the immorality of riches (Matthew, 19:23-24), because it shows the grinding poverty of the ordinary people and Jesus's compassionate anger at what they suffer. The representation can also be related to Pasolini's Marxism, to extend the cluster further. The DVD could therefore be given to somebody who was trying to understand the figure of Jesus as portrayed by Matthew.

Wittgenstein himself encountered the Gospels as a living reality during the First World War in the form of the Gospel harmony by Tolstoy (1997). According to Monk (1990:116) it became 'kind of talisman' for him; he carried it everywhere he went and asserted that 'you cannot imagine the effect it can have upon a person'. The effect on its readers is a measure of any translation, however defined. Wittgenstein read Tolstoy's Russian text in German translation, therefore at least four steps away from the presumed Aramaic words of Jesus, but for him the Tolstoy was an original work, on account of the role that it played in his life, which returns us to where this argument began: that the NT is not used as a translation per se in how people read it and use it in their lives.

A task of the translation theorist after Wittgenstein will be to describe individual NT translations once they have been positioned within the cluster. I therefore offer a case study of one of the texts in Table 11: the NT translation by Barnstone (2009).

\subsubsection{A description of Barnstone's The Restored New Testament}

Barnstone's translation was published in 2009 and is the practical working out of a project sketched in an endnote to his 1993 theoretical work The Poetics of Translation, given as (124) (Barnstone 1993:278).

Yet it is time to read the magnificent literature of the Bible in renditions equal to modern versions of classical Greek and Latin authors. In contrast to serious classical scholars, however, biblical scholars relentlessly invent strange texts alien to English 
language and literature. ... Given the alien-to-art-and-intellect translations of sacred texts, the Bible awaits its English metafora. Waiting there, in the darkness of letters, is the great book.

Barnstone's translation is self-consciously literary. It is based on a reading of the HG ST as literature - in line with the reading of the NT as literature discussed in $2.5-$ and aims to produce a TT that can be read as literature: Barnstone announces his intention as being to give 'a chastely modern, literary version of a major world text' (2010:14). The work is signalled as a translation in its full title: The Restored New Testament: A New Translation with Commentary, Including the Gnostic Gospels Thomas, Mary, and Judas. There are over three hundred pages of commentary, on matters theological, translational, linguistic and historical, and copious explanatory and linguistic notes throughout the text.

Why choose this text as a case study? Any text could have been chosen and Wittgensteinian tools applied, but I think that Barnstone can be read as Wittgensteinian, much as I read Weinberger as Wittgensteinian in 4.3, influenced by the reading of Stevens as Wittgensteinian by Cook and Read (2010:482). Barnstone sees Wittgenstein's philosophy as important for what it can tell us about translation (1993:6) and provides, I shall argue, a surveyable representation of the NT. In addition, I respect Barnstone as a theorist, a poet and a translator. His NT is also of interest because it is a radical translation in a field marked by its conservatism, as Barnstone argues in (124), and may therefore illustrate new ways of translating of interest to the translation theorist and ultimately to the reflective practitioner.

I begin with an example from Mark 9:1. The ST is given as (125), a translation from the New Jerusalem Bible as (126) for purposes of comparison and Barnstone's translation as (127).

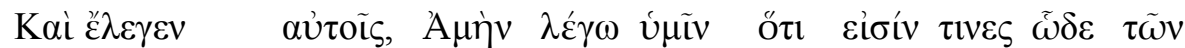
Kai elegen autois, Amên legô humin hoti eisin tines hôde tôn and was-saying to-them indeed I-say to-you that are some here of-those

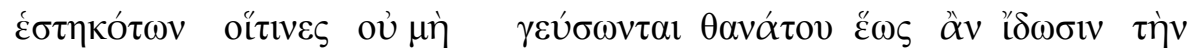
hestêkotôn hoitines ou mê geusôntai thanatou heôs an idôsin tên having-stood who not-at-all will-taste of-death until they-see the 


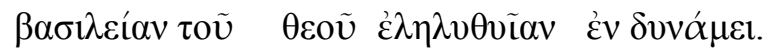

basileian tou theou elêluthuian en dunamei.

kingdom of-the God having-come in power

And he said to them, 'In truth I tell you, there are some standing here who will not taste death before they see the kingdom of God come with power'.

And he said to them,

Amain, I say to you,

There are some of you standing here

Who will not taste death

Until you see that the kingdom of God has come

With power.

Robinson (1993:62), commenting on the portrait of Jesus given in many English translations, asserts: 'He feels familiar: he speaks our language just as we speak it, without liturgical adornment, without all the solemnities of ecclesiastical tradition, in flat prose, like any other ordinary person'. With Barnstone, this is not the case. Barnstone states that his 'great discovery was the invisible poet hitherto hidden in unlineated Greek prose' (2010:1291), so that his aim became to give us the 'poems of Jesus', which he describes as being 'uniformly sonorous in their metaphysic and of-the-earth peasant, village, fisherman, and farmland settings' (2010:40). ${ }^{55}$ Translation as transference, translation 'that slights poetic language', is to be avoided (2010:24), in line with the post-Wittgensteinian refusal to see meaning as something that can be extracted and moved, as discussed in Chapter 2. Where the New Jerusalem Bible normalises what is a very dramatic statement about the imminent end of the world, Barnstone's translation stresses the drama and can be seen as poetic because: it retains the Aramaic 'Amain', rather than making Jesus sound like an Enlightenment philosopher by using an adverb such as 'truly'; it is set out as verse, so that certain expressions are foregrounded, such as 'With power' in line 6; the use of verse has the effect of slowing the speed at which the pronouncement is read, hence making it more solemn; Barnstone maintains the repetition of 'you' in

\footnotetext{
${ }^{55}$ See Cupitt \& Armstrong (1977:53) on how back-translation of the sayings of Jesus shows an Aramaic verse form. Barnstone has gone on to publish the poetry in a single volume: The Poems of Jesus Christ (2012).
} 
lines 2 and 3, which enhances the fact this is a warning to a crowd of spectators, and by implication to the reader or the listener; he also maintains the tense of ' $\dot{\lambda} \lambda \eta \lambda v \theta v \tilde{i} \alpha \nu$ ' [elêluthuian], which is third person singular feminine accusative

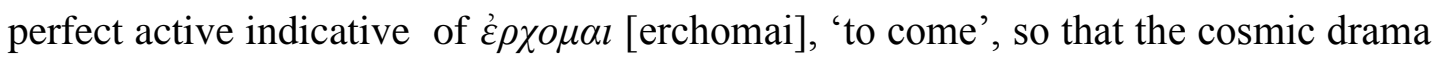
is intensified by the fact that Kingdom 'has come', i.e. its advent is realised in language even if not in time. Barnstone allows the Greek to speak. I therefore think that the translation in (127) works successfully as a poem. That Barnstone is an effective literary translator is shown in his discussion (1993:99-104) of his own

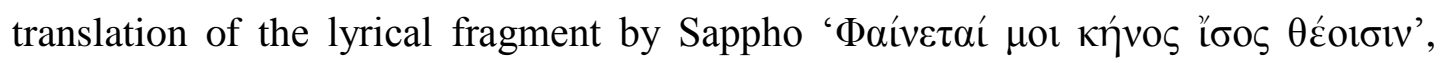
where he gives the ST and discusses translations by four other poets, so that there is a surveyable representation of the ST. His NT translation does not offer, in the paratextual material, any analogous examples of how he translates style; but the text, while it appears to be written in the language of giving information, is not about giving information, to paraphrase Wittgenstein ( $Z$ 160). Barnstone's Jesus is not Robinson's man in the street whom we might meet in downtown New York, but a mystical figure (an impression strengthened by the inclusion of three Gnostic Gospels, which present a more spiritualised Christ than the canonical Gospels). Barnstone is not the first to translate the poetry in the Bible, but what distinguishes this translation is its consistency: for example, the New Jerusalem Bible (1990) translates some speeches of Jesus as verse (e.g. Matthew 5:3-10), but most of them as prose. Barnstone's work can therefore be said to be a surveyable representation, because it restores the style of the HG.

What is most striking about Barnstone's translation, however, is the rendering of proper names. Barnstone avoids the standard translations found in other English renderings. Where translations, for example, refer to 'Simon Peter', (from

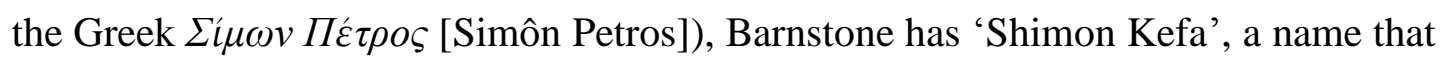
would, I think, cause comprehension difficulties even to somebody who knows the NT but who meets the name out of context. Barnstone's translation of names, as part of his project of restoration, is based on the names that people and places had in the early first century. I illustrate this in Table 13, which gives examples of HebrewAramaic, HG and Latin names and how Barnstone translates them. The examples from the New Jerusalem Bible are included because they are typical of English 
renderings in common use, and I give the rationale for Barnstone's translation choice following his explanations in footnotes.

\section{TABLE 13: NOMENCLATURE IN BARNSTONE}

\begin{tabular}{|c|c|c|c|}
\hline $\begin{array}{l}\text { HG (Aland et al., } \\
\text { 1968) }\end{array}$ & $\begin{array}{l}\text { ENGLISH (New } \\
\text { Jerusalem Bible, } \\
\text { 1990) }\end{array}$ & $\begin{array}{l}\text { BARNSTONE } \\
(2009)\end{array}$ & $\begin{array}{l}\text { NOTE ON } \\
\text { BARNSTONE }\end{array}$ \\
\hline $\begin{array}{l}\text { Inбoũs } \\
\text { Iêsous }\end{array}$ & Jesus & Yeshua & 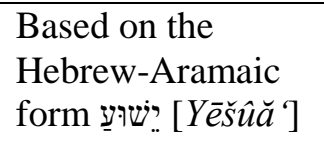 \\
\hline 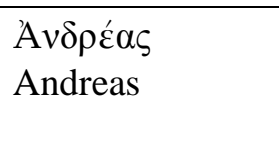 & Andrew & Andreas & 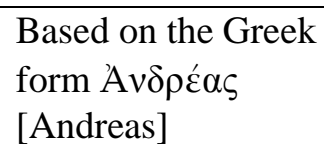 \\
\hline 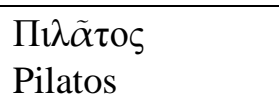 & Pilate & Pilatus & $\begin{array}{l}\text { Based on Latin form } \\
\text { Pilatus }\end{array}$ \\
\hline
\end{tabular}

Barnstone looks to the form of life that lies behind the words in the HG text. He comments, for example, on how he does not want his readers 'to watch Andrew ... pausing in London and Chicago but Andreas ... walking a Greek city' (2010:14). For Barnstone, this strategy is also a tool for combating the anti-Semitism he discerns in the NT and its translations (2010:18). To name the figure known in English as Jesus 'Yeshua', for example, is to stress his Semitic origins. Here is also an example of why Wittgenstein is justified in attacking the correspondence theory of meaning he sees in Augustine (PI 1). It may seem that the name 'I ought to be straightforward to translate on account of a direct correspondence to 'Jesus', but this is not the case. Things are almost always more complicated than the Augustinian paradigm suggests. Even a transliteration of the HG form of Jesus's name, 'Iesous' or 'Jesous', does not give the conventional English form, and, as Barnstone (2009:141) shows, Jesus would have been known by his contemporaries by what he transliterates as 'Yeshua', which could be transliterated differently (e.g. 'Yeshuah'). Casey (2010:143) comments that the traditional English rendering is 'Joshua'. Equivalence can only exist as something constructed, not as something assumed or essential, as argued in 4.4.1.2.

How successful is Barnstone's translation as a surveyable representation? On the negative side: there is no discussion of the translation of style and no online 
support specifically for this text (although there are vast internet resources available for NT translators and readers). On the positive side: it advertises itself as a translation; it extends the canon to give a surveyable representation of Christianity in the first century by including the non-canonical Gnostic Gospels of Thomas, Mary, and Judas (Barnstone, 2009: 537-612, with Marvin Meyer); it allows the reader an insight into the process of translation through its paratextual material and footnotes. Overall it seems to me to make a difficult situation clearer as well as functioning as literature.

Is it the great book for which Barnstone hoped? I think that a Wittgensteinian view militates against the existence of one great translation, but points towards the possibility of many great translations. To assume that one great book is waiting in the darkness, as Barnstone does, is still to be in thrall to the Platonic myth that is one of the targets of the PI. Other great translations into English are already available and more may be written as the consciousness of the NT as literature grows (Keefer, 2008). The translation by King (2004), for example, makes radical decisions on translating the form of the HG that differ from those of Barnstone, but that seem to me to be successful. An example of this is his translation of Luke 6:20, given as (131), with (128) representing the HG, (129) the rendering of the New Jerusalem Bible (2009) and (130) the translation by Barnstone (2009).

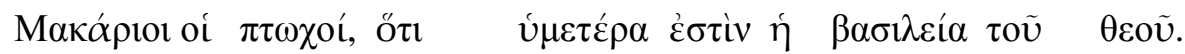
Makarioi hoi ptôchai, hoti humetera estin hê basileia tou theou. blessed the poor because yours is the kingdom of-the God

Blessed are the poor

For yours is the kingdom of God.

How blessed are you who are poor: the kingdom of God is yours.

Congratulations to the poor - for yours is the Kingdom of Heaven. 
It is to express no criticism of (129) or (130) to say I find the translation in (131) remarkable. King avoids the commonplace and archaic 'blessed' and offers an expression that makes the reader stop to ask why on earth the poor should be congratulated. It is to wrench language out of the ordinary and to change the way the world is seen. The same language-game is being played in ST and TT, which is the aim of any translator using Wittgenstein (Gledhill, 2007:5). Adopting a view of translation as not being about transference opens up many possibilities. I am personally interested in the possibility of a verse translation of the NT using rhyme and metre, as in my own rendering of (128), offered as (132), part of a sequence in iambic pentameter with rhymed couplets.

And the poor can be happy indeed,

for the Kingdom of the God has arrived.

The NT lives in its translations, not its translation.

In this case study I have made no reference to any of the major translation theories, apart from mentioning that the study could be seen as an example of DTS. This link with translation studies could be extended to other translation theories through Wittgensteinian methods, as shown in Table 14, which is based on Table 10 and shows how theories and Wittgensteinian tools can be related to Barnstone's TT.

TABLE 14: TRANSLATION THEORIES, WITTGENSTEIN AND BARNSTONE

\begin{tabular}{|l|l|l|}
\hline THEORY & $\begin{array}{l}\text { WITTGENSTEINIAN } \\
\text { TOOL }\end{array}$ & $\begin{array}{l}\text { EXAMPLE IN } \\
\text { BARNSTONE (2009) }\end{array}$ \\
\hline DTS (Toury, 1980) & $\begin{array}{l}\text { DTS is influenced by the } \\
\text { Wittgensteinian contention } \\
\text { that the task of philosophy is } \\
\text { to describe (PI 40). }\end{array}$ & $\begin{array}{l}\text { The work contains 300 (out } \\
\text { of 1485) pages of paratextual } \\
\text { material describing function } \\
\text { and context. }\end{array}$ \\
\hline $\begin{array}{l}\text { Linguistic theories } \\
\text { (Malmkjaer, 2005) }\end{array}$ & $\begin{array}{l}\text { The PI is a philosophical } \\
\text { investigation of how } \\
\text { language works }(P I 1 \mathrm{ff}) .\end{array}$ & $\begin{array}{l}\text { Stress is placed on the } \\
\text { language-games played, e.g. } \\
\text { that Mark's voice is that of a } \\
\text { spoken tale, not of a learned } \\
\text { report in difficult syntax } \\
\text { (2009:30). }\end{array}$ \\
\hline
\end{tabular}




\begin{tabular}{|c|c|c|}
\hline $\begin{array}{l}\text { Equivalence theories (Nida } \\
\& \text { Taber, 1969) }\end{array}$ & $\begin{array}{l}\text { Meaning is seen as use (PI } \\
43) \text {, so that equivalence can } \\
\text { be seen as something that is } \\
\text { constructed. }\end{array}$ & $\begin{array}{l}\text { Barnstone constructs one set } \\
\text { of possible equivalences for } \\
\text { the names of people and } \\
\text { places }(2009: 14) \text {. }\end{array}$ \\
\hline $\begin{array}{l}\text { Skopos theory (Reiss \& } \\
\text { Vermeer, 1984) }\end{array}$ & $\begin{array}{l}\text { The form of life }(P I 19) \text { in } \\
\text { which a translation is used } \\
\text { can be discussed. }\end{array}$ & $\begin{array}{l}\text { The translation is designed } \\
\text { to give pleasure, information } \\
\text { and awareness of } \\
\text { background }(2009: 15) \text {. }\end{array}$ \\
\hline $\begin{array}{l}\text { Polysystem theory (Evan- } \\
\text { Zohar, 1990) }\end{array}$ & $\begin{array}{l}\text { Family resemblance and the } \\
\text { cluster-concept (PI 67) can } \\
\text { be used to describe systems. }\end{array}$ & $\begin{array}{l}\text { The text can be related to } \\
\text { others: like King (2004), it is } \\
\text { translated from HG, for } \\
\text { example. }\end{array}$ \\
\hline $\begin{array}{l}\text { Feminist theory (Simon, } \\
\text { 1996) }\end{array}$ & $\begin{array}{l}\text { Wittgensteinian tools can } \\
\text { facilitate feminist analysis } \\
\text { (Scheman \& O'Connor, } \\
\text { 2002) }\end{array}$ & $\begin{array}{l}\text { Barnstone's surveyable } \\
\text { representation of the NT } \\
\text { world includes the Gnostic } \\
\text { Gospel of Mary, the only } \\
\text { early Christian text voiced } \\
\text { by a woman (2009:575-588) }\end{array}$ \\
\hline $\begin{array}{l}\text { Post-colonial theory } \\
\text { (Bassnett \& Trivedi, 1999) }\end{array}$ & $\begin{array}{l}\text { Wittgensteinian tools can } \\
\text { facilitate political analysis } \\
\text { (Holt, 1977). }\end{array}$ & $\begin{array}{l}\text { The use of Roman names } \\
\text { alongside Aramaic ones in } \\
\text { the TT foregrounds the } \\
\text { colonial situation in which } \\
\text { Jesus lived (e.g. Mark 15:1). }\end{array}$ \\
\hline $\begin{array}{l}\text { Relevance theory (Gutt, } \\
\text { 2000) }\end{array}$ & $\begin{array}{l}\text { Communication (PI } 1 \mathrm{ff} .) \text { is } \\
\text { described as a practice. }\end{array}$ & $\begin{array}{l}\text { Barnstone stresses the need } \\
\text { for a new translation because } \\
\text { language and literary } \\
\text { conventions change over } \\
\text { time }(2009: 13) \text {. }\end{array}$ \\
\hline $\begin{array}{l}\text { Stylistics (Boase-Beier, } \\
\text { 2006b) }\end{array}$ & $\begin{array}{l}\text { Meaning is seen as a } \\
\text { physiognomy (PI 128). }\end{array}$ & $\begin{array}{l}\text { Barnstone stresses his } \\
\text { translation of the poetry of } \\
\text { the NT (2009:14). }\end{array}$ \\
\hline
\end{tabular}

Each theory could be investigated in greater depth. With respect to skopos theory, for example, Barnstone's translation could be compared in its function to the recent German translation of the NT and other early Christian writings by Klaus Berger and Nord (1999), which also attempts to present a broader view of early Christianity than is found in the canonical texts. The texts have the same skopos. Theories are always partial (Hermans, 1985:12). As Guy Deutscher (2005:285) puts it, our labels are not perfect at catching every aspect of language, which recalls Wittgenstein's insistence that there are different philosophical methods and not a single one (PI 133). To divide people into sellers and buyers, for example, is useful at times but only 
captures part of the whole situation, for buyers can be sellers as well ( $C V$ p.26). What remains is theory in the sense of a view of the text in question, as argued in 1.3. This whole case study is my theory of the text.

Barnstone's strategy has been facilitated by his own theory of the NT, by the way in which he sees this cluster. We can describe what he has done by using tools from Wittgenstein, and then we can move on to other ways of theorising Barnstone. We therefore develop a theory of Barnstone. The process is dynamic. This case study aims to be a surveyable representation of a surveyable representation. It sees one particular translation as Wittgensteinian, which is to commend it as well worth reading and to offer it as an example of good practice to the reflective practitioner. To the translation theorist it offers an example of how to describe a text in dialogue with philosophy. To both practitioner and theorist it tells something about the surveyable representation that is literary translation. 


\subsection{Conclusions}

Bellos (2011:2) argues that the main issue in translation studies is not to understand what translation is, but to understand 'what translation does'. The later work of Wittgenstein provides a set of tools for anybody engaged in this quest because it facilitates the description of any TT. It allows the various practices of translation to be juxtaposed in family resemblance, so that the beetle is taken out of the box (PI 293). The translation theorist can form his or her own theory of translation, in line with the advice given by Pym (2010:166), quoted as (133).

When theorising translation, when developing your own translation theory, first identify a problem - a situation of doubt requiring action, or a question in need of an answer. Then go in search of ideas that can help you work on that problem. There is no need to start in any one paradigm, and certainly no need to belong to one.

A study of the later Wittgenstein can be of benefit to the translation theorist because it matches Pym's advice in three ways. Firstly, the phenomenon must precede any theorising about it, according to Wittgenstein, for whom description is crucial. Secondly, I have shown that certain of Wittgenstein's ideas are very useful for the translation theorist, such as: the surveyable representation; family resemblance; the language-game; the form of life; meaning as use. Thirdly, the Wittgensteinian approach militates against commitment to any one paradigm, because it is antidoctrinal. This chapter has used work by three translation theorists - Chesterman (1997), Toury $(1995,1980)$ and Tymockzo (2007) - to show how Wittgenstein has influenced the field and to suggest ways in which his influence could be extended.

Another motto Wittgenstein (RPP I 889) considered for his work was from Goethe: 'Don't look for anything behind the phenomena: they themselves are the theory' (1901:261). Wittgenstein, by destroying the Platonic paradigm, shows us that there is nothing metaphysical lurking behind phenomena. What we can do is to describe phenomena and how we approach them. We can show what translation does. I have written this chapter with the translation theorist in mind, but have shown that clarity about theory will affect practice, because how we view things inevitably influences how we do things (Toury, 1995:17-20). To translate means having a view of a text: the phenomenon is the theory, as Goethe states and as Wittgenstein shows. 
In Chapter 5, I consider what overall conclusions can be drawn from reading Wittgenstein's story in the context of the theory and practice of translation. 


\section{CONCLUSION}

The trouble about progress is that it always looks much greater than it really is.

Nestroy $(1926: 216)^{56}$

${ }^{56}$ Translation by Hacker \& Schulte (PI p.2) 


\subsection{Wittgenstein's story}

This thesis, as stressed in Chapter 1, has aimed to show that my reading of the later Wittgenstein can be of use to the reflective practitioner of translation, in the way Kerr (1988) aims to show that his reading of Wittgenstein can be of use in theology. I have examined the three ways in which translation operates: the reading for translation of the ST (Chapter 2); the writing of the TT (Chapter 3); the theorisation of the TT (Chapter 4). I have argued that my reading of Wittgenstein shows how translation is anthropic at all three stages and that Wittgensteinian tools can help the reflective practitioner deal with the issues that arise from the phenomenon of translation. This thesis is therefore not about Wittgenstein, but rather about translation, under Wittgensteinian investigation. In the Conclusion, I sum up the implications of translation after Wittgenstein, following Wittgenstein's remark on how inquiry has to move beyond merely narrating what has taken place: 'Why do I want to tell him about an intention too, over and above telling him what I did ... because I want to tell him something about myself, which goes beyond what happened at the time' (PI 659).

In his memoir of Wittgenstein, Malcolm (1958:53) gives the recollection quoted as (134).

Wittgenstein related a riddle for the purpose of throwing some light on the nature of philosophy. It went as follows: Suppose that a cord was stretched around the earth at the equator. Now suppose that a piece one yard long was added to the cord. If the cord was kept taut and circular in form, how much above the surface of the earth would it be? Without stopping to work it out, everyone present was inclined to say that the distance from the earth would be so minute that it would be imperceptible. But this is wrong. The actual distance would be nearly six inches. Wittgenstein declared that it is this kind of mistake that occurs in philosophy. It consists in being misled by a picture. In the riddle the picture itself is correct enough: for a piece one yard long would be an insignificant fraction of the length of the whole cord. But we are misled by it to draw a wrong conclusion. A similar thing happens in philosophy: we are constantly deceived by mental pictures which are in themselves correct.

The story can stand as a parable for the project of the later Wittgenstein. A new way of looking at the world is offered that brings clarity. In terms of applying this to translation, the last sentence of (134) could, I contend, be written as follows: 'A similar thing happens in translation; we are constantly deceived by mental pictures 
which are in themselves correct'. An example of this is the view that translation is transfer, as argued in 3.1.

It is significant that Wittgenstein uses a narrative to show others the nature of his later philosophy, rather than using more traditional tools of philosophical inquiry, such as syllogism or sustained argument. A story is told and, if accepted by his listeners as convincing, it can then be used as the basis of a new way of doing philosophy: here, a re-evaluation of the way that we can be deceived by geometry is called for, which involves a new way of seeing the world. Narratives are fundamental to the way that we live. In a study of what he terms the 'literary mind', Mark Turner (1998:168) argues that this is because narrative is basic to how the human mind functions, so that language results from story; his thesis reverses what Turner describes as the more usual view that sees story as a product of language. Jonathan Safran Foer, in an argument against eating animals, claims that the stories we tell each other are more important than reason in determining what we do (2009:8). It is possible to tell a story about human life that involves slaughtering animals and eating them, or else one in which this is not the case, and an individual may make up his or her mind on what to do depending on which story he or she wants to tell in his or her own life.

I correspondingly see the later Wittgenstein as telling a story about language that can change the way that the world is seen and, by implication, the way that translation is seen and conducted. The PI, significantly, contains many stories, some extended, about how people behave, in line with Wittgenstein's stress on seeing things from different angles ( $C V$ p.9). In Table 15, I show those stories upon which I have drawn, indicating the source and the chapter in my thesis in which I use them.

\section{TABLE 15: WITTGENSTEIN'S STORIES}

\begin{tabular}{|l|l|l|l|}
\hline STORY & SOURCE & CHAPTER & DESCRIPTION \\
\hline $\begin{array}{l}\text { Augustine's } \\
\text { account of } \\
\text { language }\end{array}$ & PI 1 & 2 & $\begin{array}{l}\text { Augustine describes how he } \\
\text { learned language as a child as } \\
\text { a process of ostensive } \\
\text { definition. }\end{array}$ \\
\hline The shopping trip & PI 1 & 3 & $\begin{array}{l}\text { The purchase of five red } \\
\text { apples shows that language is } \\
\text { transactional. }\end{array}$ \\
\hline
\end{tabular}




\begin{tabular}{|l|l|l|l|}
\hline The builders & PI2 ff. & 2,4 & $\begin{array}{l}\text { The activity of building } \\
\text { proceeds using a limited } \\
\text { number of expressions. }\end{array}$ \\
\hline $\begin{array}{l}\text { The beetle in the } \\
\text { box }\end{array}$ & PI 293 & 4 & $\begin{array}{l}\text { You cannot know what a } \\
\text { beetle is, if it is kept in a box. }\end{array}$ \\
\hline $\begin{array}{l}\text { The cord round } \\
\text { the earth. }\end{array}$ & $\begin{array}{l}\text { Malcolm } \\
(1984: 53)\end{array}$ & 5 & Appearances can deceive. \\
\hline $\begin{array}{l}\text { The strange wood } \\
\text { sellers }\end{array}$ & RFM I-143ff. & 5 (below) & $\begin{array}{l}\text { Wood sellers are described } \\
\text { who reckon the price of wood } \\
\text { unconventionally. }\end{array}$ \\
\hline
\end{tabular}

The $P I$ can be seen as narrative in nature. Wittgenstein (PI p.4) describes it as an album. The description is fitting, for a reading of the $P I$ is similar to being with somebody taking you through a selection of photographs, showing picture after picture and describing them, whilst drawing you into dialogue about the pictures. I do not want to suggest that the whole book tells one story, only that a vision of being human does emerge. The cumulative effect of the parables, the questions, the dialogues, the discussions and the examples is formidable. Cook and Read (2010:484), writing about the poem 'Thirteen Ways of Looking at a Blackbird' by Stevens, imagine a series of short stories, 'Thirteen Ways of Looking at Language', which would be a series of scenarios designed to make the reader re-examine his or her language. They conclude: 'But actually, one doesn't have to imagine that series: Wittgenstein did actually write it.' A Wittgensteinian book on translation might similarly be written using a series of (surveyably represented) translations. This approach, suggested by that of Weinberger and Paz (1987) (as described in 4.3), has been followed in this thesis: I offered case studies (in 3.5 and 4.5, of my translations of Mörike and of Barnstone's translation of the NT respectively) to show how translation after Wittgenstein could function. Other translations, such as Adair (1995) or Whitinger (2005) have been referred to in passing, using Adair in 3.4 as an example of a translation that plays the same language-games as its ST and Whitinger in 3.5 as an example of a translation that does not.

If the story of the PI offers a story of language that is of use to the reflective practitioner of translation, it is important to set this against another story that offers a different picture, the picture from which Wittgenstein would liberate his readers in a 
process analogous to therapy (PI 133), just as the correct answer to Wittgenstein's riddle of the rope in text (133) is set up against the false picture of an extended rope round the world on which we intuitively rely. The PI begins with a quotation from Augustine, an autobiographical narrative on how he as a child learned to speak by being offered ostensive definitions by his parents (PI 1). Wittgenstein undermines Augustine's account by offering other narratives (such as the story of the trip to the shops to buy red apples in PI 1), which are intended to come across as more convincing. But it is important to note that this is not a clash of theories. As Monk (2007:285) notes: Augustine 'is not articulating a theory about language and what follows that passage is not an attempt by Wittgenstein to refute a theory. The point of opening the book with that quotation, rather, is that it gives a perfect example of the kind of pre-philosophical picture of the relation between words and objects that Wittgenstein believes gives rise to philosophical ideas and theories and, therefore to confusion. Wittgenstein's task ... is to locate the source of the Augustinian picture and to try to replace it with another picture, one which does not give rise to the relevant philosophical confusions.' And the Augustinian paradigm does not go away but remains constantly in the background of the $P I$, representing a tendency against which it is always necessary to struggle.

Just as there is talk of folk psychology, common-sense accounts of human behaviour that seem to make sense but that are misleading when analysed (Stich \& Ravenscroft, 1994), so the Augustinian picture, according to Wittgenstein, is one that is widely and deeply but unconsciously held. It can be categorised as a folk linguistics that is profoundly dualist. Given the sort of beings we are, it is not surprising that we do interpret the world in a dualist way. Steiner (1997:135), for example, makes the assertion quoted as (135).

... the hybrid nature of the language-experience, its material-immaterial, abstractconcrete, physical-mental dualism is a central donné $e^{57}$ of consciousness. We cannot escape from the inherent coincidentia oppositorum ${ }^{58}$.

${ }^{57}$ French: 'given fact'.

${ }^{58}$ Latin: 'coincidence of opposites'. 
As Wittgenstein (PI 340) asserts, the prejudice to which we are in thrall is not a stupid one. The dualist tendency is manifest in many important figures in western intellectual history, as noted in 3.1, such as Eckhart or Kafka. To note that an author is dualist is not to imply anything about the quality of his or her work, of course. From a translation point of view, however, the dualist story is pernicious when it influences our approach to rendering the literary in another language. In Chapter 3, I showed, through an analysis of Berman (2004), that literary translation has often been deformed by being approached as if it were non-literary translation in the belief that it is possible to separate form and content. Translation becomes a transfer of information, which is not what literature is about, a point made by Benjamin (2004:75).

At the very least, Wittgenstein's story shows that translation is possible. As Steiner (1998:97) notes, it is an operational model of the linguistic process and as such refutes any deterministic parallelism of thought and speech (such as that associated with the work of Whorf), through its proposal that the meaning of a word is its use in the language (PI 43). If the meaning of a word is not its use in the language, then Benjamin's proposal (2004:83) that the best translation is an interlinear gloss would seem reasonable, the best we might hope for. But why stop there? What about the word-for-word literal translation into the same language, as depicted by Jorge Luis Borges (2000) as a literary reductio ad absurdum? In his story, the translation into Spanish by Pierre Menard of the Spanish novel Don Quixote by Miguel de Cervantes intends to produce work that would coincide - word for word and line for line - with the work of Cervantes. The product is seen as a supreme act of translation because it replicates the prose of the earlier author (Cervantes) in the modern world of the translator (Menard). As the narrator comments: 'The Cervantes text and the Menard text are verbally identical, but the second is almost infinitely richer' (2000:40). The inherent absurdity of the strategy even though a changed context may make words richer than when they were written, it is hardly practical to recommend translating SL into SL to aspiring translators shows the need for an operational model.

Wittgenstein tells a story about language and how it is used. The PI gives a rich picture of this use: words are seen in context, as part of the flow of human life, in accordance with what he writes in LWPP II 118: 'An expression has meaning only in the stream of life'. The stream of life is presented in many different ways in the 
PI. Language is shown to be constituted by its activities, so that we can speak of language-games, such as reporting an event, telling a joke or translating a text (PI 23); a language-game only makes sense against a form of life (PI 19); concepts are seen as blurred and linked by family resemblance, rather than as essential (PI 67); grammar can be both surface and deep (PI 664); meaning is a physiognomy because the meaning of an utterance depends on its style (PI 568); it becomes more important to look than to think (PI 66); it is possible to make a surveyable representation, a description of what has been seen (PI 122) etc. Such a story is of immense value to the reflective practitioner of translation because it is a story about language that offers practical tools. The translator who is brought to see how language works is in a better position to read the ST, to translate the ST and to theorise the TT. Here is the ultimate value of reading Wittgenstein, who was recorded by Rhees (1970:43) as claiming: 'I don't try to make you believe something you don't believe, but to make you do something you won't do'.

Hacker (2007b:116-117) sums up Wittgenstein's contribution to philosophy in the text given as (136).

[Wittgenstein] resolved many of the deep problems that have dogged our subject for centuries, sometimes indeed for more than two millennia, problems about the nature of linguistic representation, about the relationship between thought and language, about solipsism and idealism, self-knowledge and knowledge of other minds, and about the nature of necessary truth and of mathematical propositions. He ploughed up the soil of European philosophy of logic and language. He gave us a novel and immensely fruitful array of insights into philosophy of psychology. He attempted to overturn centuries of reflection on the nature of mathematics and mathematical truth. He undermined foundationalist epistemology. And he bequeathed us a vision of philosophy as a contribution to human understanding - understanding of the forms of our thought and of the conceptual confusions into which we are liable to fall.

Fundamental to this reading of Wittgenstein is that what is offered is a contribution to human understanding, not to human knowledge, which implies that Wittgenstein can be applied wherever we attempt to make sense of the human condition, a condition that involves translation. Given that translation is a language-game (PI 23), it is a practice particularly suited for the application of Wittgenstein's account, which begins and ends with language. Whilst it is difficult to see how the work of certain philosophers, such as Hume, could be regarded as essential reading for translators 
anxious to master their craft, to read Wittgenstein can bring practical benefits because it transforms our understanding about language. Having read Wittgenstein, even the standard generic opposition between the literary text and the non-literary text can fall away. A text is literary not because of its genre but because of the way that it can be used. An advertisement, for example, can display literary language, through use of alliteration etc., and can be said to have a literary function if this is the case. A poem can fail to display literary language by not making any demands on its reader, for example, and can be said to fail to have a literary function. Wittgenstein enables us to see things as three-dimensional, much as the colour octahedron (referred to by Wittgenstein as a surveyable representation, $P R$ 51-52) enables us to see the spectrum in a way that is three-dimensional as opposed to twodimensional. Literature is shown to be about the creative use of language, as is the translation of literature, and tools are offered to enable the translator to move on from this insight. At the very least we are delivered from false paradigms. We are able to free ourselves from misleading pictures and to fly out of the fly-bottle (cf. PI 309). But there is more than this. A whole world of possibilities is opened up as Wittgenstein's work in turn opens up new ways of translating once the false paradigms have been shattered, once we realise that there is no paradigm to which we must conform. Wittgenstein offers tools, not a blueprint of how to translate. As Winch (2008:82) asserts: 'a historian or sociologist of religion must have some religious feeling if he is to make sense of the religious movement he is studying and understand the considerations which govern the lives of its participants'. The translator similarly needs to develop literary feeling, and the Wittgensteinian approach can facilitate its development, whether he or she is reading the ST, writing the TT or theorising the TT. Philosophy is a practical activity, not a working-out of some doctrine. Wittgenstein is to be seen not as a linguistic policeman but as a therapist and as a coach. After that it is down to the translator. As Giles Foden (2012:16), discussing creative writing, puts it: 'now you're on your own mate, it's your skin in the game'. 


\subsection{Practice and theory}

Gary Hagberg (1995:1) notes how, following Wittgenstein, it is 'now widely understood that any particular concept of linguistic meaning to which one subscribes can shape one's beliefs in related fields of philosophy such as the philosophy of mind, metaphysics and the philosophy of perception, and of course aesthetics'. How we see language determines how we see the world. If translation is viewed as an aesthetic undertaking, as in the translation of literary texts, then it follows that to subscribe to the concept of linguistic meaning associated with the later Wittgenstein is to shape one's beliefs about translation and therefore one's practice of translation in line with that philosophy. Here is the major effect of applying Wittgenstein to translation studies: that it will change the way we see things and therefore the way we do things.

Wittgenstein, as argued in 1.3, was not a theorist, though many have taken him to be a guru. What he was offering was not a theory in the sense of a doctrine, but what Baker and Hacker (1986:35) call 'a single penetrating vision'. His work remains opposed to any attempt to build a theory of language, despite this being the tendency in contemporary analytical philosophy (Baker \& Hacker, 1986:29) and it therefore cannot form the basis of any theory of translation or any philosophy of translation, not even a Wittgensteinian one. Wittgenstein 'in effect reverses the traditional direction of fit between meaning and understanding, completely reorienting the role of explanation in an account of the nature of language and linguistic competence' (Baker \& Hacker, 1986:29).

It might therefore be thought that the Wittgensteinian position should be a resolute 'no theory' approach, which is what some of his followers have advocated (Read, 2007a). What would this actually mean? Richard Allen and Malcolm Turvey argue that if the later Wittgenstein is right then 'theory itself is in most cases a logically inappropriate form of explanation for humanistic subject matter' (2001:2). Their argument rests on a view of theory as an attempt to see unity in diverse phenomena and hence to reveal a hidden link between the phenomena under investigation. Wittgenstein's work would resist theory conceived thus because it sees phenomena linked by family resemblance rather than by unity (PI $67 \mathrm{ff}$.) and also sees nothing as being hidden, because everything lies open to view (PI 126). The project of the $P I$ is descriptive, so that we 'may not advance any sort of theory. There must not be anything hypothetical in our considerations' (PI 109). Wittgenstein 
compares a rule to a signpost: 'Does the signpost leave no doubt about the way I have to go? Does it show which direction I am to take when I have passed it, whether along the road or the footpath or cross-country?' (PI 85). As Allen and Turvey (2001:9) comment, doubt does not arise in how we interpret a signpost, because a signpost is traditionally used in a certain way: 'It is embedded in a practice in which the accepted thing is to follow the pointing finger, rather than going the opposite way'. We do not have a theory of the signpost but rather a practice of the signpost.

However, it all depends on what you mean by theory, as they say in philosophy. The term 'theory' can be shown to exist in a network of family resemblance. As Dwight Furrow (1995:1) argues, it has so many uses and applies in so many different contexts 'that it probably cannot be given a very precise definition capturing all of its instances'. A theory can be any of the following: a hypothesis; an explanation; a finished piece of work; a view; a doctrine; a stance taken towards practice; soft (as in the humanities); hardcore (as in the sciences). The final two items in the list are of key importance here. In 1.3, I cited Iser's assertion (2006:5) that predictive hardcore theory is proper to the sciences and descriptive soft theory is proper to the humanities. Wittgenstein can be used to support Iser's assertion. As Allen and Turvey $(2001: 24)$ maintain, the rejection in the humanities of what Iser would call hardcore theory 'by no means rules out descriptive or explanatory generalisations about human behaviour from the realm of humanistic scholarship. ... The key point is, however, that such generalisations should not be confused with theoretical generalisations, such as those found in the natural sciences, even though generalisations about human beings may sometimes seem like "discoveries" of hidden "laws" governing human behaviour'. Hence Allen and Turvey would rule out the application of a theory such as structuralism within the humanities (2001:26 ff.). We are not looking for laws in subjects such as history or literary studies, in the sense of something that both describes and predicts behaviour. A barrister who speaks of law, for example, means something very different from what a physicist means by the term. In the humanistic investigation of translation, we can follow Wittgenstein and not advance any theory if we put first the text, its translation and its examination, rather than beginning by advancing a doctrine. Such an approach is in line with good practice in translation, as Steiner (1998:311) notes: 'Like mutations in the improvement of the species, major acts of translation seem to have a chance necessity. The logic comes after the fact. What we are dealing with is not a science, 
but an exact art'. To see translation as an exact art opens the door on how theory understood as soft theory, as something appropriate to an art not to a science - may be used in translation after Wittgenstein.

There is an analogy with how we describe human behaviour. As Hacker (2001:70) argues in a discussion of how a reading of Wittgenstein can be of benefit to those involved in the humanities, there is not a single form of explanation appropriate to understanding human behaviour. To account for why Anna did something, it might be necessary to look at: her motives (including her desires and wants); the reasons why she acted; the tendencies observed in her (including her customs, habits and dispositions of character); the physical and normative constraints to which she is subject etc. It is similarly the case that to understand a text, more than one soft theory is necessary. The translation theories reviewed in 4.5, for example, can in many cases be used in parallel to describe the TT: I can examine its function with reference to skopos theory; its style by reference to stylistics; its place in the canon by reference to polysystems theory etc. In that these are soft theories, they do not cancel each other out, just as it would make no sense to say to someone that because we have explained Anna's motives, it is pointless to look at her habits. Such an investigation from multiple perspectives is in line with the way the $P I$ is written.

Robinson (1991:xvi) makes the point that it is time 'to offer translators tools, not rules', because rules tend to suggest that a translation can be done according to a formulaic view of equivalence. As Boase-Beier (2010c:36) asserts, theories about how to translate 'are not meant to be sets of instructions and they serve translators ... badly when so used'. Wittgenstein's ideas in the PI can be used as tools by the reflective practitioner of translation, as in Table 16, which shows nine Wittgensteinian tools.

\section{TABLE 16: WITTGENSTEINIAN TOOLS FOR TRANSLATION STUDIES}

\begin{tabular}{|l|l|}
\hline WITTGENSTEINIAN TOOL & EXAMPLE OF APPLICATION \\
\hline The language-game (PI $23 \mathrm{ff})$. & $\begin{array}{l}\text { The language-game of the ST can be } \\
\text { identified and played in the TT. }\end{array}$ \\
\hline The form of life (PI 19) & $\begin{array}{l}\text { The form of life of the ST can be identified } \\
\text { and related to the form of life of the } \\
\text { projected readership of the TT. }\end{array}$ \\
\hline
\end{tabular}




\begin{tabular}{|l|l|}
\hline Following a rule (PI 185 ff.) & $\begin{array}{l}\text { Rules are descriptive of practice not } \\
\text { prescriptive. It is practice that is fundamental } \\
\text { to inquiry. }\end{array}$ \\
\hline Grammatical investigation (PI 90) & $\begin{array}{l}\text { Terms can be investigated to ensure clarity } \\
\text { and consistency in describing a translation. }\end{array}$ \\
\hline Deep and surface grammar (PI 664) & $\begin{array}{l}\text { The deep grammar of a sentence can be } \\
\text { investigated to show how surface grammar } \\
\text { may be misleading. }\end{array}$ \\
\hline Meaning as use (PI 43) & $\begin{array}{l}\text { To see meaning as use can emancipate the } \\
\text { translator from a naive view of equivalence } \\
\text { as dictionary meaning. }\end{array}$ \\
\hline The surveyable representation $(P I 122)$ & $\begin{array}{l}\text { The TT can be seen as an attempt to give a } \\
\text { surveyable representation of the ST, both in } \\
\text { how it is translated and how it is presented. }\end{array}$ \\
\hline Private language (PI 269 ff.) & $\begin{array}{l}\text { Wittgenstein's argument against a private } \\
\text { language shows the translator that it is a } \\
\text { mistake to see a perfect language lying } \\
\text { behind a text. }\end{array}$ \\
\hline Meaning blindness $(P P 118 \mathrm{ff})$. & $\begin{array}{l}\text { The literariness of the ST can be taken into } \\
\text { account so that translation is not seen as } \\
\text { transferring information. }\end{array}$ \\
\hline
\end{tabular}

These are both practical tools and theoretical tools. They can be used when translating a text and also to support the translational strategies chosen. What a translator says about his or her rendering or about a particular view of the ST or TT may carry more force for a reader if it is related to the work of Wittgenstein. This is how Steiner (1998) uses Wittgenstein, for example, to support his own argumentation. Is this to fall into the informal fallacy of argumentum ad verecundiam $^{59}$, i.e. the assumption that because an authority is quoted in support of a premise, then that premise must be true? I think that one must be aware of this danger, just as Searle (1987:342) comments that references to Wittgenstein outside philosophy are often 'a kind of name-dropping' ${ }^{60}$ The referencing of Wittgenstein must be done in the spirit of Wittgenstein. Steiner does not merely appeal to Wittgenstein but presents Wittgenstein's views and works through them (Steiner, 1998:169 ff.), which has been the procedure of this thesis.

\footnotetext{
${ }^{59}$ Latin: 'appeal to reverence'.

${ }^{60}$ See the discussion of Perloff in 1.5.3.
} 
There is a significant example of how Wittgenstein's work can be used in translation in Robinson's guide to becoming a translator (2003), where he tries to undermine the picture of the translator sitting opposite a text, magisterially rendering it like Jerome in his isolated cave. Robinson aims to show that translation is as much about people as texts, and uses Wittgenstein for support, as in the quotation given as (137) (Robinson 2003:112).

While words and meanings are unquestionably important ... they are really only important for the translator (as for most people) in the context of someone actually using them, speaking or writing them to someone else. When the Austrian philosopher Ludwig Wittgenstein quipped ... that 'the meaning of a word is its use in the language', he meant that people using language always take precedence - or at least should take precedence - over meanings in the dictionary, semantic fields in the abstract.

Robinson (2003:112-113) illustrates this by telling a story of Jim and Maria who cohabit and speak English, although this is not Maria's first language. At times they have a misunderstanding over the word 'silly', which Jim uses as a term of endearment but which Maria takes to be offensive. She learns eventually that the way the word is used means that Jim is not trying to hurt her, and she is then able to notice the occasions when he does use it to mean 'stupid'. Therefore translators typically translate into languages in which they are fluent. Robinson (2003:101) gives examples of translations that have been produced because this practice was ignored, for example, the sign found in English in a Moscow hotel room: 'If this is your first visit to Russia, you are welcome to it.' He describes this as an instance of 'the "bad" translation done by someone who doesn't speak the target language fluently, and has painstakingly found all the words in the dictionary'. In this example from Moscow, the problem is that it is difficult for a native speaker of English not to read this as expressing sarcasm, because of the way that the expression 'you are welcome to it' is commonly used to indicate contemptuous dismissal, in contrast to the phrase 'you're welcome', which is a polite expression of recognition. (The point also holds, though Robinson does not make it, that the translator needs to be able to use the SL properly also.) 
Robinson's referencing of Wittgenstein is then linked to a practical application (2003:124-126). Robinson asks the question: 'If, as Ludwig Wittgenstein says, "the meaning of a word is its use in the language", and that use varies from person to person and from situation to situation, how is it ever possible to know what someone else means?' Robinson gives a series of exercises - such as considering the multiple meanings of common words, repeating taboo words or deliberately speaking in bad grammar - in order to encourage the reader to explore Wittgenstein's concept, an approach in line with the method of the PI and Robinson's anthropic view of translation. A false picture of the practice of translation is destroyed and the way is open for clarity in practice, though no prescriptions are given for practice. Authority is not so much appealed to as demonstrated and it seems to me that this is a reasonable way to represent a philosopher who struggled against dogmatism and for the achievement of flexibility without loss of rigour (Kuusela, 2008:3).

If Wittgenstein is correct in his approach to language, then what he wrote will in turn influence the practice of the translator, just as Robinson aims to change the practice of those who read his book through his appeal to Wittgenstein. Here is an example of how theory can influence practice. Boase-Beier (2010b:27) asserts that because soft theories are explanatory 'they become part of the way we approach the world in a very practical sense. They may not dictate practice, but they will certainly influence it'. Wittgenstein is of use to the reflective practitioner of translation because he can free him or her from false paradigms. Fawcett and Guadarrama García (2010:10) explain the typically apologetic western translator's note found in the paratext to many literary translations by the fact that behind it 'probably lies, for example, the Augustinian, the Lutheran, or the Romantic paradigm, all of them models upon which, according to Robinson (1991:3-123), the edifice of mainstream western translation theory can be seen to rest'. As argued in 5.1, these dualistic paradigms are destroyed by Wittgenstein in a process analogous to therapy (PI 133), whilst the vision of the later work can enable the translator to move forward with clarity. As Janik \& Toulmin (1973:261) assert, Wittgenstein must be seen 'not merely as a terminus ad quem, but also a possible terminus a quo, ${ }^{, 61}$.

${ }^{61}$ The Latin terms signify 'finishing point' and 'starting point' respectively. 
To read the later Wittgenstein is, I think, to be offered a short-cut to being enabled to view clearly the issues at the heart of translation. As Kerr (1988:170) notes: 'After working through Wittgenstein's writings we simply have a different way of expressing ourselves ... we have simply changed the subject'. Philosophy does, as Wittgenstein remarks (PI 124), indeed leave everything as it is: it can only describe language and cannot give any foundation. What can happen, though, is that the user of language (i.e. Wittgenstein's reader) can be changed and can act differently. It is the conviction of this thesis that such change is desirable. Translation studies must look outside its field, to philosophy, if it wants to understand itself. In Chapter 1, I discussed the link between translation studies and philosophy and have shown throughout this thesis how Wittgenstein's philosophy can offer support to translation studies. I do not see Wittgenstein's work being used to provide a philosophy of translation. I doubt whether any such thing is possible, but to investigate the question fully would lie outside the scope of this thesis. In the Introduction, I cited Read (2007:4) that what matters is whether Wittgenstein's chosen methods work and whether we can learn to go on. I have shown, by reference to translation, that the methods do work and that we can go on. There is a twofold movement. The ideas of Wittgenstein illuminate the phenomenon of translation. The phenomenon of translation illuminates the work of Wittgenstein. (The second point is incidental to this thesis, but important in itself.)

Wittgenstein can be used as a way of identifying and reading other works that might be useful to the reflective practitioner of translation, just as many Wittgensteinian philosophers have used Wittgenstein as a way of elucidating and applying other philosophers in the canon: Anscombe, for example, returned to Aristotle after her reading of Wittgenstein (Teichmann, 2008). An example of how this might be done in translation studies is to read Goethe's comments on translation (2004), through Wittgenstein. Goethe sees three kinds of translation of the ST: the prose version (translation); the parody (adaptation); the translation of perfect identity (transmutation). It could be shown how his three kinds of translation exist in a family resemblance of translated texts and how his work is a description of phenomena rather than a theoretical stipulation, both of which are Wittgensteinian goals. Wittgenstein offers tools to test where other authors have been right about translation. Following Cook and Read (2010), who see Stevens as Wittgensteinian, I similarly view Weinberger as Wittgensteinian in 4.3. 
It would be possible to compile a Wittgensteinian reading list for translators, as a tool for translator training. Figure 2 is one such list. Many others are possible. This is a project that can only be sketched here. Barnstone and Steiner acknowledge the influence of Wittgenstein. Berman, Goethe and Weinberger are in parallel with his thinking. Klee addresses art, not language, but offers a primer that is truly Wittgensteinian in showing its reader how to look at the world. Tymockzo applies Wittgenstein in order to extend the western model of translation and to enhance the translator's form of life. Finally there is the PI itself. The purpose of any book on Wittgenstein for translators must be to direct them to the text that Wittgenstein wrote. The books in the list point towards the $P I$ and my thesis is similarly a signpost to the work of the later Wittgenstein.

\section{FIGURE 2: A WITTGENSTEINIAN READING LIST FOR TRANSLATION}

Barnstone, W. (1993) The Poetics of Translation

Berman, A. (2004) 'Translation and the Trials of the Foreign'

Goethe (2004) 'Translation'

Klee, P. (1989) Pedagogical Sketchbook

Robinson, D. (2003) Becoming a Translator

Steiner, G. (1998) After Babel

Tymoczko, M. (2007) Enlarging Translation, Empowering Translators

Weinberger, E. \& O. Paz (1987) 19 Ways of Looking at Wang Wei

Wittgenstein, L. (2009) Philosophical Investigations 


\subsection{Why Wittgenstein}

In 1941, Wittgenstein (McGuinness, 2008:341) wrote to G.E. Moore and recommended the German poem 'Das heilige Feuer' ('The Holy Fire') by C.F. Meyer, stressing that if Moore were to read it then it would tell him exactly what Wittgenstein wanted to say. McGuinness gives the German text together with his own translation (McGuinness, 2008:341-342), which I quote here as (138) and (139) respectively.

Auf das Feuer mit dem goldnen Strahle onto the fire with the golden beam Heftet sich in tiefer Mitternacht fixes itself in deep midnight Schlummerlos das Auge der Vestale, sleepless the eye of-the vestal Die der Göttin ewig Licht bewacht. who of-the Goddess eternal light watches

Wenn sie schlummerte, wenn sie entschliefe, if she slumbered if she fell-asleep Wenn erstürbe die versäumte Glut, if died the neglected glow Eingesargt in Gruft und Grabestiefe entombed in crypt and grave's-depth Würde sie, wo Staub und Moder ruht! would-be she where dust and mould rests

Eine Flamme zittert mir im Busen, a flame trembles to-me in-the breast Lodert warm zu jeder Zeit und Frist, blazes warm to every time and span Die entzündet durch den Hauch der Musen which kindled by the breath of-the muses Ihnen ein beständig Opfer ist. to-them a constant sacrifice is

Und ich hüte sie mit heil'ger Scheue, and I tend it with holy awe $\mathrm{Daß}$ sie brenne rein und ungekränkt; that it may-burn pure and untroubled Denn ich weiß, es wird der ungetreue for I know it is the untrue Wächter lebend in die Gruft versenkt. watcher living into the crypt lowered 
On the fire with its golden rays

In the deepest hours of the night

Unsleepingly the Vestal bends her gaze

To guard the goddess's eternal light.

Should she slumber, should she drop to sleep,

Should the neglected embers fade and die,

In coffin-vault must she be buried deep,

Alone with dust and foul decay to lie.

Within my breast another flame does shine,

It leaps up warm at every tide and turn,

A standing offering at the Muses' shrine:

By their breath kindled, for them does it burn.

And close I tend it, with a holy dread,

Pure and unsullied seek its light to save,

Knowing, that, who this wardship has betrayed,

Will be sent down to a living grave.

Wittgenstein stresses: 'My whole object in writing to you was to say: may a good spirit be with you and keep you from getting dizzy and falling down'.

Recent commentators have stressed the importance when reading Wittgenstein of being aware of the spirit in which he wrote (Monk 2002:14) and Meyer's poem does, I think, illustrate this: the deep ethical seriousness of the philosophical enterprise; the high price to be paid for failure; the need to be absolutely attentive to phenomena. The poem reflects this ethic in the stateliness of its verse and the beauty of its imagery. It is therefore ironic that the translation in (139) undermines Meyer's poetic achievement through failing to echo the style of the ST in (138). The translation on the surface conveys the information of the ST but the English reads awkwardly. May (1994:1) states that a translation should rebuild a work at all levels and asks her reader to imagine trying to rebuild an onion: 'translation repacks all the strata of a text, sometimes arranging them loosely, sometimes fitting them well, sometimes striving to reproduce one stratum exactly at the expense of all the others, but inevitably affecting each layer by changes in the others'. Text (139) has the same rhyme scheme as the Meyer (though McGuinness does not replicate the alternating feminine and masculine rhymes of the ST) but pays a high price for it. It is reminiscent of Wittgenstein's assertion that trying to draw a 
single chart of a nurse's perambulations on various floors of a hospital would be of no use to anybody (Pascal, 1984:13).

Examples of how the translation fails are: neither the ST nor the TT is given a title by McGuinness, though Meyer's title is mentioned in a note; lines 1 and 2 set up a trochaic pattern that is broken clumsily in line 3; the adverb 'unsleepingly' in line 2 is clumsy and the image of the Vestal Virgin bending her gaze unsleepingly is ridiculous; in line 4 the iambic pattern clashes with a natural reading of 'goddess's'; the repetition of $/ \mathrm{sh} /$ in lines 5 and 6 makes the poem difficult to recite with dignity; 'embers' in line 6 is an unfortunate choice because it confuses the order of events, because embers have already undergone a process of fading; the image of the 'coffin-vault' in line 7, whilst interesting in itself, is unsatisfactory in context because people are not buried in vaults, whilst a Roman Vestal Virgin would not have been placed in a coffin-vault; the 'living grave' of line 16 is an oxymoron which does not represent the German image of being sent living to the grave where the Vestal will die; the syntax of the final two lines is confusing. The rendering is hardly a surveyable representation of the masterful prosody of Meyer and it shows how the work of Wittgenstein has not been applied to translation. The ST is a great poem in the German canon. Whilst I do not expect McGuinness to produce a great poem for the English canon, I am disappointed that he offers his readers what amounts to a clumsy parody, and it is difficult to imagine anybody, let alone Wittgenstein, recommending this translation as summing up exactly what he or she wanted to say. That this translation should appear in an important edition of Wittgenstein's letters is nothing short of disastrous. (The translation by Winch of a poem by Wittgenstein ( $C V$ p.100) is successful precisely because, as Winch (ibid.) states, the rhythms of the German are suggested 'only roughly' and there is no attempt to render rhyme.)

There has been a failure here to apply Wittgenstein. As Crary (2000b:140) asserts, Wittgenstein stresses the role of human agency in language, so that his view of meaning 'calls on us ... to use - and perhaps stretch - our imagination', given that language cannot be assessed from an external perspective. If his philosophy demands the use of the imagination, then the application of his philosophy to translation will likewise demand the use of the imagination. McGuinness has failed to see the poem as an onion and has concentrated on rebuilding rhymed meaning, which is more like trying to rebuild a potato. In any case, as I indicated above, much of the meaning is 
lost. Wittgenstein offers a vision for rebuilding the onion, and the tools to undertake the task. In 1.3 I asked, 'Why Wittgenstein?' The answer is that he can be of use in showing the translator possible ways of proceeding, for example: by playing the language-games of the ST rather than looking for equivalent effects; by considering the form of life represented in the ST; by aiming to produce a surveyable representation in the TT, both in how the ST has been rendered and how the text is presented to the reader.

Wittgenstein used to say that a philosopher who did not take part in discussions was like a boxer who never went into the ring (Drury, 1973:vii). I think something similar applies to translation. Translation is a practice. It is easy to criticise McGuinness's work, but it is important to be able to show that one's views can have a practical application and that it is possible - here - to translate (138) so that it shows the spirit in which Wittgenstein wrote. Having criticised McGuinness's translation, I therefore offer my own. In line with what I wrote in Chapter 4 about the organisation of translation after Wittgenstein, I set my three translations out in (140) on page 247 as a surveyable representation. Other forms of representation are possible, just as other translations are possible. A problem has been solved, though there was no systematic way of solving it: one poem has simply been replaced by another (cf. $Z$ 698). The representation is explained in Table 17, which maps the ST and its three translations.

\section{TABLE 17: A SURVEYABLE REPRESENTATION OF (140)}

\begin{tabular}{|l|l|}
\hline $\begin{array}{l}\text { The ST by C.F. Meyer: this has not been } \\
\text { glossed, as glossing makes the German } \\
\text { harder to follow and I am assuming a context } \\
\text { outside translation studies where the reader } \\
\text { is reading for pleasure rather than } \\
\text { scholarship. }\end{array}$ & $\begin{array}{l}\text { My first poetic translation of the ST, which } \\
\text { aims to rebuild the form. The formal rhyme } \\
\text { scheme of the ST is echoed in the use of half } \\
\text { rhyme but rhyme is not allowed to lead the } \\
\text { translation. }\end{array}$ \\
\hline $\begin{array}{l}\text { A plain prose but lineated translation of the } \\
\text { ST that enables the reader to see what is } \\
\text { going on in the German and that follows the }\end{array}$ & $\begin{array}{l}\text { My second poetic translation of the ST, a } \\
\text { relocation where the voice is more self- } \\
\text { conscious, more contemporary (instead of } \\
\text { Muses, the narrator is 'amused' in line 8). } \\
\text { There are intertextual references, like the } \\
\text { title's links to Hopkins's 'sweet fire' of } \\
\text { inspiration (1985:68). The rhyme scheme is } \\
\text { abba etc. rather than abab etc. }\end{array}$ \\
\hline
\end{tabular}




\section{DAS HEILIGE FEUER}

Auf das Feuer mit dem goldnen Strahle Heftet sich in tiefer Mitternacht

Schlummerlos das Auge der Vestale, Die der Göttin ewig Licht bewacht.

Wenn sie schlummerte, wenn sie entschliefe, Wenn erstürbe die versäumte Glut, Eingesargt in Gruft und Grabestiefe Würde sie, wo Staub und Moder ruht!

Eine Flamme zittert mir im Busen, Lodert warm zu jeder Zeit und Frist, Die entzündet durch den Hauch der Musen Ihnen ein beständig Opfer ist.

Und ich hüte sie mit heil'ger Scheue, $\mathrm{Da} ß$ sie brenne rein und ungekränkt; Denn ich weiß, es wird der ungetreue Wächter lebend in die Gruft versenkt.

\section{THE HOLY FIRE}

To the fire with its golden beam fixes in deep midnight unsleeping the eye of the Vestal who guards the Goddess's eternal light.

If she slumbered, if she fell asleep, if the neglected glow were to die, entombed in crypt and depths of grave she would be, where lie dust and mould!

A flame burns in my breast, blazes warm at every time and span, which, kindled by the breath of the Muses, is a constant sacrifice to them.

And I tend it with holy awe, that it may burn pure and untroubled, for I know that the untrue watcher is sent living into the crypt.

\section{THE HOLY FIRE}

Onto the fire with the golden beam fixes itself in deep midnight the sleepless eye of the virgin who guards the Goddess's eternal flame.

If she slumbered or fell asleep, if the flame, neglected, were to die, she would be entombed in the crypt, with dust and mould, in the depths!

A flame trembles in my own breast, it blazes warm at every time, kindled by the breath of the Muses, to them a constant sacrifice.

And I tend it with a holy awe, that it may burn pure and without harm; for I know, that the untrue watcher is sent living to the crypt.

\section{SWEET FIRE}

She must keep her eye, as Vestal, on the thing in the corner, the sacred flame, and must not close her eye. Midnight's the time, but the Goddess's light is eternal.

She knows that if she falls and if she sleeps on the job then things are looking grave: her grave, in fact, with the sort of rave you tend to get with the mould and the dust.

And strangely, when I try to make a poem, amused by what I write, I think my heart is burning with what some describe as art. I can be Vestal, any place, any time.

I'm awake. I keep the flame alight, I want it to burn, pure as diamond, and I know that this isn't just some errand: to fall asleep involves an endless night. 
Can we then take Wittgenstein as an oracle, who will provide for our every translating need? Laurence Goldstein (1999:ix) warns against this move: 'Much of Wittgenstein scholarship is sycophantic: many writers ... think that Wittgenstein, in his late writings, was right about just everything'. Such has not been the point of view of this thesis, for I have not assumed that Wittgenstein is right about matters but have given extended examples from the PI and have worked through them to show why I hold Wittgenstein to be right in his vision of language. Anscombe (Monk 1990:497) recalls how reading Wittgenstein for the first time functioned as medicine that effectively attacked the throbbing nerve of her philosophical worries. There is more to the human person than a throbbing nerve, but it makes a great difference to one's life to have the throbbing nerve soothed. I think Wittgenstein in his later writings on language has a vision that is immensely important, but he did not address all the philosophical issues that face a translator, nor can answers be read from his work, as if from an almanac. If I were faced with a question of ethics in translation - whether to translate a text that I found offensive, for example - and wanted support for my course of action, then Wittgenstein might be of use to clarify the terms in which I put things, but I should be wise to look also at philosophers who have written on morals, such as Aristotle or Kant. To think that Wittgenstein is sufficient is to fail to read the PI carefully. It begins, for example, with a motto from Nestroy (1926:216), which was, strangely, left untranslated until the 2009 English edition: 'The trouble about progress is that it always looks much greater than it really is' ( $P I$ p.2). The motto is a clue to how Wittgenstein cannot be approached as offering the final truth about all matters. The reflective practitioner of translation cannot open the PI to find a theory of translation or a philosophy of translation; nor can these be adduced from what Wittgenstein writes in that book. Philosophy has taken note of his work and moved on, with Wittgenstein becoming a point of reference for many philosophers rather than an oracle. It would be absurd to claim that a reading of Wittgenstein absolves the linguist from reading Chomsky, for example. It is necessary to see on which level something is being addressed (cf. Schiffer, 2006). If somebody wanted to know how language is acquired by children, I should recommend that he or she reads Chomsky or his followers. If somebody wanted to know how language is used, I should recommend reading Wittgenstein. To limit oneself to Wittgenstein is to make a category error. As Kerr (1998:187) notes at the end of his discussion of theology after Wittgenstein: 'There must be 
other methods besides Wittgenstein's; but ... it would be perverse ... to avoid his studies of what we may properly say'.

Moreover, as Adrian Moore (1997:244) notes, to toe the Wittgensteinian line too willingly will often mean failing to feel the allure, which Wittgenstein himself felt, for the views he was opposing. The PI opens with a long quotation (PI 1) from Augustine precisely because the story told by Augustine is a compelling one. Within the field of translation, for example, the allure can be seen - by analogy with folk psychology - of what I referred to in 5.1 as folk translation, the way we naturally assume that translation is a process of transference. An example of the allure of folk translation is in Ronald Knox (1957:4) who reduces the field of translation to two questions: should the literal or the literary come first and is the translator free to render the ST as he or she chooses? Steiner (1998:251) notes, with reference to Knox, that this is to oversimplify, but that 'over some two thousand years of argument and precept, the beliefs and disagreements voiced about the nature of translation have been almost the same'. These are the issues that inevitably arise when approaching the task of translation. In a recent study of Indian philosophy, for example, Sue Hamilton (2001:ii), when discussing her own translations from the Sanskrit, wonders 'how literally' to translate and whether it is permissible to paraphrase in order to 'convey the point of what was being said'. Here are the same questions asked by Knox over forty years previously. It is important to recognise the natural tendency to ask these questions. To Knox and to Hamilton I might imagine Wittgenstein saying what I represent in (141).

$(141)$

'Does the literal or the literary come first?'

- Translation is a language-game. Look at the games being played in the ST and play similar games in what you write.

'Is the translator free to render the ST as he or she wishes?'

- Say what you please, as long as it does not prevent you from seeing how things are. 
It is a dialogue, which is fitting, because the PI is a dialogical book. Wittgenstein's two imagined responses are based on PI 23 and PI 79 respectively. Why Wittgenstein? Because this is a dialogue in which it is profitable to participate, one which can facilitate the philosophical turn for which I argued in 1.1. 


\subsection{Translation after Wittgenstein}

Alexander Gavin (2006) argues that the death of the poet Philip Sidney in 1586 changed the face of English Literature by giving other poets a standard against which they could measure themselves, so that writing English verse became a matter of 'writing after Sidney', i.e. with Sidney in mind, as opposed to the trivial truth that any work produced after Sidney's death was 'writing after Sidney'. Similarly the work of Wittgenstein has had an incalculable influence inside and outside philosophy since his death at Storey's End in Cambridge in 1951. Hagberg (1995:1) refers to 'the post-Wittgensteinian climate' in the humanities in general. All translation now is translation after Wittgenstein: trivially, in that it comes after his death; actually, in that Wittgenstein has changed the intellectual landscape; potentially, in that translators may choose to learn from his methods and to apply them.

The PI contains in its Preface Wittgenstein's statement of intent that is given as (142) (PI, p.4).

I should not like my writing to spare other people the trouble of thinking. But, if possible, to stimulate someone to thoughts of his own.

It is thinking things out for oneself that matters. Anscombe, for example, whilst a follower of Wittgenstein, battled against being known as his disciple, as Teichmann (2008:4) describes: 'Some followers of Wittgenstein have been content to repeat what he said in different ways, but Anscombe's philosophy is truer to the spirit of Wittgenstein's precisely in its not doing that'. The point of translation after Wittgenstein would be to use the concerns of the later Wittgenstein to explore ways of translating and of describing ST and TT. While writing this thesis, I have at times had Wittgensteinian philosophers expressing astonishment at my project, because Wittgenstein did not address the issue of translation directly at any length, so that there would be little material available for me to comment on. My interlocutors had made the assumption that the point of the thesis would be exegetical, in line with how Daniel Whiting (2010:vi) notes that the current boom industry in textual analysis of Wittgenstein is largely a matter of exegesis with little attention paid to the 
application of his philosophy. That Wittgenstein mentions translation rarely does not mean that he is of no interest to translators. He offers tools, an approach and a vision that can be applied outside philosophy and that point beyond exegesis. Wittgenstein maintained that the correct response to the reading of any philosophical text is to throw it across the room and to begin to work out one's own ideas (Schroeder, 2006:119). This attitude applies to writing about translation after Wittgenstein, following what Wittgenstein himself wrote about his work: 'I am by no means sure that I should prefer a continuation of my work by others to a change in the way people live which would make all these questions superfluous' ( $C V$ p.61). For 'live', we might read 'translate'. One consequence of translation after Wittgenstein would be that of translations after Wittgenstein. Whilst I do not think that it is possible to use Wittgenstein to come up with a theoretical philosophy of translation, translations after Wittgenstein might be said to be a practical philosophising of translation. To return to the image of the early Wittgenstein ( $T-L P$ 6.54): the translator must throw away the ladder after climbing it, and get down to the task of rendering texts.

There are indications that the time is propitious for a discovery of Wittgenstein in the world of literary translation, and I give three such indications. Firstly, Hoffman and Lasdun, writing in 1994, note a boom in the notion of poetic translation (1994:ix) and this boom has continued with the trend of established poets producing translations of classic work, such as Simon Armitage's rendering of the Middle English poem Sir Gawain and the Green Knight (2008). Armitage writes in his introduction that his translation was based on a reading of the ST that discerns that 'poetry is at work' there that 'seems to demand a poetic response' (2008:x). By 'poetry', Armitage is not referring to the form of his ST, but to its expressive function. It is in the notion of poetic translation where Wittgenstein can be of use, because instead of writing about something that 'seems' to demand a certain type of response, the translator can view ST and TT in terms of language-games. Secondly, the volume of essays edited by Gibson and Huemer on the literary Wittgenstein (2004) contains an essay by Perloff (2004) on this notion of poetic translatability. I argued in 1.5.3 that this essay is unsatisfactory, but it brings translation after Wittgenstein to the marketplace of ideas. Thirdly, the University of Vienna in 2010 hosted a conference on Wittgenstein and translation (papers in Kross and Ramharter, forthcoming). The papers concentrated on how to translate Wittgenstein, with only 
Martin Kusch ${ }^{62}$ (2012) discussing Wittgenstein on translation from within philosophy. These tendencies must be brought together: the interest in poetic translation, the philosophical notion of poetic translatability and a Wittgensteinian approach to translation. Wittgensteinian scholarship now seems more open to applying his work outside philosophy. The mission statement of the British Wittgenstein Society (2010:np), for example, stresses that it exists to ensure that Ludwig Wittgenstein's philosophy 'continues to play a fertile and creative role in 21 st century thought' by addressing 'the many other disciplines (psychology, anthropology, sociology, education, sciences, aesthetics etc.) that Wittgenstein's work has impacted and will continue to impact'. Translation, whilst not mentioned as such, can be one of these disciplines. My thesis is also a signpost to future use of Wittgenstein in that it will, I intend, become a published book on translation after Wittgenstein that will address Wittgenstein on translation from the point of view of translation studies.

A question facing the literary translator at the beginning of the twenty-first century is that of machine translation. Chesterman (Chesterman \& Wagner, 2002:115) asks if, in a world where a computer has defeated a world champion at chess, the only hope for translators is to specialise as literary translators, 'since literature is surely beyond a machine's capability'. To investigate whether this is the case or not goes beyond the scope of my thesis, but I think that two points can be made with reference to Wittgenstein. Firstly, the Wittgensteinian stress on the way that language-games are linked to human forms of life does offer grounds for supposing that only those who have known what it is to lead a form of life could translate a literary work that embodies a form of life: 'Shared human behaviour is the system of reference by which we interpret an unknown language' (PI 206). Secondly, even if a computer were to translate Sir Gawain and the Green Knight, there would be grounds for believing that this would be unsatisfactory for us. As Scott (2000:4) asserts, 'were such a perfect version achievable, it would make translation a process of absolutely no interest to any audience other than machine translators'. What is of interest to readers of Armitage (2008) is that the rendering is by Armitage: rendering a literary text is not an area which admits of definitive solution. As Chomsky argues, the construal of knowledge as ability 'seems to be a

${ }^{62}$ Kusch's paper is available in an online version at the time of writing. 
paradigm example of the practice that Wittgenstein held to be a fundamental source of philosophical error' (2000:51). The issue of machine translation after Wittgenstein is, however, a topic for further research and one that will no doubt have to respond to developments in artificial intelligence and natural language processing.

Wagner (Chesterman \& Wagner, 2002:133) concludes with respect to theory and practice that 'narrowly prescriptive theory wouldn't work' for the translator and that 'perhaps what we need instead is a different kind of theory, that we could help create: practice-oriented theory - a theory rooted in best practice, directed at improved practice, and attentive to practitioners throughout the profession'. Wittgenstein is not mentioned by Wagner or by Chesterman in their dialogue, but Wagner's stress on practice-based theory does demand a Wittgensteinian response. To bring Wittgenstein's later work into translation studies discourse is the basic recommendation of this thesis. In my own case, I carry out the project of applying Wittgenstein in my own translation work and in my analysis of translation, using his methods in my own professional practice as well as writing a book outside the confines of an academic thesis, aimed at a professional audience.

In his crime novel A Philosophical Investigation, Philip Kerr (1993) depicts a twenty-first century serial killer known as Wittgenstein, code-named as such by a secret government project, who consciously imitates aspects of the life and thought of his namesake. He engages the investigating detective, Jake, in a battle of wills, so that Jake finds herself reading the life and works of the philosopher Wittgenstein in an attempt to find the killer. One evening she curls up with the PI instead of her usual thriller and concludes that the philosopher and the detective are engaged on a similar forensic task (Kerr, 1993:247). She sees a message for every detective in the historical Wittgenstein's description of his method in philosophy as showing the way out of the fly-bottle (PI 309). Similarly, the Wittgensteinian approach can offer the reflective practitioner of translation a new way of viewing his or her discipline. In detective work, what is crucial can be just such a new way of seeing. It is when Jake realises that there might be an intellectual aspect to the series of murders, when she is prepared to engage on a philosophical rather than a criminal investigation, that she is at last able to make progress and eventually apprehend the killer. The investigation we need is philosophical. 


\subsection{Story's end}

All stories come to an end. The consequences of reading Wittgenstein in order to transform translation studies can be summed up as follows: a false paradigm of translation (as transference) is destroyed; the concept of translation is broadened; tools are offered with which to read, to translate and to theorise.

In RFM I-143 ff., Wittgenstein tells the story of the wood sellers, which is given as (143).

People pile up logs and sell them, the piles are measured with a ruler, the measurements of length, breadth, and height multiplied together, and what comes out is the number of pence which have to be asked and given. They do not know 'why' it happens like this; they simply do it like this: that is how it is done. ... Very well; but what if they piled the timber in heaps of arbitrary, varying height and then sold it at a price proportionate to the area covered by the piles? And what if they even justified this with the words: 'Of course, if you buy more timber you must pay more'? ... How could I show them that - as I should say - you don't really buy more wood if you buy a pile covering a bigger area? - I should, for instance, take a pile which was small by their ideas and, by laying the logs around, change it into a 'big' one. This might convince them - but perhaps they would say: 'Yes, now it's a lot of wood and costs more' - and that would be the end of the matter. - We should presumably say in this case: they simply do not mean the same by 'a lot of wood' and 'a little wood' as we do; and they have a different system of payment from us.

As David Cerbone (2000:300) asserts, given the failure of the proposed demonstration, communication with these wood sellers has broken down. Could we translate what they have to say, assuming their language were not ours? Kusch (2012:9) imagines the wood sellers using the word 'myynti' ${ }^{63}$, and argues (against Glock, 2008:28) that translation would be possible: 'What justifies translating "myynti" as "measuring and selling wood" is nothing to do with charity and rationality; it is simply the similarity between the tribe's behaviour and our behaviour when we measure and sell wood'. There is in essence nothing more unfathomable about their practice than about the medieval practice of selling wood by the ell (Glock, 2008:38), or such contemporary practices as charging more for a first edition of a book if it is signed by the author: 'The problem we confront in thinking about this community is not a problem in their practices, but rather a

\footnotetext{
${ }^{63}$ Finnish: 'sale’.
} 
problem for $u s$ in interpreting just what it is that they are doing' (Cerbone, 2000:301). The context has to be taken into account and the imagination used, in accordance with what Wittgenstein (PI 583) has to say about significance: 'What is happening now has significance - in these surroundings. The surroundings "give it its importance"'. And were the wood sellers to write poems, novels or plays, then we could translate those too. Whether we would translate well is, of course, another question.

In $P I$ 65, given as (144), Wittgenstein imagines a dialogue with an interlocutor who seems to represent the author of the $T-L P$.

Here we come up against the great question that lies behind all these considerations. - For someone might object against me: 'You make things easy for yourself! You talk about all sorts of language-games, but have nowhere said what is essential to a language-game, and so to language: what is common to all these activities, and makes them into language or parts of language. So you let yourself off the very part of the investigation that once gave you the most headache, the part about the general form of the proposition and of language.'

And this is true. - Instead of pointing out something common to all that we call language, I'm saying that these phenomena have no one thing in common in virtue of which we use the same word for all - but there are many kinds of affinity between them. And on account of this affinity, or these affinities, we call them all 'languages'.

The search for the general form of the proposition that motivates the T-LP (and for which the picture theory of language accounts) is over. The later Wittgenstein examines languages as we find them, not a hidden language or a perfect language. Forms of life do not even coincide with languages: a German Lutheran may - in certain respects - have more in common with an American Lutheran than he or she has in common with a German Catholic. What is necessary, according to Wittgenstein, is to understand different kinds of people, not different kinds of words; to understand different practices, not different conceptual schemes (Kusch, 2012). Perhaps this is why Wittgenstein expressed himself hostile to the invented language of Esperanto: 'Esperanto. Our feeling of disgust, when we utter an invented word with invented derivative syllables. The word is cold, has no associations \& yet plays at "language" ( $C V$ p.60). (Wittgenstein's judgement ignores that invented languages 
such as Esperanto or Klingon can become forms of life as people form language communities. ${ }^{64}$ )

Where language is not cold but full of associations is the literary. As Pound puts it, literature is 'language charged with meaning' and great literature is 'language charged with meaning to the utmost possible degree' (1934:28); literature is 'news that stays news' (1934:29). Literary translation begins with recognising this strangeness. In Chapter 2, I showed how Wittgensteinian can allow this recognition to take place. In Chapter 3, I stressed that Wittgenstein can help the translator in his or her task of translation, of replacing a literary work by another literary work, where there is no necessary correlation but where affinities can be found. In Chapter 4, I showed how Wittgenstein can enable the TT to be theorised. The three chapters form a full programme for the training of the literary translator. The PI can be added to reading lists. Methods derived from the $P I$ can be applied. The philosophy of the later Wittgenstein offers a toolkit of models and narratives to help translators and translation theorists make decisions (Kay, 2011:176), which is the answer to the research question asked in 1.6.

The story comes to a close. In that it is about the rendering of literature, it is a literary story. In 4.4.1.6, I argued that such terms as 'equivalence' are interpretative fictions, following Robinson (1991:259). At the end of my thesis I state that literary translation itself is a fiction, following Boase-Beier's description of it as a pretence (2006:108-110). Scott (2008:16) is wrong to see literary translation as a forgery, because most literary translators do not set out to deceive their readers, excepting cases of pseudo-translation. But it is correct to see literary translation as a fiction, perhaps the oldest in existence (Bellos, 2011:121). It is a language-game, and its glory is that surveyable representations of texts have been shown to be possible. Wittgenstein can facilitate future attempts to understand and to practise the game, what Bell (2011:215) calls 'walking the tightrope of illusion'.

I began this thesis in 1.1 by citing a poem by Lomas as text (1), as an example of how Wittgenstein has claimed the attention of creative writers and by referring to the assertion by Eagleton (1994:153) that 'Frege is a philosopher's philosopher, Sartre the media's idea of an intellectual, and Bertrand Russell every shopkeeper's image of the sage. ... But Wittgenstein is the philosopher of poets and

${ }^{64}$ See Orent (2008). 
composers, playwrights and novelists ...'. Wittgenstein's story has its roots not in the Jena of Frege or in the Paris of Sartre and not, ultimately, in the Cambridge of Russell, but in the literary Vienna of Kraus and Nestroy. This understanding of Wittgenstein is both terminus ad quem and teminus a quo (Janik \& Toulmin, 1973:261) for applying Wittgenstein in literary studies and for explaining why he ought to be of interest to those engaged with the translation of poems, plays and novels.

I choose to end with a poem of my own, a literary production, which I give as (145) and which addresses literary translation after Wittgenstein. It is in dialogue with the poem by Meyer given as (138), the poem Wittgenstein saw as expressing exactly what he wished to say (McGuinness, 2008:341), and it may therefore be regarded as another translation of that poem. In a sense, this poem says everything that I want to say. Translation is a language-game. The story comes to an end. The story carries on.

\section{PLAY}

An Austrian with no tie asked me to translate a German joke: an English but different joke got an English laugh in the final act. I look at the flame and I stay awake.

He told me a story about those who sell their wood for a price given how it is spread and asked if I thought them illogical.

I look at the text and I stay awake.

He asked if I would join him in a game of tennis, and he told me to start but not how hard to hit or where to run. I look at my words and I stay awake.

He showed me a bottle and released the fly which flew away and did not come back and life seemed full with the bottle empty. To read a translation, stay awake. 


\section{BIBLIOGRAPHY}

Adair, G. (tr) (1995) Georges Perec: A Void, London: The Harvill Press

Aland, K., M. Black, C. Martini, B. Metzger, A. Wirkgen (eds) (1968) The Greek New Testament, London: United Bible Societies

Allen, R. \& M. Turvey (2001) Wittgenstein, Theory and the Arts, Routledge: London \& New York

Ambrose, A. (ed) (1979) Wittgenstein's Lectures: Cambridge 1932-1935, Oxford: Blackwell

Annas, J. (2000) Ancient Philosophy, Oxford: Oxford University Press

Anscombe, E. (tr) (2001) Ludwig Wittgenstein: Philosophical Investigations, Oxford: Blackwell

Antin, D. (1998) 'Wittgenstein among the Poets', in Modernism, Modernity, 149-166 AQA (9 May 2010) http://store.aqa.org.uk

Arbués, M., M. Burrel, M. Parayre, H. Salceda \& R. Vega (trs) (1997) Georges Perec: El secuestro, Barcelona: Editorial Anagrama

Armitage, S. (tr) (2008) Sir Gawain and the Green Knight, London: Faber \& Faber Arnold, M. (1960) 'On Translating Homer', in On the Classical Tradition, Ann Arbor: University of Michigan Press, 97-216

Arrojo, R (2010) 'Philosophy and translation', in Y. Gambier \& L. van Doorslaer (eds) Handbook of Translation Studies, Amsterdam: John Benjamins, 246251

Attridge, D. (2004) The Singularity of Literature, London \& New York: Routledge Augustine (1961) Confessions, tr. by R. S. Pine-Coffin, Harmondsworth: Penguin Austin, J.L. (1962) Sense and Sensibilia, Oxford: Clarendon Press

Ayer, A.J. (1985) Wittgenstein, London: Weidenfeld \& Nicholson

Ayer, A.J. (1990) Language, Truth and Logic, London: Penguin

Baker, G. (2004) Wittgenstein's Method: Neglected Aspects, Oxford: Blackwell

Baker, G.P. \& P.M.S. Hacker (1986) 'Wittgenstein Today’, in S. Shanker (ed), 24-35

Baker, G. P. \& P.M.S. Hacker (2009) Wittgenstein: Rules, Grammar and Necessity, Oxford: Wiley-Blackwell

Baker, M. (2008) 'Foreword', in Nikolaou \& Kyritsi, xiii-xiv

Barnes, J. (30 May 2012) 'Writer's Writer and Writer's Writer's Writer' www.lrb.co.uk/v22/n22

Barnstone, W. (1993) The Poetics of Translation, New Haven \& London: Yale 
University Press

Barnstone, W. (tr) (2009) The Restored New Testament, New York \& London:

W.W. Norton

Barnstone, W. (tr) (2012) The Poems of Jesus Christ, New York \& London: W.W.

Norton \& Co.

Bassnett, S. (2003) Translation Studies, London \& New York: Routledge

Bassnett, S. \& H. Trivedi (eds) (1999) Post-Colonial Translation: Theory and

Practice, London: Routledge

Bate, J. (2011) English Literature, Oxford: Oxford University Press

Beevor, A. (2009) 'The Kindly Ones by Jonathan Littell', in The Times, February 20

Beigbeder, F. (2000) 99 francs, Paris: Grasset

Bell, A. (2000) 'Mörike', in O. Classe (ed) Encyclopedia of Literary Translation into

English Volume 2, London \& Chicago: Fitzroy Dearborn, 971-972

Bell, A. (23 July 2009a) 'Astérix: What's in a Name?'

www.literarytranslation.com/workshops/asterix

Bell, A. (tr) (2009b) Franz Kafka: The Castle, Oxford: Oxford University Press

Bell, A. (2011) 'Translating W.G. Sebald', in J. Catling \& R. Hibbitt (eds) Saturn's

Moons: W.G. Sebald - A Handbook, Legenda: London, 209-215

Bellos, D. (2011) Is That a Fish in Your Ear? London: Particular Books

Benjamin, A. (1989) Translation and the Nature of Philosophy: A New Theory of

Words, London: Routledge

Benjamin, W. (1999) 'The Storyteller', tr. by H.B. Jovanovich, in Illuminations,

London: Pimlico, 83-107

Benjamin, W. (2004) 'The Task of the Translator', tr. by H. Zohn, in L. Venuti (ed), $75-85$

Berger, J. (1977) Ways of Seeing, London: Penguin

Berger, K. \& C. Nord (trs) (1999) Das Neue Testament und frühchristliche

Schriften, Frankfurt-am-Main \& Leipzig: Insel

Berman, A. (2004) 'Translation and the Trials of the Foreign', tr. by L. Venuti, in

L. Venuti (ed), 276-289

Berthier, R., J-M. Faure \& B. Le Sourd (2004) L'Évangile de Jésus-Christ, Paris:

Fleurus

Die Bibel in gerechter Sprache (2007) Gütersloh: Gütersloher Verlagshaus

The Bible: Authorized King James Version (2008), Oxford: Oxford University Press 
The Bible: New Revised Standard Version (1995), Oxford: Oxford University Press Blackburn, S. (1999) Think, Oxford: Oxford University Press

Boase-Beier, J. (1998) 'Can You Train Literary Translators?', in P. Bush \&

K. Malmkjaer (eds) Rimbaud's Rainbow, Amsterdam: John Benjamins, 3341

Boase-Beier, J. (2006a) 'Loosening the grip of the text: theory as an aid to creativity' in E. Loffredo \& M. Perteghella (eds) Translation and Creativity, London \& New York: Routledge, 47-56

Boase-Beier, J. (2006b) Stylistic Approaches to Translation, Manchester: St. Jerome

Boase-Beier, J. (2010a) ‘Series Editor’s Introduction', in P. Mosley (tr) François Jacqmin: The Book of the Snow, Todmorden: Arc, 11

Boase-Beier, J. (2010b) 'Preface', in A. Fawcett et al. (eds), xi-xii

Boase-Beier, J. (2010c) 'Who Needs Theory?', in A. Fawcett et al. (eds), 25-38

Boase-Beier, J. (2011) A Critical Introduction to Translation Studies, London \& NewYork: Continuum

Boase-Beier, J. \& M. Holman (1999) The Practices of Literary Translation, Manchester: St. Jerome

Boase-Beier, J. \& K. Lodge (2003) The German Language, Oxford: Blackwell Borges, J. L. (2000) 'Pierre Menard, Author of the Quixote', in Fictions, tr. by

A. Hurley, London: Penguin, 33-43

Bourdieu, P. (2003) Social Structures of the Economy, tr. by C. Turner, Cambridge: Polity

Bradley, F.H. (1893) Appearance and Reality: A Metaphysical Essay, London: Allen \& Unwin

Bratton, F. G. (1967) A History of the Bible, Boston: Beacon Press

British Wittgenstein Society (3 September 2010)

www.britishwittgensteinsociety.herts.ac.uk

Brodzki (2007) Can These Bones Live? Stanford: Stanford University Press

Broeck, R. van den (1978) 'The Concept of Equivalence in Translation Theory: Some Critical Reflections', in J. Holmes, J. Lambert \& R. van den Broeck (eds) Literature and Translation: New Perspectives in Literary Translation, Leuven: acco, 29-37

Brougham, H., C. Fox \& I. Pace (1997) Uncommon Ground: The Music of Michael Finnissy, Aldershot: Ashgate 
Brown, P. (1967) Augustine of Hippo, Boston \& London: Faber \& Faber

Brown, R. \& P. Comfort (trs) (1990) The New Greek-English Interlinear New Testament, Carol Stream: Tyndale House

Burke, M. (2003) 'Literature as parable', in J. Gavins \& G. Steen (eds) Cognitive Poetics in Practice, London \& New York: Routledge, 115-128

Burke, S. (1998) The Death and Return of the Author, Edinburgh: Edinburgh University Press

Carruthers, P. (2006) The Architecture of the Mind, Oxford: Clarendon Press

Cathcart, T. \& D. Klein (2007) Plato and a Platypus Walk into a Bar, London: Penguin

Casey, M. (2010) Jesus of Nazareth, London: T. \& T. Clark

Catford, J.C. (1965) A Linguistic Theory of Translation: An Essay in Applied Linguistics, Oxford: Oxford University Press

Cavell, S. (2000) 'The Availability of Wittgenstein's Later Philosophy', in S. Shanker (ed), 36-57

Cavell, S. (2001) 'The Investigations' Everyday Aesthetics of Itself', in T. McCarthy \& S. Stidd (eds) Wittgenstein in America, Oxford: Oxford University Press, 250-266

Cerbone, D. (2000) 'How to do things with wood', in A. Crary \& R. Read (eds), 293-314

Chabris, C. \& D. Simons (2011) The Invisible Gorilla, London: HarperCollins

Chartered Institute of Linguists (30 May 2010)

www.iol.org.uk

Chaucer, G. (1965) The General Prologue to the Canterbury Tales, Cambridge: Cambridge University Press

Chesterman, A. (1997) Memes of Translation, Amsterdam: John Benjamins

Chesterman, A. \& E. Wagner (2002) Can Theory Help Translators? Manchester:

St. Jerome

Chesterton, G.K. (1996) The Collected Works of G.K. Chesterton, San Francisco: Ignatius Press

Chomsky, N. (2000) New Horizons in the Study of Language and Mind, Cambridge: Cambridge University Press

Cicero (1997) 'The Best Kind of Orator', in D. Robinson (ed), 7-10

Clancy, P. (2006) 'Nine Years in Provence', in In Other Words 27, 6-12 
Classic Persuasion (13 May 2010)

http://classicpersuasion.org

Cockburn, D. (2009) 'Emotion, Expression and Conversation', in Y. Gustafsson et al., 126-144

Cohen, M. (2005) Wittgenstein's Beetle and Other Classic Thought Experiments, Oxford, Blackwell

Coleridge, S.T. (1975) Biographia Literaria, London: J.M. Dent

Conan Doyle, A. (2005) The Sign of Four, London: Ægypan Press

Constantine, D. (tr) (2001) Hölderlin's Sophocles: Oedipus \& Antigone, Newcastle: Bloodaxe

Constantine, D. (tr) (2005) Johann Wolfgang von Goethe: Faust Part I, London: Penguin

Constantine, D. (2009) Nine Fathom Deep, Tarset: Bloodaxe

Cook, J. \& R. Read (2010) 'Wittgenstein and Literary Language', in G. Hagberg \& W. Jost (eds) A Companion to the Philosophy of Literature, Oxford: WileyBlackwell, 467-490

Cook, L. (2007) 'Foreword', in R. Read (2007a), xiii-xx

Cooter, J. \& M.V.L. Barclay (eds) (2006) A Coleopterist's Handbook, Orpington:

The Amateur Entomologists' Society

Copi, I. \& C. Cohen (1994) Introduction to Logic, New York: Macmillan

Coppola, S. (dir) (2003) Lost in Translation, Momentum/Focus /Tohokushina/ American/Elemental

Crary, A. (2000a) 'Introduction', in A. Crary \& R. Read (eds), 1-18

Crary, A. (2000b) 'Wittgenstein's Philosophy in Relation to Political Thought', in

A. Crary \& R. Read (eds), 118-140

Crary, A. \& R. Read (eds) (2000) On the New Wittgenstein, London \& New York: Routledge

Crick, J. (tr) (2009) Franz Kafka: The Metamorphosis and Other Stories, Oxford: Oxford University Press

Critchley, S. (2001) Continental Philosophy, Oxford: Oxford University Press

Cronin, M. (2009) Translation goes to the Movies, London \& New York: Routledge

Crystal, D. (2003) The Cambridge Encyclopedia of the English Language,

Cambridge: Cambridge University Press

Cupitt, D. \& P. Armstrong (1977) Who Was Jesus? London: BBC 
Davidson, D. (2001) Inquiries into Truth and Interpretation, Oxford: Oxford University Press

Davidson, J. P. (2011) Planet Word, London: Michael Joseph

Dawkins, R. (1976) The Selfish Gene, Oxford: Oxford University Press

DeAngelis, W.J. (2007) Ludwig Wittgenstein - A Cultural Point of View, Aldershot: Ashgate

Deguy, M. (tr) (2008) 'Seamus Heaney: Pylos: Poème lu par Michel Deguy’, in Poésie 122-123, 52

Derbyshire, K. (tr): Clemens Meyer: All The Lights, High Wycombe: And Other Stories

Derrida, J. (1985) 'Les Tours de Babel', tr. by J. Graham, in J. Graham (ed) Difference in Translation, Ithaca \& London, 165-208

Descartes, R. (1968) The Meditations, in Discourse on Method and the Meditations, tr. by F.E. Sutcliffe, London: Penguin, 93-170

Deutscher, G. (2005) The Unfolding of Language, London: Arrow

Deutscher, G. (2010) Through the Language Glass, London: Arrow

Drury, M. (1973) The Danger of Words, London: Routledge \& Kegan Paul

Drury, M. (1984) 'Conversations with Wittgenstein', in R. Rhees, 97-121

Duffy, B. (1987) The World As I Found It, New York: Ticknor \& Fields

Eagleton, T. (1994) 'My Wittgenstein', in Common Knowledge 3, 152-7

Eagleton, T. (1996) Literary Theory, Minneapolis: University of Minnesota Press

Eagleton, T. (2007) How to Read a Poem, Oxford: Blackwell

Eagleton, T. (2008) 'Palace of pain', in The Guardian, 8 March

Edmonds, D. \& J. Eidinow (2001) Wittgenstein's Poker, London: Faber \& Faber

Edmundson, M. (1995) Literature against philosophy, Plato to Derrida: a defence of poetry, Cambridge: Cambridge University Press

Evan-Zohar, I. (1990) Polysystem Studies, Tel Aviv: Porter Institute

Fagles, R. (tr) (1990) Homer: The Iliad, London: Penguin

Fawcett, A. \& K. L. Guadarrama García (2010) 'Introduction', in Fawcett et al., 1-19

Fawcett, A., K.L. Guadarrama García \& R. Hyde Parker (eds) (2010) Translation: Theory and Practice in Dialogue, London: Continuum

Fish, S. (1996) 'What is stylistics and why are they saying such terrible things about it?', in J.J. Weber (ed), 94-112

Fish, S. (1980) 'Is There a Text in This Class?', in Is There a Text in This Class?, 
Cambridge: Harvard University Press, 303-321

FitzGerald, E. (1980) Letters, Princeton: Princeton University Press

Foden, G. (ed) (2012) Body of Work, Woodbridge: Full Circle

Foer, J. S. (2009) Eating Animals, London: Hamish Hamilton

Fontane, T. (2000) Effi Briest, Stuttgart: Reclam

Frankfurt, H. (2005) On Bullshit, Princeton \& Oxford: Princeton University Press

Freud, S. (1999) The Interpretation of Dreams, tr. by J. Crick, Oxford: Oxford University Press

Furrow, D. (1995) Against Theory, Routledge: New York \& London

Gaffney, P. (1999) “"The achieve of, the mastery of the thing!” Pierre Leyris's Verse Translation of Gerard Manley Hopkins', in J. Boase-Beier \& M. Holman (eds), 45-58

Gavin, A. (2006) Writing after Sidney: the literary response to Sir Philip Sidney, 1586-1640, Oxford \& New York: Oxford University Press

Gentzler, E. (2001) Contemporary Translation Theories, Clevedon: Multilingual Matters

Gibson, J. (2004) 'Reading for Life', in J. Gibson \& W. Huemer (eds), 109-124

Gibson, J. \& W. Huemer (eds) (2004) The Literary Wittgenstein, London: Routledge

Gledhill, J. (2007) How to Translate Thomas Mann's Works, Saarbrücken: DVM

Gledhill, J. \& P. Wilson (trs) (2007) Martin Luther: Luther Brevier/Luther's Breviary, Weimar: Wartburg

Glock, H-J. (2008) 'Relativism, Commensurability and Translatability', in J. Preston (ed) Wittgenstein and Reason, Oxford: Blackwell, 21-46

Goethe, J.W. von (1901) Maximen und Reflexionen, Leipzig: Biographisches Institut Goethe, J.W. von (1967) Gedichte, Stuttgart: Reclam

Goethe, J.W. von (1972) Faust, Munich: C.H. Beck

Goethe, J.W. von (2004) 'Translations', tr. by S. Sloan, in L. Venuti (ed), 64-66

Goethe, J.W. von (2008) Werke Volume 12, Munich: C.H. Beck

Goldstein, L. (1999) Clear and Queer Theory, London: Duckworth

Gorlée, D. (1994) Semiotics and the Process of Translation, Amsterdam \& Atlanta: Rodopi

Gounod, C. (1962) Faust, New York: International Music

Grandin, T. \& C. Johnson (2005) Animals in Translation, London: Bloomsbury

The Green Bible (2008) London: Collins 
Green, J., S. McKnight, \& I.H. Marshall (eds) Dictionary of Jesus and the Gospels, Downers Grove \& Leicester: InterVarsity Press

Grossman, E. (2010) Why Translation Matters, New Haven \& London: Yale University Press

Groth, M. (2004) Translating Heidegger, New York: Humanity Books

Guetti, J. (1993) Wittgenstein and the Grammar of Literary Experience, Athens \& London: University of Georgia Press

Gustafsson, Y., C. Kronqvist \& M. McEachrane (eds) (2009) Emotions and Understanding: Wittgensteinian Perspectives, Basingstoke: Palgrave Macmillan

Gutt, E-A. (2000) 'A theoretical account of translation - without a translation theory' in Target 2 (2), 135-164

Hacker, P.M.S. (2001) 'The anatomy of human understanding', in R. Allen \& M. Turvey (eds), 39-74

Hacker, P.M.S. (2004) 'Was he trying to whistle it?', in Crary \& Read (eds), 353388

Hacker, P.M.S. (2007a) Human Nature: the Categorical Framework, Oxford: Blackwell

Hacker, P.M.S. (2007b) 'Gordon Baker's Late Interpretation of Wittgenstein', in G. Kahane et al. (eds), 88-122

Hacker, P.M.S. (10 March 2010a) 'Philosophy: a Contribution, not to Human Knowledge, but to Human Understanding' www.nfo.sjc.ox.ac.uk/scr/hacker/docs

Hacker, P.M.S. (2010b) 'Meaning and Use', in D. Whiting (ed), 26-44

Hacker, P.M.S. \& J. Schulte (2009) 'Editorial Preface to the Fourth Edition and Modified Translation', in L. Wittgenstein, viii-xvii

Hagberg, G. (1995) Art as Language, Ithaca \& London: Cornell University Press Hall, M. (1986) 'Introduction', in M. Henry (tr), 7-18

Hamilton, S. (2001) Indian Philosophy, Oxford: Oxford University Press

Handayani, E. (2011) 'A View from Indonesia', in In Other Words 38, 33-41

Hardy, T. (2007) Jude the Obscure, London: Penguin

Hartmann von Aue (1972) Gregorius, Wiesbaden: Brockhaus

Harvey, R. (1963) “"Minnesang” and the "Sweet Lyric" in German Life and Letters Volume 17 Issue 1, 14-26 
Hastings, S. (1994) The Illustrated Children's Bible: The New Testament, London: Dorling Kindersley

Heidegger, M. (1996) Hölderlin's Hymn 'The Ister', Bloomington: Indiana University Press

Heidegger, M. (2010) Being and Time, tr. by J. Stambaugh \& D. Schmidt, Albany:

State University Press of New York

Heine, H. (1976) Gedichte, Stuttgart: Reclam

Henry, M. (tr) (1986) Denis Diderot: Jacques the Fatalist, London: Penguin Herder, J.G. (1977) ‘The Ideal Translator as Morning Star’, in D. Robinson (ed), 207-208

Hermans, T. (ed) (1985) The Manipulation of Literature, London \& Sydney: Croom Helm

Hermans, T. (2007a) 'Literary Translation', in P. Kuhiwczak \& K. Littau (eds), 7791

Hermans, T. (2007b) The Conference of the Tongues, Manchester: St Jerome

Herodotus (1963) Histories, tr. by A. de Selincourt, London: Penguin

Hoffman, M. \& J. Lasdun (eds) (1994) After Ovid: New Metamorphoses, London: Faber \& Faber

Hofstadter, D. (1979) Gödel, Escher, Bach: an Eternal Golden Braid, London: Penguin

Hölderlin, F. (1952) Sämtliche Werke: Übersetzungen, Stuttgart: W. Kohlhammer Holmes, J. (2004) 'The Name and Nature of Translation Studies', in L. Venuti (ed), 180-192

Holt, R. (1997) Wittgenstein, Politics and Human Rights, London: Routledge Hopkins, G.M. (1985) Poems and Prose, London: Penguin

House, J. (1997) Translation Quality Assessment: A Model Revisited, Tübingen: Narr

Huemer, W. (2004) 'Wittgenstein, Language and Philosophy of Literature', in J. Gibson \& W. Huemer (eds), 1-13

Hughes, T. (tr) (1997) Ovid: Tales from Ovid, London: Faber \& Faber Hughes, T. (tr) (1999) Aeschylus: The Oresteia, London: Faber \& Faber Hughes, T. (tr) (2006) Selected Translations, London: Faber \& Faber Hughes, T. (tr), T. Supple, S. Reade (eds) (1999) Ted Hughes' Tales from Ovid, London: Faber \& Faber 
Hunter, A. (tr.) (2002a) Frédéric Beigbeder: £9.99, London: Picador

Hunter, A. (tr.) (2002b) Catherine Millet: The Sexual Life of Catherine M., London: Serpent's Tale

Hutchinson, P., R. Read \& W. Sharrock (2008) There is no such thing as a social science, Farnham: Ashgate

Ignatius Loyola (2005) Spiritual Exercises, in Personal Writings, tr. by J. Munitiz, London: Penguin, 281-360

Iser, W. (2006) How to Do Theory, Oxford: Blackwell

Jackson, W.H. (1994) Chivalry in Twelfth-Century Germany: The Works of Hartmann von Aue, Cambridge: Brewer

Jakobson, R. (1959) ‘On Linguistic Aspects of Translation’, in R. Brower (ed) On Translation, Cambridge, Massachusetts: Harvard University Press, 232-239

Jakobson, R. (1960) 'Closing Statement: Linguistics and Poetics', in T. Sebeok (ed) Style and Language, Cambridge, Massachusetts: MIT Press, 350-377

James, W. (1981) The Principles of Psychology, Cambridge, Massachusetts: Harvard University Press

Jandl, E. (2000) reft und light: Poems by Ernst Jandl with Multiple Versions by American Poets, Providence: Burning Deck

Janik, A. \& S. Toulmin (1973) Wittgenstein's Vienna, London: Weidenfeld \& Nicholson

Jarman, D. (dir) (1993) Wittgenstein, BFI/Channel 4/Uplink/Bandung

Jay, P. \& C. Lewis (eds) (1996) Sappho through English poetry, London: Anvil Jerome (tr) (1911) Nouum testamentum latine, Oxford: Clarendon

Jerome (1977) 'Letter to Pammachius', tr. by P. Carroll, in D. Robinson (ed), 23-30

Johnson, S. (1755) Dictionary of the English Language, Dublin: W.E. Jones

Joyce, J. (1950) Finnegans Wake, London: Faber \& Faber

Joyce, J. (1992) Ulysses, London: Penguin

Joyce, J. \& N. Frank (trs) (1979) 'James Joyce: Anna Livia Plurabella: passi di

Finnegans Wake', in J. Joyce Scritti italiani, Milan: Arnoldo Montadori

Editore, 216-233

Kafka, F. (1963) Short Stories, Oxford: Oxford University Press

Kahane, G., E. Kanterian \& O. Kuusela (eds) (2007) Wittgenstein and His

Interpreters, Oxford: Blackwell

Kay, J. (2011) Obliquity, London: Profile 
Kazantzakis, N. (1975) The Last Temptation of Christ, tr. by P.A. Bien, London: Faber \& Faber

Keefer, K. (2008) The New Testament as Literature, Oxford: Oxford University Press

Keil, F. \& R.Wilson (2000) ‘Explaining Explanation', in Explanation and Cognition, Cambridge, Massachusetts \& London: MIT Press, 1-18

Kellett, A. (1996) Ee By Gum, Lord, Skipton: Dalesman Publishing Company

Kelly, L.G. (1977) The True Interpreter, Oxford: Blackwell

Kenny, A. (2006) Wittgenstein, Oxford: Blackwell

Kerr, F. (1988) Theology after Wittgenstein, Oxford: Blackwell

Kerr, F. (2008) 'Work on Oneself': Wittgenstein's Philosophical Psychology,

Arlington: The Institute for the Psychological Sciences Press

Kerr, P. (1993) A Philosophical Investigation, London: Arrow

Kierkegaard, S. (2004) Either/Or: A Fragment, London: Penguin

King, N. (tr) (2004) The New Testament, Stowmarket: Kevin Mayhew

Klagge, J. \& A. Nordmann, 'Editorial Preface', in L. Wittgenstein, Philosophical

Occasions, Indianapolis \& Cambridge: Hackett, vii-X

Klebes, M. (2006) Wittgenstein's Novels, Routledge: New York \& London

Klee, P. (1989) Pedagogical Sketchbook, tr. by S. Moholy-Nagy, London: Faber \&

Faber

Knox, R. (1957) On English Translation, Oxford: Clarendon Press

Kross, M. \& E. Ramharter (eds) (forthcoming) Wittgenstein Übersetzen

Kuhiwczak, P. \& K. Littau (eds) (2007) A Companion to Translation Studies, Clevedon, Buffalo, Toronto: Multilingual Matters

Kusch, M. (11 January 2012) 'Wittgenstein on Translation' www.MartinKusch/Papers

Kuusela, O. (2008) The Struggle Against Dogmatism, Cambridge \& London: Harvard University Press

La nota del traduttore (16 November 2011)

$\underline{\text { www.lanotadeltraduttore.it }}$

Lakoff, G. (1987) Women, Fire and Dangerous Things, Chicago: University of Chicago

Lakoff, G. \& M. Johnson (2003) Metaphors We Live By, Chicago: University of Chicago Press 
Lasdun, J. (2009) 'The exoticism of evil', in The Guardian, 28 February

Lavery, M. \& R. Read (2009) 'Philosophy is/as the power of words', in

A. Kenkmann (ed) Teaching Philosophy, London: Continuum, 99-115

Lawson, S. (2009) 'Expert Advice', in In Other Words 33, 43-49

Le Laboureur, L. (1669) Avantages de la langue françoise sur la langue latine, Paris: Guillaume de Luyne

Le Roy, M. (dir) (1939) The Wizard of Oz, MGM

Levý, J. (2000) 'Translation as a Decision Process', in L. Venuti (ed) The

Translation Studies Reader [First Edition], London \& New York: Routledge, 148-159

Lewis, R. (1999) When Cultures Collide, London: Nicholas Bradley Publishing

Lichtenberg, G. (1984) Aphorismen, Stuttgart: Reclam

Littell, J. (2006) Les Bienveillantes, Paris: Gallimard

Lloyd-Jones, H. (tr) (1994) Sophocles: Antigone, The Women of Trachis, Philoctetes, Oedipus at Colonus, Cambridge \& London: Harvard University Press

Lodge, A. (1998) 'French is a Logical Language', in L. Bauer \& P. Trudgill (eds) Language Myths, London: Penguin, 23-31

Logue, C. (tr) (2001) Homer: War Music: an account of books 1-4 and 16-19 of Homer's Iliad, London: Faber \& Faber

Lomas, H. (2009), A Casual Knack of Living, Todmorden: Arc

Longfellow. H.W. (1904) The Poetical Works of Henry Wadsworth Longfellow, London: Oxford University Press

Lotbinière-Harwood, S. de (1991) Re-belle et infidèle: la traduction comme pratique de re-écriture au feminin, Montreal: Editions du Remue-ménage

Louth, C. (1988) Hölderlin and the Dynamics of Translation, Oxford: Legenda

Lowe-Porter, H. (tr) (1992) Thomas Mann: Doctor Faustus, London: Penguin

Lowell, R. (1971) Imitations, London: Faber \& Faber

Luke, D. (1997) (tr) Eduard Mörike: Mozart's Journey to Prague; Selected Poems, London: Libris

Luther, M. (1997) Circular Letter on Translation, tr. by D. Robinson, in

D. Robinson (ed), 84-98

Luther, M. (tr) (1999) Die Bibel, Stuttgart: Deutsche Bibelgesellschaft

Lycan, W. (2008) Philosophy of Language, New York \& London: Routledge

Lyne, R. (2002) 'Ovid in English Translation', in P. Hardie (ed) The Cambridge 
Companion to Ovid, Cambridge: Cambridge University Press, 249-263

MacAlpine, A. \& R. Hunter (trs) (2000) Daniel Paul Schreber: Memoirs of My

Nervous Illness, New York: NYRB

Macpherson, J. (2003) The Poems of Ossian and Related Works, Edinburgh:

Edinburgh University Press

Madden, M. (2006) 99 Ways to Tell a Story, London: Jonathan Cape

Magee, J. (1987) The Great Philosophers, Oxford: Oxford University Press

Makaryk, I. (ed) (1993) Encyclopedia of Contemporary Literary Theory, Toronto:

University of Toronto Press

Malcolm, N. (1958) Ludwig Wittgenstein: A Memoir, Oxford: Oxford University Press

Malcolm, N. (1966) 'Wittgenstein's Philosophical Investigations', in G. Pitcher (ed) Wittgenstein: The Philosophical Investigations, New York: Doubleday, 65103

Malcolm, N. (1977) Thought and Knowledge, Ithaca \& London: Cornell University Press

Malcolm, N. (1984) 'Introduction', in R. Rhees, xiii-xix

Malmkjaer, K. (2004) 'Censorship or error: Mary Howitt and a problem in Descriptive TS', in G. Hansen, K. Malmkjaer \& D. Gile (eds) Claims, Changes and Challenges in Translation Studies, Amsterdam: John Benjamins

Malmkjaer, K. (2005) Linguistics and the Language of Translation, Edinburgh: Edinburgh University Press

Malmkjaer, K. (2010) 'The Nature, Place and Role of a Philosophy of Translation in Translation Studies', in A. Fawcett et al. (eds), 201-218

Mandell, C. (tr) (2010) Jonathan Littell: The Kindly Ones, London: Vintage

Marlowe, C. (1986) Dr Faustus, London: Abacus

Martin, C. (ed) (1998) Ovid in English, London: Penguin

Martin, R.B. (1981) Gerard Manley Hopkins: A Very Private Life, London: Flamingo

Marx, K. \& F. Engels (1970) The German Ideology, [translator uncredited], London: Lawrence \& Wishart

May, R. (1994) The Translator in the Text, Evanston, Illinois: Northwestern University Press 
McGinn, M. (2008) Wittgenstein and the Philosophical Investigations, London \& New York: Routledge

McGuinness, B. (ed) (2008) Wittgenstein in Cambridge, Oxford: Blackwell

McKinney, M. (2005) 'Pillow Book Talk', in Meanjin 64.4, 54-59

Midgeley, M. (2001) Science and Poetry, London \& New York: Routledge

Minhinnick, R. (2003) The Adulterer's Tongue, Manchester: Bloodaxe

Miroux, F. (2010) 'Translating Poetry: decoding meaning or recomposing harmony?', in In Other Words 36, 96-108

Mitchell, R. (1992) “"Tell by Showing”: an Exercise Against Technique', in R. Behn \& C. Twichell (eds) The Practice of Poetry, New York: Quill, 56-58

Mithen, S. (1996) The Prehistory of the Mind, London: Phoenix

Monk, R. (1990) Ludwig Wittgenstein: The Duty of Genius, London: Cape

Monk, R. (2002) 'Philosophical Biography', in J. Baggini \& J. Stangroom (eds) New British Philosophy, London \& New York: Routledge, 11-24

Monk, R. (2007) 'Wittgenstein's Philosophy of Mathematics', in G. Kahane et al. (eds), 269-294

Moore, A.W. (1997) 'Review of P.M.S. Hacker's Wittgenstein's Place in TwentiethCentury Analytic Philosophy', in Philosophical Books 38, 242-5

Moore, G. (1998) Believing in God, Edinburgh: T \& T Clark

Mörike, E. (1975) Gedichte, Stuttgart: Reclam

Moyal-Sharrock (2009) 'The Fiction of Feeling: Really Feeling for Anna Karenina' in Y. Gustafsson et al. (eds), 165-184

Mullan, J. (2011) 'Midnight's Children', in The Guardian, 26 February

Müller, J-D. (2007) Rules for the Endgame, tr. by W. Whobrey, Baltimore: John Hopkins University Press

Munday, J. (2001) Introducing Translation Studies, London \& New York: Routledge

Munday, J. (ed) (2009) The Routledge Companion to Translation Studies, London: Routledge

Murdoch, I. (1973) The Black Prince, London: Chatto \& Windus

Murdoch, I. (1997) The Fire and the Sun: Why Plato Banished the Artists, in Existentialists and Mystics, London: Penguin, 386-463

Nabakov, V. (2004) 'Onegin in English', in L. Venuti (ed), 276-289

Naffis-Sahely, A. (2011) A Single-Minded Homer, in PNR 199, 58-61

Nestroy, J. (1926) Die Volksstücke, Vienna: Anton Scholl 
The New Jerusalem Bible (1990) London: Darton, Longman, Todd

Newman, B. (1993) Greek-English Dictionary of the New Testament, Stuttgart:

Deutsche Bibelgesellschaft

Newmark, P. (1988) A Textbook of Translation, New York: Prentice Hall

Das Nibelungenlied (1972) Wiesbaden: Brockhaus

Nida, E. \& C. Taber (1969) The Theory and Practice of Translation, Leiden:

\section{E.J. Brill}

Nietzsche, F. (2001) The Gay Science, tr. by J. Nauckhoff \& A. Del Caro, Cambridge: Cambridge University Press

Nietzsche, F. (2004) 'Translations', tr. by W. Kaufman, in L. Venuti (ed), 67-68

Nikolaou, P. \& M. Kyritsi (eds) (2008) Translating Selves, London: Continuum

Nord, C. (1997) Translating as a Purposeful Activity, Manchester: St Jerome

Norris, C. (2007) Fiction, Philosophy and Literary Theory, London: Continuum

Nozedar, A. (2010) The Illustrated Signs and Symbols Sourcebook, London: HarperCollins

NT Gateway (15 June 2012)

www.ntgateway.com

Numminen, M.A. (1989) The Tractatus Suite, Eteepäin!

Orent, A. (2008) In the Land of Invented Languages, New York: Spiegel \& Grau

Osers, E (tr) (2009) Vitězlav Nezval: Prague with Fingers of Rain, Tarset: Bloodaxe

Ovid (2004) Metamorphoses, Oxford: Oxford University Press

Page, N. (1998) The Tabloid Bible, London: Collins

Parkinson, R. (2005) The Rosetta Stone, London: British Museum Press

Parks, T. (2007) Translating Style, Manchester: St Jerome

Pascal, B. (1982) Les Pensées, Paris: Editions du Cerf

Pascal, F. (1984) 'Wittgenstein: A Personal Memoir', in R. Rhees (ed), 12-49

Pasley, M. (1963) 'Introduction', in F. Kafka, 7-36

Pasley, M. (tr) (1992) Franz Kafka: The Transformation and Other Stories, London: Penguin

Pasolini (dir) (1964) Il Vangelo secondo Mattheo, Acro/Lux

Paterson, D. (tr) (2006) Orpheus: A Version of Rilke's Die Sonnette an Orpheus, London: Faber \& Faber

Patmore, A. (2006) The Truth About Stress, London: Atlantic Books

Patterson, D. (ed) (2004) Wittgenstein and Law, Aldershot: Ashgate 
Paul, G. (ed) (2009) Translation in Practice, Champaign \& London: Dalkey Archive Press

Perec, G. (1968) La disparition, Paris: Gallimard

Perloff, M. (2004) “"But isn't the same at least the same?”: Wittgenstein and the question of poetic translatability', in J. Gibson \& W. Huemer (eds), 34-54

Pevear, R. \& L. Volokhonsky (trs) (2000) Leo Tolstoy: Anna Karenina, London: Penguin

Pilkington, A. (2000) Poetic Effects, Amsterdam: John Benjamins

Pinker, S. (1994) The Language Instinct, London: Penguin

Pinker, S. (2007) The Stuff of Thought, London: Allen Lane

Piper, F. \& S. Murphy (2002) Cryptography, Oxford: Oxford University Press

Pirie, G. (tr) (2008) Jean de la Fontaine: Fables, London: Hesperus

Plato (1977) Cratylus, in Plato Volume 4, London: Heinemann, 6-191

Plato (1998) The Republic, tr. by R. Waterfield, Oxford: Oxford University Press

Poe, E.A. (2003) Poems and Poetics, New York: Library of America Press

Pope, A. (tr) (1931) Homer: The Iliad, London: Nonesuch Press

Pope, R. (2005) Creativity: Theory, History, Practice, London \& New York:

Routledge

Pound, E. (1934) The ABC of Reading, New York: New Directions

Pound, E. (2004) ‘Guido’s Relations', in L. Venuti (ed), 86-93

Pseudo-Dionysius (1986) The Divine Names and the Mystical Theology, tr. by C. E. Rolt, London: SPCK

Pym, A. (2007) 'Philosophy and Translation', in P. Kuhiwczak \& K. Littau (eds), 24-44

Pym, A. (2010) Exploring Translation Theories, London \& New York: Routledge

Queneau, R. (1947) Exercices de style, Paris: Gallimard

Raveh, D. (2008) 'Lost in translation: shifts of self and identity in the English versions of Patañjali's Yogasütra', in P. Nikolaou and M-V. Kyritsi (eds), $169-182$

Read, R. (2004) 'Throwing Away the Bedrock', in Proceedings of the Aristotelian Society $105,81-98$

Read, R. (2007a) Applying Wittgenstein, London: Continuum

Read, R. (2007b) Philosophy for Life, London: Continuum

Read, R. (2010) 'The Philosophical Investigations as a war book', in New Literary 
History 41, 593-612

Reiss, K. \& H.J. Vermeer (1984) Grundlegung einer allgemeinen Translationstheorie, Tübingen: Niemeyer

Rhees, R. (1970) Discussions of Wittgenstein, London: Routledge \& Kegan Paul

Rhees, R. (ed) (1984) Recollections of Wittgenstein, Oxford: Oxford University Press

Rheims-Douai Bible (1582) Rheims: John Fogny

Rice, A. (2006) Christ the Lord: The Road to Cana, London: Arrow

Richter, D. (2009) 'On the Pursuit of Happiness', in Y. Gustafsson et al. (eds), 185201

Ricoeur, P. (2006) On Translation, tr. by E. Brennan, London: Routledge

Ringmar, M. (2009) "“I had the misfortune of being introduced by a rotten translation",, in B.J. Epstein (ed) Northern Lights: Translation in the Nordic Countries, Bern: Peter Lang, 259-274

Robinson, D. (1991) The Translator's Turn, London \& Baltimore: The John Hopkins University Press

Robinson, D. (ed) (1997) Western Translation Theory from Herodotus to Nietzsche, Manchester: St. Jerome

Robinson, D. (2003) Becoming a Translator, London \& New York: Routledge

Robinson, H. (2003) 'Gareth Moore’s Radical Wittgensteinianism', in New Blackfriars Volume 84 Number 989/990, 353-360

Robinson, J. (2005) Deeper than Reason: Emotion and its Role in Literature, Music and Art, Oxford: Clarendon Press

Robson, D. (2011) 'Your Clever Body', in New Scientist, 15 October, 35-38

Rorrison, H. \& H. Chambers (tr) (2000) Theodor Fontane: Effi Briest, London: Penguin

Rorty, R. \& G. Vattimo (2005) The Future of Religion, New York: Columbia University Press

Rozema, P. (dir) (1999) Mansfield Park, Buena Vista/Miramax HAL/BBC

Russell, B. \& A. Whitehead (1927) Principia Mathematica, Cambridge:

Cambridge University Press

Sanders, E.P. (1993) The Historical Figure of Jesus, London: Penguin

Sass, L. (1994) The Paradoxes of Delusion, Ithaca \& London: Cornell University Press 
Savickey, B. (1999) Wittgenstein's Art of Investigation, London \& New York: Routledge

Schadewaldt, W. (1970) 'Hölderlins Übersetzungen des Sophokles', in Hellas und Hesperien, Volume II, Zürich: Artemis-Verlag, 275-332

Scheman, N. (2002) 'Introduction', in N. Scheman \& P. O’Connor (eds), 1-25

Scheman, N. \& P. O'Connor (eds) (2002) Feminist Interpretations of Ludwig Wittgenstein, University Park: Pennsylvania University Press

Schiffer, S. 'Two Perspectives on Knowledge of Language', in E. Sosa \& E. Villanueva (eds) Philosophy of Language: Philosophical Issues Volume 16 , Issue $1,275-287$

Schleiermacher, F. (2004) 'On the Different Methods of Translating', in L. Venuti (ed), 43-63

Schön, D. (1987) Educating the Reflective Practitioner, San Francisco: Jossey-Bass Scorsese, M. (dir) (1988) The Last Temptation of Christ, Universal/Cineplex Odeon Schreber, D.P. (2003) Denkwürdigkeiten eines Nervenkranken, Giessen:

Psychosozial-Verlag

Schroeder, S. (2001) 'The coded-message model of literature', in R. Allen \& M. Turvey (eds), 210-228

Schroeder, S. (2006) Wittgenstein, Cambridge: Polity

Schulte, J. (2004) “"The life of the sign: Wittgenstein on reading a poem', in J. Gibson \& W. Huemer (eds), 146-164

Scott, C. (2000) Translating Baudelaire, Exeter: University of Exeter Press

Scott, C. (2008) 'Our Engagement with Literary Translation', in In Other Words 32, $16-29$

Searle, J. (2011) 'Wittgenstein and the Background', in American Philosophical Quarterly Volume 48 Number 2, 119-128

Sebald, W.G. (2001) Austerlitz, tr. by A. Bell, London: Penguin

Sedivy, S. (2004) 'Wittgenstein against interpretation', in J. Gibson \& W. Huemer (eds), 165-185

Seleskovitch, D. \& M. Lederer (1984) Interpréter pour traduire, Paris: Didier Shakespeare, W. (1972) King Lear, London: Penguin

Shanker, S. (ed) (1986) Ludwig Wittgenstein: Critical Assessments Volume II, London \& New York: Routledge

Simon, S. (1996) Gender in Translation: Cultural Identity and the Politics of 
Transmission, London: Routledge.

Slater, M. (2009) 'Jean de la Fontaine, Fables, translated by Gordon Pirie', in In Other Words 27, 76-78

Snell-Hornby (2006) The Turns of Translation Studies, Amsterdam: John Benjamins Society of Authors (7 December 2011)

$\underline{\text { www.societyofauthors.org/translation-faqs }}$

Sontag, S. (1996) 'Against Interpretation', in D. Lodge (ed) $20^{\text {th }}$ Century Literary Criticism, London \& New York: Longman, 652-661

Sophocles (1994) Antigone, The Women of Trachis, Philoctetes, Oedipus at Colonus, Cambridge \& London: Harvard University Press

Spears, B. (2008) Womanizer, Jive Records

Spence, S. (2010) 'The Anxieties of Texting', in The Rialto 69, 42

Sperber, D. \& D. Wilson (1995) Relevance: Communication and Cognition, Oxford: Blackwell

Spivak, G. (2007) 'Translation as Culture', in P. St-Pierre \& P.C. Kar (eds) In Translation - Reflections, Refractions, Transformations, Amsterdam: John Benjamins, 263-276

Stafford, F. (2003) 'Introduction', in J. Macpherson, v-xxii

Stanton, E. (ed) (1985) The Woman's Bible, Edinburgh: Polygon

Steiner, G. (1998) After Babel, Oxford: Oxford University Press

Stern, D. (2007) 'The Uses of Wittgenstein's Beetle: Philosophical Investigations $\S 293$ and Its Interpreters', in G. Kahane et al. (eds), 248-268

Stich, S. \& I. Ravenscroft (1994) 'What is folk psychology?', in Cognition 50, 447468

Stockwell, P. (2002) Cognitive Poetics, London \& New York: Routledge

Stokes, R. (tr) (2005) Franz Kafka: Metamorphosis and other stories, London: Hesperus

Stone, W. (tr) (2005) Georg Trakl: To the Silenced, Todmorden: Arc

Stoppard, T. (1980) Dogg's Hamlet, Cahoot's Macbeth, London: Faber \& Faber

Sweeney, M. \& J. Hartley Williams (2005) Teach Yourself Writing Poetry, London: Teach Yourself Books

Sweney, M. (2010) 'Prague with Fingers of Rain by Vítězlav Nezval, translated from the Czech by Ewald Osers', in In Other Words 35, 97-98

Szirtes, G. (forthcoming) 'Reproduction Furniture' 
Tabakowska, E. (1993) Cognitive Linguistics and Poetics of Translation, Tübingen: Narr

Taleb, N.N. (2007) The Black Swan, London: Penguin

Taylor, C. (1989) Sources of the Self, Cambridge: Cambridge University Press

Teichmann, R. (2008) The Philosophy of Elizabeth Anscombe, Oxford: Oxford University Press

Terry, P. (ed) (1980) Ovid Metamorphosed, London: Chatto \& Windus

Thirlwell, J. (1966) In Another Language, New York: Alfred A. Knopf

Tolkien, J.R.R. (1968) The Lord of the Rings, London: George Allen \& Unwin

Tolstoy, L. (1997) The Gospel in Brief, tr. by F.A. Flowers III, Lincoln \& London: University of Nebraska Press

Toury, G. (1980) In Search of a Theory of Translation, Tel Aviv: Porter Institute for Poetics and Semiotics

Toury, G. (1995) Descriptive Translation Studies and Beyond, Amsterdam: John Benjamins

Travis, C. (2008) 'Annals of Analysis', in Occasion-Sensitivity: Selected Essays, Oxford: Oxford University Press, 65-93

Travis, C. (10 May 2011) 'The Proposition's Progress' http://sites.google.com/site/charlestraviswebsite

Turner, M. (1996) The Literary Mind, New York \& Oxford: Oxford University Press Tymoczko, M. (2006) 'Reconceptualizing Western Translation Theory', in T. Hermans (ed) Translating Others Volume 1, Manchester: St. Jerome, 1322

Tymoczko, M. (2007) Enlarging Translation, Empowering Translators, Manchester: St. Jerome

UEA (11 February 2010) www.uea.ac.uk/lit/Courses/Postgraduate/MA+in+Literary +Translation University of London (2004) Diploma in Theology and BD: Examination papers and Examiners' Reports, London: University of London Press

Venuti, L. (1998) The Scandals of Translation, London \& New York: Routledge

Venuti, L. (ed) (2004) The Translation Studies Reader [Second Edition], London \& New York: Routledge

Venuti, L. (2008) The Translator's Invisibility, London \& NewYork: Routledge

Wales, K. (2001) A Dictionary of Stylistics, London: Longman 
Walker, J. (2006) Halliwell's Film, London: HarperCollins

Weber, J.J. (1996) The Stylistics Reader, London, New York, Sydney, Auckland

Weinberger, E. \& O. Paz (1987) 19 Ways of Looking at Wang Wei, London:

Asphodel

Weissbort, D. (2006) 'Introduction', in T. Hughes, vii-xi

Wheeler, A. (1934) Catullus and the Traditions of Ancient Poetry, Berkeley: University of California Press

Whiting, D. (ed) (2010) The Later Wittgenstein on Language, Basingstoke: Palgrave Macmillan

Whitinger, R. (tr) (2005) Eduard Mörike: Nolten the Painter, New York: Camden House

Whorf, B. (1956) Language, Thought and Reality, Cambridge: MIT Press

Wierzbicza, A. (1997) Understanding Cultures Through Their Key Words, Oxford: Oxford University Press

Wilson, B. (1991) Gaudí Afternoon, London: Virago

Wilson, P. (tr) (2009) 'Françoise Wuilmart: "The Idiot of the Literary family?”, in In Other Words 33, 40-42

Winch, P. (2008) The Idea of a Social Science and its Relation to Philosophy, London \& New York: Routledge

Within Temptation (2007) 'What Have You Done' on The Heart of Everything, Roadrunner Records

Wittgenstein, L. (1964) Philosophical Remarks, tr. by R. Hargreaves \& M.A.E. Aue, Oxford: Blackwell

Wittgenstein, L. (1966) Lectures and Conversations on Aesthetics, Psychology and Religious Belief, Oxford: Blackwell

Wittgenstein, L. (1969) On Certainty, tr. by D. Paul \& G.E.M. Anscombe, Oxford: Blackwell

Wittgenstein, L. (1974) Philosophical Grammar, tr. by A. Kenny, Oxford: Blackwell Wittgenstein, L. (1977) Wörterbuch für Volksschulen, 'Preface' tr. by E. Leinfeller, Vienna: Hölder-Pichler-Tempsky

Wittgenstein, L. (1978) Remarks on the Foundations of Mathematics, tr. by

G.E.M. Anscombe, Oxford: Blackwell

Wittgenstein (1979) Notebooks 1914-1916, tr. by G.E.M. Anscombe, Oxford:

Blackwell 
Wittgenstein, L. (1980a) Culture and Value, tr. by P. Winch, Oxford: Blackwell

Wittgenstein, L. (1980b) Remarks on the Philosophy of Psychology [2 volumes], tr.

by C.G. Luckhardt \& M.A.E. Aue, Oxford: Blackwell

Wittgenstein, L. (1981) Zettel, tr. by G.E.M. Anscombe, Oxford: Blackwell

Wittgenstein, L. (1982) Last Writings on Philosophical Psychology, tr. by

C.G. Luckhardt \& M.A.E. Aue, Oxford: Blackwell

Wittgenstein, L. (1990) Tractatus Logico-Philosophicus, tr. by C. K. Ogden, London \& New York: Routledge

Wittgenstein, L. (2005) Big Typescript, tr. by C.G. Luckhardt \& M.A.E. Aue, Oxford: Blackwell

Wittgenstein, L. (2009) Philosophical Investigations [includes Philosophy of Psychology - A Fragment], tr. by G.E.M. Anscombe, P.M.S. Hacker \& J. Schulte, Oxford: Wiley-Blackwell

Wolf, H. (1926) Gedichte von Eduard Mörike für eine Singstimme und Klavier, New York \& London: Peters

Wright, G.H. von (1958) 'Biographical Sketch', in N. Malcolm, 1-22

Wright, J. (1917) A Grammar of the Gothic Language, Oxford: Oxford University Press

Wuilmart, F. (2009) 'The Idiot of the Literary family?', tr. by P. Wilson, in In Other Words 33, 40-42

Zukofsky, L. \& C. Zukofsky (trs) (1969) Catullus, London: Cape Goliard Press 